\title{
ENSINO, PESQUISA E CONTRIBUIÇÕES CIENTÍFICAS EM UDONTOLOGIA
}

\section{JOLUME I}

\author{
ORGANIZAÇÃO \\ PAULA MILENA MELO CASAIS \\ ARYANE DE AZEVEDO PINHEIRO
}

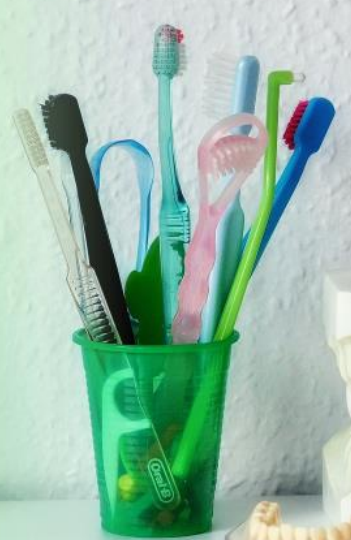




\title{
ENSINO, PESQUISA E CONTRIBUIÇÕES CIENTÍFICAS EM ODONTOLOGIA
}

\section{VOLUME I}

\author{
ORGANIZAÇÃO
}

PAULA MILENA MELO CASAIS ARYANE DE AZEVEDO PINHEIRO 
2021 - Editora Amplla

Copyright (C) Editora Amplla

Editor Chefe: Leonardo Pereira Tavares

Design da Capa: Editora Amplla

Diagramação: Higor Costa de Brito

Ensino, pesquisa e contribuições científicas em odontologia - Volume I está licenciado sob CC BY 4.0.

(c) (i) Esta licença exige que as reutilizações deem crédito ao criador. Ele permite que os ou formato, mesmo para fins comerciais.

O conteúdo da obra e seus dados em sua forma, correção e confiabilidade são de responsabilidade exclusiva dos autores, não representando a posição oficial da Editora Amplla. É permitido o download da obra e o compartilhamento desde que sejam atribuídos créditos aos autores. Todos os direitos para esta edição foram cedidos à Editora Amplla.

ISBN: 978-65-88332-75-7

DOI: 10.51859/amplla.epc757.1121-0

Editora Amplla

Campina Grande - PB - Brasil contato@ampllaeditora.com.br www.ampllaeditora.com.br

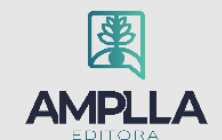




\section{CONSELHO EDITORIAL}

Andréa Cátia Leal Badaró - Universidade Tecnológica Federal do Paraná Andréia Monique Lermen - Universidade Federal do Rio Grande do Sul Antoniele Silvana de Melo Souza - Universidade Estadual do Ceará Bergson Rodrigo Siqueira de Melo - Universidade Estadual do Ceará Bruna Beatriz da Rocha - Instituto Federal do Sudeste de Minas Gerais Caio César Costa Santos - Universidade Federal de Sergipe Carina Alexandra Rondini - Universidade Estadual Paulista Carla Caroline Alves Carvalho - Universidade Federal de Campina Grande Carlos Augusto Trojaner - Prefeitura de Venâncio Aires Carolina Carbonell Demori - Universidade Federal de Pelotas Cícero Batista do Nascimento Filho - Universidade Federal do Ceará Clécio Danilo Dias da Silva - Universidade Federal do Rio Grande do Norte Daniela de Freitas Lima - Universidade Federal de Campina Grande Denise Barguil Nepomuceno - Universidade Federal de Minas Gerais Dylan Ávila Alves - Instituto Federal Goiano Edson Lourenço da Silva - Instituto Federal de Educação, Ciência e Tecnologia do Piauí Elane da Silva Barbosa - Universidade Estadual do Ceará Érica Rios de Carvalho - Universidade Católica do Salvador Gilberto de Melo Junior - Instituto Federal do Pará Higor Costa de Brito - Universidade Federal de Campina Grande Italan Carneiro Bezerra - Instituto Federal da Paraíba Ivo Batista Conde - Universidade Estadual do Ceará Jaqueline Rocha Borges dos Santos - Universidade Federal Rural do Rio de Janeiro Jessica Wanderley Souza do Nascimento - Instituto de Especialização do Amazonas João Henriques de Sousa Júnior - Universidade Federal de Santa Catarina João Manoel Da Silva - Universidade Federal de Alagoas

João Vitor Andrade - Universidade de São Paulo Joilson Silva de Sousa - Instituto Federal do Rio Grande do Norte José Cândido Rodrigues Neto - Universidade Estadual da Paraíba Jose Henrique de Lacerda Furtado - Instituto Federal do Rio de Janeiro Josenita Luiz da Silva - Faculdade Frassinetti do Recife Josiney Farias de Araújo - Universidade Federal do Pará Karina de Araújo Dias - SME/Prefeitura Municipal de Florianópolis Laíze Lantyer Luz - Universidade Católica do Salvador Lindon Johnson Pontes Portela - Universidade Federal do Oeste do Pará Lucas Capita Quarto - Universidade Federal do Oeste do Pará Lúcia Magnólia Albuquerque Soares de Camargo - Unifacisa Centro Universitário Luciana de Jesus Botelho Sodré dos Santos - Universidade Estadual do Maranhão Luís Paulo Souza e Souza - Universidade Federal do Amazonas Luiza Catarina Sobreira de Souza - Faculdade de Ciências Humanas do Sertão Central Manoel Mariano Neto da Silva - Universidade Federal de Campina Grande

Marcelo Alves Pereira Eufrasio - Centro Universitário Unifacisa Marcelo Williams Oliveira de Souza - Universidade Federal do Pará Marcos Pereira dos Santos - Faculdade Rachel de Queiroz Marcus Vinicius Peralva Santos - Universidade Federal da Bahia Marina Magalhães de Morais - Universidade Federal de Campina Grande Nadja Maria Mourão - Universidade do Estado de Minas Gerais Natan Galves Santana - Universidade Paranaense Nathalia Bezerra da Silva Ferreira - Universidade do Estado do Rio Grande do Norte Neide Kazue Sakugawa Shinohara - Universidade Federal Rural de Pernambuco Neudson Johnson Martinho - Faculdade de Medicina da Universidade Federal de Mato Grosso Patrícia Appelt - Universidade Tecnológica Federal do Paraná Paulo Henrique Matos de Jesus - Universidade Federal do Maranhão 
Rafael Rodrigues Gomides - Faculdade de Quatro Marcos

Reângela Cíntia Rodrigues de Oliveira Lima - Universidade Federal do Ceará

Rebeca Freitas Ivanicska - Universidade Federal de Lavras

Renan Monteiro do Nascimento - Universidade de Brasília

Ricardo Leoni Gonçalves Bastos - Universidade Federal do Ceará

Rodrigo da Rosa Pereira - Universidade Federal do Rio Grande

Sabrynna Brito Oliveira - Universidade Federal de Minas Gerais

Samuel Miranda Mattos - Universidade Estadual do Ceará

Shirley Santos Nascimento - Universidade Estadual Do Sudoeste Da Bahia

Silvana Carloto Andres - Universidade Federal de Santa Maria

Silvio de Almeida Junior - Universidade de Franca

Tatiana Paschoalette Rodrigues Bachur - Universidade Estadual do Ceará

Telma Regina Stroparo - Universidade Estadual do Centro-Oeste

Thayla Amorim Santino - Universidade Federal do Rio Grande do Norte

Virgínia Maia de Araújo Oliveira - Instituto Federal da Paraíba

Virginia Tomaz Machado - Faculdade Santa Maria de Cajazeiras

Walmir Fernandes Pereira - Miami University of Science and Technology

Wanessa Dunga de Assis - Universidade Federal de Campina Grande

Wellington Alves Silva - Universidade Estadual de Roraima

Yáscara Maia Araújo de Brito - Universidade Federal de Campina Grande

Yasmin da Silva Santos - Fundação Oswaldo Cruz

Yuciara Barbosa Costa Ferreira - Universidade Federal de Campina Grande 


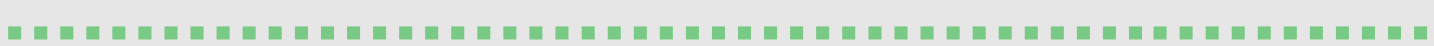

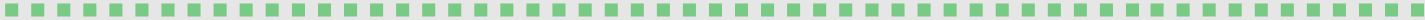

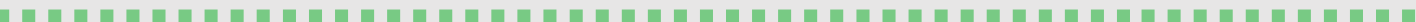

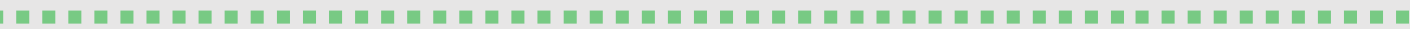

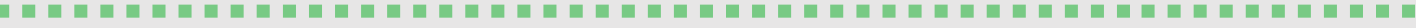

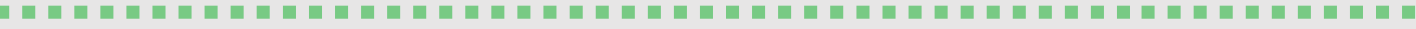

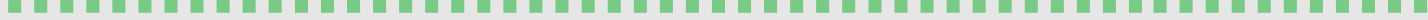
블

\section{只梗}

\section{AMPLLA}

2021 - Editora Amplla

Copyright (C Editora Amplla

Editor Chefe: Leonardo Pereira Tavares

Design da Capa: Editora Amplla

Diagramação: Higor Costa de Brito

\section{Dados Internacionais de Catalogação na Publicação (CIP)}

Ensino, pesquisa e contribuições científicas em odontologia [livro eletrônico] / organização Paula Milena Melo Casais, Aryane de Azevedo Pinheiro. -Campina Grande : Editora Amplla, 2021.

$2 \mathrm{v} \cdot(577 \mathrm{p}$.

Formato: PDF

ISBN : $978-65-88332-75-7 \quad(\mathrm{~V} .1)$

ISBN : $978-65-88332-76-4 \quad(\mathrm{v} .2)$

1. Saúde bucal. 2. Reabilitação oral. 3. Rotina Clínica. 4. Clínica odontológica. 5. Manifestações orais de doenças. I. Casais, Paula Milena Melo. II. Pinheiro, Aryane de Azevedo. III. Título.

Sueli Costa - Bibliotecária - CRB-8/5213

(SC Assessoria Editorial, SP, Brasil)

Índices para catálogo sistemático:

1. Odontologia 617.6

Editora Amplla

Campina Grande - PB - Brasil

contato@ampllaeditora.com.br www.ampllaeditora.com.br 
Caro Leitor,

A Odontologia encontra-se em constante evolução técnica e científica desde o século XIX, com a criação da primeira faculdade de Odontologia nos Estados Unidos marco do surgimento da Odontologia Flexneriana. Neste período, a prática odontológica era essencialmente focada no biologismo, individualismo, tecnicismo e um elevado grau de fragmentação do conhecimento, através das especializações. Em 1950, com o advento da Odontologia social, há uma visão mais ampla da profissão, com valorização das ações preventivas e de promoção à saúde.

Estes históricos avanços na Odontologia, no que concerne à assistência à saúde bucal, vem acompanhados de uma percepção ampliada da prática clínica, na qual a saúde bucal não pode ser dissociada da saúde sistêmica e dos determinantes sociais, destacando a importância da prestação dos serviços na Odontologia considerando o conceito da integralidade, princípio doutrinário do Sistema Único de Saúde.

Atrelado à evolução do cuidado à saúde bucal, o desenvolvimento de estudos e o incremento das novas tecnologias qualificam os atendimentos, ao subsidiar o planejamento criterioso das intervenções, garantindo resultados com maior eficiência, eficácia e segurança para os pacientes. Portanto, acadêmicos e cirurgiões dentistas vislumbram a necessidade de atualizar-se para atuação qualificada, nos âmbitos público e privado, no ensino da Odontologia e em outros setores da saúde.

Diante disso, a prática dos profissionais, em qualquer que seja sua área de atuação na Odontologia, deve ser embasada em produções científicas de qualidade e atualizadas, respaldadas pela ampla experiência e conhecimento metodológico dos pesquisadores.

Nesta perspectiva, esta obra, composta por estudos desenvolvidos por profissionais e acadêmicos de distintas regiões do Brasil, irá subsidiar reflexões sobre diversas temáticas relacionadas aos avanços nas pesquisas científicas na Odontologia. Através de revisões da literatura e estudos observacionais descritivos, como relatos de caso, os autores abordam conteúdos fundamentais para a rotina clínica, considerando novas técnicas, materiais e estratégias para diagnóstico e reabilitação oral; uso de práticas integrativas complementares na clínica odontológica; comprometimento 


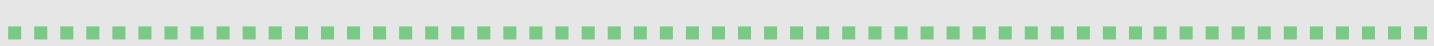

10

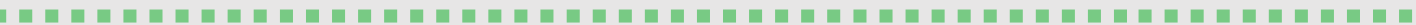

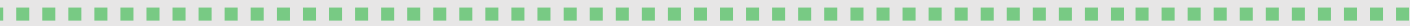

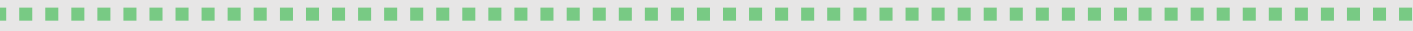

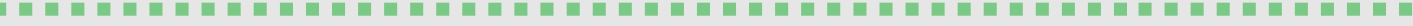

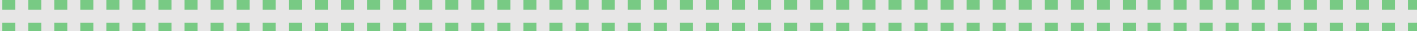

sistêmico de manifestações orais; impacto da pandemia de COVID-19 (Doença do novo coronavírus) na saúde bucal e repercussões na saúde mental dos profissionais da Odontologia, além de atualizações na biossegurança.

Desejo uma excelente leitura a todos e anseio que, as produções científicas aqui apresentadas, auxiliem na construção de novos estudos e sejam utilizadas como base para aprimorar a prática clínica e subsidiar o ensino da Odontologia.

Paula Milena Melo Casais

Cirurgiã dentista (UFBA)

Mestre em Ciências da Saúde (UFBA)

Especialista em Saúde da Família (ESPBA) e Microbiologia (UFBA) 


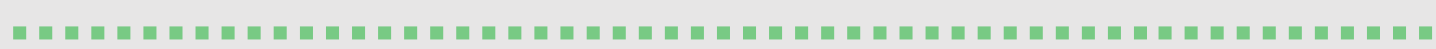

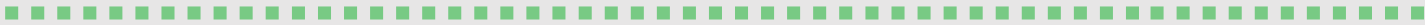

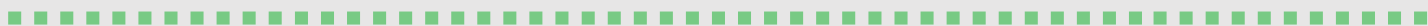

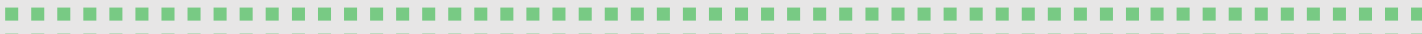

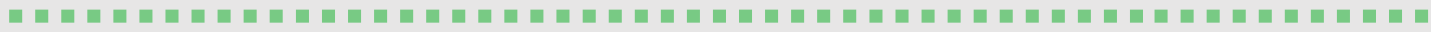

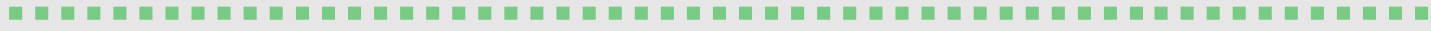

(2)

\section{SUMÁRIO}

CAPÍTULO I - ESTÉTICA PERIODONTAL NA HARMONIZAÇÃO DO SORRISO 10

DOI: 10.51859/AMPLLA.EPC757.1121-1

CAPITULO II - PERIODONTITE CRÔNICA E NÍVEIS SÉRICOS DE HEPCIDINA E HEMOGLOBINA .21

DOI: 10.51859/AMPLLA.EPC757.1121-2

CAPÍTULO III - A ASSOCIAÇÃO ENTRE DOENÇA DE CROHN E DOENÇA PERIODONTAL 35

DOI: 10.51859/AMPLLA.EPC757.1121-3

CAPÍTULO IV - A RELAÇÃO DA PERIODONTITE E A DOENÇA DE ALZHEIMER: UMA REVISÃO DE LITERATURA . .51

DOI: 10.51859/AMPLLA.EPC757.1121-4

CAPÍTULO V - O USO DOS PRÓBIOTICOS NO TRATAMENTO DA DOENÇA PERIODONTAL: UMA REVISÃO INTEGRATIVA DA LITERATURA...

69

CAPÍTULO VI - TRATAMENTO DAS LESÕES ENDO PERIODONTAIS. .80

CAPÍTULO VIII - HALL TECHNIQUE: TRATAMENTO DE MÍNIMA INTERVENÇ̃̃O EM LESÕES DE CÁRIE EM MOLARES DECÍDUOS 110 DOI: 10.51859/AMPLLA.EPC757.1121-8

CAPÍTULO IX - TRATAMENTO DE DENTES ACOMETIDOS POR AMELOGÊNESE IMPERFEITA: RELATO DE CASO 119 DOI: 10.51859/AMPLLA.EPC757.1121-9

CAPÍTULO X - PROCEDIMENTOS RESTAURADORES EM DENTES COM TRATAMENTO ENDODÔNTICO. .126 DOI: 10.51859/AMPLLA.EPC757.1121-10

CAPÍTULO XI - MATERIAIS CERÂMICOS APLICADOS EM ODONTOLOGIA.. .139 DOI: 10.51859/AMPLLA.EPC757.1121-11

CAPÍTULO XII - REABILITAÇ̃̃O DENTAL, FACETAS INDIRETAS, COROA TOTAL SOBRE DENTE E IMPLANTE: RELATO DE CASO..150 DOI: $10.51859 /$ AMPLLA.EPC757.1121-12

CAPÍTULO XIII - O USO DE ALINHADORES ESTÉTICOS PARA TRATAMENTO ORTODÔNTICO .160 DOI: 10.51859/AMPLLA.EPC757.1121-13

CAPÍTULO XIV - REABILITAÇÃO ESTÉTICO-FUNCIONAL EM ODONTOPEDIATRIA . .173 DOI: 10.51859/AMPLLA.EPC757.1121-14

CAPÍTULO XV - TRANSPLANTE DENTÁRIO AUTÓGENO: UMA ABORDAGEM NA ODONTOPEDIATRIA .185 DOI: 10.51859/AMPLLA.EPC757.1121-15 CAPÍTULO XVI - LESÕES BUCAIS DE TECIDOS MOLES COMUNS NA PRIMEIRA INFÂNCIA. 197 


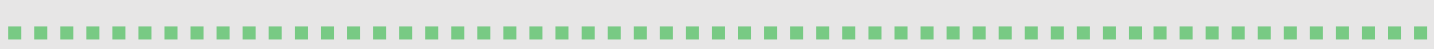

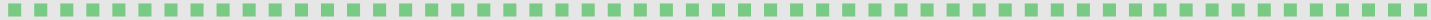

30

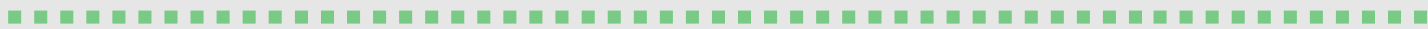

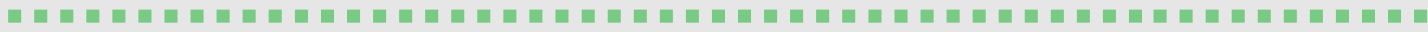

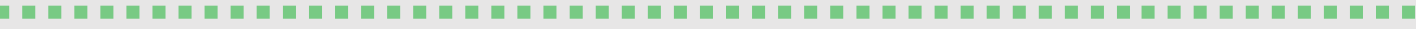

2

CAPÍTULO XVII - MANEJO DA ANSIEDADE NA CLÍNICA DE ODONTOPEDIATRIA

CAPÍTULO XVIII - CARACTERÍSTICAS EPIDEMIOLÓGICAS DE PACIENTES COM FISSURA LABIOPALATINA NÃO SINDRÔMICA ....225 DOI: 10.51859/AMPLLA.EPC757.1121-18

CAPÍTULO XIX - DIAGNÓSTICO DE INFECÇ̃̃ES SEXUALMENTE TRANSMISSIIVEIS POR MEIO DE LESÕES ORAIS .239 DOI: 10.51859/AMPLLA.EPC757.1121-19

CAPÍTULO XX - LASERTERAPIA NA PREVENÇÃO E TRATAMENTO DA MUCOSITE EM PACIENTES ONCOLÓGICOS .258 DOI: 10.51859/AMPLLA.EPC757.1121-20

CAPÍTULO XXI - IMPORTÂNCIA DA HIGIENE ORAL E DA DOENÇA CARDÍACA: UMA REVISÃO INTEGRATIVA .275 DOI: 10.51859/AMPLLA.EPC757.1121-21

CAPITULO XXII - PROTOCOLOS DE ATENDIMENTO ODONTOLÓGICO NO PRÉ-OPERATÓRIO DE CIRURGIA CARDIOVASCULAR....285 DOI: 10.51859/AMPLLA.EPC757.1121-22 CAPÍTULO XXIII - CUIDADOS PALIATIVOS NA ODONTOLOGIA .297 DOI: 10.51859/AMPLLA.EPC757.1121-23 


\title{
CAPITULO I
}

\section{ESTÉTICA PERIODONTAL NA HARMONIZAÇÃO DO SORRISO}

\author{
DOI: 10.51859/AMPLLA.EPC757.1121-1
}

\author{
Wesley De Souza Pereira ${ }^{1}$ \\ Leyriane Mendes Paiva ${ }^{2}$ \\ Tharlles Bruno Lima Silva ${ }^{1}$ \\ Valbson Nascimento Aquino ${ }^{1}$ \\ Karla Geovanna Ribeiro Brígido ${ }^{3}$ \\ Jandenilson Alves Brígido ${ }^{3}$
}

\footnotetext{
${ }^{1}$ Graduando do Curso de Odontologia. Centro Universitário Fametro - UNIFAMETRO

2 Graduanda do Curso de Odontologia. Centro Universitário Fametro - UNIFAMETRO

${ }^{3}$ Docente do Curso de Odontologia. Centro Universitário Fametro - UNIFAMETRO
}

\section{RESUMO}

A busca pela estética na área de odontologia é crescente, e isso pode ser explicado pelos diversos avanços dos materiais dentários e pelas técnicas que possibilitam que bons resultados estéticos sejam alcançados, proporcionando harmonia do sorriso. O objetivo dessa revisão foi analisar como os tratamentos estéticos das estruturas periodontais podem ter relevância na harmonização do sorriso. Foram utilizadas as bases de dados BVS, PUBMED e Ebsco host como fonte de pesquisas, além de buscas manuais, sendo selecionados 13 artigos. Quando existe uma harmonia entre a estética branca e vermelha, é possível obter sucesso nos tratamentos reabilitadores estéticos. Após o relato de insatisfação do paciente com sua estética bucal, é necessário avaliar além de seus dentes, o contorno, continuidade e exposição gengival, de maneira que se houver alguma irregularidade ou descontinuidade, possa ser realizado o planejamento para restabelecer a harmonia. A harmonia estética do sorriso engloba um sistema multidisciplinar odontológico, portanto é necessário mais estudo para avaliar os fatores que podem prejudicar a estética e estabelecer medidas para tratá-los. A cirurgia plástica periodontal possui um impacto positivo na harmonia do sorriso em procedimentos como mudança da cor da mucosa e gengivoplastia, sendo que esta última pode ser associada ao uso da toxina botulínica, apresentando bons resultados na eliminação do sorriso gengival e no tratamento da estética vermelha. A preservação das ameias e papilas interdentais são importantes para harmonia do sorriso, de modo a evitar os espaços escuros, e o ácido hialurônico tem sido utilizado para solucionar esses casos.

Palavras-chave: Sorriso. Estética. Cirurgia periodontal. 


\section{INTRODUÇÃO}

É de conhecimento geral que as pessoas têm procurado cada vez mais os padrões de beleza odontológicos, sendo importante lembrar que a harmonização do sorriso não se resume apenas às cores dos elementos dentários, mas deve ser levado em conta também a relação da proporção entre os dentes e altura cervical das margens gengivais. Outro fator que contribui para esse equilíbrio estético é ter um contorno gengival saudável, um arco gengival côncavo e harmônico, de modo que não haja discrepância e irregularidades nas curvaturas (DA ROCHA et al., 2019).

$\mathrm{Na}$ busca pelo sorriso esteticamente perfeito muitas vezes apenas os dentes (estética branca) são devidamente avaliados e tratados, enquanto a gengiva (estética vermelha) passa a ser apenas coadjuvante no processo da harmonia dentária. Entretanto, um bom tratamento estético não pode ser conduzido dessa forma, visto que apenas os procedimentos relacionados aos dentes não são capazes de promover a harmonia do sorriso desejada, sendo assim necessária uma intervenção interdisciplinar para alcançar o resultado esperado (PONTES et al., 2016).

A cirurgia plástica periodontal é fundamental para o paciente, pois além da melhoria na saúde bucal, em procedimentos como aumento de coroa clínica ou enxerto de tecido, pode proporcionar maior qualidade de vida, uma vez que o sorriso é uma forma de comunicação e integralização social (SOUSA et al., 2019). Por isso, é muito relevante o tema proposto, não apenas para proporcionar estética, mas também para restabelecer os aspectos funcionais, psicossociais e possibilitar melhores condições de saúde bucal e qualidade de vida, pois devido a estética, muitos pacientes têm vergonha de sorrir e se comunicar, afetando suas relações sociais (GONTIJO et al., 2020).

A gengivoplastia é o procedimento cirúrgico periodontal mais indicado para restaurar a forma e contornos gengivais, com objetivo de possibilitar a melhor higiene e estética, sendo assim uma grande aliada no planejamento da harmonia do sorriso, pois quando existe grande quantidade de tecido gengival na coroa dentária, a estética fica prejudicada, principalmente se a linha do sorriso for alta (PONTES et al., 2016).

Outro fator que tem potencial para prejudicar a estética do sorriso são os "triângulos pretos" ou "black spaces", que são defeitos nas papilas que geram um fator estético bem desagradável ao paciente. Além disso, a perda da papila pode causar 
cáries, devido ao acúmulo de alimentos e placas bacterianas e também tem potencial para alterar a pronúncia das palavras (SPANO et al., 2019). Os blacks spaces podem ser causados por doenças periodontais, diastemas, traumas, maus posicionamentos dentários, e também por procedimentos estéticos em que são colocadas facetas dentárias sem um ponto de contato satisfatório fazendo com que as ameias gengivais sejam prejudicadas e por falta de um condicionamento gengival adequado ficam esses espaços antiestéticos (SPANO et al., 2019).

O sorriso gengival é uma característica que afeta diretamente a estética do sorriso, e para proporcionar a melhor harmonia estética, muitos procedimentos podem auxiliar no tratamento da remoção da gengiva, de modo que não tenha uma exposição exagerada. Dentre esses tratamentos, tem-se a utilização da toxina botulínica, gengivoplastia, miectomia, reposicionamento do lábio e cirurgia ortognática. 0 tratamento ideal vai depender da etiologia desse sorriso gengival. No caso da realização da gengivoplastia uma estratégia que pode auxiliar é a confecção do mock up pois nos ajuda a prever o resultado final do tratamento e, assim, evita decepções e repetições desnecessárias. Ademais, a confecção do mock up diminui o tempo da cirurgia por ser um guia cirúrgico, tornando o trabalho mais completo e preciso (DA ROCHA et al., 2019). Já a toxina botulínica é um procedimento terapêutico menos invasivo, rápido e seguro, em comparação com as cirurgias. Apresentam resultado harmônico, entretanto seu efeito é temporário, havendo a necessidade de novas aplicações (PEDRON, 2016).

Dessa forma, o objetivo desta revisão foi analisar como os tratamentos estéticos das estruturas periodontais podem ter relevância na harmonização do sorriso.

\section{METODOLOGIA}

Este estudo apresenta uma revisão de literatura, em que foram realizadas buscas bibliográficas nos portais eletrônicos Biblioteca Virtual em Saúde (BVS), PUBMED e Ebsco Host, além de buscas manuais, utilizando os descritores "Sorriso", "Estética", "Cirurgia periodontal" e os termos correspondentes em inglês.

Os critérios de inclusão para esta revisão foram: estudos publicados de 2011 até 2021; estudos nos idiomas português e inglês; estudos clínicos, analíticos, descritivos, estudos in vitro, relato de caso, estudos de coorte e estudos investigativos. Já os critérios de exclusão foram: artigos incompletos, artigos duplicados e estudos que não se 
apresentaram pertinentes ao tema. Após a busca nas bases de dados virtuais foram encontrados 533 trabalhos, sendo selecionados 321 artigos para leitura de títulos e resumos, respeitando os critérios de inclusão e exclusão, elegendo-se 42 estudos, para análise detalhada. Após a avaliação do texto completo restaram 13 artigos para compor esta revisão.

\section{RESULTADOS E DISCUSSÃO}

O levantamento abordou o período de publicações de 2012 a 2020. Dentre os 13 artigos selecionados, 8 foram relatos de caso, 4 estudos transversais e 1 estudo de revisão de literatura (Tabela 1 ).

Tabela 1 - Artigos selecionados na busca eletrônica.

\begin{tabular}{|c|c|c|c|c|}
\hline AUTOR/ANO & OBJETIVO & $\begin{array}{l}\text { TIPO DE } \\
\text { ESTUDO }\end{array}$ & AMOSTRA & PRINCIPAIS ACHADOS \\
\hline $\begin{array}{l}\text { KAPOOR et } \\
\text { al., } 2020\end{array}$ & $\begin{array}{l}\text { Avaliar uma nova forma } \\
\text { de reduzir ou eliminar } \\
\text { papilas defeituosas, junto } \\
\text { com a aplicação de ácido } \\
\text { hialurônico (HA). }\end{array}$ & $\begin{array}{l}\text { Estudo } \\
\text { transversal }\end{array}$ & $\begin{array}{l}6 \text { pacientes, } 4 \\
\text { mulheres e } 2 \\
\text { homens }\end{array}$ & $\begin{array}{l}\text { Observou-se que a injeção } \\
\text { de HÁ gel é seguro e } \\
\text { diminuiu de forma } \\
\text { significativa os espaços } \\
\text { negros na zona estética. }\end{array}$ \\
\hline $\begin{array}{l}\text { UZÊDA et al., } \\
2020\end{array}$ & $\begin{array}{c}\text { Apresentar um caso de } \\
\text { substituição de facetas } \\
\text { de resinas por facetas de } \\
\text { porcelana. }\end{array}$ & $\begin{array}{l}\text { Relato de } \\
\text { caso }\end{array}$ & $\begin{array}{l}\text { Paciente do } \\
\text { sexo feminino, } \\
25 \text { anos }\end{array}$ & $\begin{array}{l}\text { A relação da periodontia, } \\
\text { com a gengivoplastia, e a } \\
\text { dentística foi essencial } \\
\text { para o sucesso do caso. }\end{array}$ \\
\hline $\begin{array}{c}\text { PATIL et al., } \\
2020\end{array}$ & $\begin{array}{l}\text { Analisar a eficácia clínica } \\
\text { da infiltração de ácido } \\
\text { hialurônico gel na papila } \\
\text { interdental deficiente. }\end{array}$ & $\begin{array}{c}\text { Estudo } \\
\text { transversal }\end{array}$ & $\begin{array}{l}8 \text { pacientes, } 3 \\
\text { homens e } 5 \\
\text { mulheres }\end{array}$ & $\begin{array}{l}\text { A aplicação de ácido } \\
\text { hialurônico foi eficaz de } \\
\text { certo modo e é uma forma } \\
\text { minimamente invasiva de } \\
\text { reparar as papilas } \\
\text { interdentais. }\end{array}$ \\
\hline $\begin{array}{l}\text { GONTIJO et } \\
\text { al., } 2020 .\end{array}$ & $\begin{array}{l}\text { Relatar um caso de } \\
\text { reabilitação estética a } \\
\text { partir do planejamento } \\
\text { digital do sorriso para } \\
\text { avaliar as possibilidades } \\
\text { para um procedimento } \\
\text { restaurador e } \\
\text { periodontal cirúrgico. }\end{array}$ & $\begin{array}{l}\text { Relato de } \\
\text { caso }\end{array}$ & $\begin{array}{l}\text { Paciente do } \\
\text { sexo } \\
\text { masculino } \\
\text { com } 22 \text { anos } \\
\text { de idade. }\end{array}$ & $\begin{array}{l}\text { Necessidade na } \\
\text { otimização do } \\
\text { atendimento ao paciente } \\
\text { pois uma má estética } \\
\text { pode afetar relações } \\
\text { sociais, assim como gerar } \\
\text { um sentimento de auto- } \\
\text { estima. }\end{array}$ \\
\hline $\begin{array}{c}\text { SOUSA et al., } \\
2019\end{array}$ & $\begin{array}{l}\text { Apresentar a combinação } \\
\text { de gengivoplastia, } \\
\text { clareamento e o uso de } \\
\text { resina composta para o }\end{array}$ & $\begin{array}{l}\text { Relato de } \\
\text { caso }\end{array}$ & $\begin{array}{l}\text { Paciente do } \\
\text { sexo femino, } \\
21 \text { anos }\end{array}$ & $\begin{array}{l}\text { A demanda e necessidade } \\
\text { dos pacientes e também } \\
\text { dos profissionais, e o } \\
\text { desenvolvimento na área } \\
\text { restauradora, promove }\end{array}$ \\
\hline
\end{tabular}




\begin{tabular}{|c|c|c|c|c|}
\hline AUTOR/ANO & OBJETIVO & $\begin{array}{l}\text { TIPO DE } \\
\text { ESTUDO }\end{array}$ & AMOSTRA & PRINCIPAIS ACHADOS \\
\hline $\begin{array}{l}\text { SANTOS et } \\
\text { al. } 2016\end{array}$ & $\begin{array}{l}\text { Demonstrar as técnicas } \\
\text { de gengivoplastia e } \\
\text { facetas que, combinadas, } \\
\text { têm o objetivo de } \\
\text { proporcionar um sorriso } \\
\text { mais harmonioso. }\end{array}$ & $\begin{array}{l}\text { Relato de } \\
\text { caso }\end{array}$ & $\begin{array}{l}\text { Paciente do } \\
\text { sexo } \\
\text { masculino, } 23 \\
\text { anos }\end{array}$ & $\begin{array}{l}\text { O uso de modelos, tanto } \\
\text { para orientar a } \\
\text { gengivoplastia e a } \\
\text { restauração de resina } \\
\text { composta forneceu um } \\
\text { trabalho rápido com } \\
\text { previsibilidade }\end{array}$ \\
\hline $\begin{array}{c}\text { SILVA et al., } \\
2015\end{array}$ & $\begin{array}{l}\text { Descrever a resolução } \\
\text { estética e funcional de } \\
\text { um caso clínico de um } \\
\text { sorriso desarmonioso, } \\
\text { dentes pequenos e } \\
\text { escurecidos, além de } \\
\text { sorriso gengival. }\end{array}$ & $\begin{array}{l}\text { Relato de } \\
\text { caso }\end{array}$ & $\begin{array}{l}\text { Paciente do } \\
\text { sexo feminino, } \\
\text { leucoderma }\end{array}$ & $\begin{array}{l}\text { A aparência dos dentes é } \\
\text { essencial para a estética } \\
\text { facial, não somente a cor, } \\
\text { mas também a forma } \\
\text { gengival, altura do lábio } \\
\text { superior e do sorriso. }\end{array}$ \\
\hline $\begin{array}{l}\text { MOTTA et } \\
\text { al., } 2012\end{array}$ & $\begin{array}{l}\text { Avaliar as características } \\
\text { odontológicas na } \\
\text { percepção do sorriso } \\
\text { estético pelos estudantes } \\
\text { de odontologia. }\end{array}$ & $\begin{array}{c}\text { Estudo } \\
\text { transversal }\end{array}$ & $\begin{array}{c}60 \text { estudantes, } \\
22 \text { homens, } 38 \\
\text { mulheres }\end{array}$ & $\begin{array}{l}\text { Características dentárias } \\
\text { podem afetar a percepção } \\
\text { da estética do sorriso, } \\
\text { mas nem todos foram } \\
\text { percebidos de imediato } \\
\text { pelos estudantes. Dentre } \\
\text { as características } \\
\text { analisadas, o espaço } \\
\text { escuro tinha o resultado } \\
\text { estético mais } \\
\text { desfavorável. }\end{array}$ \\
\hline
\end{tabular}

Fonte: Autoria própria.

A estética facial pode ser melhorada pela harmonia do sorriso, que é composta pelos dentes, lábios e gengiva. Quando existe uma harmonia entre a estética branca e vermelha, é possível obter sucesso nos tratamentos reabilitadores estéticos. O sorriso se torna harmônico e belo quando o tecido gengival exposto aparece menos de $3 \mathrm{~mm}$, e quando essa medida é ultrapassada, uma condição não estética surge, denominada sorriso gengival (PEDRON, 2016).

Hoje os padrões de beleza estéticos são muito procurados e a exigência dos pacientes e o senso estético moderno é alto. O tratamento odontológico não compreende apenas a promoção de saúde, mas também na obtenção de um sorriso harmonioso, em que a aspiração do paciente é ser visto como bonito, e com desejo de eliminar qualquer característica desagradável (SOUSA et al., 2019). 
É importante dizer que o sorriso gengival de forma isolada não pode ser considerado como um fator que prejudica a estética, pois é necessário avaliar como esse tecido gengival se relaciona com os dentes e com os lábios (SILVA et al., 2015). A opinião do paciente também é muito importante, pois o conceito de beleza é subjetivo, dependendo da pessoa que vai analisar e também sofre com influências culturais e sociais (DA ROCHA et al., 2019).

Segundo Motta et al. (2012), a estética é uma percepção ou sensação, e se torna subjetiva pelas variedades de gosto e opiniões que existem. Entretanto, num estudo feito por Oliveira et al. (2018), foi revelado as características de um sorriso considerado mais belo e atraente. Esses sorrisos apresentavam arcos paralelo, incisivos ovais com bordas arredondadas, aumento da ameia incisal, redução do espaço conector na progressão distal, exposição dos incisivos superiores, exposição mínima dos dentes inferiores e papilas interdentais, ausência de assimetrias, diastemas, espaços negros e inclinação do plano incisal.

Durante o sorriso, a gengiva e as estruturas periodontais são expostas, podendo ser classificadas conforme a altura da exposição gengival. Vale lembrar que as linhas de referência nos ajudam a identificar imperfeições no sorriso, já a linha sagital mediana nos auxilia a identificar assimetrias, e a linha baixa pode nos indicar um sorriso baixo (SANTOS et al., 2016). Muitas etiologias são propostas para ocasião do sorriso gengival, tais como o excesso vertical da maxila, erupção passiva tardia, problemas na formação do osso alveolar, causas hereditárias, freio labial mal posicionado ou muito volumoso, comprimento reduzido da coroa clínica dos dentes e hiperfunção dos músculos envolvidos no sorriso, ou seja, o excesso da exposição gengival pode ser causado por fatores dento-gengivais (PONTES et al., 2016).

Além do excesso de gengiva, outra característica que muitas vezes traz desconforto ao paciente é a cor da mucosa gengival, que pode se apresentar com uma coloração escura e, assim, estabelece potencial para prejudicar a estética e harmonia do sorriso (ZARONE et al., 2017). A gengivoplastia tem sido a principal escolha de tratamento à estética vermelha, por ser um procedimento simples e eficiente, que restabelece contornos gengivais e aumenta a coroa dentária (DA ROCHA et al., 2019). Dentre os principais benefícios da gengivoplastia então o alinhamento e nivelamento das gengivas sem harmonia, a retirada total ou diminuição do sorriso gengival, a 
modificação da arquitetura tecidual e recuperação de dentes com fraturas dentárias (PONTES et al., 2016). Além da gengivoplastia, tem-se outros procedimentos que aparecem como aliados da harmonização do sorriso, tais como miectomia e a cirurgia ortognática, porém esses são mais invasivos.

Uma opção terapêutica mais conservadora, que tem apresentado resultados relevantes de cunho estético nos tecidos gengivais, é o uso da toxina botulínica, em que pesquisas recentes apontam como um método efetivo, rápido e seguro. Ela atua inibindo o fluxo de acetilcolina na junção neuromuscular, evitando, assim, a contração do músculo. A toxina botulínica mais utilizada é a do tipo $A$, sendo o tratamento de primeira escolha em casos de hiperfunção muscular, pois reduz as contrações musculares do lábio superior, de modo a reduzir exposição gengival (PEDRON, 2016). Vale lembrar que os efeitos da toxina botulínica na estética do sorriso apresentaram melhores resultados, quando associada à gengivoplastia, possibilitando menores possibilidades de recidivas.

A estética branca também é fundamental para harmonia do sorriso. Com os avanços tecnológicos dos sistemas adesivos, cerâmicas e das técnicas odontológicas, mais opções de tratamento surgem para restabelecer a estética branca, tais como as lentes de contato produzidas com cerâmicas e também restaurações convencionais com resina (SILVA et al., 2015). O uso de resina composta tem se mostrado muito relevante e eficaz ao longo dos anos em relação ao restabelecimento estético, podendo corrigir o tamanho e formato dos dentes (SANTOS et al., 2016). Os procedimentos com resina são rápidos e possuem baixo custo, porém as cerâmicas têm se apresentado como uma ótima opção para procedimentos de restauração estética indireta, em que recobre a face vestibular dos dentes e são fixadas por um material adesivo. As principais vantagens das facetas cerâmicas em relação às resinas é que elas possibilitam menor acúmulo de biofilme, maior resistência à fratura e desgaste, proporcionando uma maior durabilidade do material, além da estabilidade de cor ser maior (UZÊDA et al., 2020).

É muito importante, nos procedimentos odontológicos, respeitar os espaços biológicos. Isso inclui os formatos das ameias e papilas dentárias, de modo que não sejam perdidas, visto que as papilas interdentais são muito importantes para o sorriso estético e sua perda pode causar malefícios à saúde bucal, como acúmulo de biofilme, cáries dentárias e dificuldade de pronúncia (SPANO et al., 2019). 
Os Black Spaces podem ser causados por inúmeros fatores, tais como o envelhecimento, mediante a alteração do epitélio e redução da altura das papilas. Outro fator é o biótipo periodontal, que dependendo do suprimento sanguíneo, os riscos de recessões após traumas ou cirurgias são maiores. Durante a movimentação ortodôntica e tratamentos estéticos como colocação de facetas também surgem esses riscos do aparecimento dos black spaces (PUGLIESE et al., 2019). Visto que são totalmente prejudiciais à estética do sorriso, surge então a necessidade de combatê-los com intuito de promover a harmonia do sorriso. Um tratamento que vem se mostrando promissor na área estética odontológica é a injeção do ácido hialurônico, que apresentou bons resultados na reconstrução da papila interdental, porém apenas pequenas deficiências apresentam melhoras satisfatórias para harmonia estética do sorriso (PATIL et al., 2020). Muitas técnicas são propostas para restabelecer o tecido papilar, tais como a curetagem periódica com preservação da papila, retalho pedículo e a aplicação do ácido hialurônico, sendo este último menos invasivo e confortável ao paciente (KAPOOR et al., 2020).

A harmonia estética do sorriso engloba um sistema multidisciplinar odontológico, portanto é necessário mais estudo para avaliar os fatores que podem prejudicar a estética e estabelecer medidas para tratá-los.

\section{CONSIDERAÇÕES FINAIS}

A cirurgia plástica periodontal possui um impacto positivo na harmonia do sorriso em procedimentos como mudança da cor da mucosa e gengivoplastia, sendo que esta última pode ser associada ao uso da toxina botulínica, apresentando bons resultados na eliminação do sorriso gengival e no tratamento da estética vermelha.

A preservação das ameias e papilas interdentais são importantes para harmonia do sorriso, de modo a evitar os espaços escuros, e o ácido hialurônico tem sido utilizado para solucionar esses casos.

\section{REFERÊNCIAS}

DA ROCHA, E. F.; HEMMER, B.; DA ROCHA, V. C. F. Harmonização do sorriso através da cirurgia plástica periodontal: um relato de caso. Revista Eletrônica Acervo Saúde. v. 26 n. 26, p. e780-e780, 2019. 
GONTIJO, G. M. V.; NETO, J. G.; DOS SANTOS, K. V. R.; DE SOUZA, J. B.; DE CASTRO, A. T. Harmonização do sorriso por meio de cirurgia periodontal e restaurações diretas em resina composta. Revista Odontológica do Brasil Central, v. 29, n. 88, p.2933, 2020.

KAPOOR, S.; DUDEJA, A. Derma fillers: Ray of light in black triangles-A pilot study. Contemporary Clinical Dentistry, v. 11, n. 1, p. 55, 2020.

MOTTA, A. F. J. D.; MUCHA, J. N.; SOUZA, M. M. G. D. Influence of certain tooth characteristics on the esthetic evaluation of a smile. Dental Press Journal of Orthodontics. v. 17, n. 3, p. e1-e6, 2012.

OLIVEIRA, P. L. E.; MOTTA, A.; PITHON, M.; MUCHA, J. Details of pleasing smiles. Int J Esthet Dent. v. 13, n. 4, p. 494-514, 2018.

PATIL, S. C.; DHALKARI, C. D.; INDURKAR, M. S. Hyaluronic acid: Ray of hope for esthetically challenging black triangles: A case series. Contemporary Clinical Dentistry. V. 11, n. 3, p. 280, 2020.

PEDRON, I. G. Toxina botulínica tipo A associada a cirurgia gengival ressectiva no manejo do sorriso gengival. Journal of Clinical Dentistry \& Research. v. 13, n. 3, p. 62-67, 2016.

PONTES, S. A.; DUARTE, P. M.; DE OLIVEIRA, A. C. G.; COELHO, E. F.; ESTEVES, F. M.; DE MELLO, G. B. R.; RETAMAL-VALDES, B. S. Aumento de coroa clínica estético minimamente invasivo: relato de caso de 12 meses. Revista Saúde-UNG-Ser. v. 10, n. 3/4, p. 55-64, 2017.

PUGLIESE, F.; HESS, R.; PALOMO, L. Black triangles: Preventing their occurrence, managing them when prevention is not practical. Seminars in Orthodontics. $v$. 25, n. 2, p. 175-186, 2019.

SANTOS, F. R., ZAMBONI, F. T., YAMAGUCHI, P. S., STORRER, C. L. M., OSTERNACK, F. H. R., DE OLIVEIRA, N. D., \& DELIBERADOR, T. M. Correction of gummy smile prior to restorative procedures: case report. RSBO Revista Sul-Brasileira de Odontologia. v. 13, n. 2, p. 124-130, 2016.

SILVA, W. D. O.; ALMEIDA, R. F.; LEAL, L.; de CARVALHO JUNIOR, E. U. Recontorno estético multidisciplinar com cirurgia plástica gengival e laminados cerâmicos de dissilicato de lítio: passo a passo. Revista Dental Press de Estética. v. 12, n. 4, p. 101-118, 2015.

SOUSA, S. M. L.; DE ARAÚJO, I. D. T.; ABRANTES, P. S.; BORGES, B. C. D.; DE ASSUNÇÃO, I. V. Harmonização do sorriso com gengivoplastia e resina composta. Revista Ciência Plural, v. 5, n. 3, p. 143-152, 2019. 
SPANO S. J.; GHILZON, R.; LAM, D. K.; GOLDBERGI, M. B.; TENENBAUM, H. C. Subperiosteal Papilla Augmentation with a non-animal-derived hyaluronic acid Overlay technique. Clinical advances in periodontics. V. 10, n. 1, p. 4-9, 2020.

UZÊDA, K. R. T.; DE ARAÚJO, I. D. T.; DE OLIVEIRA, V. J.; DOS SANTOS, A. J. S.; BORGES, B. C. D.; DE ASSUNÇÃO, I. V. Harmonização do sorriso com laminados cerâmicos: relato de caso. Revista Ciência Plural. V. 6, n. 3, p. 239-254, 2020.

ZARONE, F.; LEONE, R.; FERRARI, M.; SORRENTINO, R. Treatment Concept for a Patient with a High Smile Line and Gingival Pigmentation: A Case Report. International Journal of Periodontics \& Restorative Dentistry. v. 37, n. 2, p. 55-64, 2017. 


\title{
CAPITULO ॥ \\ PERIODONTITE CRÔNICA E NIVEIS SÉRICOS DE HEPCIDINA E HEMOGLOBINA
}

\author{
DOI: 10.51859/AMPLLA.EPC757.1121-2
}

\author{
Rosana Costa Casanovas ${ }^{1}$ \\ Sandra Augusta Moura Leite ${ }^{1}$ \\ César Augusto Abreu-Pereira ${ }^{2}$ \\ Vandilson Pinheiro Rodrigues ${ }^{1}$ \\ Isaac Suzart Gomes Filho ${ }^{3}$ \\ Marcus Gomes Bastos ${ }^{3}$ \\ Antônio Luiz Amaral Pereira ${ }^{1}$
}

\footnotetext{
${ }^{1}$ Professor Associado do Departamento de Odontologia I. Universidade Federal do Maranhão - UFMA.

2 Doutorando em Odontologia. Universidade Estadual Paulista - UNESP.

${ }^{3}$ Universidade Estadual de Feira de Santana, Feira de Santana, Bahia, Brasil.
}

\section{RESUMO}

Objetivo: Investigar a influência da periodontite crônica nos níveis séricos de hepcidina e hemoglobina em indivíduos sistemicamente saudáveis, bem como avaliar a associação entre interleucina-6 (IL-6) e hepcidina com as variáveis do hemograma, marcadores inflamatórios e reservas de ferro em indivíduos com periodontite. Métodos: Este estudo transversal incluiu 67 pacientes sistemicamente saudáveis, sendo 36 no grupo com diagnóstico de periodontite crônica e 31 no grupo sem esta doença. Foram coletados dados clínicos, periodontais e laboratoriais. Os grupos foram comparados estatisticamente de acordo com as variáveis numéricas ou categóricas, bem como o uso de teste de correlação, com nível de significância de 5\%. Resultados: Não houve diferença estatisticamente significante entre os grupos $(p>0,05)$, quanto às variáveis relacionadas ao hemograma, marcadores inflamatórios e reservas de ferro. Os achados também não demonstraram associação estatisticamente significante entre a IL-6 e a hepcidina com as variáveis do hemograma, marcadores inflamatórios e reserva de ferro em indivíduos com periodontite $(p>0,05)$. Conclusão: Em indivíduos sistemicamente saudáveis, a periodontite crônica não se mostrou associada com os níveis séricos de hepcidina e hemoglobina, no entanto as evidências preliminares sinalizam para os valores da VHS aumentada, bem como os níveis diminuídos de hematócrito e ferro sérico. Essas alterações sutis devem ser consideradas, pois podem contribuir para a carga inflamatória e suas consequências na eritropoiese, em indivíduos sistemicamente comprometidos com outras comorbidades.

Palavras-chave: Periodontite crônica. Hepcidinas. Hemoglobinas. Inflamação. Anemia. 


\section{INTRODUÇÃO}

A periodontite crônica é uma doença infecto-inflamatória das estruturas periodontais que protegem e sustentam os dentes, causada por microrganismos específicos, principalmente por bactérias gram-negativas e anaeróbias, resultando em um processo inflamatório crônico. Essa inflamação crônica de baixa intensidade tem sido sugerida como um mecanismo que determina a plausibilidade biológica entre as doenças periodontais a outras doenças/condições sistêmicas, a exemplo das cardiovasculares, cerebrovasculares, diabetes mellitus, artrite reumatoide, nascimento de bebês prematuros e/ou de baixo peso, doença respiratória obstrutiva, dentre outras. (KHADER et al., 2004; ALMEIDA et al., 2006; O'CONNEL et al., 2008; DETERT et al., 2010; GOMES-FILHO et al., 2010; SHI et al., 2013).

A perpetuação da resposta do hospedeiro devido à infeç̧ão bacteriana persistente interrompe os mecanismos homeostáticos e resulta na liberação pelos macrófagos e monócitos de mediadores, incluindo as citocinas pró-inflamatórias (Interleucina [IL]-1, IL-6, fator de necrose tumoral alfa [TNF- $\alpha$ ]), proteases (metaloproteinases [MMPs]) e prostanoides (prostaglandina $E_{2}$ [PGE2]). Além disso, estimulam a produção de proteínas de fase aguda como a Proteína C-reativa (PCR), sendo a IL-6 seu principal indutor (PAGE, 1998; GROSKA et al., 2003; IDE at al., 2003; LOOS, 2005; FORNER et al., 2006; MARCACCINI et al., 2009).

Dentre as proteínas de fase aguda cuja produção é aumentada durante a infecção e inflamação, está a hepcidina, que é predominantemente produzida pelo fígado e excretada pela urina, tendo como principais funções a regulação homeostática do metabolismo de ferro e a modulação da defesa orgânica (Ganz, 2007). A hepcidina age ligando-se à ferroportina, um transportador de ferro presente principalmente nos enterócitos, macrófagos e hepatócitos. O aumento da hepcidina circulante, devido ao estímulo inflamatório, induz internalização e degradação de ferroportina. A perda de ferroportina da superfície celular impede a saída de ferro do interior das células para o plasma, resultando na baixa saturação de transferrina, consequente diminuição da eritropoiese, contribuindo para a anemia da doença crônica (DOMENICO et al., 2007; NEMETH \& GANZ, 2009). Investigando indivíduos com doença renal, Vilela et al. (2011) observaram o impacto do tratamento periodontal na melhora dos níveis de 
hemoglobina circulante ao estudarem os principais marcadores inflamatórios, como IL6, PCR e prohepcidina, sendo considerada investigação pioneira sobre a associação entre periodontite crônica e o pró-hormônio da hepcidina.

Diante da alta prevalência da periodontite crônica na população (PIHLSTROM et al., 2005; HUGOSON \& NORDERYD, 2008; HOLTFRETER et al., 2010) e sendo ela um processo infeccioso/inflamatório local com resposta sistêmica, traduzida por aumento de PCR, IL-6 e possivelmente da hepcidina, o objetivo deste estudo foi investigar se há associação da periodontite crônica com os níveis séricos de hepcidina e hemoglobina em indivíduos sem outras doenças, bem como avaliar a associação entre IL-6 e hepcidina com variáveis do hemograma, marcadores inflamatórios e reservas de ferro entre indivíduos com periodontite crônica.

\section{METODOLOGIA}

\subsection{DESENHO DO ESTUDO}

O estudo foi aprovado pelo Comitê de Ética em Pesquisa Humana da Universidade Federal do Maranhão, São Luís, Maranhão, Brasil, sob o parecer n² 23115010215/2011-16. Todos os participantes assinaram o termo de consentimento livre e esclarecido concordando em participar do estudo. Foi realizado um estudo transversal, de abril a outubro de 2013 , com indivíduos que aguardavam atendimento nas Clínicas de Periodontia e Semiologia do Curso de Odontologia da Universidade Federal do Maranhão, São Luís, Brasil. A amostra foi composta por 67 indivíduos, de ambos os sexos, na faixa etária de 30 a 65 anos, sem outras doenças, com no mínimo 20 dentes, selecionados de um total de 125 indivíduos segundo os critérios de elegibilidade. Destes, dois grupos foram formados de acordo com a presença ou não da infecção periodontal: grupo com periodontite (36 indivíduos) e grupo sem periodontite (31 indivíduos).

\subsection{CRITÉRIOS PARA SELEÇ̃̃O DA AMOSTRA}

Não foram incluídos no estudo indivíduos com diagnóstico de diabetes mellitus, insuficiência cardíaca congestiva, doença renal crônica, neoplasias malignas, AIDS, hipertensos, gestantes, lactantes, imunossuprimidos por medicação, portadoras de alterações no fluxo menstrual, fumantes ou ex-fumantes há menos de 10 anos, usuários de aparelho ortodôntico, história de uso de anti-inflamatórios esteroides ou não 
esteroides e antibioticoterapia nos 3 meses anteriores ao estudo e durante a pesquisa, bem como indivíduos em reposição de ferro para tratamento de anemia e realização de raspagem subgengival e cirurgia periodontal nos 6 meses anteriores à investigação.

No grupo com periodontite foram incluídos indivíduos sistemicamente saudáveis, portadores de periodontite crônica no estágio avançado, com pelo menos dois dentes com nível de inserção clínica $\geq 6 \mathrm{~mm}$ e profundidade de sondagem $\geq 5 \mathrm{~mm}$ em um ou mais sítios (MACHTEl et al., 1992), associada à presença de sangramento à sondagem. O grupo sem periodontite foi composto por indivíduos sem doenças sistêmicas. Quanto aos aspectos periodontais foram observados ausência de sangramento, profundidade de sondagem até $3 \mathrm{~mm}$ e índice de placa de até $25 \%$ (ARMITAGE, 1999).

Figura 1: Fluxograma do estudo.

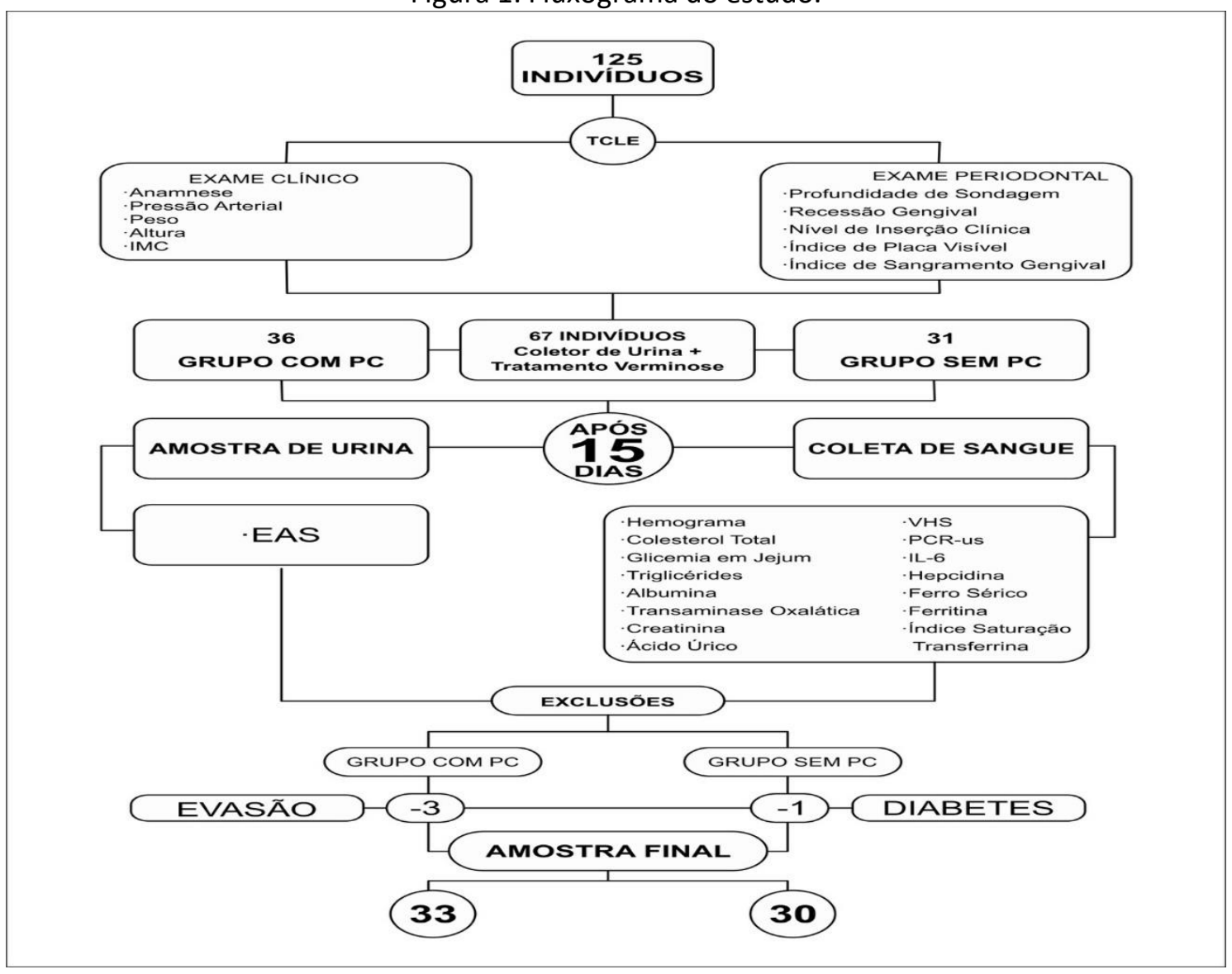

Fonte: Elaboração própria.

\subsection{PROCEDIMENTOS DE COLETA DE DADOS CLÍNICOS}

Na primeira visita foi realizado o preenchimento da ficha clínica para seleção de voluntários sem doenças sistêmicas pré-diagnosticadas e inclusão no estudo, além do 
exame clínico geral e periodontal; entrega do coletor de urina e ingestão de medicamento para tratamento de verminose [Albendazol (Prati-Donaduzzi \& Cia LTDA, Paraná, BRASIL) de 400mg em dose única]. Após 15 dias, os indivíduos que cumpriram os critérios iniciais da seleção retornaram para coleta de sangue e entrega da amostra de urina para avaliação dos marcadores bioquímicos. De acordo com os resultados dessas análises laboratoriais, os indivíduos foram mantidos ou excluídos do estudo após a eliminação daqueles com diagnóstico de doenças sistêmicas não identificadas previamente (Figura 1).

O exame das condições clínicas sistêmicas foi realizado por um único examinador devidamente treinado para o correto preenchimento da ficha clínica. Foi realizada a anamnese para obtenção dos dados pessoais, da história médica e odontológica atual e pregressa, história familiar, medicamentos em uso, possíveis alterações do fluxo menstrual, bem como a aferição da pressão arterial, peso, altura e, por fim, cálculo do índice de massa corporal obtido pela divisão do peso pela altura ao quadrado.

O exame clínico periodontal utilizando uma sonda periodontal milimetrada tipo Williams PCPUNC-156 (Hu-Friedy ${ }^{\oplus}$,Mgf.Co.Inc.,Chicago,USA) incluiu a sondagem de seis sítios por dente (mésio-vestibular, médio-vestibular, disto-vestibular, disto-lingual, médio-lingual, mésio-lingual), realizado por um único examinador, cirurgião-dentista especialista em periodontia e previamente treinado. O coeficiente de concordância intraexaminador foi 0,81 para profundidade de sondagem e 0,77 para nível de inserção clínica, indicando que não houve viés sistemático na medição (Teste Kappa). Os seguintes parâmetros clínicos foram avaliados: Profundidade à Sondagem (PS), Recessão Gengival (RG) e Nível de Inserção Clínica (NIC), além do Índice de Placa Visível (IPV), Índice de Sangramento à Sondagem (ISS) segundo Ainamo \& Bay, 1975.

\subsection{ANÁLISES LABORATORIAIS}

Amostras de sangue venoso ( $20 \mathrm{ml})$ foram coletadas em tubos a vácuo após $12 \mathrm{~h}$ de jejum. Uma parte do sangue total foi coletado em EDTA e uma alíquota, separada para avaliação do hemograma, pela técnica de impedância por laser no aparelho ADVIA 2120. O restante do sangue anticoagulado com EDTA foi centrifugado por 10 minutos a 3000rpm para a separação do plasma, aliquotado e armazenado a -70ㄷ C até as análises futuras das concentrações de IL-6. 
Os seguintes exames laboratoriais foram realizados: Hemograma, Colesterol Total, Glicemia em Jejum, Triglicérides, Albumina, Transaminase Oxalática, Creatinina, Ácido Úrico, Velocidade de Hemossedimentação (VHS), PCR-us, IL-6, Hepcidina, Ferro Sérico, Ferritina, Índice de Saturação de Transferrina, além de exame de urina para elementos anormais e sedimentoscopia (EAS).

O soro foi obtido pela adição de sangue venoso em tubo contendo um ativador da coagulação. Após centrifugação por 15 minutos a 1800rpm, o soro foi separado. Parte do soro foi aliquotado para avaliação colorimétrica da ferritina pela técnica de quimioluminescência (Modular Roche, Roche Diagnostic System, New Jersey, USA); ferro sérico pela técnica de Ferrozine (Backman, Synchron Clinical System, San Diego, USA) e índice de saturação de transferrina, pela técnica Goodwin modificada (Backman, Synchron Clinical System, San Diego, USA) usando o ADVIA 2400. A nefelometria foi utilizada para as dosagens da PCR-us e o restante do soro foi estocado a $-70^{\circ} \mathrm{C}$ para análise da hepcidina.

A IL-6 e a hepcidina foram avaliadas pela técnica de imunoensaio por meio do kit ELISA (IBL International, Hamburg, GERMANY) específico, de acordo com as instruções do fabricante. As leituras foram realizadas por leitor automático de microplacas, e a absorbância foi lida no comprimento de onda de $450 \mathrm{~nm}$ em espectrofotômetro MULTISKAN EX (Multiskan EX, Labsystems, Bucharest, ROMANIA).

\subsection{ANÁLISE ESTATÍSTICA}

Inicialmente, a análise descritiva foi conduzida da variável independente principal (periodontite) e de todas as covariáveis do estudo, expressa pela média, desvio padrão, mediana e intervalo interquartílico, para as variáveis numéricas e pela frequência relativa e percentual para variáveis categóricas.

A comparação das variáveis clínicas, periodontais, do hemograma, marcadores inflamatórios e reservas de ferro entre os grupos com periodontite e sem periodontite foi feita pelo teste $t$ de Student para amostras independentes ou Teste de MannWhitney (não paramétrico) para dados numéricos e pelo teste $\chi^{2}$ para dados categóricos. A correlação entre variáveis numéricas foi analisada pelo coeficiente de correlação de Spearman. O critério de determinação de significância adotado foi o nível de 5\%. A 
análise estatística foi processada pelo programa SAS ${ }^{\oplus}$ System versão 6.11 (SAS Institute, Inc., Cary, North Carolina,USA).

\section{RESULTADOS}

A Tabela 1 apresenta a distribuição das variáveis demográficas, clínicas, laboratoriais e parâmetros periodontais segundo os grupos com e sem periodontite. Os achados demonstraram que não houve diferenças estatisticamente significantes entre os grupos de comparação para as variáveis demográficas, clínicas e laboratoriais ( $p>$ 0,05). No entanto, os parâmetros clínicos periodontais apresentaram diferenças estatisticamente significantes entre os grupos, com maiores médias apresentadas no grupo de indivíduos com periodontite.

Observou-se, ainda, que para o grupo com periodontite houve predomínio de participantes mulheres, maiores médias de idade, de pressão sistólica e diastólica, de índice de massa corporal, de glicemia, bem como de taxa de filtração glomerular, em comparação com o grupo sem periodontite.

Quanto às variáveis relacionadas ao hemograma, marcadores inflamatórios e reservas de ferro, pode-se observar na Tabela 2 que não houve diferença estatisticamente significante entre os grupos com e sem periodontite $(p>0,05)$, para todas as variáveis analisadas.

A Tabela 3 apresenta a associação entre a IL-6 e hepcidina com variáveis relativas ao hemograma, aos marcadores inflamatórios e de reservas de ferro no grupo de indivíduos com periodontite, por meio do coeficiente de correlação de Spearman $\left(r_{s}\right)$ e seu respectivo nível descritivo $(p)$. Os achados demonstram que não existe associação estatisticamente significante entre a IL-6 e a hepcidina com as variáveis referidas $(p>$ $0,05)$. 
Tabela 1. Distribuição das variáveis demográficas, clínicas, laboratoriais e parâmetros periodontais segundo os grupos com e sem periodontite.

\begin{tabular}{|c|c|c|c|c|c|c|c|}
\hline \multirow{2}{*}{ Variáveis } & \multicolumn{3}{|c|}{ Grupo com periodontite $(n=33)$} & \multicolumn{3}{|c|}{ Grupo sem periodontite $(n=30)$} & \multirow{2}{*}{$\mathbf{P}$} \\
\hline & n (\%) & Média \pm dp & Mediana (IIQ) & n (\%) & Média \pm dp & Mediana (IIQ) & \\
\hline \multicolumn{8}{|l|}{ Demográficas/ Clínicas/ } \\
\hline \multicolumn{8}{|l|}{ Laboratoriais } \\
\hline Gênero & & & & & & & 0,96 \\
\hline Masculino & $13(39,4)$ & & & $12(40,0)$ & & & \\
\hline Feminino & $20(60,6)$ & & & $18(60,0)$ & & & \\
\hline Idade & & $41,1 \pm 7,8$ & $40(30-58)$ & & $39,7 \pm 8,9$ & $39,5(30-68)$ & 0,44 \\
\hline Pressão Arterial Sistólica & & $110,6 \pm 12,2$ & $110(90-140)$ & & $110,0 \pm 14,0$ & $110(90-130)$ & 0,78 \\
\hline Pressão Arterial Diastólica & & $68,8 \pm 9,3$ & $70(50-90)$ & & $67,3 \pm 7,8$ & $70(50-80)$ & 0,50 \\
\hline Índice de Massa Corporal ${ }^{1}$ & & $26,1 \pm 3,7$ & $25,9(18-33,3)$ & & $25,9 \pm 4,0$ & $25,8(18,2-37,9)$ & 0,78 \\
\hline Glicemia & & $84,9 \pm 8,2$ & $84(72-103)$ & & $83,4 \pm 7,3$ & $82(73-110)$ & 0,41 \\
\hline Taxa de Filtração Glomerular & & $105,4 \pm 24,4$ & $101(69-168,9)$ & & $104,1 \pm 26,4$ & $104,7(60,8-161,3)$ & 0,86 \\
\hline \multicolumn{8}{|l|}{ Parâmetros Periodontais } \\
\hline Profundidade de Sondagem & & $2,44 \pm 0,48$ & $2,40(1,72-3,53)$ & & $1,82 \pm 0,24$ & $1,85(1,19-2,24)$ & 0,0001 \\
\hline Nível de Inserção Clínica & & $2,96 \pm 0,54$ & $2,82(2,07-4,02)$ & & $2,05 \pm 0,33$ & $2,05(1,22-2,83)$ & 0,0001 \\
\hline Índice de Placa Visível & & $8,61 \pm 8,33$ & $6,19(0-37,6)$ & & $2,13 \pm 2,62$ & $0,88(0-7,62)$ & 0,0001 \\
\hline Índice de Sangramento à Sondagem & & $11,6 \pm 9,90$ & $9,17(0-37,6)$ & & $1,18 \pm 1,22$ & $0,89(0-4)$ & 0,0001 \\
\hline
\end{tabular}

Fonte: Elaboração própria.

Tabela 2. Distribuição das variáveis do hemograma, marcadores inflamatórios e de reserva de ferro segundo os grupos com e sem periodontite.

\begin{tabular}{|c|c|c|c|c|c|c|}
\hline \multirow[t]{2}{*}{ Variáveis } & \multicolumn{2}{|c|}{$\begin{array}{c}\text { Grupo com periodontite }(n= \\
\mathbf{3 3})\end{array}$} & \multicolumn{2}{|c|}{ Grupo sem periodontite $(n=30)$} & \multirow{2}{*}{$\begin{array}{l}\text { Valor de } \\
\text { referência }\end{array}$} & \multirow[t]{2}{*}{$\mathbf{P}$} \\
\hline & Média \pm dp & Mediana (IIQ) & Média \pm dp & Mediana (IIQ) & & \\
\hline \multicolumn{7}{|l|}{ Hemograma } \\
\hline Hemoglobina $(\mathrm{g} / \mathrm{dL})$ & $13,5 \pm 2,2$ & $13,6(6,4-16,3)$ & $14,2 \pm 1.4$ & $14(10,2-16,8)$ & $12,0-16,0$ & 0,18 \\
\hline Hematócrito $(\%)$ & $41,0 \pm 5,8$ & $41,3(24,3-49,2)$ & $43,4 \pm 4,1$ & $42,8(32,4-50,5)$ & $36,0-48,0$ & 0,07 \\
\hline Eritrócitos (milhões $\left./ \mathrm{mm}^{3}\right)$ & $4,62 \pm 0,48$ & $4,6(3,55-5,64)$ & $4,78 \pm 0,45$ & $4,73(3,84-5,69)$ & $3,9-5,3$ & 0,28 \\
\hline Volume Corpuscular Médio (fL) & $87,1 \pm 12,1$ & $89(38,5-103,9)$ & $90,8 \pm 4,3$ & $91,6(80,1-97,8)$ & $80,0-100,0$ & 0,29 \\
\hline Hemoglobina Corpuscular Média (pg) & $29,0 \pm 3,4$ & $29,7(14,7-34,3)$ & $29,7 \pm 1,5$ & $29,9(25,2-31,8)$ & $27,0-33,0$ & 0,66 \\
\hline \multicolumn{7}{|l|}{ Marcadores inflamatórios } \\
\hline Proteína C-reativa ultrassensível (mg/dL) & $0,28 \pm 0,34$ & $0,12(0,01-1,29)$ & $0,25 \pm 0,39$ & $0,08(0,01-1,90)$ & $<0,50^{3}$ & 0,41 \\
\hline Interleucina $6^{1}(\mathrm{pg} / \mathrm{mL})$ & $16,0 \pm 8,6$ & $14,0(8,4-58,7)$ & $14,6 \pm 5,2$ & $12,9(11,3-39,4)$ & $\leq 13,0$ & 0,28 \\
\hline $\operatorname{Hepcidina}^{2}(\mathrm{ng} / \mathrm{mL})$ & $65,6 \pm 14,3$ & $64,2(38,1-98,6)$ & $60,9 \pm 13,0$ & $62,7(23,9-82,5)$ & $13,3-54,4$ & 0,19 \\
\hline Velocidade de Hemossedimentação (mm) & $6,64 \pm 5,61$ & $5(1-23)$ & $5,47 \pm 8,17$ & $3(1-45)$ & $\leq 10,0$ & 0,09 \\
\hline \multicolumn{7}{|l|}{ Reservas de ferro } \\
\hline Ferro Sérico $(\mu \mathrm{g} / \mathrm{dL})$ & $88,8 \pm 38,0$ & $89(10-199)$ & $104,6 \pm 31,8$ & $108,5(18-155)$ & $\begin{array}{l}\mathrm{H}: 65,0-175,0 \\
\mathrm{M}: 50,0-170,0\end{array}$ & 0,08 \\
\hline Índice de Saturação de Transferrina (\%) & $34,5 \pm 16,1$ & $32,5(3,4-70,3)$ & $39,4 \pm 13,5$ & $38(4,7-64,3)$ & $20,0-55,0$ & 0,19 \\
\hline Ferritina $(\mathrm{ng} / \mathrm{mL})$ & $125,2 \pm 130,6$ & $77,8(2,5-500,1)$ & $127,1 \pm 127,6$ & $73,3(7,6-549,9)$ & $\begin{array}{l}\mathrm{H}: 22,0-322,0 \\
\mathrm{M}: 10,0-291,0\end{array}$ & 0,96 \\
\hline
\end{tabular}

${ }^{1}$ Perda de uma informação no grupo com periodontite. ${ }^{2}$ Perda de duas informações em ambos os grupos. ${ }^{3}$ Negativo para doenças inflamatórias na fase aguda. $\pm \mathrm{dp}=$ desvio-padrão. IQQ = Intervalo interquartílico $\left(1^{\circ}\right.$ quartil- $3^{\circ}$ quartil $) . \mathrm{H}=$ valores para homens. $\mathrm{M}=$ valores para mulheres.

Fonte: Elaboração própria. 
Tabela 3. Associação entre a Interleucina-6 (IL-6) e hepcidina com as variáveis do hemograma, marcadores inflamatórios e reservas de ferro no grupo com periodontite.

\begin{tabular}{|c|c|c|c|c|}
\hline \multirow{2}{*}{ Variável } & \multicolumn{2}{|c|}{ IL-6 $\left(n=32^{1}\right)$} & \multicolumn{2}{|c|}{ Hepcidina $\left(\mathrm{n}=31^{2}\right)$} \\
\hline & $\mathbf{r}_{\mathbf{s}}$ & $\boldsymbol{P}$ & $\mathbf{r}_{\mathrm{s}}$ & $\boldsymbol{P}$ \\
\hline \multicolumn{5}{|l|}{ Hemograma } \\
\hline Hemoglobina & 0,150 & 0,41 & $-0,043$ & 0,82 \\
\hline Hematócrito & 0,191 & 0,30 & $-0,050$ & 0,79 \\
\hline Volume Corpuscular Médio & $-0,202$ & 0,27 & 0,308 & 0,092 \\
\hline Hemoglobina Corpuscular Média & $-0,223$ & 0,22 & 0,288 & 0,12 \\
\hline \multicolumn{5}{|l|}{ Marcadores inflamatórios } \\
\hline Proteína C- reativa ultrassensível & 0,031 & 0,87 & 0,047 & 0,80 \\
\hline IL-6 ${ }^{1}$ & & & 0,178 & 0,35 \\
\hline Velocidade de Hemossedimentação & $-0,295$ & 0,10 & 0,026 & 0,89 \\
\hline \multicolumn{5}{|l|}{ Reservas de ferro } \\
\hline Ferro Sérico & $-0,039$ & 0,83 & 0,018 & 0,92 \\
\hline Índice de Saturação de Transferrina & 0,085 & 0,64 & $-0,108$ & 0,56 \\
\hline Ferritina & 0,020 & 0,91 & 0,032 & 0,86 \\
\hline
\end{tabular}

Fonte: Elaboração própria.

\section{DISCUSSÃO}

De acordo com os principais achados da presente investigação, observou-se que a periodontite crônica não se mostrou associada com os níveis séricos de hepcidina e hemoglobina, tendo essa hipótese sido levantada pelo conhecimento de que a periodontite é uma doença inflamatória que poderia aumentar os níveis de hepcidina, proteína de fase aguda, e resultar em alterações hematimétricas. Como não foram encontrados estudos prévios sobre a temática, este trabalho é o primeiro a estimar a associação entre a infecção periodontal e os níveis de hepcidina e hemoglobina no sangue. Outros achados obtidos nesta pesquisa merecem ser destacados e discutidos diante da sua relevância para o tema em questão, além de que o nível de significância entre os grupos de comparação se apresentou limítrofe.

A velocidade de hemossedimentação (VHS), por exemplo, medida que evidencia a atividade inflamatória, apresentou-se em nível sérico maior no grupo de indivíduos com periodontite do que naqueles sem a infecção periodontal. O VHS é um parâmetro valioso que fornece ao profissional de saúde uma medida inespecífica da resposta sistêmica frente a uma doença infecciosa ou inflamatória, sugerindo uma alteração plasmática de várias proteínas relacionadas à inflamação. Essa sinalização foi 
confirmada por outros estudos e, ainda, a sua diminuição foi verificada após terapia da infecção periodontal, com resultados estatisticamente significantes (HUTTER et al. 2001; AGARWAL et al., 2009; PRADEEP et al., 2011).

Outros parâmetros que merecem ser destacados são o hematócrito e o ferro sérico. No grupo de indivíduos com periodontite crônica, tanto os valores de hematócrito quanto os de ferro sérico foram menores do que naqueles participantes sem o diagnóstico da infecção periodontal. O valor mais baixo de hematócrito neste grupo pode ser atribuído a um menor número de eritrócitos nos indivíduos com a infecção periodontal, conforme achados de estudos prévios (HUTTER et al., 2001; GOKHALE et al., 2010; PATEL et al., 2014; KOLTE et al., 2014). Reforçando o caráter de anemia da doença crônica, e consequente bloqueio da liberação de ferro intracelular, foram observados menores valores de ferro sérico nos participantes com diagnóstico de periodontite crônica. Esta diminuição do ferro sérico é compatível com as características da anemia da inflamação, confirmadas pelos valores normais do volume corpuscular médio (VCM) no grupo de indivíduos com a infecção periodontal. Sabe-se que valores do VCM diminuídos (microcitose) sugerem deficiência de ferro, característicos da anemia ferropriva; ao passo que valores elevados (macrocitose) são causados por deficiência de vitaminas, características de outro tipo de anemia, a perniciosa (WARD, 1979; SAMSON, 1983).

Neste sentido, a hipótese gerada no presente estudo de que indivíduos sem outras doenças apenas com periodontite crônica apresentem níveis de hepcidina e hemoglobina inferiores àqueles periodontalmente saudáveis tem a sua plausibilidade biológica baseada no conhecimento de que, em resposta à infecção periodontal, as células do sistema de defesa do hospedeiro liberam mediadores imunoinflamatórios, a exemplo da IL-6, TNF$\alpha$, MMPs e PGE2, bem como estimulam a produção de proteínas de fase aguda, como a PCR e a hepcidina (D’AIUTO et al.,2004; LOOS, 2005; FORNER, 2006; YAZDI et al., 2013). Esta última proteína de fase aguda tem como principais funções a modulação da defesa orgânica e a regulação homeostática do metabolismo de ferro (GANZ, 2007).

Sendo a periodontite considerada uma doença crônica, em 2001, Hutter et al. investigaram se indivíduos com diagnóstico de periodontite moderada ou grave apresentavam sinais de anemia em comparação àqueles sem periodontite. Observaram menor número de eritrócitos e, consequentemente, menor valor de hematócrito e 
concentração de hemoglobina, levando ao diagnóstico de anemia em $23 \%$ dos participantes com periodontite e apenas em $7 \%$ daqueles sem periodontite. 0 presente estudo não encontrou resultados estatisticamente significantes como os obtidos por Hutter et al.; no entanto, foram observados valores médios de hematócrito mais baixos no grupo de indivíduos com periodontite, com nível de significância limítrofe. Outras investigações confirmam esses achados, pois também verificaram a associação entre periodontite crônica e anemia (GOKHALE et al.,2010; PRADEEP et al., 2011; PATEL et al., 2014; KOLTE et al., 2014).

O presente estudo não encontrou associação entre a IL-6 e hepcidina com as variáveis do hemograma, PCR-us e de reserva de ferro em indivíduos com periodontite, sendo estes achados contrários àqueles obtidos por Vilela et. al. (2011), que observaram a associação significativa entre a prohepcidina após terapia periodontal e os deltas da IL-6, PCR-us, ferritina e saturação de transferrina no grupo sem doença renal. Entretanto, apenas a IL-6 se mostrou independentemente associada à prohepcidina, com significância estatística, após a análise de regressão linear múltipla. Sabe-se que a IL-6 é o principal indutor de produção de proteínas de fase aguda (PAGE, 1998; GROSKA et al., 2003; NEMETH et al., 2004; LOOS, 2005; FORNER et al., 2006; MARCACCINI et al., 2009), justificando de forma plausível o estudo da sua associação com o nível de hepcidina em indivíduos com o diagnóstico de periodontite.

Marcaccini et al. (2009) encontraram diferença estatisticamente significante entre os grupos de indivíduos com e sem periodontite crônica no que diz respeito aos níveis de IL-6. Por outro lado, eles não observaram diferenças entre os grupos de comparação e os parâmetros bioquímicos e hematológicos avaliados, corroborando os achados do presente estudo.

No presente estudo, o diagnóstico da anemia foi comprovado com o emprego da relação entre parâmetros vermelhos do sangue, com os níveis de marcadores inflamatórios e reservas de ferro. Outros trabalhos utilizaram apenas o hemograma para diagnóstico de anemia, não comprovando a sua relação com outros marcadores (GOKHALE et al.,2010; PRADEEP et al., 2011; PATEL et al., 2014; KOLTE et al., 2014). Diante dos achados acima descritos, este parece ser o primeiro estudo a associar a periodontite crônica com a hepcidina sérica, marcadores inflamatórios (IL-6, PCR-us) e reservas de ferro. 
Dessa maneira, a utilização da hepcidina para o diagnóstico e prognóstico de distúrbios de ferro, bem como o desenvolvimento de agonistas e antagonistas da hepcidina para tratamento das diversas formas de anemia estão longe de ser compreendidos e precisam de avaliação em estudos clínicos futuros com tamanhos maiores de amostras (NEMETH \& GANZ, 2006; NEMETH, 2010; GANZ \& NEMETH, 2011).

\section{CONSIDERACÕ̃ES FINAIS}

A presente investigação é a primeira a estudar a associação entre a periodontite e níveis séricos de hepcidina e hemoglobina em pacientes sistemicamente saudáveis e embora os achados não tenham mostrado associação, evidências preliminares devem ser consideradas diante dos valores da VHS aumentada, bem como hematócrito e ferro sérico diminuídos. Essas alterações sutis não devem ser ignoradas, pois elas podem não ser preocupantes em indivíduos saudáveis, no entanto, podem contribuir sobremaneira à carga inflamatória e suas consequências na eritropoiese quando associadas a outras comorbidades.

\section{REFERÊRENCIAS}

AINAMO, J.; BAY, I. Problems and proposals for recording gingivitis and plaque. International dental journal, v. 25, n. 4, p. 229-35, 1975.

ALMEIDA, R. F. et al. Associação entre doença periodontal e patologias sistêmicas. Revista Portuguesa de Medicina Geral e Familiar, v. 22, n. 3, p. 37990, 2006.

AGARWAL, N.; KUMAR, V.S.C; GUJJARI, S.A. Effect of periodontal therapy on hemoglobin and erythrocyte levels in chronic generalized periodontitis patients: An interventional study. Journal of Indian Society of Periodontology, v. 13, n. 1, p. 6, 2009

ARMITAGE, G.C. Development of a classification system for periodontal diseases and conditions. Annals of periodontology, v. 4, n. 1, p. 1-6, 1999.

D'AIUTO, F.; READY, D.; TONETTI, M.S. Periodontal disease and C-reactive proteinassociated cardiovascular risk. Journal of periodontal research, v. 39, n. 4, p. 236-41, 2004.

DETERT, J. et al. The association between rheumatoid arthritis and periodontal disease. Arthritis research \& therapy, v. 12, n. 5, p. 1-7, 2010. 
DE DOMENICO, I. et al. Hepcidin regulation: ironing out the details. The Journal of clinical investigation, v. 117, n. 7, p. 1755-8, 2007.

FORNER, L. et al. Increased plasma levels of IL- 6 in bacteremic periodontis patients after scaling. Journal of Clinical Periodontology, v. 33, n. 10, p. 724-9, 2006.

GANZ, T. Molecular control of iron transport. Journal of the American Society of Nephrology, v. 18, n. 2, p. 394-400, 2007.

GANZ, T.; NEMETH, E. The hepcidin-ferroportin system as a therapeutic target in anemias and iron overload disorders. Hematology 2010, the American Society of Hematology Education Program Book, v. 2011, n. 1, p. 538-42, 2011.

GOKHALE, S. et al. Evaluation of blood parameters in patients with chronic periodontitis for signs of anemia. Journal of periodontology, v. 81, n. 8, p. 1202-6, 2010.

GOMES-FILHO, I.S. et al. Periodontal therapy and low birth weight: preliminary results from an alternative methodologic strategy. Journal of periodontology, v. 81, n. 12, p. 1725-33, 2010.

GÓRSKA, R. et al. Relationship between clinical parameters and cytokine profiles in inflamed gingival tissue and serum samples from patients with chronic periodontitis. Journal of clinical periodontology, v. 30, n. 12, p. 1046-52, 2003.

HOLTFRETER, B. et al. Prevalence of periodontal disease and treatment demands based on a German dental survey (DMS IV). Journal of clinical periodontology, v. 37, n. 3, p. 211-9, 2010.

HUGOSON, A.; NORDERYD, O. Has the prevalence of periodontitis changed during the last 30 years?. Journal of clinical periodontology, v. 35, p. 338-45, 2008.

HUTTER, J. W. et al. Lower numbers of erythrocytes and lower levels of hemoglobin in periodontitis patients compared to control subjects. Journal of clinical periodontology, v. 28, n. 10, p. 930-6, 2001.

IDE, M. et al. Effect of treatment of chronic periodontitis on levels of serum markers of acute-phase inflammatory and vascular responses. Journal of clinical periodontology, v. 30, n. 4, p. 334-40, 2003.

KHADER, Y. S.; ALBASHAIREH, Zakereyya SM; ALOMARI, Mousa A. Periodontal diseases and the risk of coronary heart and cerebrovascular diseases: A metaanalysis. Journal of periodontology, v. 75, n. 8, p. 1046-53, 2004.

KOLTE, R.A.; KOLTE, A.P.; DESHPANDE, N.M. Assessment and comparison of anemia of chronic disease in healthy subjects and chronic periodontitis patients: A clinical and hematological study. Journal of Indian society of Periodontology, v. 18, n. 2, p. 183, 2014.

LOOS, B.G. Systemic markers of inflammation in periodontitis. Journal of periodontology, v. 76, p. 2106-15, 2005. 
MACHTET, E.E. et al. Clinical criteria for the definition of "established periodontitis". Journal of periodontology, v. 63, n. 3, p. 206-14, 1992.

MARCACCINI, A.M. et al. Circulating interleukin- 6 and high-sensitivity C-reactive protein decrease after periodontal therapy in otherwise healthy subjects. Journal of periodontology, v. 80, n. 4, p. 594-602, 2009.

NEMETH, E. Targeting the hepcidin-ferroportin axis in the diagnosis and treatment of anemias. Advances in hematology, v. 2010, 2010.

NEMETH, E.; GANZ, T. Hepcidin and iron-loading anemias. haematologica, v. 91, n. 6, p. 727-32, 2006.

NEMETH, E.; GANZ, T. The role of hepcidin in iron metabolism. Acta haematologica, v. 122, n. 2-3, p. 78-86, 2009.

NEMETH, E. et al. IL-6 mediates hypoferremia of inflammation by inducing the synthesis of the iron regulatory hormone hepcidin. The Journal of clinical investigation, $v$. 113, n. 9, p. 1271-6, 2004.

O'CONNELL, P.A.A et al. Effects of periodontal therapy on glycemic control and inflammatory markers. Journal of periodontology, v. 79, n. 5, p. 774-83, 2008.

PAGE, R.C. The pathobiology of periodontal diseases may affect systemic diseases: inversion of a paradigm. Annals of periodontology, v. 3, n. 1, p. 108-20, 1998.

PATEL, M.D.; SHAKIR, Q.J.; SHETTY, A. Interrelationship between chronic periodontitis and anemia: A 6-month follow-up study. Journal of Indian Society of Periodontology, v. 18, n. 1, p. 19, 2014.

PIHLSTROM, B.L.; MICHALOWICZ, B.S.; JOHNSON, Newell W. Periodontal diseases. The lancet, v. 366, n. 9499, p. 1809-20, 2005.

PRADEEP, A.R.; ANUJ, S.; RAJU, A. Anemia of chronic disease and chronic periodontitis: does periodontal therapy have an effect on anemic status?. Journal of periodontology, v. 82, n. 3, p. 388-94, 2011.

SAMSON, D. The anaemia of chronic disorders. postgraduate medical journal, v. 59, n. 695, p. 543, 1983.

SHI, Z. et al. Oral hygiene care for critically ill patients to prevent ventilator associated pneumonia [Intervention Protocol]. Cochrane Database of Systematic Reviews, n. 2, p. 1-14, 2013.

VILELA, E.M. et al. Treatment of chronic periodontitis decreases serum prohepcidin levels in patients with chronic kidney disease. Clinics, v. 66, n. 4, p. 657-62, 2011.

WARD, P.C.J. Investigation of macrocytic anemia. Postgraduate medicine, v. 65, n. 2, p. 203-13, 1979.

KIANY Y. et al. Effect of nonsurgical periodontal treatment on C-reactive protein levels in maintenance hemodialysis patients. Renal failure, v. 35, n. 5, p. 711-7, 2013. 


\title{
CAPITULO III \\ AASSOCIAÇÃO ENTRE DOENÇA DE CROHN E DOENÇA PERIODONTAL
}

DOI: 10.51859/AMPLLA.EPC757.1121-3

\author{
Lorraine Ribeiro Santana ${ }^{1}$ \\ Lara Victória Dittz de Abreu Costa ${ }^{1}$ \\ Tainã Figueiredo Santos ${ }^{1}$ \\ Jéssica Vergna Neves ${ }^{1}$ \\ Alfredo Carlos Rodrigues Feitosa ${ }^{2}$
}

${ }^{1}$ Graduanda do curso de Odontologia. Universidade Federal do Espírito Santo - UFES.

2 Professor Titular do Departamento de Clínica Odontológica. Universidade Federal do Espírito SantoUFES

\section{RESUMO}

A doença de Crohn é uma patologia inflamatória intestinal crônica, podendo ter influência ambiental, bacteriana, imunológica e genética. Essa doença tem manifestações intestinais e extra-intestinais, podendo atingir a cavidade oral em 5,8\% dos casos. O diagnóstico da doença de Crohn se baseia em uma anamnese detalhada e exames complementares laboratoriais, endoscópicos e histológicos. O estudo trata-se de uma revisão bibliográfica levando em consideração as produções efetuadas sobre a relação da periodontite e da doença de Crohn. Constatou-se que a doença periodontal, assim como a doença de Crohn são multifatoriais, e estudos afirmam que devido ambas possuírem mecanismos patogênicos comuns, possivelmente dividindo o mesmo perfil linfocitário, acredita-se que os pacientes com doença de Crohn apresentam maior prevalência de periodontite. Em razão das doenças supracitadas possuírem relação entre si é necessário atendimento multiprofissional, incluindo cirurgião-dentista e especialistas em gastroenterologia.

Palavras-chave: Doença de Crohn. Doença Periodontal. Periodontite. Odontologia. 


\section{INTRODUÇÃO}

A doença de Crohn (DC) é uma doença inflamatória intestinal que se caracteriza como uma condição complexa, mediada imunologicamente, podendo afetar qualquer parte do sistema gastrointestinal e descrita como uma doença de perfil inflamatório crônico (BRITO et al., 2006). O mecanismo etiopatogênico da doença de Crohn ainda não está bem elucidado, porém a literatura a descreve como uma condição multifatorial envolvendo questões ambientais, bacterianas, resposta imune e fatores genéticos em indivíduos suscetíveis (HABASHNEH et al., 2012; LAURITANO et al., 2019). De acordo com o Ministério da Saúde, a prevalência e a incidência da DC situam-se em torno de 50:100.000 e 5:100.000, respectivamente, em países desenvolvidos (BRASIL, 2017). Além disso, uma estimativa da prevalência realizada na cidade de São Paulo relatou 14,8 casos de DC por 100.000 habitantes (VICTORIA et al., 2009).

A DC pode ocorrer em qualquer idade, normalmente variando entre os 15 e 30 anos de idade, porém a doença de Crohn em crianças é rara (HUANG et al., 2020; LAURITANO et al., 2019). Os sintomas podem variar entre dor abdominal, diarreia, presença de sangue nas fezes, perda de peso, deficiência na absorção de nutrientes e lesões na mucosa intestinal, caracterizados como manifestações intestinais da doença de Crohn (KAMMERMEIER et al., 2016; LAURITANO et al., 2019). Os indivíduos acometidos pela doença de Crohn, geralmente, apresentam ocorrências extraintestinais envolvendo olhos, boca, sistema nervoso, pele, articulações e fígado, sendo que $5,8 \%$ são expressões orais (SHE et al., 2020). As manifestações orais podem preceder o aparecimento dos sintomas do envolvimento gastrointestinal ou ocorrer juntamente com esses sintomas. Segundo Huang et al. (2020), cerca de $30 \%$ dos casos de crianças com doença de Crohn apresentaram lesões em boca antes do envolvimento intestinal.

Devido ao envolvimento sistêmico que essa condição apresenta, a doença de Crohn foi descrita como uma doença que também afeta o aparelho de inserção periodontal, sendo correlacionada com a doença periodontal (DP) (HUANG et al., 2020).

A patogênese da DP apresenta semelhança com a doença de Crohn, pois podem ser influenciados tanto por fatores genéticos, quanto ambientais. Esta coincidência 
entre doença de Crohn e periodontite pode ser devido ao fato de que uma resposta imune aberrante desempenhe um papel em ambas as doenças (VAVRICKA et al., 2013).

Johannsen et al. (2015) também demonstraram que existe uma maior prevalência de doença periodontal em pacientes com doença de Crohn do que a população em geral, com casos em que são comuns a ocorrência da perda de inserção óssea alveolar e maior quantidade de bolsas periodontais.

Devido à abundância e à diversidade das manifestações da doença de Crohn, seu diagnóstico nem sempre é fácil e atempado. O diagnóstico da doença de Crohn baseiase na análise de sintomas clínicos e dados de testes por imagens, como a endoscopia digestiva, colonoscopia e gastroscopia endoretal (BOIRIVANT; COSSU, 2012).

Os testes laboratoriais também são utilizados para diagnóstico, podendo ser incluídos os exames de fezes, hemograma, hemossedimentação, frações proteicas, transaminases, fosfatase alcalina e gama glutamiltransferase, função pancreática, níveis de ferro e zinco séricos, cálcio e magnésio. Também auxiliam no diagnóstico, os exames anatomopatológicos como a biópsia e a amostragem para análise da mucosa do cólon (CLARK-SNUSTAD; LEE, 2016).

Entre os sintomas recorrentes para diagnóstico, a diarreia crônica (mais de 4 semanas) é o mais comum, sendo que cerca de $60 \%$ a $70 \%$ dos pacientes com doença de Crohn apresentam outros sintomas, tais como dor abdominal e perda de peso, prévias ao diagnóstico (DEEPAK et al., 2017).

O tratamento médico das manifestações orais na doença de Crohn inclui terapias tópicas e sistêmicas combinadas com instruções dietéticas. O primeiro e mais importante passo no tratamento das lesões bucais é o controle da doença intestinal, sendo comum o uso de corticosteroides em períodos de atividade da doença. A doença de Crohn é incurável e a base da terapia é o tratamento médico com cirurgia reservada para o tratamento de complicações (KATSANOS et al., 2015).

Assim, a presente pesquisa bibliográfica teve como objetivo realizar um levantamento na literatura por meio da consulta aos portais eletrônicos Bireme, Google Scholar, PubMed e Scielo, abordando a doença de Crohn, suas manifestações sistêmicas e sua relação com a doença periodontal a fim de enfatizar a necessidade da atenção dos cirurgiões-dentistas e dos médicos no diagnóstico e tratamento dessa doença. 


\section{REVISÃO BIBLIOGRÁFICA}

\subsection{DIAGNÓSTICO}

O diagnóstico da doença de Crohn se baseia na sintomatologia do paciente; nos exames de imagem, dentre eles: ultrassonografia, tomografia computadorizada e ressonância magnética, a fim de avaliar a extensão da doença e presença de complicações, como estenoses ou fístulas; nos exames endoscópicos; nos exames histológicos; e nos exames laboratoriais (BARATELA; THOMES; FEITOSA, 2020; TORRES et al., 2017).

O exame físico deve avaliar os sinais de toxicidade sistêmica, desnutrição, desidratação, anemia ou má absorção. Os pacientes podem ter uma massa sensível no quadrante inferior direito, representando alças intestinais espessadas, mesentério espessado ou abscesso (TORRES et al., 2017).

Os exames endoscópicos são o padrão ouro para diagnóstico. Os achados típicos desses exames são inflamação segmentar e ulcerações serpiginosas. A colonoscopia é importante na vigilância da neoplasia colorretal e no gerenciamento de possíveis complicações, como a estenose. Já os exames histológicos apresentam um foco crônico, inflamatório, irregular, descontínuo e transmural. A marca histológica da doença é o granuloma epitelióide, que é visto em apenas cerca de 15\% das biópsias, mas em até $70 \%$ dos casos em espécimes cirúrgicos (TORRES et al., 2017). A interpretação da histologia depende do padrão e da distribuição do processo inflamatório (KALMAR, 1994).

Os achados laboratoriais típicos incluem trombocitose, proteínas de fase aguda aumentadas (proteína C-reativa) e anemia. A proteína C-reativa é um biomarcador para monitorar a doença, entretanto um terço dos pacientes não apresentam aumento. Em casos mais graves pode ocorrer baixa concentração de albumina e deficiência de vitaminas. Cerca de 60 a 70\% dos indivíduos com Crohn possuem anticorpos, sendo o mais prevalente o anti-Saccharomyces cerevisiae IgA (ASCA), porém sua sensibilidade e especificidade são muito baixas para fins de diagnóstico. As concentrações de calprotectina fecal se correlacionam com infiltrados de neutrófilos no intestino e servem como marcador substituto de inflamação intestinal devido sua alta sensibilidade e especificidade (KALMAR, 1994; TORRES et al., 2017). 


\subsection{MANIFESTAÇÕES CLIINICAS INTESTINAIS E EXTRAINTESTINAIS}

\subsubsection{MANIFESTAÇÕES INTESTINAIS DA DOENCA DE CROHN}

A doença de Crohn afeta principalmente o trato gastrointestinal e, frequentemente, apresenta-se como dor abdominal, febre e sinais clínicos de obstrução intestinal ou diarreia com passagem de sangue, muco ou ambos (BAUMGART; SANDBORN, 2012). A perda de peso aguda ou crônica pode estar presente, assim como deficiências na absorção de nutrientes, abscessos, fístulas na região perianal, fístulas que comunicam o intestino com outros órgãos e estenoses (KAMMERMEIER et al., 2016).

\subsubsection{MANIFESTACOÕES EXTRA-INTESTINAIS DA DOENCA DE CROHN}

A doença de Crohn está associada a uma ampla gama de manifestações extraintestinais (MAROTTO et al., 2020). Desta forma, as manifestações extra-intestinais incluem:

\subsubsection{MANIFESTAÇÕES MUCOCUTÂNEAS}

\section{- Eritema nodoso}

Inicia-se clinicamente com nódulos subcutâneos sensíveis ou dolorosos, vermelhos ou violáceos e às vezes são acompanhados de febre. Presume-se que seja uma reação de hipersensibilidade a diferentes antígenos (HARBORD et al., 2016).

\section{- Estomatite aftosa}

Geralmente acompanha distúrbios intestinais e é caracterizada por múltiplas dores, úlceras multiformes com margens eritematosas e uma base pseudomembranosa amarela, afetando a mucosa bucal ou labial (MAROTTO et al., 2020).

\section{- Pioestomatite vegetante}

É a mais rara e mais grave, caracterizado por lesões mucosas e pustulosas, podendo afetar a gengiva labial, mucosa labial, palato mole e duro, mas também frequentemente envolve as partes vaginal, nasal e a mucosa periocular (MAROTTO et al., 2020).

\subsubsection{MANIFESTAÇÕES MUCOCUTÂNEAS REATIVAS}

\section{- Pioderma gangrenoso}


Inicia-se como uma pústula ou nódulo eritematoso que se espalha rapidamente pela pele e desenvolve-se numa úlcera profunda com bordas violáceas irregulares. As ulcerações profundas frequentemente contêm material purulento (VAVRICKA et al., 2015).

\subsubsection{MANIFESTAÇÕES OCULARES}

\section{- Episclerite}

Afeta as camadas mais profundas do olho podendo causar deficiência visual se não diagnosticada precocemente. É caracterizada por hiperemia aguda, irritação, ardor, sensibilidade e dor intensa associada à palpação (VAVRICKA et al., 2015).

\section{- Esclerite}

Condição mais rara, porém, mais grave, podendo causar perda de visão. Geralmente se apresenta como hiperemia ocular grave com dor irradiada para face e couro cabeludo, piorando à noite (HARBORD et al., 2016).

\section{- Uveíte}

É a inflamação da câmara média do olho. Os sintomas característicos são dor, fotofobia, dor de cabeça e deficiência visual. O tratamento previne a cegueira (MAROTTO et al., 2020).

\subsubsection{MANIFESTAÇÕES HEMATOLÓGICAS}

É caracterizada pela anemia, em razão da doença crônica ou da deficiência de ferro. A anemia megaloblástica ocorre devido à deficiência de vitamina B12 ou folato, principalmente devido a absorção dessas substâncias ocorrerem no íleo (MAROTTO et al., 2020).

\subsubsection{MANIFESTACÕES GASTROINTESTINAIS}

\section{- Colangite esclerosante primária}

É uma doença hepática colestática crônica caracterizada por evolução progressiva da inflamação, estenose obliterativa e destruição dos ductos biliares intra e extra-hepáticos. Se manifesta clinicamente na forma de fadiga, icterícia, dor abdominal, prurido, deficiência vitamínica e níveis elevados de fosfatase alcalina e bilirrubina. Autoanticorpos não específicos, como anticorpos anti-nucleares, anti-músculo liso e 
anti-citoplasmáticos perinucleares (pANCAs) são detectados em até $65 \%$ dos pacientes (HARBORD et al., 2016).

\section{- Cálculos biliares}

As causas estão associadas a manifestações ileais, ressecção ileal e longo prazo de nutrição parenteral. Os riscos de complicações são devido a cálculos maiores do que 2,5 cm ou múltiplos cálculos com um diâmetro maior que $3 \mathrm{~mm}$ (VAVRICKA et al., 2015).

\section{- Pancreatite aguda}

É a manifestação pancreática mais frequente, caracterizada por processo inflamatório agudo decorrente da autodigestão do pâncreas, causado pelas próprias enzimas pancreáticas (MAROTTO et al., 2020).

\section{- Pancreatite autoimune}

Processo inflamatório com proeminente infiltrado linfocitário associado à fibrose do pâncreas, envolvendo disfunção orgânica. É clinicamente caracterizado pela icterícia obstrutiva indolor com ou sem massa pancreática e resposta dramática aos esteroides (MAROTTO et al., 2020).

\subsubsection{MANIFESTAÇÕES MUSCULOSQUELÉTICAS}

\section{- Artrite periférica}

A artrite periférica (oligoartrite e artrite poliarticular) pode preceder os sintomas intestinais na doença de Crohn e, em contraste com outras formas de artrite como a reumatóide, mostra pouca ou nenhuma destruição articular. Afeta de $10 \%$ a $20 \%$ dos pacientes. A oligoartrite geralmente afeta menos de cinco grandes articulações, correlaciona-se com a atividade da doença de Crohn e responde à otimização dos medicamentos, enquanto a artrite poliarticular afeta mais do que cinco articulações e não tem relação com a atividade da doença (BAUMGART; SANDBORN, 2012).

\section{- Osteoporose}

O paciente com doença de Crohn correm risco de osteoporose devido ao uso de corticosteroides, por diminuição da absorção de vitaminas, minerais e perda óssea induzida por inflamação, devendo assim ser suplementado com cálcio e vitamina $D$, enquanto estiver em uso desses medicamentos (BAUMGART; SANDBORN, 2012). 


\subsection{DOENÇA PERIODONTAL E DOENÇA DE CROHN}

A interação entre a doença periodontal e a doença de Crohn tem sido estudada ao longo dos anos na busca de evidências claras sobre os mecanismos que correlacionam as duas condições. A associação entre essas duas doenças foi descrita por Lamster et al. (1978) em um caso no qual o paciente apresentava doença de Crohn e destruição periodontal severa e progressiva (KALMAR, 2000; KESKIN et al., 2015; LAMSTER et al., 1978; LIRA-JUNIOR; FIGUEREDO, 2016).

A doença de Crohn e a doença periodontal são condições patológicas multifatoriais, resultado de uma interação complexa entre a microbiota local desregulada e a resposta imunoinflamatória do indivíduo, sofrendo influência de fatores ambientais, genéticos e fatores de risco ligados ao estilo de vida (AGOSSA et al., 2017; GRAVES, 2008; KESKIN et al., 2015; LIRA-JUNIOR; FIGUEREDO, 2016; POYATO-BORREGO et al., 2020). Tanto a doença periodontal, quanto a doença inflamatória intestinal apresentam processos inflamatórios em sua progressão e compartilham mediadores comuns, os quais estão ligados aos danos teciduais (LIRA-JUNIOR; FIGUEREDO, 2016; SHE et al., 2020).

A doença periodontal, mais especificamente a periodontite, apresenta comportamento semelhante à doença de Crohn, no qual o perfil patogênico é Th1 (AGOSSA et al., 2017; BRITO et al., 2006). Segundo uma revisão sistemática realizada por Papageorgiou et al. (2017), a doença inflamatória intestinal apresenta significativa associação com o aumento do risco de doença periodontal.

De acordo com Figueredo et al. (2017), pelo fato da doença de Crohn e a doença periodontal possuírem mecanismos patogênicos comuns, possivelmente dividindo o mesmo perfil linfocitário, acredita-se que os pacientes com doença de Crohn apresentam maior prevalência de periodontite, e indivíduos jovens são propensos a desenvolver periodontite especialmente em formas mais graves e progressiva (KESKIN et al., 2015). Segundo Kalmar (2000), indivíduos com doença inflamatória intestinal apresentam uma prevalência de $11,9 \%$ maior de doença periodontal. Observa-se que o metabolismo ósseo desses pacientes se encontra alterado e a perda de inserção óssea é comum nessas condições (LIRA-JUNIOR; FIGUEREDO, 2016). 
Alterações gengivais como espessamento significativo do tecido gengival e alterações gengivais semelhantes a paralelepípedos, equivalentes aos achados intestinais na doença de Crohn ativa, podem ocorrer (KELSEN et al., 2015). A gengiva desses pacientes pode encontrar-se hiperplásica, edemaciada, eritematosa e granular, caracterizando um quadro clínico de mucogengivite, uma das características clínicas mais comuns na doença inflamatória intestinal oral (LIRA-JUNIOR; FIGUEREDO, 2016). Pacientes com doença de Crohn ativa tendem a apresentar escores mais altos de gengivite, e estudos indicam maior tendência de sangramento à sondagem, formação de bolsas periodontais profundas e perda óssea significativa quando comparada com grupos controles (AGOSSA et al., 2017; BRITO et al., 2006; ECKEL et al., 2017; HUANG et al., 2020; SIGUSCH, 2004).

A literatura apoia a compreensão da patogênese da doença de Crohn como sendo decorrente de fatores diversos que a ligam à doença periodontal. Teorias que conectam ambas as condições são alvos de estudo, incluindo fatores genéticos, resposta imune inflamatória, alterações na microbiota e fatores ambientais ligados a estilo de vida (CHI et al., 2018).

\subsubsection{REDUÇÃO DA BIODIVERSIDADE MICROBIANA E IMPACTO NA MICROBIOTA INTESTINAL}

O desenvolvimento da doença periodontal (DP) em pacientes com doença de Crohn foi associado a dois fatores principais, a resposta imunoinflamatória do indivíduo e a redução e alteração da biodiversidade da microbiota oral (HUANG et al., 2020). Estudos investigaram sobre alterações na diversidade da microbiota oral em crianças com DC, e demonstraram diminuição da diversidade da microbiota oral nesses pacientes (DOCKTOR et al., 2012). Na transição de saúde periodontal para a periodontite, a microbiota das bolsas periodontais passa a ser predominantemente anaeróbia Gramnegativa, incluindo Porphyromonas gingivalis, Treponema denticola, Tannerella forsythia, Aggregatibacter actinomycetemcomitans, dentre outras (KHAN et al. 2015; WADE, 2013).

A predisposição à doença periodontal foi relacionada a este impacto microbiológico (SHE et al., 2020). As bactérias somente não são capazes de induzir a doença inflamatória intestinal e a doença periodontal, porém as modificações nos 
complexos microbianos que levam a alteração são necessárias (AGOSSA et al., 2017). A disbiose da microbiota intestinal é típica na doença de Crohn e surte impacto não somente no desenvolvimento dos distúrbios intestinais, como também nas doenças inflamatórias orais (PIRAS et al., 2017).

Por outro lado, a microbiota dos biofilmes orais envolvidos na doença periodontal pode estar relacionada com a disbiose intestinal e a função da barreira das células epiteliais do intestino, contribuindo negativamente para a patogênese da doença de Crohn, acentuando a doença (HUANG et al., 2020; POYATO-BORREGO et al., 2020). Foi sugerido que a inflamação crônica decorrente da microbiota oral poderia prejudicar a cicatrização de lesões na mucosa do trato gastrointestinal (OJHA et al., 2007). Além disso, os patógenos periodontais geram alterações na composição da microbiota intestinal (SHE et al., 2020).

Grandes quantidades de bactérias orais são engolidas constantemente. Em estudo realizado para avaliar a microbiota intestinal humana, observou-se espécies de bactérias orais presentes no intestino, apesar de apresentarem baixa atividade transcricional. (FRANZOSA et al., 2014).

Tendo em vista esses resultados, aponta-se uma complexa interação entre os patógenos da doença periodontal e a doença de Crohn, havendo uma correlação entre as duas condições com alteração da composição da microbiota e aumento da resposta inflamatória (LIRA-JUNIOR; FIGUEREDO, 2016).

\subsubsection{ALTERACG̃O NA RESPOSTA IMUNOINFLAMATÓRIA}

A disfunção imunológica e a resposta inflamatória são fatores relacionados ao dano tecidual e a progressão observados na DP e na DC (LIRA-JUNIOR; FIGUEREDO, 2016; PAPAGEORGIOU et al., 2017). Os principais mediadores envolvidos nos danos teciduais encontrados são as citocinas (SHE et al., 2020). Pacientes com doença de Crohn apresentam níveis elevados de algumas citocinas pró-inflamatórias, principalmente aqueles com doença ativa (LIRA-JUNIOR; FIGUEREDO, 2016). Na doença periodontal, a patogênese é exercida pela resposta do hospedeiro através do controle das respostas imune inata e adaptativa, regulado pelas citocinas Th1/Th2 e o desequilíbrio entre as respostas ativam Th17 e a expressão de outras citocinas, modulando assim a expressão 
da doença, levando à resposta inflamatória e perda óssea (BRITO et al., 2006; FIGUEREDO et al., 2017).

Os neutrófilos desempenham papel importante na patogênese da doença periodontal. Estudos demonstraram uma hiper-atividade dos neutrófilos periféricos em pacientes com Doença Inflamatória intestinal ativa sugerindo que essa maior atividade metabólica seja responsável pela perda óssea alveolar rápida e progressiva (HUANG et al., 2020; KALMAR, 2000; LIRA-JUNIOR; FIGUEREDO, 2016). Por outro lado, observaram um defeito na quimiotaxia dos neutrófilos, com $45 \%$ de atividade menor quando comparado a controles saudáveis. Sugere-se que esse fato ocorra devido a pré-ativação dos neutrófilos por mediadores inflamatórios na corrente sanguínea (BRITO et al., 2006; LIRA-JUNIOR; FIGUEREDO, 2016).

Níveis elevados de algumas citocinas são relatados em estudos sobre a associação entre a DC e a DP. Uma hiperatividade de células T foi descrita, bem como níveis elevados de PGE2 no fluido gengival de pacientes com Doença inflamatória intestinal e periodontite (KALMAR, 2000; KESKIN et al., 2015; LIRA-JUNIOR; FIGUEREDO, 2016). Algumas das citocinas são alvo de estudo, dentre elas, o fator de necrose tumoral (TNF- $\alpha$ ), descrito como uma potente citocina pró-inflamatória que pode correlacionar ambas as condições. O TNF- $\alpha$ é encontrado em níveis elevados em pacientes com doença de Crohn e doença periodontal e relacionado à reabsorção óssea e à sinalização de demais citocinas (CHI et al., 2018; KESKIN et al., 2015; POYATO-BORREGO et al., 2020; SCHULZ et al., 2014). A resposta imunoinflamatória alterada nos pacientes com doença de Crohn e com doença periodontal apresenta níveis significativamente mais elevados de IL-10, IL-4, IL-21, IL-23, IFN- $\gamma$, IL-18, IL-1ß, dentre outras (BRITO et al., 2006; CHI et al., 2018; FIGUEREDO et al., 2017; LIRA-JUNIOR; FIGUEREDO, 2016). Os estudos propõem que essas alterações na rede de citocinas representam um passo inicial e potencial ligação entre a etiopatogenia da doença periodontal e da doença de Crohn (SCHULZ et al., 2014).

\subsection{QUESTÕES AMBIENTAIS}

Variáveis como estilo de vida devem ser considerados, pois estão associados entre a doença periodontal e a doença de Crohn (CHI et al., 2018). O tabagismo foi o fator de risco mais relacionado às duas condições. Estudos apontam a atividade da 
doença de Crohn e o tabagismo como fatores de risco significativos para periodontite e dados demonstram que os pacientes ex-fumantes com doença de Crohn apresentavam alta prevalência de doença Periodontal (SHE et al., 2020).

\subsection{TRATAMENTO}

O tratamento tem como objetivo o controle dos sintomas, a indução da remissão clínica e a manutenção da remissão com o mínimo de efeitos adversos e a decisão do mesmo ocorre de acordo com a idade, comorbidade, sintoma, estado de inflamação, localização e extensão da doença e o risco geral de doença (VEAUTHIER; HORNECKER, 2018; WILKINS; JARVIS; PATEL, 2011).

Duas formas de tratamento são utilizadas para a doença de Crohn, onde a primeira e mais utilizada começa comcorticosteroides ou produtos de mesalazina e avança para imunomoduladores ou agentes Antifator de Necrose Tumoral (TNF) com base na gravidade da doença, e, a segunda forma se inicia com agentes Anti-TNF (WILKINS; JARVIS; PATEL, 2011).

Na atividade da doença de Crohn de leve a moderada o paciente é ambulatorial e apto a fazer alimentação oral e uso de medicamentos. Assim, são utilizados a mesalazina, como a sulfassalazina e ácido 5-aminossalicílico, antibióticos, especialmente metronidazol e ciprofloxacina e budesonida que é um glicocorticoide oral (KNUTSON et al., 2003; WILKINS; JARVIS; PATEL, 2011).

Já na doença moderada a grave, a terapia com corticosteroides é com prednisona até a melhora dos sintomas. Azatioprina e 6-mercaptopurina também podem induzir efetivamente a remissão em pacientes com doença de Crohn, porém relata-se efeitos adversos. Portanto, para pacientes intolerantes aos mesmos pode ser substituído pelo metotrexato. Agentes anti-TNF também podem ser utilizados em pacientes que não respondem a corticosteroides ou terapia imunossupressora (KNUTSON et al., 2003; WILKINS; JARVIS; PATEL, 2011).

Na doença grave o paciente requer hospitalização emergencial e consulta com médico gastroenterologista, sendo que a avaliação cirúrgica urgente é recomendada para pacientes com sintomas de obstrução intestinal, onde um abscesso requer drenagem cirúrgica percutânea ou aberta. Corticosteroides parenterais e antibióticos 
devem ser administrados, e o suporte nutricional deve ser fornecido (KNUTSON et al., 2003; WILKINS; JARVIS; PATEL, 2011).

No período de remissão o paciente encontra-se assintomático ou sem sequelas e a azatioprina é eficaz para a manutenção (KNUTSON et al., 2003).

\section{CONSIDERACÕES FINAIS}

Os pacientes com doença de Crohn apresentam um quadro clínico complexo, com sintomas intestinais e extra-intestinais, tais como lesões mucocutâneas, problemas oculares, doenças no fígado, patologias esqueléticas e lesões na cavidade oral, incluindo a doença periodontal. Assim, o cirurgião-dentista deve informar e estimular os pacientes sobre as técnicas corretas de higiene e sugerir o aumento do número de consultas para o controle das manifestações orais. Os enfermos também devem realizar consultas com o médico gastroenterologista para ajustar o controle da terapia farmacológica, a fim de proporcionar a melhor alternativa para o paciente e melhorar sua qualidade de vida.

\section{REFERÊNCIAS}

AGOSSA, K. et al. Periodontal manifestations of inflammatory bowel disease: emerging epidemiologic and biologic evidence. J Periodontal Res, v. 52, n. 3, p. 313-324, 2017.

BARATELA, M.C.; THOMES, C.R.; FEITOSA, A.C.R. Manifestações orais da doença de Crohn. Geração de conhecimento nas ciências médicas: impactos científicos e sociais [livro eletrônico] - Campina Grande: Editora Amplla, 450 p., 2020.

BAUMGART, D. C.; SANDBORN, W. J. Crohn's disease. Lancet, v. 380, n. 9853, p. 15901605, 2012.

BOIRIVANT, M.; COSSU, A. Inflammatory bowel disease. Oral Dis, v. 18, n. 1, p. 1-15, 2012.

BRASIL. Ministério da Saúde. Portaria $n^{\circ}$ 14, de 28 de novembro de 2017. Aprova o Protocolo Clínico e Diretrizes Terapêuticas da Doença de Crohn. Secretaria de atenção à saúde. Edição. 235, Seção. 1,p. 201, 2017.

BRITO, F. et al. Inter-relação entre a doença periodontal e a doença de Crohn. Rev Ciênc Méd Biol, v. 5, n. 3, p. 261-267, 2006.

CHI, Y.C. et al. Increased risk of periodontitis among patients with Crohn's disease: a population-based matched-cohort study. Int J Colorectal Dis, v. 33, n. 10, p. 1437-1444, 2018. 
CLARK-SNUSTAD, K. D.; LEE, S. D. Diagnosing inflammatory bowel disease and differentiating it from potential mimics. Tech Gastr Endoscopy, v. 18, n. 3, p. 108115, 2016.

DEEPAK, P. et al. Crohn's disease diagnosis, treatment approach, and management paradigm: what the radiologist needs to know. Abdom Radiol,v. 42, n. 4, p. 10681086, 2017.

DOCKTOR, M.J. et al. Alterations in diversity of the oral microbiome in pediatric inflammatory bowel disease. Inflamm Bowel Dis, v. 18, n. 5, p. 935-42, 2012.

ECKEL, A. et al. Oral manifestations as the first presenting sign of Crohn's disease in a pediatric patient. J Clin Exp Dent, v. 9, n. 7, p. e934-e938, 2017.

FIGUEREDO, C.M.S. et al. Expression of Th17 related cytokines response in the gingival and intestinal tissue from patients with periodontitis and inflammatory bowel disease. Periodontia, v.27, n.1, p.11-22, 2017.

FRANZOSA, E.A. et al. Relating the metatranscriptome and metagenome of the human gut. Proc Nat Acad Sci Unit Stat Amer, v. 111, n. 22, p. 2329-38, 2014.

GRAVES, D. Cytokines that promote periodontal tissue destruction. J Periodontol, v. 79, n. 8, p. 1585-9, 2008.

HABASHNEH, R.A. et al. The association between inflammatory bowel disease and periodontitis among Jordanians: a case-control study. J Periodontal Res, v. 47, n. 3, p. 293-298, 2012.

HARBORD, M. et al. Annese European Crohn's and Colitis Organisation. The First European Evidence-based Consensus on Extra-intestinal Manifestations in Inflammatory Bowel Disease. J Crohns Colitis, v. 10, n. 3, p. 239-54, 2016.

HUANG, M.L., WU, Y.Q., RUAN, W.H. Um caso raro de doença de Crohn pediátrica e perda óssea alveolar: um relato e revisão. Transl Pediatr, v. 9, n. 5, p. 720-725, 2020.

JOHANNSEN, A. et al. Consumo de tratamento odontológico em pacientes com doença inflamatória intestinal, um estudo de registro. PLoS ONE, v. 10, n. 8, p. 1-8, 2015.

KALMAR, J.R. Crohn's disease: orofacial considerations and disease pathogenesis. Periodontol 2000, v. 6, n. 1, p. 101-115, 1994.

KAMMERMEIER, J. et al. Management of Crohn's disease. Arch Dis Child, v. 101, n. 5, p. 475-480, 2016.

KATSANOS, K.H.et al.Review article: non-malignant oral manifestations in inflammatory bowel diseases. Aliment Pharmacol Ther, v. 42, n. 1, p. 40-60, 2015. 
KELSEN, J. et al. Alterations of the Subgingival Microbiota in Pediatric Crohn's Disease Studied Longitudinally in Discovery and Validation Cohorts. Inflamm Bowel Dis, v. 21, n. 12, p. 2797-805, 2015.

KESKIN, M. et al. Two Cheers for Crohn's Disease and Periodontitis: Beta-Defensin-2 as an Actionable Target to Intervene on Two Clinically Distinct Diseases. Omics: A J Integ Biol, v. 19, n. 8, p. 443-50, 2015.

KHAN, S.A. et al. Periodontal Diseases: Bug Induced, Host Promoted. PLoS Pathog, v. 11, n. 7, p. e1004952, 2015.

KNUTSON, D., GREENBERG, G., CRONAU, H. Management of Crohn's disease - a practical approach. Am Fam Physician, v. 68, n. 4, p. 707-14, 2003.

LAMSTER, I. et al. An association between Crohn's disease, periodontal disease and enhanced neutrophil function. J Periodontol, v. 49, n. 9, p. 475-479, 1978.

LAURITANO, D. et al. Prevalence of Oral Lesions and Correlation with Intestinal Symptoms of Inflammatory Bowel Disease: A Systematic Review." Diagnostics (Basel, Switzerland), v. 9, n.3, p. 77, 2019.

LIRA-JUNIOR, R., FIGUEREDO, C.M. Periodontal and inflammatory bowel diseases: Is there evidence of complex pathogenic interactions? World J Gastroenterol, v. 22, n. 35, p. 7963-7972, 2016.

MAROTTO, D. et al. Extra-intestinal manifestations of inflammatory bowel diseases. Pharmacol Res, v. 161, n. 1, p. 105-206, 2020.

OJHA, J. et al. Gingival involvement in Crohn disease. J Am Dent Assoc,v. 138, n. 12, p. 1574-81, 2007.

PAPAGEORGIOU, S.N. et al. Inflammatory bowel disease and oral health: systematic review and a meta-analysis. J Clin Periodontol, v. 44, n. 4, p. 382-393, 2017.

PIRAS, V. et al. Prevalence of Apical Periodontitis in Patients with Inflammatory Bowel Diseases: A Retrospective Clinical Study. J Endod, v 43, n. 3, p. 389-394, 2017.

POYATO-BORREGO, M. et al. High Prevalence of Apical Periodontitis in Patients With Inflammatory Bowel Disease: An Age and Gender matched case - control Study. Inflamm Bowel Dis, v. 26, n. 2, p. 273-279, 2020.

SCHULZ, S. et al. Tumor Necrosis Factor-a and Oral Inflammation in Patients With Crohn Disease. J Periodontol, v. 85, n. 10, p. 1424-1431, 2014.

SHE, Y.Y. et al. Periodontitis and inflammatory bowel disease: a meta-analysis. BMC Oral Health,v. 20, n. 1, p. 67, 2020.

SIGUSCH, B.W. Periodontitis as manifestation of Crohn's disease in primary dentition: a case report. J Dent Child, v. 71, n. 3, p. 193-196, 2004. 
TORRES, J. et al. Crohn's disease. Lancet, v. 389, n. 10080, p. 1741-1755, 2017.

VAVRICKA, S.R. Periodontite e gengivite na doença inflamatória intestinal. Inflamm Bowel Dis, v. 19, n. 7, p. 2768-2777, 2013.

VAVRICKA, S. R. et al. Extraintestinal manifestations of inflammatory bowel disease. Inflamm Bowel Dis, v. 21, n. 8, p. 1982-1992, 2015.

VEAUTHIER, B., HORNECKER, J.R. Crohn's Disease: Diagnosis and Management. Am Fam Physician, v. 98, n. 11, p. 661-669, 2018.

VICTORIA, C.R., SASSAKS, L.Y., NUNES, H.R. de C. Incidence and prevalence rates of inflammatory bowel diseases, in midwestern of São Paulo State, Brazil. ArqGastroenterol, v. 46, n. 1, p. 20-5, 2009.

WADE, W.G. The oral microbiome in health and disease. Pharmacol Res, v. 69, n. 1, p. 137-43, 2013.

WILKINS, T., JARVIS, K., PATEL, J. Diagnosis and management of Crohn's disease. Am Fam Physician, v. 84, n.12, p. 1365-75, 2011. 


\title{
CAPITULO IV
}

\section{A RELAÇÃO DA PERIODONTITE E A DOENÇA DE ALZHEIMER: UMA REVISÃO DE LITERATURA}

DOI: 10.51859/AMPLLA.EPC757.1121-4

\author{
Marinalva de Castilho Florêncio ${ }^{1}$ \\ Alexia Catarina Carpes ${ }^{1}$ \\ Aléxia Müller Willers ${ }^{1}$ \\ Jáina Suiane da Silva Araujo ${ }^{1}$ \\ Carla Cioato Piardi ${ }^{2}$
}

${ }^{1}$ Acadêmicas de Odontologia do Centro Universitário UNIFACVEST.

2 Professora mestre em Clínica Odontológica - Periodontia.

\section{RESUMO}

Objetivo: o objetivo deste estudo é uma revisão a literatura sobre a relação entre a doença de Alzheimer (DA) e a doença periodontal (DP). Metodologia: este trabalho é uma revisão de literatura que utiliza as bases de dados PubMed, Google Acadêmico e LILACS. Foram incluídos artigos científicos publicados dos anos de 2017 à 2020, em português e inglês, o período de busca ocorreu entre setembro de 2019 até maio de 2020. Resultados: Após a Aplicação dos critérios de elegibilidade pelos autores foram incluídos no presente estudo 4 revisões sistemáticas com meta-análise e 6 estudos de caso controle. Houve ainda uma busca manual na literatura por estudos que se assemelhassem com o tema abordado. Com isso, permaneceram 10 estudos elegidos de 6 países diferentes sendo 6 estudos de caso-controle e 4 revisões de literatura sistemáticas com meta-análise publicados entre os anos de 2017 à 2020. Conclusão: Independentemente do mecanismo pelo qual a inflamação sistêmica da periodontite é desencadeada, os dados apresentados documentam claramente o potencial que ela apresenta em influenciar doenças sistêmicas, incluindo as neurológicas crônicas como DA, nesse sentido, se faz necessário estudos contínuos dos patógenos da periodontite induzida a outros sítios do organismo.

Palavras-chave: Periodontite. Microbiota bucal. Bactérias do complexo vermelho. $P$. Gingivalis. Doença de Alzheimer.

\section{INTRODUÇÃO}

Alois Alzheimer marcou a história com a descoberta da doença de Alzheimer (DA), um distúrbio cerebral irreversível e progressivo que destrói lentamente as habilidades da memória, do pensamento e da capacidade de realizar atividades comuns. 
Esse avanço conceitual levou ao reconhecimento da demência senil como uma doença, julgamento diverso ao que considerava apenas um evento normal associado ao envelhecimento (SMALL; CAPPAI, 2006).

Considerada a segunda maior patologia dentária na população de todo o mundo (ALMEIDA et al., 2006), a periodontite é uma infecção periférica crônica, que provoca uma resposta inflamatória sistêmica (LOOS, 2005), essa inflamação sistêmica induzida por

periodontite tem sido a plausibilidade de vários estudos que relacionam a periodontite como fator de risco para acidente vascular cerebral (GRAU et al., 2004), diabetes, doenças cardiovasculares, infecções respiratórias, artrite reumatoide (GRAVES, JIANG, GENCO 2000; AWANO et al., 2008) e doença de Alzheimer. Essas condições sistêmicas crônicas impactam gravemente na saúde pública, logo, a periodontite deve ser vista como prioridade no tratamento de manutenção e prevenção já que resulta em um agravo significativo nas mesmas (SHOEMARK, ALLEN, 2015; FERES et al., 2016).

O que garante a homeostase da saúde bucal é a relação entre o hospedeiro e a microbiota. Deste modo, existem fatores que conseguem modular a microbiota oral e que podem também exacerbar uma resposta inflamatória do hospedeiro. Estes são provocados pelo sistema imunológico e pelo ambiente do hospedeiro (SOCRANSKY, HAFFAJEE, 2005). No caso da periodontite, as citosinas pró-inflamatórias produzidas localmente são transmitidas através do revestimento ulcerado da bolsa periodontal para a circulação sistêmica, isso altera o caráter da periodontite de uma doença local para um distúrbio sistêmico (D'AIUTO et al., 2005; GURAV, 2014). Os patógenos periodontais e a resposta do hospedeiro elevam os níveis de citosinas pró-inflamatórias. Essa série de citosinas e agentes pró-inflamatórios são estimulados na circulação sistêmica, aumentando a carga inflamatória sistêmica (LOSSINSKY et al., 2004; SHIVERS et al, 2004; GURAV, 2014). Além disso, existe uma associação de mecanismos bacterianos e consequentemente inflamatórios relacionados a doença de Alzheimer, desta forma, este estudo tem como objetivo revisar a literatura sobre esse provável fundamento, que sustentam esse processo. 


\section{REVISÃO BIBLIOGRÁFICA}

\subsection{O AVANÇO DA POPULAÇÃO SENIL ASSOCIADO ÀS DOENÇAS CRÔNICAS}

Um dos principais fatores para fornecer uma qualidade de vida aos idosos está na manutenção e no controle de infecções (FERES et al., 2016). Dentre os vários problemas enfrentados pelos idosos está a incapacidade mastigatória associada à perda dentária e consequente desnutrição, cuja causa principal é representada por uma patologia bucal chamada periodontite (SINGHRAO et al., 2014). O aparecimento e progressão da periodontite devem estar incorporados a ferramentas de avaliação e prevenção nas idades mais avançadas, devido ao seu relacionamento de risco com outras condições sistêmicas crônicas (LANG, SUVAN, TONETTI, 2015), além do fato de ser considerada uma das infecções crônicas mais encontradas nos adultos com sua prevalência e gravidade influenciada a partir do avanço senil (FERES et al., 2016). Suas características infecto-inflamatórias de origem bacteriana se fazem presentes em quase 50\% da população mundial (EKE et al., 2012; ROMÁN-MALO, BULLON, 2017; HASHIOKA et al., 2019). Desta maneira, estima-se que a periodontite grave afete $11 \%$ da população mundial (KASSEBAUM et al., 2014; FRENCKEN et al., 2017; BILLINGS et al., 2018), colocando ela no patamar da segunda maior patologia dentária na população de todo o mundo (ALMEIDA et al., 2006).

A periodontite é uma infecção periférica crônica que provoca uma resposta inflamatória sistêmica (LOOS, 2005). Essa inflamação sistêmica induzida por periodontite tem sido a plausibilidade de vários estudos que relacionam a periodontite como fator de risco para acidente vascular cerebral (GRAU et al., 2004), diabetes, doenças cardiovasculares, infecções respiratórias, artrite reumatoide (GRAVES, JIANG, GENCO, 2000; AWANO et al., 2008) e doença de Alzheimer. Em paciente com idade avançada, existe uma maior prevalência de ocorrência pela razão do efeito cumulativo da perda periodontal ao longo do tempo (BERTOLDI et al., 2013), alterações no sistema imunológico, condições inflamatórias (HAJISHENGALLIS et al., 2014), e, como consequência, isso acarreta mudanças na microbiota subgengival (MESTNIK et al., 2010). Esses, estando inter-relacionados, podem interferir com a população microbiana de outras áreas infectadas do organismo (HAJISHENGALLIS et al., 2014; PETERSON et al., 2015), contribuindo para o aumento da susceptibilidade a infecções de natureza 
microbiana, ampliando também os efeitos da inflamação de indivíduos idosos, além de agravar o declínio da função do sistema imunológico já afetado pelo avanço natural da idade (FRANCESCHI, CAMPISI, 2014; PETERSON et al., 2015). Advindo desta análise, a periodontite contribui para um estado inflamatório sistêmico e/ou a disseminação sistêmica dos micro-organismos periodontais (HAN, WANG, 2013).

\subsection{DAS CARACTERÍSTICAS DA PERIODONTITE}

Define-se a periodontite pela caracterização de micro-organismos associados a inflamação, que resultam em perda da inserção periodontal. Nos casos de periodontite como manifestação de doenças sistêmicas, deve-se classifica-los com base na doença sistêmica primária (CATON et al., 2018; PAPAPANOU et al., 2018; TONETTI, GREENWELL, KORNMAN, 2018). Para isto, considera-se que a periodontite e certos distúrbios sistêmicos compartilham de semelhantes fatores etiológicos, genéticos e/ou ambientais, no qual pode-se incluir doenças imunológicas, bem como desordens metabólicas e endócrinas (ALBANDAR, SUSIN, HUGHES, 2018).

O diagnóstico clínico precisa ser abrangente nos efeitos de extensão e gravidade da periodontite, analisando a história da doença, os sinais e sintomas, e observando, não apenas os efeitos orais, mas também as potenciais implicações em doenças sistêmicas, visto que, essa condição altera significativamente a resposta imune do hospedeiro. Como principais características clínicas que indicam a presença de periodontite estão, quantidade e porcentagem de perda óssea radiográfica, perda de inserção clínica, profundidade a sondagem entre $4 \mathrm{~mm}$ e $\geq 6 \mathrm{~mm}$, presença de exsudato subgengival, envolvimento de lesão de furca, bem como o grau de mobilidade (CATON et al., 2018; PAPAPANOU et al., 2018; TONETTI, GREENWELL, KORNMAN, 2018).

A causa principal da DP é o biofilme dental. Dos seis complexos microbianos encontrados na placa subgengival, dois deles, complexos laranja e vermelho, incluem micro-organismos que estão intimamente associados com condições patológicas periodontais (HARVEY, 2017) com espécies gram-negativas e anaeróbias predominantes como Porphyromonas gingivalis, Treponema forsythia, Tannerella denticola, Aggregatibacter Actinomycetemcomitans, Prevotella intermédia (SOCRANSKY, HAFFAJEE, 2005; FILOCHE, WONG, SISSONS, 2010; GURAV, 2014). (PAPAPANOU et al., 2018; STEFFENS, MARCANTONIO, 2018; TONETTI, GREENWELL, KORNMAN, 2018). 


\subsection{A DOENÇA DE ALZHEIMER}

A doença de Alzheimer é a causa mais comum de demência (LANE, 2018), que afeta a saúde nos indivíduos geriátricos, sua prevalência aumenta exponencialmente com a idade, passando de $3 \%$ entre os 65 e os 74 anos e chegando a quase $50 \%$ em indivíduos com 85 anos ou mais (FERRI et al., 2005; GUTIERREZ et al., 2014). Uma das principais causadoras de distúrbios neurodegenerativos nos idosos (FERRI et al., 2005), esta patologia é caracterizada por uma sintomatologia típica constituída por um déficit amnésico inicial, seguido de apraxia associada a distúrbios de espaço e percepções visuais, levando em sua última etapa, a delírio e alucinações. (VAN DER KANT, GOLDSTEIN, OSSENKOPPELE, 2020; DIOGUARDI et al., 2020). Conforme a Associação do Alzheimer (2009), o transtorno é caracterizado pela deterioração progressiva das funções cognitivas, ausência de memória, mudanças comportamentais (ALZHEIMER'S ASSOCIATION, 2009; ROCHA et al., 2010), progressivo comprometimento cognitivo que afeta o julgamento e tomada de decisão, seguidos por distúrbios psicocomportamentais e deficiência de linguagem (GALIMBERTI, SCARPINI, 2012).

A causa da neurodegeneração que ocorre na DA ainda é questão de debate, não havendo um consenso sobre o assunto, porém, o depósito da proteína $\beta$-amilóide é identificado como principal dado patológico da DA que provoca inflamação neuronal e neurovascular, contribuindo para a neurodegeneração. Mesmo não estando claro, como esse depósito pode causar as lesões celulares características do quadro, muitos mecanismos têm sido propostos (ROCHA et al., 2010), dentre estes, as análises de como os agentes infecciosos da periodontite foram encontrados no cérebro e postulados em pacientes com DA (MAWANDA, WALLACE, 2013).

Harding (2017) relata que a condição oral afetada pela periodontite é considerada um efeito multiplicador ao grande risco do desenvolvimento da DA, isso porque a mesma é uma patologia de etiologia mista, ou seja, engloba em suas variáveis fatores ambientais, genéticos, nutricionais, depuração linfática, falta de sono, estilo de vida, distúrbios metabólicos, dentre outros. Logo, a intervenção odontológica a reduz ou impede as condições relacionadas a infecção oral, retardando a progressão da doença (HARDING et al., 2017). 


\subsection{MECANISMOS PRESUMIDOS PELOS QUAIS A PERIODONTITE CAUSA NEUROINFLAMAÇÃO}

Os mecanismos envolvidos na patogênese da DA não são claros, desta forma, estudos epidemiológicos apontam que a periodontite aumenta significativamente 0 risco da doença de Alzheimer, considerando que a inflamação desempenha um papel favorável para a sua progressão. Entre essas reações inflamatórias, a periodontite pode ser encontrada expondo o hospedeiro à presença de um processo inflamatório estável associado a bactérias que colonizam o periodonto (DOMINY et al., 2019).

São associados a relação da periodontite e a doença de Alzheimer, o mecanismo inflamatório que envolve a síntese de moléculas inflamatórias causadas por periodontite, aumentando o estado de inflamação cerebral e de fato, a interação entre as bactérias periodontais e o hospedeiro causam uma produção local de moléculas inflamatórias, como IL-1 $\beta$, IL-6, IL-8, TNF- $\alpha$ com concentrações elevadas de PCR, essas na cavidade oral podem desencadear via nervo trigêmeo e aumentar ainda mais a produção inflamatória cerebral causando uma ação simultânea às células da glia. Em favor da doença de Alzheimer e sua progressão, as citocinas pró-inflamatórias podem também induzir uma inflamação sistêmica, potencialmente capaz de atingir o sistema nervoso central via circulação sistêmica (SINGHRAO et al., 2015; DOMINY et al., 2019).

Ainda não se sabe se a inflamação periférica da periodontite está envolvida no início da progressão ou ambos, mas, presume-se que outro mecanismo presente na periodontite está envolvido na patogênese da DA. As espécies bacterianas com maior associação a ambas patologias incluem Aggregatibacter Actinomycetemcomitans,Porphyromonas gingivalis, Tannerella denticola, e Fusobacterium nucleatum. Estas podem invadir o SNC, desencadeando doenças neurodegenerativas ou interagindo com as doenças preexistentes, contudo, o principal fator em células gliais estimulantes é o LPS o associado a $P$. gingivalis (DOMINY et al., 2019).

Observa-se que a periodontite pode levar a inflamações sistêmicas através da liberação de citosinas pró-inflamatórias e invasão de bactérias da periodontite, induzindo a inflamação crônica associada à microglia, como a neuroinflamação. Destaca-se que, a neuroinflamação, através de um mecanismo biológico da 
periodontite, tende a causar o início do desenvolvimento clínico de distúrbios neurodegenerativos (HASHIOKA et al., 2019). A periodontite e doenças neurodegenerativas têm uma etiopatogenia diferente, mas compartilham fatores de risco comuns que podem influenciar seu início, gravidade e progressão.

\section{RESULTADOS}

Realizou-se uma busca na literatura nos bancos de dados selecionados previamente para este estudo artigos científicos encontrados referentes ao tema doença de Alzheimer e periodontite e sua correlação. Após a busca, encontrou-se 40 resultados na LILACS, 558 no Google Scholar e mais 191 no Pubmed, incluindo um estudo encontrado por semelhança de citação. Destes, foram selecionados previamente antes da aplicação dos critérios de elegibilidade 15, 18 e 1 estudos respectivamente de cada base de dados. Após a aplicação dos critérios de elegibilidade, incluiu-se 4 revisões sistemáticas com meta-análise e 6 estudos de caso controle. Houve ainda uma busca manual na literatura por estudos que se assemelhassem com o tema abordado. Com isso, permaneceram 10 estudos elegidos de 6 países diferentes sendo 6 estudos de casocontrole e 4 revisões de literatura sistemáticas com meta-análise publicados entre os anos de 2017 à 2020. Entre os estudos analisados, nos casos controle 4 mostraram haver uma piora na saúde bucal dos pacientes com a doença de Alzheimer (DA), enquanto que 2 não concordaram.

Os estudos do tipo caso controle analisaram 943 pacientes incluindo portadores da doença de Alzheimer, comprometimento cognitivo e pacientes saudáveis. Dentre os efeitos manifestados decorrentes das consequências causadas pela DA incluem-se o aumento nas perdas dentárias ( 3 estudos), saúde bucal crítica (6 estudos), maior número de dentes cariados ( 3 estudos), bem como maior perda óssea alveolar (4 estudos).

Entretanto, as 4 revisões sistemáticas selecionadas concluíram existir relação entre a DA e a doença periodontal (DP), totalizando (31) estudos realizados. 
Tabela 1: Principais estudos sobre a relação da periodontite e a doença de Alzheimer encontrada a partir da busca bibliográfica entre os períodos 2010 a 2020. Número de estudos

(10).

\begin{tabular}{|c|c|c|c|c|}
\hline $\begin{array}{c}\text { Autor / ano } \\
\text { / local }\end{array}$ & $\begin{array}{c}\text { Número de } \\
\text { participantes do } \\
\text { estudo e desenho } \\
\text { do estudo }\end{array}$ & Objetivo & Resultados & Conclusões \\
\hline $\begin{array}{l}\text { KAYE, et al. } \\
2010, \text { REINO } \\
\text { UNIDO }\end{array}$ & $\begin{array}{l}597 \text { homens } \\
\text { dentados na linha } \\
\text { de base do estudo } \\
\text { que foram } \\
\text { acompanhados } \\
\text { por } 32 \text { anos. } \\
\text { Estudo de coorte. }\end{array}$ & $\begin{array}{l}\text { Analisar a taxa de } \\
\text { perda dentária } \\
\text { como possível má } \\
\text { função cognitiva em } \\
\text { homens, visto que a } \\
\text { periodontite e a } \\
\text { cárie são } \\
\text { consideradas os } \\
\text { principais fatores de } \\
\text { perda dentária. }\end{array}$ & $\begin{array}{lr}86 \% & \text { dos } \\
\text { participantes } & \\
\text { tiveram a média } \\
\text { de } 12 \text { dentes } \\
\text { perdidos por } \\
\text { década, o risco de } \\
\text { cognição } \\
\text { prejudicada se } \\
\text { aproximaria } & 100 \% .\end{array}$ & $\begin{array}{l}\text { A saúde bucal é } \\
\text { determinante } \\
\text { modificável } \\
\text { importante da } \\
\text { função cognitiva e } \\
\text { demonstra que a } \\
\text { inflamação } \\
\text { periférica contribui } \\
\text { para o } \\
\text { desenvolvimento de } \\
\text { demência. }\end{array}$ \\
\hline $\begin{array}{l}\text { IDE, et al. } \\
\text { 2016, } \\
\text { ESTADOS } \\
\text { UNIDOS }\end{array}$ & $\begin{array}{l}60 \text { participantes } \\
\text { com Doença de } \\
\text { Alzheimer leve a } \\
\text { moderada, foram } \\
\text { avaliados } \\
\text { cognitivamente, e } \\
\text { recolhidas } \\
\text { amostras de } \\
\text { sangue para } \\
\text { marcadores } \\
\text { inflamatórios } \\
\text { sistêmicos. } \\
\text { Estudo de coorte. }\end{array}$ & $\begin{array}{lr}\text { Determinar } & \text { a } \\
\text { associação } & \text { da } \\
\text { periodontite com o } \\
\text { aumento } & \text { da } \\
\text { gravidade } & \text { da } \\
\text { doença } & \text { de } \\
\text { Alzheimer e o } \\
\text { declínio cognitivo, } \\
\text { pelo aumento do } \\
\text { estado pró- } \\
\text { inflamatório } \\
\text { sistêmico. }\end{array}$ & 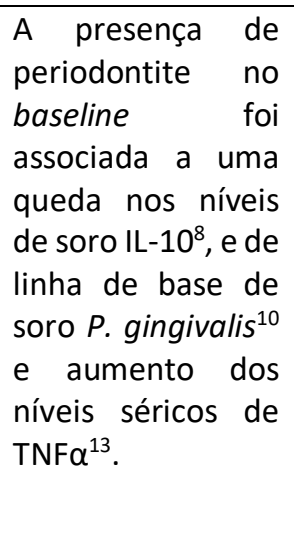 & $\begin{array}{l}\text { A presença de } \\
\text { periodontite no } \\
\text { início do estudo não } \\
\text { estava relacionada } \\
\text { ao estado cognitivo } \\
\text { basal, mas durante o } \\
\text { acompanhamento } \\
\text { de } 6 \text { meses houve } \\
\text { um aumento de } 6 \\
\text { vezes na taxa de } \\
\text { declínio. }\end{array}$ \\
\hline $\begin{array}{l}\text { STEIN, et al. } \\
\text { 2012, } \\
\text { ESTADOS } \\
\text { UNIDOS }\end{array}$ & $\begin{array}{l}158 \text { participantes } \\
\text { que estavam } \\
\text { cognitivamente } \\
\text { intactos na coleta } \\
\text { de sangue venoso } \\
\text { basal foram } \\
\text { analisados quanto } \\
\text { à imunoglobulina } \\
\text { G, níveis corporais } \\
\text { as sete bactérias } \\
\text { orais associadas à } \\
\text { periodontite. } \\
\text { Estudo de coorte. }\end{array}$ & $\begin{array}{lr}\text { Examinar os níveis } \\
\text { séricos } & \text { de } \\
\text { anticorpos } & \text { de } \\
\text { bactérias da doença } \\
\text { periodontal em } \\
\text { participantes que } \\
\text { eventualmente se } \\
\text { converteram em } \\
\text { DA }^{5} \text { comparados } \\
\text { com os níveis de } \\
\text { anticorpos em } \\
\text { indivíduos controle. }\end{array}$ & $\begin{array}{l}\text { Os níveis de } \\
\text { anticorpos para } F \\
\text { nucleatum e P } \\
\text { intermedia } \\
\text { aumentaram } \\
\text { significativamente } \\
\text { o consumo sérico } \\
\text { basal nos } \\
\text { pacientes com DA }{ }^{5} \\
\text { comparado aos } \\
\text { controles. }\end{array}$ & $\begin{array}{lr}\text { Mostrou anticorpos } \\
\text { elevados para } \\
\text { doenças } \\
\text { periodontais. } \\
\text { Diminuir a carga } \\
\text { bacteriana em } \\
\text { indivíduos anos } \\
\text { antes r do } \\
\text { comprometimento } \\
\text { cognitivo pode ser } \\
\text { importante, pois } \\
\text { doença periodontal } \\
\text { poderia contribuir } \\
\text { potencialmente } \\
\text { para o risco de } \\
\text { início/progressão da } \\
\text { DA }^{5} \text {. }\end{array}$ \\
\hline $\begin{array}{l}\text { POOLE, et } \\
\text { al. 2013, } \\
\text { INGLATERR } \\
\text { A }\end{array}$ & $\begin{array}{l}\text { Analise em secções } \\
\text { de tecido cerebral } \\
\text { obtidas de } 12 \text { a } 24 \\
\text { horas após a morte, } \\
\text { em } 10 \text { pacientes com } \\
\text { DA }^{5} \text { e } 10 \text { pacientes } \\
\text { controles não } \\
\text { relacionados à DA. } \\
\text { Estudo caso-controle }\end{array}$ & $\begin{array}{l}\text { Estabelecer uma } \\
\text { ligação entre a doença } \\
\text { periodontal e a } \\
\text { doença de Alzheimer } \\
\text { através } \\
\text { identificação das das } \\
\text { principais bactérias da } \\
\text { doença periodontal } \\
\text { sendo elas. }\end{array}$ & 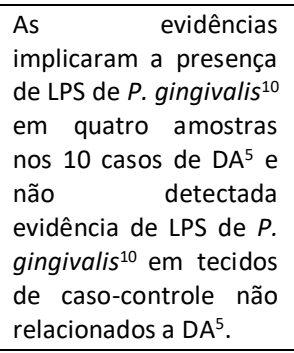 & $\begin{array}{l}\text { Concluindo que o } \\
\text { fator de virulência } \\
\text { que atinge o cérebro } \\
\text { humano sugere um } \\
\text { papel inflamatório } \\
\text { na patologia } \\
\text { existente da } \mathrm{DA}^{5} \text {. }\end{array}$ \\
\hline
\end{tabular}




\begin{tabular}{|c|c|c|c|c|}
\hline $\begin{array}{c}\text { Autor / ano } \\
\text { / local }\end{array}$ & $\begin{array}{c}\text { Número de } \\
\text { participantes do } \\
\text { estudo e desenho } \\
\text { do estudo }\end{array}$ & Objetivo & Resultados & Conclusões \\
\hline $\begin{array}{l}\text { KUBOTA; et } \\
\text { al. 2014, } \\
\text { JAPÃO }\end{array}$ & $\begin{array}{lr}28 \quad \text { pacientes } \\
\text { japoneses, } 14 \text { com } \\
\text { periodontite e } 14 \\
\text { clinicamente } & \\
\text { saudáveis e } & \text { sem } \\
\text { histórico } & \text { de } \\
\text { doença } & \\
\text { periodontal, que } \\
\text { possuíam no } \\
\text { mínimo } & \text { no } \\
\text { elementos } & \\
\text { dentários. } \\
\text { Estudo } \\
\text { controle. }\end{array}$ & $\begin{array}{l}\text { Analisar a } \\
\text { inflamação crônica } \\
\text { está associado a um } \\
\text { risco aumentado de } \\
\text { alterações } \\
\text { cognitivas declínio e } \\
\text { demência, bem da } \\
\text { periodontite. }\end{array}$ & 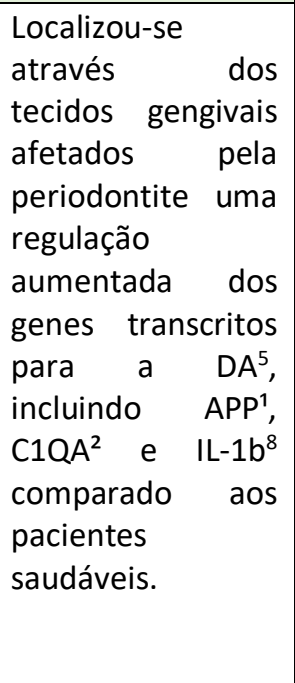 & $\begin{array}{lr}\text { As medidas de qRT- } \\
\mathrm{PCR}^{12} \text { foram } \\
\text { mecanismos úteis } \\
\text { para detectar genes } \\
\text { químicos na } \\
\text { periodontite, como } \\
\text { fatores de } \\
\text { comprometimento } \\
\text { inflamatório que } \\
\text { podem ser críticos } \\
\text { no início e } \\
\text { progressão de } \\
\text { doenças crônicas } \\
\text { relacionadas ao } \\
\text { envelhecimento, } \\
\text { como a } \mathrm{DA}^{5} \text {. }\end{array}$ \\
\hline $\begin{array}{l}\text { CHEN,WU; } \\
\text { CHANG, } \\
2017 ; \\
\text { TAIWAN }\end{array}$ & $\begin{array}{l}\text { A amostra incluiu } \\
\text { um total de } 9291 \\
\text { pacientes com } \\
\text { periodontite } \\
\text { crônica e } 18.672 \\
\text { pacientes sem } \\
\text { periodontite } \\
\text { crônica com idade } \\
\text { média } \geq 50 \text { anos, } \\
\text { com } \\
\text { acompanhamento } \\
\text { de } 10 \text { anos. } \\
\text { Estudo caso- } \\
\text { controle. }\end{array}$ & $\begin{array}{l}\text { Determinar se os } \\
\text { pacientes com } \\
\text { periodontite crônica } \\
\text { têm maior risco de } \\
\text { desenvolver Doença } \\
\text { de Azheimer. }\end{array}$ & 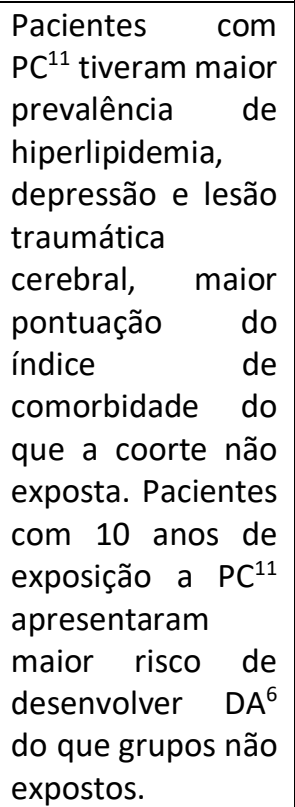 & 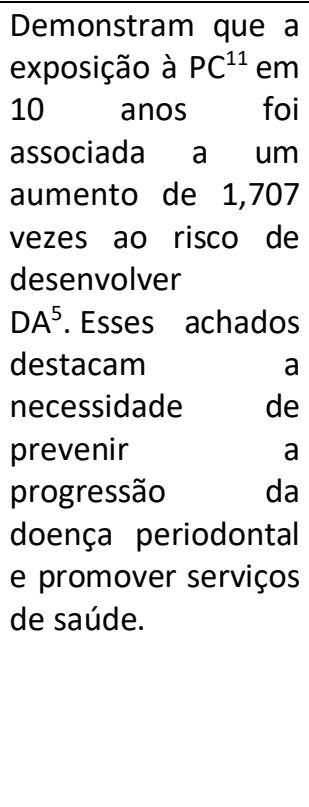 \\
\hline $\begin{array}{l}\text { MONTOYA, } \\
\text { et al. 2019, } \\
\text { ESPANHA }\end{array}$ & $\begin{array}{l}\text { Uma análise de } 29 \\
\text { biomarcadores em } \\
178 \text { casos, desses } \\
22 \text { com } \\
\text { comprometiment } \\
\text { o leve ou sem } \\
\text { demência e } 156 \\
\text { com demência, e } \\
131 \text { casos controle } \\
\text { saudáveis. } \\
\text { Estudo caso- } \\
\text { controle }\end{array}$ & $\begin{array}{lr}\text { Examinar o impacto } \\
\text { da inflamação } & \text { da } \\
\text { periodontite } & \text { na } \\
\text { relação } & \text { da } \\
\text { deficiência } & \\
\text { cognitiva/demência } \\
\text {, utilizando técnicas } \\
\text { multiplex para } \\
\text { analisar } \\
\text { conjunto } \\
\text { biomarcadores } \\
\text { inflamação } & \text { de } \\
\text { sorológica em } & \\
\text { população } & \text { de } \\
\text { idosos. } & \end{array}$ & $\begin{array}{l}\text { Observaram } \\
\text { concentrações } \\
\text { sorológicas de } \\
\text { inferiores de } \\
\text { biomarcadores em } \\
\text { pacientes com } \\
\text { comprometiment } \\
\text { o cognitivo e } \\
\text { periodontite mais } \\
\text { grave do que nos } \\
\text { controles sem } \\
\text { comprometiment } \\
\text { o cognitivo. }\end{array}$ & $\begin{array}{l}\text { Com base nos } \\
\text { resultados, não é } \\
\text { possível confirmar } \\
\text { que a inflamação } \\
\text { sistêmica derivada } \\
\text { da doença } \\
\text { periodontal tem um } \\
\text { papel relevante na } \\
\text { etiologia das } \\
\text { doenças cognitivas. }\end{array}$ \\
\hline
\end{tabular}




\begin{tabular}{|c|c|c|c|c|}
\hline $\begin{array}{c}\text { Autor / ano } \\
\text { / local }\end{array}$ & $\begin{array}{l}\text { Número de } \\
\text { participantes do } \\
\text { estudo e desenho } \\
\text { do estudo }\end{array}$ & Objetivo & Resultados & Conclusões \\
\hline $\begin{array}{l}\text { SUN, et al. } \\
2020, \\
\text { BÉLGICA }\end{array}$ & $\begin{array}{l}\text { Utilizaram dados } \\
\text { de estudos de } \\
\text { associação } \\
\text { genômica }\left(\mathrm{GWAS}^{6} \text { ) }\right. \\
\text { sobre periodontite } \\
\text { e o risco de } \mathrm{DA}^{5} \text {. } \\
\text { Da periodontite } \\
\text { (4.924 casos vs. } \\
7.301 \text { controles) } \\
\text { da DA (21.982 } \\
\text { casos vs. } 41.944 \\
\text { controles). } \\
\text { Estudo } \\
\text { controle. }\end{array}$ & 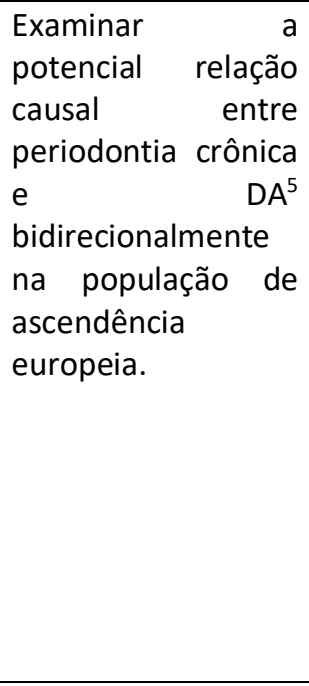 & $\begin{array}{l}\text { Não houve } \\
\text { associação de } \mathrm{DA}^{5} \\
\text { prevista } \\
\text { geneticamente } \\
\text { com o risco de } \\
\text { periodontite, ( } P= \\
0,85) \text {. }\end{array}$ & $\begin{array}{l}\text { Não houve } \\
\text { evidências } \\
\text { convincentes para } \\
\text { apoiar a } \\
\text { periodontite, sendo } \\
\text { um fator causal para } \\
\text { o desenvolvimento } \\
\text { da } \mathrm{DA}^{5} \text {. } \\
\text { Haviam também } \\
\text { evidências limitadas } \\
\text { para sugerir a } \\
\text { responsabilidade } \\
\text { genética de a DA } \\
\text { estar associada com } \\
\text { risco de } \\
\text { periodontite. }\end{array}$ \\
\hline $\begin{array}{l}\text { SOCHOCKA; } \\
\text { et al. 2017, } \\
\text { POLÔNIA }\end{array}$ & $\begin{array}{l}128 \text { pacientes, sob } \\
\text { os cuidados dos } \\
\text { Departamento de } \\
\text { Periodontia e } \\
\text { Psiquiatria da } \\
\text { Universidade } \\
\text { Médica Wroclaw } \\
\text { da Polônia e } \\
\text { Alemanha. } \\
\text { Estudo } \\
\text { transversal. }\end{array}$ & $\begin{array}{l}\text { Verificar se o mau } \\
\text { estado de saúde } \\
\text { periodontal pode } \\
\text { estar associado a } \\
\text { comprometimento } \\
\text { cognitivo e } \\
\text { demência através } \\
\text { da exacerbação da } \\
\text { inflamação } \\
\text { sistêmica. }\end{array}$ & $\begin{array}{l}\text { Confirma-se a } \\
\text { presença de } \\
\text { declínio cognitivo } \\
\text { e de mediadores } \\
\text { inflamatórios } \\
\text { relacionados com } \\
\text { problemas } \\
\text { periodontais, } \\
\text { sendo que estes, } \\
\text { agravam a } \\
\text { inflamação } \\
\text { sistêmica. }\end{array}$ & $\begin{array}{l}\text { Os processos } \\
\text { inflamatórios } \\
\text { alteram e facilitam o } \\
\text { processo da } \\
\text { prevalência de } \\
\text { vários sintomas, } \\
\text { podendo exacerbar } \\
\text { a inflamação } \\
\text { sistêmica da Doença } \\
\text { de Alzheimer e } \\
\text { aprofundar lesões } \\
\text { neurodegenerativas }\end{array}$ \\
\hline $\begin{array}{l}\text { LEBLHUBER, } \\
\text { et al. 2020, } \\
\text { ÁUSTRIA }\end{array}$ & $\begin{array}{l}\text { De } 55 \text { pacientes, } \\
20 \quad \text { pacientes } \\
\text { foram recrutados } \\
\text { com provável } \\
\text { diagnóstico da } \\
\text { doença de } \\
\text { Alzheimer. } \\
\text { Estudo } \\
\text { transversal. }\end{array}$ & $\begin{array}{l}\text { Analisar se } \\
\text { periodontite crônica } \\
\text { leva à inflamação } \\
\text { sistêmica através de } \\
\text { patógenos orais que } \\
\text { podem ser efeito a } \\
\text { doença de } \\
\text { Alzheimer. }\end{array}$ & 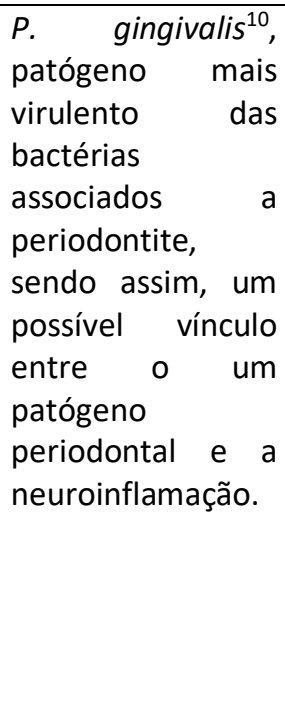 & 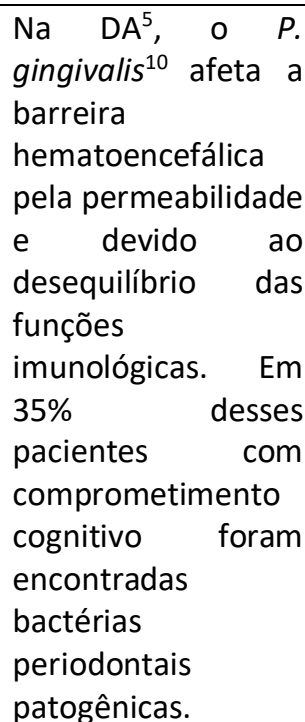 \\
\hline
\end{tabular}

Fonte: própria autoria

${ }^{1}$ Proteína Precursora de Amiloide; ${ }^{2}$ Proteína complementar de cadeias polipeptídicas; ${ }^{3}$ Comprometimento cognitivo leve; ${ }^{4}$ Clock Drawing Test; ${ }^{5}$ doença de Alzheimer; ${ }^{6}$ Associação genômica; ${ }^{7}$ interleucina 10 ; ${ }^{8}$ interleucina 1 beta; ${ }^{9}$ Mini exame de estado mental; ${ }^{10}$ Porphyromonas gingivalis; ${ }^{11}$ Periodontite crônica; ${ }^{12}$ quantitativo em tempo real - reação da cadeia polimerase; ${ }^{13}$ Fator de Necrose Tumoral Alfa.

${ }^{1}$ Proteína Precursora de Amiloide; ${ }^{2}$ Proteína complementar de cadeias polipeptídicas; ${ }^{3}$ Comprometimento cognitivo leve; ${ }^{4}$ Clock Drawing Test; ${ }^{5}$ doença de Alzheimer; ${ }^{6}$ Associação genômica; ${ }^{7}$ interleucina 10 ; 
${ }^{8}$ interleucina 1 beta; ${ }^{9}$ Mini exame de estado mental; ${ }^{10}$ Porphyromonas gingivalis; ${ }^{11}$ Periodontite crônica; ${ }^{12}$ quantitativo em tempo real - reação da cadeia polimerase; ${ }^{13}$ Fator de Necrose Tumoral Alfa.

\section{DISCUSSÃO}

Sabe-se que a presença de micro-organismos de composições particulares inicia a periodontite em indivíduos susceptíveis. Nestes pacientes, a resposta do hospedeiro e os fatores de risco cumulativos predispõem a destruição dos tecidos periodontais. Através do biofilme, os micro-organismos têm um ambiente de proteção e propriedades metabólicas que asseguram uma atuação dos patógenos de forma individual ou coletiva. Além do mais, fatores como a concentração do íon hidrogênio $(\mathrm{pH})$, o potencial de oxirredução e enzimas proteolíticas podem afetar o mecanismo de defesa do organismo do hospedeiro (MARSH 2005; LINDHE, LANG, KARRING, 2008).

Sabendo dessa significativa infecção bacteriana e carga inflamatória que afeta estruturas de suporte como elementos dentários, três principais bactérias periodontais foram detectadas no tecido cerebral com demência, sendo elas Treponema denticola, Tannerella forsythia, e com maior prevalência de $P$. gingivalis (POOLE et al., 2013). Além disso, a Pesquisa Nacional sobre Exame de Saúde e Nutrição dos Estados Unidos (NHANES III) associou a Porphyromonas gingivalis a baixo nível de conhecimento em pacientes acima de 60 anos (NOBLE et al., 2009; DíAZ-ZÚÑI et al., 2019). Concomitante a estes achados, testes realizados em camundongos conseguiram demonstrar que Porphyromonas gingivalis induz o comprometimento da memória e neuroinflamação (DING et al., 2008).

Os mecanismos envolvidos na patogênese da doença de Alzheimer não são claros, mas a inflamação desempenha um papel importante, visto que as reações inflamatórias que aumentam o estado inflamatório cerebral podem potencialmente favorecer a progressão da doença. A periodontite expõe o hospedeiro à presença de um processo inflamatório estável associado a bactérias colonizadas no periodonto (DIOGUARDI et al., 2020). A invasão do tecido cerebral por bactérias que residem no biofilme pode ocorrer através do tecido sanguíneo ou através de nervos periféricos que aceleram a neuro-inflamação (LEIRA et al., 2017).

Os resultados das revisões-sitemáticas com meta-análise sintetizam o que de melhor se tem em evidências científicas atualmente sobre a associação da DP e a DA. 
Apesar de investigarem diferentes perguntas o estudo incluído na presente revisão, algumas questões foram pertinentes como avaliar se a periodontite estava associada a DA. Através de parâmetros clínicos e inflamatórios periodontais, tais como: profundidade de sondagem, sangramento a sondagem, índice de sangramento gengival, nível de inserção clínica e índice de placa foram variáveis analisadas por metanálise. A comparação de indivíduos sistemicamente saudáveis e acometidos por DA mostrou diferença significativa entre os grupos (MALDONADO et al., 2018).

Leira et al 2017, não encontrou discordância ao avaliar a profundidade de bolsa em pacientes com DA e controles saudáveis, no entanto quando o número de dentes com bolsas periodontais maiores que $4 \mathrm{~mm}$ é observado como uma variável de $\mathrm{DP}$, não existe associação significativa. Mostrando ainda que a DP é mais prevalente em pacientes com DA, principalmente em seu estado mais graves, mostrando auto número de perdas dentárias.

Quando se fala em risco relativo de DA associado a doença periodontal podemos remeter a ideia de que somente o risco não justifica o seu aparecimento. No entanto, se considerarmos uma redução de $50 \%$ na prevalência de doença periodontal na população, poderíamos evitar cerca de 850.000 de novos casos no mundo todo (NADIM, et al., 2020).

Dioguardi et al 2019 propõem, através de sua análise quantitativa dos estudos incluídos, que entre os artigos revisados a maioria traz que a redução da higiene oral em pacientes afetados pela DA causa uma piora significativa no estado de saúde bucal destes pacientes. Mostrando que esses pacientes estão associados a um maior número de perdas de elementos dentários bem como de edentulismo em geral em comparação com outros grupos controle.

Quanto aos estudos de caso-controle, a maioria dos autores estudados concordaram haver correlação entre a DP e a DA, enquanto que dois estudos discordaram. Porém, analisou-se em um dos estudos que pacientes com mais de 10 anos com periodontite crônica, além de possuirem maior probabilidade de desenvolver DA, dispõem também do aumento de chances para ocorrer hiperlipidemia, lesão traumática cerebral e depressão. Além disso, analisou-se também que há evidências da bactéria $P$. Gingivalis em tecidos gengivais de pacientes com DA, bem como o aumento dos genes transcritos para a DA, como APP, C1QA e IL-1B. 
Enquanto isso, o estudo de Montoya et al.; 2019, verificou que indivíduos com comprometimento cognitivo e periodontite grave mostraram concentrações sorológicas de biomarcadores menores, concluindo que foi plausível confirmar que a inflamação sistêmica derivada da doença periodontal tenha relevância na etiologia das doenças cognitivas. Da mesma forma que Sun et al.; 2020, estudou a associação genômica entre a periodontite e a DA e que não exibiu, geneticamente, nenhuma relação de risco.

Diante dos estudos analisados, observa-se uma provável relação entre a periodontite e a doença de Alzheimer devido a associação de citocinas próinflamatórias, da mesma maneira que, ao decorrer do acompanhamento de pacientes com periodontite, houveram dados relativos ao aumento do comprometimento cognitivo e/ou demência, sendo esse, considerado um fator proeminente para associação a doença de Alzheimer.

\section{CONSIDERAÇÕES FINAIS}

Os estudos, em sua maioria, evidenciaram a relação entre a inflamação da periodontite e sua viabilidade de comprometer o estado cognitivo desencadeando na doença de Alzheimer. Embora as conclusões dos estudos sejam na maior parte, favoráveis a essa relação, os critérios de diagnóstico da inflamação periférica da periodontite como provável fator causal ainda estão sendo aprimorados, no que se refere às comparações e diferenças de concepção para a busca de resultados que geram a confirmação desse envolvimento.

Por fim, independentemente do mecanismo pelo qual a inflamação sistêmica da periodontite é desencadeada, os dados apresentados documentam o potencial que ela apresenta em influenciar as doenças sistêmicas, incluindo as neurológicas crônicas como a DA, sendo assim, conclui-se a relevância da continuidade dos estudos sobre os patógenos da periodontite induzida a outros sítios do organismo.

\section{REFERÊNCIAS}

ALBANDAR, J.M.; SUSIN, C.; HUGHES, F.J. Manifestations of systemic diseases and conditions that affect the periodontal attachment apparatus: Case definitions and diagnostic considerations. Journal of periodontology. v. 45, n 20, 2018 p. s183-s203. 
ALMEIDA, R. F. et al. Associação entre doença periodontal e patologias sistémicas. Revista Portuguesa de Clínica Geral, v. 22, n. 3, 2006, p. 379-390.

ALZHEIMER'S ASSOCIATION. 2009 Alzheimer's disease facts and figures. Alzheimer's \& Dementia: The Journal of the Alzheimer's Association, v. 5, 2009, p. 234-270.

AWANO, S. et al. Oral health and mortality risk from pneumonia in the elderly. Journal of Dental Research, v. 87, 2008, p. 334-339.

BERTOLDI, C. et al. Risk factors and socioeconomic condition effects on periodontal and dental health: A pilot study among adults over fifty years of age. European Journal of Dental. v. 7, 2013, p. 336-346.

BILLINGS, M. et al. Age-dependent distribution of periodontitis in two countries: Findings from NHANES 2009 to 2014 and SHIP-TREND 2008 to 2012. Journal of Clinical Periodontology, v. 45, 2018, p. 130-148.

CATON, J. G. et al. A New Classification Scheme forPeriodontal and Peri-Implant Diseases and Conditions - Introduction and Key Changes From the 1999 Classification. Journal of Clinical Periodontology, v. 45, 2018, p. 1-8.

CHEN, C. K.; WU, Y. T.; CHANG, Y. T. Association between chronic periodontitis and the risk of Alzheimer's disease: a retrospective, population-based, matchedcohort study. Archives of Oral Biology, v. 9, 2017, p. 56.

D'AIUTO, F. et al. Periodontitis: From Local Infection to Systemic Diseases. International Journal Immunopathology and Pharmacology, v. 18, 2005, p. 1-11.

DARVEAU, R. P.; HAJISHENGALLIS, G.; CURTIS, M. A. Porphyromonas Gingivalis as a Potential Community Activist for Disease. Journal of Dental Research, v. 91, 2012, p. 816-820.

DIOGUARDI, M. et al. The role of periodontitis and periodontal bacteria in the onset and progression of Alzheimer's disease: A systematic review. Journal of Clinical Medicine, v. 9, 2020, p. 495.

DOMINY, S. et al. Porphyromonas gingivalis in Alzheimer's Disease Brains: Evidence for Disease Causation and Treatment With Small-Molecule Inhibitors. Science advances, v. 5, n 1, 2019.

EKE, P. et al. Prevalence of Periodontitis in Adults in the United States: 2009 and 2010. Journal of Dental Research, v. 91, n 10, 2012, p. 914-20.

FERES, M. et al. The subgingival periodontal microbiota of the aging mouth. Periodontology 2000, v. 72, 2016, p. 30-53. 
FERRI, C. P. et al. Global Prevalence of Dementia: A Delphi Consensus Study. The lancet, v. 366,2005, p. $2112-2117$.

FILOCHE, S.; WONG, L.; SISSONS, C. H. Oral Biofilms: Emerging Concepts in Microbial Ecology. Journal of Dental Research, v. 89, 2010, p. 8-18.

FRANCESCHI, C.; CAMPISI J. Chronic Inflammation (Inflammaging) and Its Potential Contribution to Age-Associated Diseases. The Journals of Gerontology. Series A, Biological Sciences and Medical Sciences, v. 69, 2014, p. 4-9.

FRENCKEN, J. E. et al. Global Epidemiology of Dental Caries and Severe Periodontitis- A Comprehensive Review. Journal of Clinical Periodontology, v.44, 2017, p. 94105.

GALIMBERTI, D.; SCARPINI, E. Progress in Alzheimer's Disease. Journal of Neurology. v. 259, 2012, p. 201-211.

GRAU, A. J. et al. Periodontal Disease as a Risk Factor for Ischemic Stroke. Stroke, v. 35, 2004, p. 496-501.

GRAVES, D. T.; JIANG, Y.; GENCO, C. Periodontal Disease: Bacterial Virulence Factors, Host Response and Impact on Systemic Health. Current Opinion in Infectious Diseases, v. 13, 2000, p. 227-232.

GURAV, A. N. A doença de Alzheimer e periodontite. Revista da Associação Médica Brasileira (1992), v. 60, 2014, p. 173-180.

GUTIERREZ, B. A. O. et al. Impacto econômico da doença de Alzheimer no Brasil: é possível melhorar a assistência e reduzir custos? Ciência \& Saúde coletiva. v.19, n. 11, 2014.

HAJISHENGALLIS, G. Aging and Its Impact on Innate Immunity and Inflammation: Implications for Periodontitis. Journal of Oral Biosciences, v. 56, 2014, p. 30-37.

HAJISHENGALLIS, G. Periodontitis: From Microbial Immune Subversion to Systemic Inflammation. Nature Reviews Immunology, v.15, 2015, p. 30-44.

HAN, Y. W.; WANG, X. Mobile microbiome: oral bacteria in extra oral infections and inflammation. Journal of Dental Research, v. 92, 2013, p. 485-491.

HARDING, A. et al. Can Better Management of Periodontal Disease Delay the Onset and Progression of Alzheimer's Disease? Journal of Alzheimer's Disease, v. 58, 2017, p. 337-348.

HARVEY, J. D. Periodontal Microbiology. Dental Clinics of North America, v. 1, n 2, 2017, p. 253-269. 
IDE, M. et al. Periodontitis and Cognitive Decline in Alzheimer's Disease. Journal Plos One, v. 11, n 3, 2016, e0151081.

INSTITUTO BRASILEIRO DE GEOGRAFIA E ESTATÍSTICA (IBGE). Características gerais dos moradores 2012-2016. IBGE, Rio de Janeiro, 2017.

KASSEBAUM, N. J. et al. Global Burden of Severe Periodontitis in 1990-2010: A Systematic Review and Meta-Regression. Journal of Dental Research, v. 93, 2014, p. 1045-1053.

KAYE, E. K. et al. Tooth Loss and Periodontal Disease Predict Poor Cognitive Function in Older Men. Journal of the American Geriatrics Society, v. 58, 2010, p. 713-718.

KUBOTA, T. et al. Amyloid beta (A4) precursor protein expression in human periodontitis-affected gingival tissues. Journal Archives of Oral Biology, v. 59, n 6, 2014, p. 586-94.

LANE, C. A.; HARDY, J.; SCHOTT, J. M. Alzheimer's Disease. European Journal of Neurology, v. 25, 2018, p. 59-70.

LANG, N. P.; SUVAN, J. E.; TONETTI, M. S. Risk Factor Assessment Tools for the Prevention of Periodontitis Progression a Systematic Review. Journal of Clinical Periodontology, v. 42, 2015, p. 59-70.

LEBLHUBER, F. et al. Knock-on effect of periodontitis to the pathogenesis of Alzheimer's disease? Journal Wiener klinische Wochenschrift, 2020

LINDHE, J.; LANG, N.; KARRING, T. Treaty of Clinical Periodontics and Oral Implantology. 5a edição. Editora Blackwell Publishing Ltda, Oxford, 2008.

LOOS, B.G. Systemic Markers of Inflammation in Periodontitis. Journal of Periodontology, v. 76, 2005, p. 2106-2115.

LOSSINSKY, A.S.; SHIVERS, R.R. Structural pathways for macromolecular and cellular transport across the blood-brain barrier during inflammatory conditions. Review. Histology and Histopathology, v. 19, 2004, p. 535-564.

MARSH, P. D. Dental plaque: biological significance of a biofilm and community life-style. Journal of Clinical Periodontology, v. 32, n 6, 2005, p. 7-5.

MAWANDA, F.; WALLACE, R. Can Infections Cause Alzheimer's Disease? Epidemiologic Reviews, v. 35, 2013, p. 161-180.

MONTOYA, J. A. G. et al. Systemic inflammatory impact of periodontitis on cognitive impairment. Gerodontologia, v. 37, n 1, 2019, p. 11-18. 
NOBLE, J. M. et al. Periodontitis Is Associated With Cognitive Impairment Among Older Adults: Analysis of NHANES-III. Journal of Neurology, Neurosurgery and Psychiatry, v. 80, 2009, p. 1206-1211.

PAPAPANOU, P. N. et al. Periodontitis: Consensus Report of Workgroup 2 of the 2017 World Workshop on the Classification of Periodontal and Peri-Implant Diseases and Conditions. Journal of Periodontology, v. 89, 2018, p. 173-182.

PETERSON, C.T. et al. Immune homeostasis, dysbiosis and therapeutic modulation of the gut microbiota. Clinical and Experimental Immunology, v. 179, 2015, p. 363-377.

POOLE, S. et al. Determining the Presence of Periodontopathic Virulence Factors in Short-Term Postmortem Alzheimer's Disease Brain Tissue. Journal of Alzheimer's Disease, v. 36, 2013, p. 665-677.

ROCHA, P.; MARTINS, A.; TEIXEIRA, L.; REIS, J. Processo inflamatório e neuroimunomodulação na doença de Alzheimer: revisão da literatura. Revista neurociência, v.19, 2010, p. 300-313.

ROMÁN-MALO, L.; BULLON, P. Influence of the Periodontal Disease, the Most Prevalent Inflammatory Event, in Peroxisome Proliferator-Activated Receptors Linking Nutrition and Energy Metabolism. International Journal of Molecular Sciences, v. 18, n 7, 2017, p. 1438.

SHOEMARK, D. K.; ALLEN, S. J. The microbiome and the disease: reviewing the links between the oral microbiome, aging, and Alzheimer's disease. Journal of Alzheimer's Disease, v. 43, n 3, 2015, p. 725-38.

SINGHRAO, S. K. et al. Oral Inflammation, Tooth Loss, Risk Factors, and Association With Progression of Alzheimer's Disease. Journal of Alzheimer's Diseases, v. 42, 2014, p. 723-737.

SINGHRAO, S. K. et al. Porphyromonas Gingivalis Periodontal Infection and Its Putative Links With Alzheimer's Disease. Mediators of Inflammation, v. 2015, 2015, 137357.

SMALL, D. H.; CAPPAI, R. Alois Alzheimer and Alzheimer's Disease: A Centennial Perspective. Journal of Neurochemistry, v. 99, 2006, p. 708-710.

SOCHOCKA, M. et al. Association between Periodontal Health Status and Cognitive Abilitie s. The Role of Cytokine Profile and Systemic Inflammation. Current Alzheimer Research, v. 14, 2017, p. 978-990.

SOCRANSKY, S. S.; HAFFAJEE, A. D. Periodontal Microbial Ecology. Periodontology 2000, v. 38, 2005, p. 135-187. 
STEFFENS, J. P.; MARCANTONIO, R. A. C. Classificação das Doenças e Condições Periodontais e Peri-implantares 2018: guia Prático e Pontos-Chave. Revista de Odontologia da UNESP, v. 47, 2018, p. 189-197.

STEIN, P. A. et al. Serum antibodies to periodontal pathogens are a risk fator for Alzheimer's disease. Journal Alzheimer's e Dementia, v. 8 n 3, 2012. p. 196-203.

SUN, Y. Q. et al. Mixed evidence for the relationship between periodontitis and Alzheimer's disease: A bidirectional Mendelian randomization study. Journal Plos One, v. 15, n 1, 2020, e0228206.

VAN DER KANT, R.; GOLDSTEIN, L. S. B.; OSSENKOPPELE, R. Amyloid- $\beta$-independent Regulators of Tau Pathology in Alzheimer Disease. Nature Reviews Neuroscience, v. 21, 2020, p. 21-35. 


\title{
CAPITULO $V$ \\ O USO DOS PRÓBIOTICOS NO TRATAMENTO DA DOENÇA PERIODONTAL: UMA REVISÃO INTEGRATIVA DA LITERATURA
}

\author{
DOI: 10.51859/AMPLLA.EPC757.1121-5
}

\author{
Esaú Lucas Nascimento Tavares ${ }^{1}$ \\ Jardel dos Santos Silva ${ }^{2}$ \\ Jefter Haad Ruiz da Silva ${ }^{3}$ \\ Lara Pepita de Souza Oliveira 4
}

\footnotetext{
1 Mestrando em Odontologia. Programa de Pós-Graduação em Odontologia - UFAM

${ }^{2}$ Mestrando em Odontologia. Programa de Pós-Graduação em Odontologia - UFAM

${ }^{3}$ Mestrando em Odontologia. Programa de Pós-Graduação em Odontologia - UFAM

${ }^{4}$ Mestranda em Odontologia. Programa de Pós-Graduação em Odontologia - UFAM
}

\section{RESUMO}

A periodontite é uma doença inflamatória crônica, multifatorial e que possui como principal agente determinante o biofilme bacteriano disbiótico, causando a destruição progressiva dos tecidos de sustentação dentário. Do outro lado, os probióticos constituem um grupo de micro-organismos vivos que, quando usados de maneira correta, trazem benefícios na saúde do hospedeiro. Desta forma, nas últimas décadas o uso dos probióticos vem sido sugerido como forma adjuvante no tratamento da periodontite, visando melhorar os resultados da terapia periodontal básica. Objetivo: realizar uma revisão de literatura sobre as evidências disponíveis relacionadas ao uso dos probióticos no tratamento da doença periodontal. Método: Foram realizadas buscas nas bases de dados Scielo, ScienceDirect e PubMed usando os termos "probiotics", "periodontitis" e "oral health". No total foram usados 22 artigos, sendo 13 ensaios clínicos randomizados, 4 revisões sistemáticas e meta-análise e 5 artigos de revisão. Resultados e discussão: Observou-se a eficácia dos probióticos na redução da profundidade de sondagem e índice de sangramento principalmente com o uso das cepas de Lactobacillus reuteri e Lactobacillus rhamnosus na forma de pastilhas e ingestão, respectivamente. Além do potencial uso dos probióticos como substituto para os microbianos sistêmicos. Conclusão: $O$ uso dos probióticos como adjuvantes no tratamento periodontal apresentam resultados favoráveis, no entanto, a heterogeneidade dos estudos acaba prejudicando a força das evidências e dificultando o estabelecimento de um protocolo clínico, portanto, ainda se faz necessário mais pesquisas para elucidar os benefícios de seu uso.

Palavras-chave: Probióticos. Doença periodontal. Saúde bucal. 


\section{INTRODUÇÃO}

Os probióticos são definidos como micro-organismos vivos que, ao serem administrados em doses corretas, provocam benefícios na saúde do hospedeiro (GRUNER et al., 2016). Entre os benefícios podemos destacar: os efeitos antibacterianos, antifúngicos e antivirais, através dos seus subprodutos como ácido lático e peróxido de hidrogênio; a regulação da flora bacteriana local; e até mesmo a modulação do sistema imunológico do indivíduo (GATEJ et al., 2017).

Geralmente os micro-organismos mais usados como probióticos são as bactérias que pertencem ao gênero Lactobacillus e Bifidobacterium, sendo disponibilizados mais comumente através de suplementos e alimentos fermentados como bebidas lácteas, sucos concentrados, queijos, entre outros (GATEJ et al.,2017).

Apesar da maioria dos estudos estarem relacionados com as vantagens de seu uso na manutenção da saúde dos sistemas gastrointestinal e geniturinário, atualmente as evidências têm apontado que os probióticos podem ser benéficos na prevenção e tratamento das doenças orais como a candidíase, halitose, cárie e doença periodontal (AMEZ et al.,2017).

A doença periodontal ou periodontite é uma doença inflamatória crônica multifatorial que possui como principal fator etiológico o biofilme bacteriano disbiótico. Ao penetrar gradativamente no sulco gengival, as bactérias periodontopatogênicas induzem uma resposta imune/inflamatória local com potencial destrutivo dos tecidos de sustentação dentária que incluem inserção conjuntiva, cemento e osso alveolar; podendo resultar até mesmo na perda do elemento dental (LANG et al., 2018; PAPAPANOU et al., 2018). O tratamento da periodontite consiste basicamente no desbridamento mecânico através da raspagem e alisamento radicular, podendo ser cirúrgico ou não cirúrgico e, em alguns casos, associada a administração sistêmica de antimicrobianos (SANZ et al., 2020). No entanto, além da preocupação com a resistência bacteriana relacionada à prescrição dos antibióticos, o biofilme patogênico também pode ser reestabelecido em algum momento após o tratamento. Desta forma, o uso dos probióticos vem sido sugerido de forma adjuvante no tratamento da periodontite, com o objetivo de melhorar os resultados da terapia periodontal básica e também prevenir a recolonização das bactérias periodontogênicas (GATEJ et al.,2017). 
Todavia, obter uma efetividade dos probióticos na cavidade bucal constitui-se num desafio, visto que é necessário que ele possua alguns requisitos como não oferecer riscos à saúde do indivíduo, sobreviver ao ambiente local da cavidade oral e às respostas imunológicas do hospedeiro (BASTOS et al.,2013). Em relação a seu mecanismo no tratamento da doença periodontal, acredita-se que as bactérias probióticas podem aderir e colonizar as superfícies do elemento dentário, desta forma acabam competindo com o biofilme patógeno e, através da liberação de subprodutos com ação antibacteriana, dificultam a recolonização das superfícies pelos mesmos; além de capacidade de modulação das respostas imunes do hospedeiro (VIVES-SOLER, CHIMENOS-KÜSTNER, 2015).

O objetivo desse trabalho é realizar uma revisão integrativa da literatura acerca das evidências disponíveis relacionadas ao uso dos probióticos no tratamento da doença periodontal.

\section{MÉTODO}

Trata-se de uma revisão integrativa da literatura acerca do uso dos probióticos no tratamento da doença periodontal. Foram realizadas buscas nas bases de dados Scielo, ScienceDirect e PubMed. Os descritoress utilizados no estudo (DeCS/MeSH) foram os termos em inglês "probiotics", "periodontitis" e "oral health". Foram incluídos artigos de revisão, ensaios clínicos randomizados, revisões sistemáticas e meta-análises com índices periodontais como nível de inserção clínica, profundidade de sondagem, índice de sangramento e índice de placa como desfecho. Foram selecionados todos os artigos em língua inglesa e portuguesa publicados entre os anos de 2010 e 2021. A seleção inicial dos artigos se deu por meio da leitura dos títulos e do resumo, excluindo os manuscritos que não fossem condizentes com a temática proposta. No total foram usados 22 artigos, sendo 13 ensaios clínicos randomizados, 4 revisões sistemáticas associadas com meta-análise e 5 artigos de revisão.

\section{RESULTADOS E DISCUSSÃO}

Foi possível observar que os estudos clínicos sobre o uso dos probióticos na periodontite são bastante heterogêneos, pois muitos diferem quanto às cepas 
probióticas usadas, as dosagens, vias de administração, tamanho da amostra, severidade da doença periodontal entre outros. Apesar disso, as evidências têm demostrado resultados satisfatórios (GATEJ et al.,2017).

\subsection{FORMAS DE ADMINISTRAÇ̃̃O E CEPAS PROBIÓTICAS}

Buscando um melhor efeito no meio bucal, além da ingestão, os probióticos também podem ser disponibilizados através de fórmulas e instrumentos com uma liberação local lenta como pastilhas e gomas de mascar. A maioria das pesquisas realizadas em humanos usam as cepas probióticas de Lactobacillus e Bifidobacterium spp visto que em muitos países existem esses produtos de forma comercializada (CARDOSO et al.,2018).

As evidências atuais demonstram que uso dos Lactobacillus reuteri, principalmente na forma de pastilhas após terapia periodontal prévia, tem se apresentado uma alternativa promissora, com melhoras nos parâmetros clínicos periodontais e redução da carga microbiana patogênica como Aggregibacter actinomycetemcomitans, Porphyromonas gingivalis e Prevotella intermedia. (VIVEKANANDA et al.,2010; MARTIN-CABEZAS et al.,2016).

Para analisar os efeitos de pastilhas contendo a cepa de Lactobacillus reuteri no tratamento adjuvante da periodontite e detectar o nível de colonização desse probiótico nas bolsas periodontais após o tratamento, Tekce et al (2015) elaboraram um ensaio clínico randomizado com 40 pacientes. Esses pacientes passaram por uma avaliação periodontal onde foi mensurado profundidade de sondagem (PS), índice de sangramento à sondagem (ISS), índice de placa (IP) e nível de inserção clínica (NIC) e em seguida foram separados aleatoriamente em dois grupos. O grupo I recebeu raspagem e alisamento radicular (RAR) mais pastilhas contendo L. reuteri e o grupo II recebeu a RAR mais placebo. Após o tratamento, foi possível observar que os índices periodontais do grupo I apresentaram melhora significativas quando comparadas com o grupo II, além da diminuição da necessidade de cirurgia.

Outras formas de administração dos probióticos também têm se demostrado como boas alternativas para a manutenção do status de saúde periodontal em pacientes que realizaram tratamento para periodontite. Alguns estudos demonstraram que o uso de enxaguantes bucais com colutórios à base de Lactobacillus salivarius usados por um 
período de um mês provocou melhorias no índice de sangramento gengival e profundidade de sondagem (SAJEDINEJAD et al.,2018); assim como administração semanal através de dispositivos subgengivais por um período de 15 dias após a raspagem e alisamento radicular (PENALA et al., 2016).

O uso do probiótico por meio da ingestão oral também demonstra bons resultados. Iwasaki et al (2016) elaboraram um estudo clínico randomizado, duplo-cego e controlado por placebo para examinar os efeitos da administração oral de Lactobacillus plantarum na terapia periodontal. Para isso selecionaram 39 pacientes submetidos à terapia periodontal de suporte e separaram, de forma aleatória, em um grupo designados para receber uma cápsula contendo $10 \mathrm{mg}$ de Lactobacillus plantarum e outro grupo uma cápsula com placebo. Após o tratamento os participantes foram instruídos a realizar a ingestão dessas cápsulas de forma diária por 12 semanas. Durante esse período foi mensurado os parâmetros periodontais de índice de placa (IP), índice de sangramento à sondagem (ISS) e profundidade de sondagem (PS). Ao final das doze semanas, os pesquisadores constataram que o sangramento à sondagem e o número de dentes com profundidade de sondagem $\geq 4 \mathrm{~mm}$ foram significativamente reduzidos em ambos os grupos. No entanto houve uma redução estatisticamente significante $(p<0,05)$ de sítios com profundidade de sondagem $\geq 4 \mathrm{~mm}$ no grupo que realizou a ingestão do probiótico, sugerindo que a que a ingestão diária do mesmo pode diminuir a profundidade das bolsas periodontais em pacientes submetidos à terapia periodontal de suporte.

\subsection{EFEITO DOS PROBIÓTICOS NO PERIODONTO}

Alguns estudos também têm demostrado que o uso dos probióticos auxilia na diminuição do nível de inflamação causada pela doença periodontal (GATEJ et al.,2017). Szkaradkiewicz et al (2014) realizaram um ensaio clínico para mensurar a o nível das citocinas pró-inflamatórias (TNF-a, IL-1b e IL-17) em pacientes com periodontite crônica e tratados de forma adjuvante com a cepa probiótica de Lactobacillus reuteri. Foram selecionados 38 pacientes adultos diagnosticados com periodontite crônica moderada, em seguida foram divididos em dois grupos. No grupo teste $(n=24)$ os pacientes passaram pela terapia periodontal básica e foram orientados a mascarem as pastilhas com o probióticos duas vezes ao dia após a escovação, enquanto o grupo controle $(n=14)$ 
passou somente pela terapia periodontal básica. Todos os participantes tiveram amostras de fluido crevicular coletadas para análise dos mediadores pró-inflamatórios. Após o tratamento os pesquisadores constataram que o grupo teste manifestou uma melhora nos índices periodontais e uma diminuição significativa nos níveis das citocinas pró-inflamatórias TNF-a, IL-1b e IL-17 quando comparados com o grupo controle.

Resultado similar também foi encontrado no estudo clínico realizado por Ince et al (2015), no qual 30 pacientes com periodontite crônica foram divididos em grupo teste e grupo controle para avaliar o efeito da suplementação com o probiótico contendo $L$. reuteri na terapia periodontal em relação aos seus parâmetros clínicos e bioquímicos. Os participantes tiveram seus índices periodontais mensurados e o grupo teste recebeu o tratamento através da RAR mais pastilhas com L. reuteri, enquanto o grupo controle recebeu RAR e placebo. Além disso, também foram recolhidas amostras do fluido gengival crevicular para análise esporádica dos marcadores inflamatórios MMP-8 e TIMP-1. Após o tratamento, constatou-se que os parâmetros periodontais e bioquímicos do grupo teste foram significativamente melhores em relação ao grupo controle. Esses achados sugerem que o uso de pastilhas com Lactobacillus reuteri 2 vezes ao dia por 3 semanas pode ser um suplemento útil para retardar a recolonização, melhorar os resultados clínicos e diminuir os marcadores inflamatórios da doença periodontal.

\subsection{EFEITOS NA terapia PERIODONTAL básica E PARÂMETROS PERIODONTAIS}

Laleman et al (2015) realizaram um ensaio clínico com 48 pacientes acometidos com doença periodontal para avaliar o efeito adjuvante de um comprimido probiótico contendo Streptococcus oralis, Streptococcus uberis e Streptococcus rattus na terapia periodontal. Após exame periodontal inicial, foi realizado raspagem e alisamento radicular, os participantes foram divididos em grupo placebo ou probiótico e instruídos a usar o comprimido duas vezes ao dia durante 12 semanas. Após esse período não foi detectada nenhuma diferença estatisticamente significante ao comparar o uso adjuvante de um placebo com o comprimido contendo os estreptococos investigados após o tratamento periodontal.

Em contra-partida, Morales et al (2016) realizaram um ensaio clínico randomizado duplo-cego para avaliar os efeitos do uso dos probióticos na terapia 
periodontal não cirúrgica, para isso 28 pacientes sistemicamente saudáveis, mas com doença periodontal crônica foram selecionados. Esses pacientes foram divididos em grupo teste e controle e em seguida passaram por exame clínico periodontal onde foram medidos profundidade de sondagem (PS), nível de inserção clínica (NIC), índice de sangramento (IS) e índice de placa (IP). Após avaliação clínica foi realizada a terapia periodontal não cirúrgica através de raspagem e alisamento radicular, posteriormente à última sessão os pacientes foram instruídos a realizar a ingestão de Lactobacillus rhamnosus através de sachês dissolvidos em $150 \mathrm{ml}$ de água uma vez por dia por 3 meses. Após 1 ano de acompanhamento os pesquisadores observaram que ambos os grupos apresentaram melhoras nos parâmetros periodontais, no entanto o grupo que realizou a ingestão dos probióticos (teste) apresentou maior redução nas profundidades de sondagem, principalmente em bolsas $>6 \mathrm{~mm}$, quando comparados com o grupo que ingeriu o placebo (controle), reduzindo assim a necessidade de intervenção cirúrgica.

A revisão sistemática e meta-análise realizada por Martin-Cabezas et al (2016) também dá suporte à essas evidências, visto que, após análise de ensaios clínicos randomizados observaram que uso adjuvante de $L$. reuteri após raspagem e alisamento radicular mostrou um ganho estatisticamente significativo de nível de inserção clínica $(0,42 \mathrm{~mm}, \mathrm{p}=0,002)$ e redução do índice de sangramento à sondagem $(14,66, p=0,003)$ especialmente em bolsas periodontais profundas.

Por outro lado, dois anos depois, Morales et al (2018) elaboraram um novo ensaio clínico duplo-cego randomizado para avaliar e comparar os efeitos do probiótico em forma de sachê contendo a cepa de Lactobacillus rhamnosus e do antimicrobiano sistêmico Azitromicina como adjuvantes na tratamento periodontal não-cirúrgico. Dessa vez foram selecionados 47 pacientes com periodontite crônica e que foram distribuídos aleatoriamente nos grupos probiótico $(n=16)$, antibiótico $(n=16)$ e controle $(n=15)$. Todos os pacientes passaram por avaliação clínica periodontal e tiveram amostras de biofilme retiradas de sítios com bolsas $>4 \mathrm{~mm}$, em seguida foi realizado tratamento periodontal não cirúrgico de raspagem e alisamento radicular. Para o grupo probiótico foi administrado o sachê três vezes ao dia por três meses, enquanto o grupo antibiótico recebeu Azitromicina 500mg uma vez ao dia por 5 dias. Após 9 meses foi constatado que todos os grupos apresentaram melhoras clínicas nos parâmetros periodontais, enquanto os grupos probiótico e antibiótico mostraram maior redução na microbiota 
cultivável. No entanto não houve diferença significativas entre os grupos. Os desfechos desses estudos demonstram que os probióticos, também administrados em forma de ingestão, são benéficos em termos de melhoras nos parâmetros periodontais, além de possuir uma boa ação antimicrobiana, sendo uma alternativa ao uso dos antibióticos sistêmicos.

Para avaliar a eficácia de diferentes cepas probióticas como adjuvantes na terapia periodontal não-cirúrgica, Vives-Soler e Chimenos-Küstner (2020) realizaram uma revisão sistemática de nove ensaios clínicos randomizados comparando o tratamento periodontal não- cirúrgico associado a probióticos e o tratamento periodontal não-cirúrgico com um placebo. Após análise observaram que não houve melhora significativa da profundidade de sondagem das bolsas periodontais em geral, mas em bolsas de profundidade moderadas entre 4 a $6 \mathrm{~mm}$ mostraram maiores reduções nos grupos que fizeram uso dos probióticos, diminuindo a necessidade de cirurgia. Constataram também uma diminuição dos sítios com sangramento à sondagem e com presença de placa após o tratamento nos grupos testes. Concluíram então que os probióticos podem fornecer um benefício adicional na raspagem e alisamento radicular, no entanto, são necessários mais estudos sobre a dose, via de administração e cepas usadas.

Sob outra perspectiva, a revisão sistemática e meta-análise elaborada por Donos et al (2020) de 5 ensaios clínicos randomizados sugeriu que, em comparação com o placebo, o tratamento com probióticos resultou em um benefício na redução $0,38 \mathrm{~mm}$ (IC 95\% -0,14 $\mathrm{mm}$ a 0,90 $\mathrm{mm}$ ) na profundidade de sondagem, no entanto com pouca relevância clínica $(<0,5 \mathrm{~mm})$. Enquanto a meta-ánalise dos 10 estudos clínicos de Ho (2020) revelou um ganho significativo de inserção clínica e redução na profundidade de sondagem nos grupos associados com probióticos. No entanto não percebeu diferença significativa no nível dos patógenos periodontais entre os grupos e que não houve também dados imunológicos suficientes nos ensaios clínicos analisados. Ambas as revisões destacam os benefícios do uso dos probióticos, mas que a heterogeneidade dos estudos pode ter reflexo nos resultados e que as evidências atuais são insuficientes para formular recomendações clínicas. 


\section{CONSIDERAÇÕES FINAIS}

Diante das evidências disponíveis, é possível observar que o uso dos probióticos na terapia periodontal não-cirúrgica possui resultados clínicos animadores, com razoável benefício quando usado de forma adjuvante no tratamento, sobretudo com melhoras nos parâmetros periodontais com redução da profundidade de sondagem e índice de sangramento. Podemos destacar a eficácia do uso das cepas de Lactobacillus reuteri e Lactobacillus rhamnosus na forma de pastilhas e ingestão, respectivamente. Além do mais, os probióticos tem demostrado potencial para prevenção da recolonização das superfícies dentárias pelo biofilme patógeno e como substituto para o uso dos antibióticos sistêmicos. No entanto, a heterogeneidade dos estudos acaba prejudicando a força das evidências. Portanto, ainda se faz necessário mais pesquisas para elucidar os mecanismos de ação, os tipos de cepas recomendadas, as dosagens e vias de administração para estabelecer um protocolo de uso clínico.

\section{REFERÊNCIAS}

AMEZ, M.S. et al. Probiotics and oral health: a systematic review. Medicina oral, patología oral y cirugía bucal. Ed. inglesa, v. 22, n. 3, p. 19, 2017.

BASTOS, E.M. et al. Probióticos na terapia periodontal. Revista Brasileira de Odontologia, v. 69, n. 2, p. 224, 2013.

CARDOSO, M.V. et al. Probióticos associados ao tratamento das doenças periodontais: revisão de literatura. Revista da Faculdade de Odontologia-UPF, v. 23, n. 1, 2018.

DONOS, N. et al. The adjunctive use of host modulators in non-surgical periodontal therapy. A systematic review of randomized, placebo-controlled clinical studies. Journal of clinical periodontology, v. 47, p. 199-238, 2020.

GATEJ, S. et al. Probiotics and periodontitis-A literature review. Journal of the International Academy of Periodontology, v. 19, n. 2, p. 42-50, 2017.

GRUNER, D. et al. Probiotics for managing caries and periodontitis: systematic review and meta-analysis. Journal of dentistry, v. 48, p. 16-25, 2016.

HO, S.N. et al. A systematic review and meta-analysis of clinical, immunological, and microbiological shift in periodontitis after nonsurgical periodontal therapy with adjunctive use of probiotics. Journal of Evidence Based Dental Practice, v. 20, n. 1, p. 101397, 2020. 
iNCE, G. et al. Clinical and biochemical evaluation of lozenges containing Lactobacillus reuteri as an adjunct to non-surgical periodontal therapy in chronic periodontitis. Journal of periodontology, v. 86, n. 6, p. 746-754, 2015.

IWASAKI, K. et al. Daily intake of heat-killed Lactobacillus plantarum L-137 decreases the probing depth in patients undergoing supportive periodontal therapy. Oral Health Prev Dent, v. 14, n. 3, p. 207-14, 2016.

LALEMAN, I. et al. The effect of a streptococci containing probiotic in periodontal therapy: a randomized controlled trial. Journal of clinical periodontology, v. 42, n. 11, p. 1032-1041, 2015.

LANG, N.P. et al. Mark. Periodontal health. Journal of periodontology, v. 89, p. S9-S16, 2018.

MARTIN-CABEZAS, R. et al. Clinical efficacy of probiotics as an adjunctive therapy to nonsurgical periodontal treatment of chronic periodontitis: A systematic review and meta-analysis. Journal of clinical periodontology, v. 43, n. 6, p. 520-530, 2016.

MORALES, A. et al. Clinical effects of Lactobacillus rhamnosus in non-surgical treatment of chronic periodontitis: a randomized placebo-controlled trial with 1-year follow-up. Journal of periodontology, v. 87, n. 8, p. 944-952, 2016.

MORALES, A. et al. Microbiological and clinical effects of probiotics and antibiotics on nonsurgical treatment of chronic periodontitis: a randomized placebo-controlled trial with 9-month follow-up. Journal of Applied Oral Science, v. 26, 2018.

PAPAPANOU, P.N. et al. Periodontitis: Consensus report of workgroup 2 of the 2017 World Workshop on the Classification of Periodontal and Peri-Implant Diseases and Conditions. Journal of periodontology, v. 89, p. S173-S182, 2018.

PENALA, S. et al. Efficacy of local use of probiotics as an adjunct to scaling and root planing in chronic periodontitis and halitosis: A randomized controlled trial. Journal of research in pharmacy practice, v. 5, n. 2, p. 86, 2016.

SAJEDINEJAD, N. et al. Lactobacillus salivarius NK02: a potent probiotic for clinical application in mouthwash. Probiotics and antimicrobial proteins, v. 10, n. 3, p. 485-495, 2018.

SANZ, M. et al. Treatment of stage I-III periodontitis - The EFP S3 level clinical practice guideline. Journal of clinical periodontology, v. 47, p. 4-60, 2020.

SZKARADKIEWICZ, A.K.; STOPA, J; KARPIŃSKI, T.M. Effect of oral administration involving a probiotic strain of Lactobacillus reuteri on pro-inflammatory cytokine response in patients with chronic periodontitis. Archivum immunologiae et therapiae experimentalis, v. 62, n. 6, p. 495-500, 2014. 
TEKCE, M. et al. Clinical and microbiological effects of probiotic lozenges in the treatment of chronic periodontitis: a 1-year follow-up study. Journal of clinical periodontology, v. 42, n. 4, p. 363-372, 2015.

VIVEKANANDA, M. R.; VANDANA, K. L.; BHAT, K. G. Effect of the probiotic Lactobacilli reuteri (Prodentis) in the management of periodontal disease: a preliminary randomized clinical trial. Journal of Oral Microbiology, v. 2, n. 1, p. 5344, 2010.

VIVES-SOLER, A; CHIMENOS-KÜSTNER, E. Effect of probiotics as a complement to nonsurgical periodontal therapy in chronic periodontitis: a systematic review. Medicina oral, patologia oral y cirugia bucal, v. 25, n. 2, p. e161, 2020. 


\title{
CAPITULO VI
}

\section{TRATAMENTO DAS LESÕES ENDO PERIODONTAIS}

DOI: 10.51859/AMPLLA.EPC757.1121-6

\author{
Antonia Nadiane da Silva Peixoto ${ }^{1}$ \\ Arthur Moura de Alcântara ${ }^{2}$ \\ Jéssica da Silva Rodrigues ${ }^{1}$ \\ Karla Beatriz Nogueira de Mesquita ${ }^{1}$ \\ Karla Geovanna Ribeiro Brígido ${ }^{3}$ \\ Jandenilson Alves Brígido ${ }^{3}$
}

\begin{abstract}
${ }^{1}$ Graduanda do Curso de Odontologia - Centro Universitário Fametro - UNIFAMETRO
2 Graduando do Curso de Odontologia - Centro Universitário Fametro - UNIFAMETRO

${ }^{3}$ Docente do Curso de Odontologia - Centro Universitário Fametro - UNIFAMETRO
\end{abstract}

\section{RESUMO}

A lesão endo periodontal é uma condição com abrangência pulpar e periodontal, em que ambas estruturas podem ser atingidas de forma simultânea ou desenvolver-se em momentos distintos. Assim, o objetivo deste presente estudo foi avaliar a efetividade das terapias disponíveis voltadas às lesões do complexo endo periodontal, ressaltar as suas falhas, acertos e evidenciar um melhor tratamento para cada caso. Trata-se de uma revisão de literatura e para a execução deste trabalho foram coletados dados nas plataformas de pesquisa do Portal Regional da Biblioteca Virtual em Saúde (BVS), Medline/Pubmed e Scielo, publicados nos últimos 5 anos. Quando se trata de uma lesão endodôntico-periodontal, em que a enfermidade pulpar tem caráter primário com envolvimento periodontal posterior, o tratamento preconizado neste caso é a terapia endodôntica inicial por meio do tratamento de canal do elemento dentário acometido pela patologia. Em contrapartida, em uma lesão periodonto-endodôntica, no qual a progressão da infecção vai da região periodontal para o interior da cavidade pulpar, as alternativas terapêuticas são de juntar os tratamentos. Portanto, é um consenso literário o fato do tratamento de lesões endo periodontais ser um grande desafio para os profissionais dentistas, devido a sua variedade de etiologias, necessidade de uma classificação prévia correta e diagnóstico conciso, ter uma microbiota diversificada e precisar da contribuição do paciente quanto a mudar os seus hábitos de higiene oral e participar de forma ativa.

Palavras-chave: Doença. Endodontia. Periodontia. 


\section{INTRODUÇÃO}

A lesão endo periodontal é uma condição com abrangência pulpar e periodontal, em que ambas estruturas podem ser atingidas de forma simultânea ou desenvolver-se em momentos distintos (PEREIRA; ARBOLEDA, 2020). O maior desafio clínico quanto à lesão supracitada, denota-se na dificuldade em identificar a etiologia para chegar em um diagnóstico conciso que possibilite a execução de um tratamento eficaz.

Tal problemática existe, pois as etiologias são diversas, de forma que as lesões endo-perio podem expressar-se devido a fatores como: acidentes em instrumentações endodônticas que causam a interligação entre o conteúdo pulpar e o periodonto (CAMEJO; DOMECH; PORTELA, 2018); o extravasamento de endotoxinas e subprodutos resultantes da atividade de bactérias do interior do canal radicular (NAKAMURA et al, 2017); a similitude da composição das espécies de microorganismos (DUQUE et al, 2018); bem como vias anatomo-fisiológicas contaminadas por patógenos (MAKEEVA et al, 2020).

Desta maneira a análise do fator causal, dos aspectos clínicos e exames complementares, que podem ser efetivados, serão somatórios ao processo diagnóstico e por benefício irão influenciar diretamente no tratamento e prognóstico do paciente.

Diante da forma que as lesões endo-perio podem apresentar-se, a literatura denota que pesquisadores estão investigando tratamentos alternativos com novas tecnologias para tentar resolver tais condições e restabelecer a saúde bucal dos pacientes. Assim, foi realizado esse estudo com o intuito de elencar os tratamentos multidisciplinares existentes e investigar as alternativas terapêuticas inovadoras.

É de suma importância que os cirurgiões-dentistas entendam sobre a gravidade das lesões endo periodontais e como um correto tratamento pode influenciar na saúde, bem-estar e qualidade de vida dos pacientes.

Diante desse contexto, o objetivo do presente estudo foi avaliar a efetividade das terapias disponíveis voltadas às lesões do complexo endo periodontal, ressaltar as suas falhas, acertos e evidenciar o melhor tratamento para cada caso. 


\section{METODOLOGIA}

Trata-se de um estudo de revisão de literatura e para a execução deste trabalho foram coletados dados nas plataformas de pesquisa do Portal Regional da Biblioteca Virtual em Saúde (BVS), Medline/Pubmed e Scielo com as palavras-chave: "Doença", "Endodontia" e "Periodontia".

Um ponto forte metodológico deste estudo é a alta sensibilidade da pesquisa, pois ao não limitar os filtros apareceram resultados que teriam sido excluídos desnecessariamente. Desta maneira, deu-se procedência com os seguintes termos: últimos 5 anos (2016-2021), texto completo e todos os idiomas. Foram encontrados 798 artigos, em que após a leitura do título e resumo, 23 foram selecionados para a leitura completa, dos quais 13 artigos foram eleitos para o desenvolvimento do trabalho.

Foram utilizados como critérios de inclusão: estudos clínicos que englobaram a etiologia das lesões endo periodontais e que investigaram como chegar a um diagnóstico coeso; estudos sobre a influência da patogenicidade das lesões endo-perio para com o tratamento; estudos sobre a variedade de tratamentos e os seus possíveis prognósticos; artigos com metodologias concisas e resultados e objetivos explícitos de forma clara; pesquisas fundamentadas e com relevância científica. Os critérios de exclusão foram: artigos que não estivessem dentro dos objetivos de inclusão e que não apresentassem relevância quanto a temática, revisões de literatura, monografias, dissertações e teses.

\section{RESULTADOS E DISCUSSÃO}

Tabela 1 - Fichamento dos estudos selecionados para o presente estudo.

\begin{tabular}{|c|c|c|c|c|}
\hline AUTOR ANO & OBJETIVO & $\begin{array}{c}\text { TIPO DE } \\
\text { ESTUDO }\end{array}$ & AMOSTRA & PRINCIPAIS ACHADOS \\
\hline $\begin{array}{c}\text { BETANCOURT; } \\
\text { ELGUETA; } \\
\text { FUENTES, } \\
2017\end{array}$ & $\begin{array}{c}\text { Relatar a eficácia } \\
\text { clínica da fibrina rica } \\
\text { em leucócitos no } \\
\text { tratamento de uma } \\
\text { lesão endo } \\
\text { periodontal } \\
\text { combinada de um } \\
\text { primeiro pré-molar } \\
\text { superior. }\end{array}$ & $\begin{array}{c}\text { Relato de } \\
\text { caso }\end{array}$ & 1 paciente & $\begin{array}{l}\text { Estudos in vivo mostraram que a L- } \\
\text { PRFomove a regeneração } \\
\text { periodontal e melhora oumento } \\
\text { do osso alveolar. Neste relato foi } \\
\text { observado um ganho no nível de } \\
\text { apego clínico e redução da } \\
\text { profundidade de sondagem. Porém, } \\
\text { não se observou nenhum ganho } \\
\text { ósseo em qualquer aspecto do } \\
\text { dente. }\end{array}$ \\
\hline
\end{tabular}




\begin{tabular}{|c|c|c|c|c|}
\hline AUTOR ANO & OBJETIVO & $\begin{array}{l}\text { TIPO DE } \\
\text { ESTUDO }\end{array}$ & AMOSTRA & PRINCIPAIS ACHADOS \\
\hline $\begin{array}{c}\text { PEREIRA; } \\
\text { ARBOLEDA, } \\
2020\end{array}$ & $\begin{array}{l}\text { Relatar um caso } \\
\text { descrevendo o } \\
\text { diagnóstico, o } \\
\text { tratamento } \\
\text { multidisciplinar e o } \\
\text { acompanhamento a } \\
\text { longo prazo de um } \\
\text { dente } \\
\text { comprometido por } \\
\text { uma lesão } \\
\text { endodôntica. }\end{array}$ & $\begin{array}{l}\text { Relato de } \\
\text { caso }\end{array}$ & 1 paciente & $\begin{array}{l}\text { O tratamento bem sucedido das } \\
\text { lesões endo periodontais requer } \\
\text { um diagnóstico preciso, que é } \\
\text { fundamental para fornecer uma } \\
\text { terapia adequada na sequência } \\
\text { de tratamento correta. }\end{array}$ \\
\hline $\begin{array}{c}\text { CAMEJO; } \\
\text { DOMECH; } \\
\text { PORTELA, } \\
2018\end{array}$ & $\begin{array}{c}\text { Identificar a } \\
\text { frequência de } \\
\text { acidentes que } \\
\text { causam a } \\
\text { comunicação entre } \\
\text { o espaço pulpar e o } \\
\text { periodonto. }\end{array}$ & $\begin{array}{l}\text { Estudo } \\
\text { descritivo e } \\
\text { transversal }\end{array}$ & $\begin{array}{c}50 \\
\text { pacientes }\end{array}$ & $\begin{array}{l}52,0 \% \text { das vias falsas } \\
\text { corresponderam ao grupo de } \\
\text { pacientes de } 35 \text { a } 59 \text { anos. Os } \\
\text { dentes mais acometidos foram } \\
\text { os incisivos com 40,0\%. } \\
\text { Descobriu-se que } 60,0 \% \text { das } \\
\text { perfurações foram causadas por } \\
\text { terapia endodôntica e a } \\
\text { periodontite foi detectada em } \\
30,0 \% \text { dos dentes perfurados. }\end{array}$ \\
\hline $\begin{array}{l}\text { CARDOSO et } \\
\text { al., } 2016\end{array}$ & $\begin{array}{c}\text { Investigar e } \\
\text { quantificar bactérias } \\
\text { cultiváveis e seus } \\
\text { níveis de } \\
\text { endotoxinas na } \\
\text { infecção } \\
\text { endodôntica } \\
\text { persistente. }\end{array}$ & $\begin{array}{l}\text { Estudo } \\
\text { transversal }\end{array}$ & $\begin{array}{c}10 \\
\text { pacientes }\end{array}$ & $\begin{array}{l}\text { Níveis mais elevados de } \\
\text { endotoxinas em dentes } \\
\text { obturados foram relacionados à } \\
\text { presença de sintomas clínicos e } \\
\text { maior área de destruição óssea. } \\
\text { Assim, a maior área de } \\
\text { destruição óssea foi relacionada } \\
\text { a maiores níveis de IL-1ß e TNF- } \\
\text { a secretados por macrófagos e } \\
\text { células de fibroblastos. }\end{array}$ \\
\hline $\begin{array}{l}\text { NAKAMURA } \\
\text { et al., } 2017\end{array}$ & $\begin{array}{l}\text { Comparar a eficácia } \\
\text { da ativação } \\
\text { ultrassônica com a } \\
\text { da irrigação não } \\
\text { ativada na remoção } \\
\text { de bactérias e } \\
\text { endotoxinas dos } \\
\text { canais radiculares. }\end{array}$ & $\begin{array}{l}\text { Ensaio clínico } \\
\text { randomizado. }\end{array}$ & $\begin{array}{c}50 \\
\text { pacientes }\end{array}$ & $\begin{array}{l}\text { Mostrou-se que a ativação } \\
\text { ultrassônica é mais eficaz que a } \\
\text { irrigação de agulhas na remoção } \\
\text { de bactérias de canais } \\
\text { radiculares em ambiente clínico. } \\
\text { Porém, quanto à redução da } \\
\text { endotoxina, a ativação } \\
\text { ultrassônica não diminuiu } \\
\text { significativamente os níveis } \\
\text { restantes de LPS se comparada } \\
\text { ao grupo de irrigação da agulha. }\end{array}$ \\
\hline
\end{tabular}




\subsection{ETIOLOGIA DAS LESÕES ENDO PERIODONTAIS}

Sabe-se que as lesões do complexo endo-periodontal podem ter etiologias diversas, como microrganismos, os quais irão influenciar significativamente no curso da doença, e consequentemente em seu prognóstico e tratamento (DUQUE et al., 2018). Um fator também contribuinte pode ser a condição sistêmica apresentada pelo paciente, como por exemplo, a diabetes não-controlada do tipo 2 , em que os portadores dessa condição são mais vulneráveis ao aparecimento ou agravamento de infecções orais e lesões perirradiculares devido o seu sistema imunológico deficitário. Tal condição pode levar a alterações significativas no componente pulpar, como redução do fluxo sanguíneo que leva o elemento dentário a necrose e modificações a nível periodontal (DHOUM et al., 2018).

Outro fator predisponente para o surgimento destes tipos de lesões são as intercomunicações que podem ser criadas forçadamente entre a cavidade pulpar e o periodonto. Esta comunicação pode ocorrer mediante a eventos variados, em que se pode mencionar acidentes advindos da instrumentação endodôntica, onde os microrganismos podem migrar de um sítio para o outro, assim como as reabsorções dentárias e perfurações (CAMEJO; DOMECH; PORTELA, 2018).

Portanto, percebe-se que a questão anatômica tem grande relevância no que diz respeito à proximidade das estruturas e a maior facilidade de comunicação entre as mesmas, no qual torna-se um fator primordial para a evolução dessas lesões combinadas (CAMEJO; DOMECH; PORTELA, 2018).

\subsection{MICROBIOTA DAS LESÕES ENDO PERIODONTAIS}

Estudos apontam que em infecções endodônticas persistentes há predominância de bactérias gram-negativas e que as endotoxinas e os subprodutos gerados da atividade dessas bactérias podem ser associados à gravidade da destruição óssea e ao desenvolvimento de possíveis sintomas (CARDOSO et al., 2016). No entanto, Louzada et al. (2020) identificaram por meio de sua pesquisa clínica que a microbiota predominante em bolsas periodontais e canais radiculares de elementos dentários, que se apresentaram vitais e estão associados a uma condição periodontal, é polimicrobiana por possuir bactérias gram-negativas, gram-positivas, anaeróbias facultativas e outras espécies estritas de anaeróbios. 
Desse modo, torna-se claro que o conhecimento quanto a microbiota e os seus subprodutos poderão influenciar no entendimento da patologia vigente, bem como ser somatório na escolha das possíveis terapêuticas e condutas de tratamento. Pois, diante da susceptibilidade que esses patógenos podem apresentar ou resistência, o cirurgiãodentista ficará atento em selecionar estratégias que tenham resultados positivos (LOUZADA et al., 2020).

\subsection{TRATAMENTO DAS LESÕES ENDO PERIODONTAIS}

Tendo classificado e diagnosticado corretamente, pode-se evoluir para o planejamento e execução do tratamento de acordo com o tipo de lesão identificada, em que dentre os procedimentos a serem aplicados tem-se aqueles de viés mais tradicional, assim como os alternativos que são destacados pela literatura.

\subsubsection{TRATAMENTOS CONVENCIONAIS}

Quando se trata de uma lesão endodôntico-periodontal, em que a enfermidade pulpar tem caráter primário com envolvimento periodontal posterior, o tratamento preconizado neste caso é a terapia endodôntica inicial por meio do tratamento de canal do elemento dentário acometido pela patologia. Tal procedimento tem a finalidade de remover restos pulpares necróticos, fazer a limpeza da cavidade e consequente eliminação de patógenos. Deste modo, pode influenciar de forma significativa no prognóstico periodontal também (PEREIRA; ARBOLEDA, 2020).

Em contrapartida, em uma lesão periodonto-endodôntica, no qual a progressão da infecção vai da região periodontal para o interior da cavidade pulpar, as alternativas terapêuticas são de juntar os tratamentos. Portanto, será aplicada tanto a terapia endodôntica por meio do tratamento radicular para a eliminação do foco infeccioso e consequentemente impedir a sua comunicação com os tecidos periodontais, como a terapia periodontal também se torna fundamental com o emprego dos seus recursos curativos, onde a raspagem auxilia no combate da proliferação de bactérias que podem ser prejudiciais a saúde bucal (MAKEEVA et al., 2020).

Porém, quando a aplicabilidade das terapias supracitadas não surtirem os efeitos esperados, pode-se propor métodos como a apicectomia e a cirurgia periodontal regenerativa com o objetivo de alcançar um melhor prognóstico para a lesão (MAKEEVA et al., 2020). 
No que diz respeito às lesões classificadas como combinadas do complexo endoperiodontal, podem ser observadas quando há envolvimento concomitante das estruturas e há comunicação entre as vias. Diante disso, para garantir um resultado efetivo no tratamento e o sucesso do processo cicatrizante das lesões, é indispensável que a terapia endodôntica e a periodontal sejam realizadas em conjunto (MAKEEVA et al., 2020).

$\mathrm{Na}$ ocorrência de interligação entre as duas vias durante as perfurações, as abordagens terapêuticas preferenciais se subdividem em: (1) abordagem não cirúrgica, (2) abordagem cirúrgica ou (3) abordagens combinadas. O grau da lesão causada pela perfuração irá influenciar diretamente na abordagem escolhida e no seu prognóstico. Dessa forma, perfurações inacessíveis anatomicamente, com alto grau de destruição periodontal ou em casos de falhas nas abordagens anteriores, são indicativos de exodontia, visto que, o aparelho de inserção dentário nesses casos pode estar altamente prejudicado em função (CAMEJO; DOMECH; PORTELA, 2018).

Quanto aos materiais que atuam de forma significativa no vedamento das perfurações que podem ser causadas por acidentes de instrumentações, por exemplo, tem-se o agregado de trióxido mineral (MTA) mostrando bons resultados com a sua aplicação (CAMEJO; DOMECH; PORTELA, 2018).

\subsubsection{TRATAMENTOS ALTERNATIVOS}

É notório que a conduta multidisciplinar demonstra resultados clínicos favoráveis ao deparar-se com condições endodônticas e periodontais associadas, visto que o prognóstico de tais lesões é pior do que os de alterações periodontais e endodônticas isoladas. Portanto, nas propostas mais atuais de tratamentos o mesmo viés interdisciplinar é seguido (MAKEEVA et al., 2020).

O ozônio tem sido estudado devido a sua capacidade antimicrobiana e por ter uma excelente biocompatibilidade com os tecidos periodontais. Makeeva et al. (2020), evidenciaram que quando o gás ozônio foi usado como fator adicional ao tratamento convencional de desinfecção de canais radiculares (secagem e tratamento concomitante do canal), houve uma expressiva redução da radioluscência e início de reorganização óssea após um período de 6 meses de acompanhamento. Além disso, demonstrou-se que após a raspagem e alisamento radicular, lavar as bolsas periodontais estreitas com 
clorexidina e tratá-las com o gás referido por 18 segundos melhora significamente os resultados sem necessitar de um acesso cirúrgico que teria que ser feito se a conduta fosse a convencional.

A Fibrina rica em plaquetas e leucócitos (L-PRF) é um produto obtido através da centrifugação do sangue que pode ser utilizado para aumentar a regeneração óssea em defeitos intra-ósseos. Os autores (BETANCOURT; ELGUETA; FUENTES, 2017), descreveram a sua aplicabilidade em uma lesão endo periodontal verdadeira combinada, onde seu objetivo era ganhar margem óssea. O tratamento consistiu na realização de um procedimento endodôntico e posteriormente foi feito um retalho completo com a obtenção do sangue em veia antecubital do próprio paciente, realizouse a centrifugação e após tal ato foi obtido um coágulo de (L-PRF). Em sequência foi feita a separação da base de hemácias e o local do retalho ficou pronto para ser comprimido.

Seis meses depois da cirurgia, o exame periodontal apresentou-se com uma breve melhoria em profundidade de sondagem, entretanto, sem nenhum ganho ósseo em qualquer região. $O$ estudo ressalta a importância de novas pesquisas com a técnica, já que existem poucos trabalhos na literatura a fim de comprovar sua eficácia clínica e radiográfica. (BETANCOURT; ELGUETA; FUENTES, 2017).

Outra investigação de técnica alternativa foi feita por Nakamura et al. (2017), que por meio de um ensaio clínico randomizado avaliaram o efeito da ativação ultrassônica na redução dos níveis bacterianos e de endotoxinas ao compará-lo com um protocolo de irrigação não ativado, em que por meio de métodos quantitativos comprovou-se que a técnica ultrassônica foi mais eficaz na redução de bactérias intracanais, porém no que refere-se às endotoxinas intra radiculares o resultado foi semelhante ao da conduta não ultrassônica. Entretanto, existem poucos trabalhos quanto a essa estratégia e os seus possíveis benefícios ou malefícios para com as lesões endodônticas associadas a uma origem periodontal apical. Desta maneira, há necessidade que mais ensaios clínicos sejam efetuados para ter um maior embasamento científico.

É válido destacar que a utilização de artifícios como a tomografia de feixe cônico podem ser somatórios ao processo de tratamento das lesões endo periodontais (RESTREPO et al., 2019), assim como enxertos bem indicados em casos onde há a colaboração do paciente na higiene oral e participação no processo de tratamento, pode 
ajudar de forma positiva em terapias periodontais-endodônticas (PEREIRA; ARBOLEDA, 2020).

\section{CONSIDERAÇ̃̃ES FINAIS}

Diante do exposto, torna-se claro que é um consenso literário o fato do tratamento de lesões endo periodontais ser um grande desafio para os profissionais dentistas, devido a sua variedade de etiologias, necessidade de uma classificação prévia correta e diagnóstico conciso, ter uma microbiota diversificada e precisar da contribuição do paciente quanto a mudar os seus hábitos de higiene oral e participar de forma ativa.

Ademais, é notório que os tratamentos convencionais expostos foram resolutivos quando executados de forma multidisciplinar, porém apresentaram limitações em casos complexos, em situações em que encontrou-se um fator sistêmico associado como agravante, em condições que a infecção apresentou uma microbiota variável e resistente ou até mesmo quando fatores anatômicos dificultaram o acesso ao local requerido para o tratamento.

Adicionalmente, as técnicas alternativas passaram a ser investigadas e estudadas, tendo excelentes resultados quanto à eficácia no tratamento de lesões endodônticas-periodontais, como o uso do gás ozônio, a fibrina rica em plaquetas e leucócitos e a ativação ultrassônica. Entretanto, faz-se necessário que mais estudos sejam feitos quanto às terapias deste âmbito, pois mesmo com o avançar das tecnologias da década vigente, ainda há uma restrição de embasamentos científicos para implementações em larga escala e que tenham maior confiabilidade.

\section{REFERÊNCIAS}

AL ATTAS, M. A.; EDREES, H. Y. SAMMANI, A. M. N.; MADARATI, A. A. Multidisciplinary management of concomitant pulpal and periodontal lesion: A case report. J Taibah Univ Med Sci, v. 12, n. 5, p. 455-460, 2017.

BETANCOURT, P.; ELGUETA, R.; FUENTES, R. Treatment of endo-periodontal lesion using leukocyte-platelet-rich fibrin. A case report. Colomb Med (Cali), v. 48, n. 4, p. 204-207, 2017. 
CARDOSO, F. G.; CHUNG, A.; MARTINHO, F. C.; CAMARGO, C. H.; CARVALHO, C. A.; GOMES, B. P.; VALERA, M. C. Investigation of Bacterial Contents from Persistent Endodontic Infection and Evaluation of Their Inflammatory Potential. Braz Dent J, v. 27, n. 4, p. 412-418, 2016.

DHOUM, S.; LASLAMI, K.; ROUGGANI, F.; EL OUAZZANI, A.; JABRI, M. Endo-Perio Lesion and Uncontrolled Diabetes. Case Rep Dent, p. 7478236, 2018.

DUQUe, T. M.; PRADO, M.; HeRRerA, D. R.; GOMES, B. P. F. A. Periodontal and endodontic infectious/inflammatory profile in primary periodontal lesions with secondary endodontic involvement after a calcium hydroxide-based intracanal medication. Clin Oral Investig, v. 23, n. 1, p. 53-63, 2019.

FAN, X.; XU, X.; YU, S. et al. Prognostic Factors of Grade 2-3 Endo-Periodontal Lesions Treated Nonsurgically in Patients with Periodontitis: A Retrospective CaseControl Study. Biomed Res Int, p. 1592910, 2020.

LOUZADA, L. M.; ARRUDA-VASCONCELOS, R.; DUQUE, T. M.; CASARIN, R. C. V.; FERES, M.; GOMES B. P. F. A. Clinical Investigation of Microbial Profile and Levels of Endotoxins and Lipoteichoic Acid at Different Phases of the Endodontic Treatment in Teeth with Vital Pulp and Associated Periodontal Disease. J Endod, v. 46, n. 6 , p. $736-747,2020$.

MAKEEVA, M. K.; DAUROVA, F. Y.; BYAKOVA, S. F.; TURKINA, A. Y. Treatment of an EndoPerio Lesion with Ozone Gas in a Patient with Aggressive Periodontitis: A Clinical Case Report and Literature Review. Clin Cosmet Investig Dent, v. 12, p. 447-464, 2020.

MARTINHO, F. C.; TEIXEIRA, F. F.; CARDOSO, F. G.; FERREIRA, N. S.; NASCIMENTO, G. G.; CARVALHO, C. A.; VALERA, M. C. Clinical Investigation of Matrix Metalloproteinases, Tissue Inhibitors of Matrix Metalloproteinases, and Matrix Metalloproteinase/Tissue Inhibitors of Matrix Metalloproteinase Complexes and Their Networks in Apical Periodontitis. J Endod, v. 42, n. 7, p. 1082-1088, 2016.

NAKAMURA, V. C.; PINHEIRO, E. T.; PRADO, L. C.; SILVEIRA A. C.; CARVALHO, A. P. L.; MAYER, M. P. A.; GAVINI, G. Effect of ultrasonic activation on the reduction of bacteria and endotoxins in root canals: a randomized clinical trial. Int Endod J, v. 51, n. 1, p. e12-e22, 2018.

PELICIE CAMEJO, Gretel; VALDES DOMECH, Hidelisa; ARMAS PORTELA, Lourdes. Falsas vías en pacientes atendidos en la Facultad de Estomatología de La Habana. Rev. Med. Electrón, v.40, n.6, p.1890-1910, 2018.

PEREIRA, R.; ARBOLEDA, S. A Multidisciplinary Approach of an Endo-Perio Lesion in a Severely Compromised Tooth: An 18-Year Follow-up Case Report. J Med Life, v. 13, n. 4, p. 629-634, 2020. 
RESTREPO-RESTREPO, F. A.; CAÑAS-JIMÉNEZ, S. J.; ROMERO-ALBARRACÍN, R. D.; VILLAMACHADO, P. A.; PÉREZ-CANO, M. I.; TOBÓN-ARROYAVE, S. I. Prognosis of root canal treatment in teeth with preoperative apical periodontitis: a study with cone-beam computed tomography and digital periapical radiography. Int Endod J, v. 52, n. 11, p. 1533-1546, 2019. 


\title{
CAPITULO VII
}

\section{A RELEVÂNCIA DO TRATAMENTO RESTAURADOR ATRAUMÁTICO}

\author{
DOI: 10.51859/AMPLLA.EPC757.1121-7
}

\author{
Adriele Soares Theodosio ${ }^{1}$ \\ Wendel Chaves Carvalho ${ }^{2}$ \\ Aristéa Ribeiro Carvalho ${ }^{3}$ \\ Daniela Costa Silva ${ }^{4}$ \\ André Almeida Antunes ${ }^{5}$ \\ Allana da Silva e Silva Dias ${ }^{6}$
}

\footnotetext{
Graduanda do curso de Odontologia. Faculdade Pitágoras de São Luís - MA

${ }^{2}$ Graduando do curso de Odontologia. Faculdade Pitágoras de São Luís - MA

${ }^{3}$ Cirurgiã-Dentista. Universidade Federal do Ceará.

${ }^{4}$ Cirurgiã-Dentista. Faculdade Pitágoras de São Luís - MA

${ }^{5}$ Graduando do curso de Odontologia. Centro universitário de Belo Horizonte - Unibh (Buritis), Belo Horizonte-MG.

${ }^{6}$ Doutora e mestre em Odontologia pela UFMA; Especialista em Odontopediatria; Professora do curso de Odontologia

da Faculdade Pitágoras e Uninassau.
}

\section{RESUMO}

A explanação do tema é prevalente com alguns fatores que demonstram riscos para saúde bucal. A predominância da doença cárie é um desses mecanismos que afeta a sociedade com números bem suscetível. Apesar de toda tecnologia avançada, mas a população de maneira geral perde seus dentes muito cedo devido à dificuldade de acesso ao tratamento. Na maioria das vezes o que acontece é a falta de informação da sociedade não saber que pode ser recuperado ou até mesmo, conter o dente em boas condições, e ser renovado ainda no começo por fazer o tratamento adequado ou utilizar técnicas acessíveis e simples para a recuperação da dentição. Embora o ART seja uma abordagem que se torna uma necessidade para atender a comunidade oferecendo um serviço de qualidade e com cobertura acessível. Portanto, o objetivo deste trabalho é realizar uma revisão da literatura para estudar a entender a importância do tratamento restaurador atraumático. Por meio de revisão bibliográfica e descritiva, baseada em livros de diversos autores. Foram incluídos artigos publicados sem data limite de publicação, que ressalta sobre o assunto, com base de dados em: Scielo (Scientific Electronic Library Online), Google Acadêmico, e sites com renomes em odontologia. Contudo é nas políticas públicas que fica necessária ampliar as estratégias de forma coerente direcionando as diretrizes propostas para o controle da cárie. Desta maneira é pertinente descrever o tratamento como oportunidade para a sociedade afetadas em que seu baixo nível socio econômico desconhece as orientações eficazes ou até mesmo por não conhecer a resolutividade. É uma temática com essência importante para categoria estudantil e a sociedade em si. Pois cada momento é de avaliar a viabilidade da utilização do tratamento restaurador atraumático, sendo uma tática viável de tratamento da cárie nos programas odontológico. Em vista disso fica aqui a preocupação para gerações futuras para aprofundar melhor o assunto na contemporaneidade.

Palavras-chave: Tratamento Atraumático. Cavidade dentária. Saúde pública. 


\section{INTRODUÇã̃o}

Diante dos cenários de alguns países é possível identificar uma grande prevalência elevada de cárie dentária. São alguns pontos relevantes em que a Odontologia não consegue estabelecer ações para o controle da progressão da cárie em razão da falta de recursos financeiros e impactos sociais da população. Portanto o tratamento restaurador atraumático é um procedimento associado à saúde (SANTOS et al., 2016; PHANTUMVANIT et al., 2017).

No entanto ele atribui-se um papel importante na saúde pública, buscando assim o efetivo controle da doença cárie. Embora o objetivo do tratamento era para ser administrado em locais em que o convencional não era possível, no entanto, a técnica concedeu-se uma grande conquista no âmbito social. Ressaltar-se que apesar dos procedimentos odontológicos não ser acessível a todos, foi elaborada uma técnica para suprir as necessidades da sociedade com índice de desenvolvimento baixo. Sendo assim, uma técnica preventiva e curativa desenvolvida para a finalidade do tratamento restaurador atraumático. (MONNERAT, et al.,2013).

Sendo notório que na contemporaneidade a busca por melhoria na saúde bucal, um impasse na odontologia para prevenir a perda precoce dos dentes. Contudo é nas políticas públicas que fica necessária ampliar as estratégias de forma coerente direcionando as diretrizes propostas para o controle da cárie. Desta maneira é pertinente descrever o tratamento como oportunidade para a sociedade afetadas em que seu baixo nível socioeconômico desconhece as orientações eficazes ou até mesmo por não conhecer a resolutividade (MINISTÉRIO DA SAÚDE, 2006).

Uma temática com essência importante para categoria estudantil e a sociedade em si. Pois cada momento é de avaliar a viabilidade da utilização do tratamento restaurador atraumático, sendo uma tática viável de tratamento da cárie nos programas odontológico. Em vista disso fica aqui a preocupação para gerações futuras para aprofundar melhor o assunto na contemporaneidade (FIGUEIREDO, et al., 2008).

O processo de construção de uma sociedade saudável inicia-se pelo princípio do bem-estar do ser humano. Contudo é essencial uma qualidade na promoção da saúde para que o desenvolvimento social e econômico de uma população seja primordial em expandir a expectativa de vida e reduzir as diferenças no âmbito social. Pois o termo 
saúde vem tendo um propósito de reformulação, inclusive na odontologia que possibilita uma vida saudável em saúde bucal (OMS et al., 2006). Qual a essência do tratamento restaurador atraumático na promoção e manutenção da saúde bucal?

O presente trabalho tem por objetivo principal realizar uma revisão da literatura para estudar a importância do tratamento restaurador atraumático, e, especificamente compreender uma contextualização histórica do tratamento restaurador atraumático, descrever suas vantagens e desvantagens no procedimento e conhecer as indicações e contraindicações do tratamento restaurador atraumático.

Foi realizado um estudo qualitativo, descritivo através de revisão bibliográfica sistematizada de artigos publicados no Brasil e internacionais. Foram incluídos artigos publicados sem data limite de publicação que ressalta sobre o assunto, com base de dados em: Scielo (Scientific Electronic Library Online), Google Acadêmico, e sites com renomes em odontologia. Em relação aos pressupostos das palavras-chaves no site da SCIELO resumir-se em: Tratamento Atraumático, Cárie dentária e Saúde Pública em odontologia para aprofundar-se durante todo processo com a finalidade de esclarecer de forma exata cada ponto do trabalho.

\section{REVISÃO BIBLIOGRÁFICA}

\subsection{CONTEXTUALIZAÇ̃̃O HISTÓRICA DO TRATAMENTO RESTAURADOR ATRAUMÁTICO}

O Tratamento Restaurador Atraumático (ART, do original em inglês Atraumatic Restorative Treatment) foi criado na Tanzânia nos anos 1980s em resposta à dificuldade de tratar os pacientes de maneira convencional, pois em muitas localidades do país não havia energia elétrica para acionar os motores odontológicos. Assim, os precursores do ART preconizaram o uso de escavadores manuais para remover o tecido dentinário cariado e o preenchimento da cavidade com cimento de policarboxilato (FRENCKEN; LEAL; NAVARRO, 2012).

A história do Tratamento Restaurador Atraumático (ART), traduz-se em uma técnica minimamente invasiva, que inclui tanto a restauração de superfícies dentárias cariadas quanto a preservação de fossas e fissuras por meio da aplicação de selantes. Nessa técnica são utilizados apenas instrumentos manuais, para remover o tecido 
cariado e materiais adesivos, como os cimentos de ionômero de vidro, para restaurar a cavidade (RAGGIO; BONIFÁCIO; IMPARATO, 2011).

Foi proposto inicialmente pelo Dr. Frencken e seus coadjuvantes, portanto a medida foi desenvolvida para indivíduos que vivem em regiões carentes, onde geralmente não há eletricidade, água encanada ou seja algum suporte suficiente. É notável que dois terços da população mundial ainda são portadores de cárie, o que justifica como problema de saúde pública principalmente nos países em desenvolvimento (MARTINS et al., 2016).

É necessário destacar-se que em 1986, publicaram-se os primeiros resultados do estudo piloto em uma Associação Dental de Tanzânia, portanto nasce oficialmente o ART com uma abordagem invasiva e em seguida começa um estudo de média viscosidade até chegar numa semente de alta tenacidade para sobressair-se numa resistência maior nessa restauração (BEZERRA et al., 2014).

Desde a criação da técnica até a atualidade, muitos avanços ocorreram tanto em relação a melhorias relacionadas ao cimento de ionômero de vidro, quanto em relação aos instrumentos utilizados e à técnica restauradora. Entretanto, percebe-se ainda certa resistência por parte de pacientes, de dentistas e de responsáveis por programas de saúde bucal quanto à adoção do ART. Essa resistência ocorre, provavelmente, em função do desconhecimento sobre os avanços ocorridos com o cimento de ionômero de vidro e a falta de conhecimento preciso sobre a técnica ART (NAVARRO et al., 2015).

Contudo a instrução para o procedimento é de impedir que cárie venha obstruir a dentição. Pois se fundamenta ainda de que o tratamento seja recomendado para controlar e prevenir a cárie. No entanto a Organização Mundial de Saúde (OMS) respalda que seja viável para saúde pública, assim como a Organização Panamericana da Saúde (OPAS) orienta que os incentivos optam para sua fase restauradora dando prevalência à dentição durável (NAVARRO et.al, 2015).

O tratamento restaurador atraumático (ART) é uma técnica alternativa de tratamento para controle da doença cárie, que permite o emprego de preparos cavitários mínimos e o uso de materiais restauradores efetivos e seguros (TOURINO et al., 2002). Trata-se de um método simples, pois utiliza somente instrumentos manuais para a remoção da dentina infectada, com a restauração imediata da cavidade com um 
material restaurador adesivo, preservando-se a dentina afetada e passível de remineralização (LIMA et al., 2008).

O método do Tratamento Restaurador Atraumático (TRA) se enquadra em três seguintes tópicos: na prevenção, na restauração e seções terapêuticas. Porém a odontologia contemporânea traz-se uma visão diferenciada para o tratamento que consiste na cárie, dessa forma caracteriza-se nos três seguintes tópicos em que a intervenção restauradora e no cruzamento precoce do processo carioso manuseando matérias menos ofensivas ou causando qual quer desconforto para pacientes (KANNO et al., 2017).

No Brasil, o Ministério da Saúde preconiza ainda o uso, no âmbito da atenção básica, em populações com alta prevalência de cárie e em uma abordagem coletiva para redução da infecção bucal, apesar de ser comprovado como uma alternativa eficaz, o ART ainda é um método pouco difundido entre os programas de saúde pública e, em meio às causas para a não utilização dessa técnica, inclui-se o desconhecimento, por parte dos profissionais, de sua operacionalidade e qualidade (OMS et al., 2006).

Somente instrumentos manuais são necessários para executar o ART: espelhos bucais, exploradores, pares de pinças, cinzéis, curetas, enxadas, esculpidores, bloco de mistura e espátula, além de pares de luvas, bolinhas de algodão, cimento de ionômero cinco de vidro, verniz para proteção do material inserido na cavidade, matrizes cunhas e tiras de poliéster (SAKAMOTO et al., 2001).

A parte da dentina amolecida e altamente cariada, responsável pela progressão da lesão cariosa, pode ser removida apenas com uso de curetas e sem anestesia, por ser necrosada e insensível, enquanto se preserva a parte mais profunda e passível de remineralização. Dispensando o uso de equipamentos odontológicos tradicionais e de eletricidade, a técnica conta com a facilidade de acondicionar e transportar os instrumentos, aumentando as chances de intervenção precoce e de preservação das unidades dentárias afetadas (FIGUEIREDO et al.,2004).

Em contraste com o tratamento convencional das lesões de cárie, o ART preserva a estrutura dental, sendo minimamente invasivo e passível de ser realizado em comunidades carentes desprovidas de recursos tecnológicos mais sofisticados. Consiste na remoção da dentina infectada usando apenas instrumentos manuais, não sendo necessária ou desejável a escavação de todo tecido amolecido, pouco infectado e 
próximo à polpa dental, quando da ausência de sinais e sintomas da pulpite. Após a remoção da dentina infectada a cavidade é selada com um material ionomérico (CICCONE et al., 2004).

A opção pelo CIV baseia-se na sua capacidade de adesão química ao esmalte e dentina, o que garante um bom selamento da cavidade, e na sua característica de liberar flúor, o que preveniria a formação de cárie secundária. Além dessas características o CIV não necessita de fotopolimerização e tem coeficiente de expansão térmica semelhante ao tecido dental (MYAKI et al., 2000).

Além de menos doloroso e atraumático, o ART preserva uma maior quantidade de tecido dentário devido ao maior controle do operador quando o mesmo faz a remoção da dentina cariada. Nesta técnica, nenhum tecido dentário sadio é removido com o instrumento manual. Entretanto, quando a camada superficial de esmalte está somente com uma pequena abertura e não permite a passagem do instrumento manual, é recomendado o uso de recortadores de bordo para romper a camada de esmalte sem suporte e permitir o acesso à dentina cariada subjacente, ao contrário dos preparos cavitários convencionais, em que o tecido dental sadio é sempre removido para que haja retenção mecânica do material restaurador, no Tratamento Restaurador Atraumático o uso de instrumentos manuais limita-se a remoção de tecido dental mortificado (MYAKI et al., 2000).

Contudo o ART surgiu como uma alternativa de tratamento da cárie dentária para países em desenvolvimento, onde mais de $90 \%$ das lesões em dentina permaneciam sem serem tratadas por falta de acesso a serviços odontológicos. 0 procedimento pode ser realizado até mesmo fora do consultório, havendo somente a necessidade de um local onde o paciente possa ficar deitado, com iluminação razoável e a remoção do tecido cariado seja realizada por meio de instrumentos manuais. A partir de 1994, a Organização Mundial de Saúde (OMS) e a Federação Dentária Internacional (FDI) recomendaram o ART como parte de programas mais amplos de promoção de saúde bucal em países em desenvolvimento e posteriormente também para países desenvolvidos (RIOS et al., 2006).

Mesmo com muitos estudos conduzidos em diversas partes do mundo, com evidências científicas sobre as vantagens e desvantagens do ART, a sua aplicação ainda desperta discussões entre os cirurgiões-dentistas quanto a sua viabilidade e eficiência 
frente aos avanços tecnológicos de materiais e equipamentos, bem como quanto à credibilidade na técnica, por remover parcialmente o tecido cariado (MASSONI et al.,2006).

\subsection{VANTAGENS E DESVANTAgENS NO TRATAMENTO RESTAURADOR ATRAUMÁTICO}

Com o ART pode-se observar mudanças positivas na dentina abaixo da restauração, onde ocorrem alterações na textura do tecido, para uma consistência mais firme, esclerose da dentina, redução do número de microrganismos presentes, bem como a diminuição da virulência das bactérias remanescentes (CICCONE et al., 2004).

Além de apresentar boa eficácia, a técnica causa mínima sensibilidade operatória e pós-operatória; preserva mais estrutura dental sadia durante o preparo cavitário do que as técnicas convencionais, dando origem a pequenas cavidades e apresenta uma boa aceitação entre os usuários. Por não fazer uso de motor e sugador, pode ser considerada uma técnica de fácil aceitação por adultos e crianças (GOMES, 1999; SAKAMOTO; MOIMAZ, 2001; LIMA; SALIBA; MOIMAZ, 2008).

A técnica do ART além de simples tem grande eficácia, baixo custo, dispensa o uso de anestesia e do isolamento absoluto, sendo realizada a remoção parcial do tecido cariado com instrumentos manuais (MENEZES, et., 2009). Apesar de ter sido elaborado para ser utilizado em populações carentes, o ART possui várias aplicações em países desenvolvidos, como: introdução de tratamento odontológico precoce em bebês, pacientes extremamente ansiosos e medrosos, pacientes especiais (problemas físicos ou mentais), pacientes que vivem em clínicas de repouso e com alto risco de cárie (VENTIN et al.,2007).

A utilização do ART pode ser considerada como fator motivador dos pais para minimizar o risco à cárie em pacientes com alta atividade cariogênica, pois a técnica favorece diminuição do risco com controle dos fatores que promovem a doença. $\mathrm{O}$ uso do ART pode ser incentivado em bebês, em comunidades carentes, nas quais existe dificuldade de acesso do profissional e o número das lesões de cárie é elevado. Os autores ainda relataram que a vantagem da técnica do ART sobre as restaurações de amálgama é que o mesmo CIV que preenche a cavidade pode ser usado para selar fissuras adjacentes (CORDEIRO et al., 2001). 
Uma das características de um procedimento de impacto em saúde pública é a abrangência de suas vantagens. O TRA pode ser considerado vantajoso para todos os agentes relacionados: equipe odontológica, compreendendo cirurgião-dentista (CD), técnico em saúde bucal (TSB) e auxiliar de saúde bucal (ASB); gestor de saúde e pacientes (MONNERAT et al., 2013).

\subsection{EQUIPE ODONTOLÓGICA}

Por não necessitar de equipamentos odontológicos, o $C D$ e sua equipe podem atuar em áreas de sua responsabilidade que estão distantes da sua unidade de saúde, incluindo centros comunitários, escolas e igrejas. Não exige anestesia na maioria dos casos e não há necessidade de isolamento absoluto, o paciente se mantém tranquilo durante o procedimento, uma vez que não há dor durante no procedimento (HOLMGREN et al., 2013).

Devido também à ausência de dor, o paciente encontra-se mais tranquilo para absorver as instruções e técnicas motivacionais de educação para a saúde, as revisões são mais rápidas, pois a recidiva de cárie é baixa pelo uso do CIV de alta viscosidade, os reparos quando necessários são simples e rápidos e as restaurações em dentes em erupção, angulados ou com pacientes pouco cooperadores são mais facilmente executadas (MICKENAUTSCH et al.,2007).

\subsection{GESTOR}

Têm maior abrangência de atuação da equipe odontológica, redução de demanda para restaurações nas unidades de saúde, visto que grande parte das restaurações é realizada fora da cadeira, em escolas e centros comunitários e o protocolo de acordo com a estratégia de saúde da família, podendo o profissional conscientizar as famílias sobre a técnica e programar sua aplicação em ações pontuais, além de contar com ajuda de toda a equipe de saúde envolvida nos grupos de trabalho (FRENCKEN et al., 2010).

Com a redução da dor, aumenta a frequência do paciente ao atendimento odontológico, tanto na cadeira quanto em campo (escolas, centros comunitários e igrejas), minimizando o absenteísmo e como a técnica utiliza somente instrumentos manuais para remoção seletiva da dentina cariada, o risco de exposição pulpar é 
reduzido, o que diminui a endodontia e suas consequências, como restaurações complexas ou as exodontias por fratura de dentes tratados endodonticamente \que não foram restaurados ou mesmo fratura de dentes que aguardavam o tratamento endodôntico (SILVA et al., 2012).

A ausência de ansiedade, principalmente do paciente pediátrico, permite ao $C D$ e sua equipe maior prazer no trabalho, melhorando seu desempenho, como conseqüência dos itens anteriores, a equipe concluirá um maior número de tratamentos (altas) e os pacientes aumentam seu retorno ao consultório, pois estão menos ansiosos, o TRA também pode ser utilizado como estratégia para atendimento de grupos especiais como gestantes, pacientes idosos, com necessidades especiais, com comprometimento imunológico ou em tratamento de doenças como câncer (AGUILAR et al., 2012).

\subsection{PACIENTES}

Devido à utilização de instrumentos manuais na remoção seletiva da dentina cariada, a estrutura dental com organização de canalículos dentinários é preservada, 0 que explica a ausência de dor e com isto, há uma redução da ansiedade e por ser uma técnica simplificada e rápida, geralmente a equipe consegue restaurar vários elementos, reduzindo o número de retornos até a alta do paciente, com isto a ausência ao trabalho e escola deixa de ser um empecilho à frequência ao tratamento odontológico (HERMOSILO et al., 2009).

Por fim, temos como desvantagem a dificuldade em remover o tecido criado em cavidades relativamente pequenas utilizando apenas instrumentos de mão. Desde que instrumentos manuais podem causar fadiga no operador, que é requerido a realizar muitas ART, é de se esperar que cáries sejam deixadas sob as restaurações e a segunda desvantagem da técnica consiste nas propriedades mecânicas do material usado nas restaurações, em particular a dureza, resistência ao desgaste, comparado com outros materiais restauradores, conseqüentemente as restaurações tem que ser preferencialmente pequenas para evitar fraturas volumosas e mudanças na oclusão (BRESCIANI et al., 2006).

Um estudo in vitro que avaliou a penetração do cimento de ionômero de vidro nas fissuras de dentes extraídos e conclui que o ionômero FUJI IX possui melhor penetração nas fissuras, comparado com o VITREMER sugerindo possíveis benefícios na 
retenção clinica a longo tempo, com respeito às propriedades volumétricas, os ionômeros de vidro tem aproximadamente o mesmo coeficiente de expansão térmica da estrutura dental, a desvantagem, entretanto, é a contração do material que ocorre durante a reação química de presa, durante as primeiras horas (KIKWILU et al 2009).

Os insucessos de algumas dessas restaurações com cimento de ionômero de vidro podem ser atribuídos a combinação de preparos cavitários inadequados e propriedades físicas impróprias do material para resistir às forças oclusais ou até mesmo o resultado de contaminação salivar. Ao desconsiderar cavidades maiores, pode-se obter uma tendência de bons índices de sucesso (GOMES et al., 2003).

Como limitação, a técnica restauradora atraumática não atende a todas as necessidades curativas do paciente, por estar contra-indicada para o tratamento de lesões de cárie em estágios avançados (IMPARATO et al., 2005). Assim como a maioria dos tratamentos o ART não é totalmente eficaz possuindo algumas desvantagens como os problemas de solubilidade e degradação devido ao fenômeno de sinérese e de embebição, propriedades mecânicas desfavoráveis, baixa resistência coesiva e desgaste do material de escolha, o cimento ionômero de vidro (NUNES et al.,2003).

\section{INDICACÕ̃ES E CONTRAINDICACÕES DO TRATAMENTO RESTAURADOR ATRAUMÁTICO}

As indicações do ART listadas para o ART como dentes com lesões de cárie oclusal e ocluso-proximal onde não há aproximação pulpar e sintomatologia dolorosa, em pacientes com alto índice de lesões cariosas, pacientes de difícil manejo, cárie de acometimento precoce, gestante, pacientes com contraindicação à anestesia local, pacientes em clínicas de repouso, pacientes ansiosos e medrosos, bebês e pacientes especiais; demonstram que a aplicação desta técnica não se limita aos países em desenvolvimento, mas que a mesma é uma possibilidade útil aos países desenvolvidos (CORDEIRO et al., 2001). Também ressaltamos como foi preconizado que dentes que apresentam abscesso, exposição pulpar, fístula ou dor crônica são contraindicados para o ART (MENEZES et al., 2009).

As excelentes propriedades do cimento ionômero de vidro (CIV), como liberação de fluoretos, potencial significativo de remineralização, ser cariostático, 
biocompatibilidade pulpar e adesão química ao tecido dentário impedindo a passagem de nutrientes para o crescimento das bactérias que se localizam abaixo da restauração, fizeram deste cimento o material de eleição para aplicação no ART e um dos fatores responsáveis pelo sucesso da técnica (GARBIN et al., 2008).

Entretanto Moura et al (2004) apontaram que a baixa resistência coesiva e o desgaste deste material, o custo elevado, sua indisponibilidade no serviço público, são fatores de resistência ao seu uso como material definitivo e consequentemente provocam uma resistência de aplicação do ART por parte de alguns profissionais da Odontologia.

As considerações de Myaki entende-se que para o sucesso do ART, devem-se ter cuidados como controle da infiltração marginal, evitar a contaminação do material por saliva, utilizar correta proporção na manipulação do cimento ionômero de vidro e proteção superficial deste, realizar um preparo cavitário adequado com remoção completa de todo tecido cariado na junção amelodentinária. Descuidos por parte do profissional podem levar ao surgimento de cárie secundária, sensibilidade pósoperatória, injúria pulpar e manchamento das margens da restauração, caracterizando insucesso da técnica (MYAKI et al., 2000).

As informações indicaram as limitações de uso das restaurações atraumáticas devido a não atender a todas as necessidades curativas do paciente, por estar contraindicadas para o tratamento de lesões de cárie em estágios avançados, longevidade das restaurações e selantes por um período de tempo de três anos, pode ocorrer grande cansaço manual, devido a utilização de instrumentos manuais por longo período de tempo (SAKAMOTO et al., 2001).

Estas limitações não impedem de destaca-se sua grande importância social e a fácil aceitação por pacientes adultos e infantis. Quando utilizada corretamente, com todas as prerrogativas técnico-científicas, esta técnica pode ser de grande valia para populações carentes ou diferenciadas quer seja em zonas rurais ou suburbanas, que provavelmente pouco ou mesmo nunca teriam acesso ao tratamento odontológico convencional (LUZ et al., 2009).

Parece-nos importante não somente considerar os aspectos positivos da facilidade de aplicação da técnica, a redução de custo ou mesmo seu ganho biológico, mas ressaltarmos que o ART minimiza a mutilação causada por extrações dentárias, 
possibilita à restauração da saúde bucal do indivíduo, seu caráter educativo, e que este pode ser o tratamento de escolha em várias situações onde a falta de estrutura ou recursos impedem a possibilidade de um tratamento considerado ideal, principalmente nos programas de saúde pública. Percebemos que mesmo com vários trabalhos publicados sobre este assunto, a eficácia e efetividade do ART ainda merecem ser investigadas e que um maior conhecimento da técnica por parte dos profissionais da área, talvez diminuísse sua rejeição (RAGGIO et al., 2005).

Diante disso, quando opta- se pela técnica atraumática, o cirurgião dentista precisa estar atento às indicações e contraindicações, representado no quadro a seguir:

\subsection{INDICAÇÕES}

Nos dentes decíduos possuem as seguintes indicações:

- Em dentes posteriores classe I ou II;

- Classe III não transfixantes;

- Restaurações anteriores transfixantes, porém deve-se optar pelo CIV modicado por resina, levando em conta a necessidade estética;

- Dentes com perda de cúspides e tratados endodonticamente, pois por mais que exista a chance de fratura, até a esfoliação, desde que o meio receba recargas constantes de flúor o mesmo não terá recidiva de cárie.

- Classe V, tanto para dentes anteriores como para posteriores.

E nos dentes permanentes possuem as seguintes indicações:

- Classe III não transfixantes;

- Classe V tanto para dentes anteriores quanto posteriores;

- Classe I e II, desde que exista a presença de cúspides mesmo que fragilizadas;

- Classe II com caixa proximal retentiva;

- Classe I e II com perda da cúspide de não trabalho desde que haja retenção

\subsection{CONTRAINDICACÕES}

Nos dentes permanentes somente na classe IV, devido à falta de retenção mínima e nos dentes permanentes possuem as seguintes contraindicações:

- Classe IV, pelo mesmo motivo dos dentes decíduos;

- Classe III transfixante, em decorrência do comprometimento estético; 
- Dentes tratados endodonticamente, devido ao risco de fratura;

- Classe II, com caixa proximal expulsiva, devido ao risco de fratura e ao deslocamento da restauração;

- Perda total de uma ou mais cúspides, pelo risco de fratura e deslocamento da restauração.

- Perda da vertente interna da cúspide de trabalho, também devido ao risco de fratura ou deslocamento da restauração.

Para que se obtenha sucesso na técnica atraumática, além de conhecer as indicações e contraindicações, o profissional também deve estar atento quanto à execução da mesma, e a necessidade de uma organização prévia do local, preparação do material e instrumental, segue abaixo as etapas do TRA:

- Profilaxia;

- Seleção do quadrante, levando em conta a idade do paciente (em caso de crianças), o tamanho das cavidades e o tempo do profissional para execução do atendimento;

- Uso de cinzéis para ampliar a margem da cavidade quando necessário;

- Remoção da dentina necrosada com auxílio da colher de dentina, realizando movimentos muito suaves, com o objetivo de remover apenas o tecido amolecido;

- Separar o Bloco de papel e espátula plástica,

- Dispensar a proporção de pó e liquido de acordo com o fabricante;

- Aglutinar as partículas de pó no liquido, tal processo dura em torno de 20s, o momento exato de inseri-lo na cavidade será quando o mesmo apresentar ponto de fio;

- Isolamento relativo, tendo o profissional que ficar sempre atento à troca dos roletes de algodão quando estes estiverem úmidos,

- Pré-tratamento da superfície com o ácido poliacrílico a $10 \%$ por 15 a 20 segundos;

- Lavar e secar a cavidade com bolinha de algodão;

- Inserção do material na cavidade com espátula número 1 ou esculpidor ART, tendo também a possibilidade da utilização da seringa Centrix, onde haverá menor incorporação de bolhas;

- Pressão digital por 4 a 5 minutos, para a melhor escoamento e diminuir a presença de bolhas; 
- Remoção dos excessos, se necessário utilizar o carbono para ajuste oclusal, bem como fio dental e eventualmente tiras de poliéster;

- Depois da perda do brilho, fazer proteção com verniz que é fornecido pelo fabricante, vaselina ou esmalte;

- Recomendar para que o paciente não mastigue por uma hora, e alimentação pastosa por 24 horas (MONNERAT et al., 2013).

\section{CONSIDERAÇÕES FINAIS}

Com base na revisão da literatura realizada, a terapia de reparo não invasiva desempenha um papel importante no tratamento da cárie dentária e é usada principalmente em países em desenvolvimento. O ART é um procedimento simples e definitivo que não requer um procedimento técnico meio ambiente e apenas usos de ferramentas manuais podem remover cáries e selar a cavidade com ionômero de vidro.

O ART tem as vantagens de ser uma tecnologia de baixo custo e invasão. Suas limitações se devem principalmente à baixa resistência à abrasão e menor dureza do cimento de ionômero de vidro. É contra-indicada em pacientes com abscessos, fístulas, polpa exposta e dor espontânea, sua eficácia e efetividade ainda valem a pena estudar, e um melhor entendimento dessa técnica pelos dentistas pode reduzir seu índice de rejeição.

\section{REFERÊNCIAS}

AGUILAR, A. A. A., CAROS, T. E. R., SAAVEDRA, J. H. La práctica restaurativa atraumática: una alternative dental bien recibida po los Referências Bibliográficas niños. Ver. Panam. Salud Publica. 2012; 31 (2): 148-52.

ALVES, N. L. Desempenho clínico do cimento de ionômero de vidro no tratamento restaurador atraumático: uma revisão da literatura. 2017. 52 f. TCC (Trabalho de Conclusão de Curso de Odontologia) - Faculdade de Farmácia, Odontologia e Enfermagem, Universidade Federal do Ceará, Fortaleza, 2017.

BEZERRA. Cicero Hoton Tavares. Restauração Atraumática na Odontologia [manuscrito]: uma revisão de literatura/ Cicero Hoton Tavares Bezerra - 2014. 25p. Trabalho de conclusão de curso (graduação em odontologia) Universidade Estadual da Paraíba, Centro de Ciências Biológicas e da Saúde 2014. 
Brasil. Ministério da Saúde. Secretaria de Atenção à Saúde. Departamento de Atenção Básica. Cadernos de atenção básica, n.17. Brasília: Ministério da Saúde;

2006.

BRESCIANI, E. Clinical trials with atraumatic restorative treatment (ART) in deciduous and permanent teeth. J. Appl. Oral Sci. 2006; 14 (sp. Issue): 14-9.

CICCONE, J. C. et al. Cimentos ionoméricos empregados no tratamento restaurador atraumático (TRA). RGO, Porto Alegre, v. 52, n. 5, p. 369-372, nov./dez. 2004.

FIGUEIREDO, K. S. P. de.; FORTE, F. D. S.; SAMPAIO, F. C. Desempenho clínico de restaurações ART (tratamento restaurador atraumático) em crianças atendidas na clínica de cariologia da UFPB. Rev. Odontol. UNESP, São Paulo, v. 37, n. 4, p. 351- 355, 2008.

FIGUEIREDO, K. S. P. de.; FORTE, F. D. S.; SAMPAIO, F. C. Desempenho clínico de restaurações ART (tratamento restaurador atraumático) em crianças atendidas na clínica de cariologia da UFPB. Rev. Odontol. UNESP, São Paulo, v. 37, n. 4, p. 351- 355, 2008.

FRENCKEN JE, LEAL SC, NAVARRO MF. Twenty-five-year atraumatic restorative treatment (ART) approach: a comprehensive overview. Clinical Oral Investigations 2012; 16:1337-1346.

FRENCKEN, J. E., LEAL, S. C. The correct use of the ART Approach. J. Appl. Oral Sci. 2010; 18 (1): 1-4.

GARBIN, C. A. S. Aspectos atuais do tratamento restaurador atraumático. RFO, v. 13, n. 1, p. 25-29, jan. /abr. 2008.

GARBIN, C.; SUNDFELD, R.; DOS SANTOS, K.; CARDOSO, J. Aspectos atuais do tratamento restaurador atraumático. Revista da Faculdade de Odontologia - UPF, v. 13, n. 1, 9 ago. 2010.

GOMES, A. C. et al. O tratamento restaurador atraumático (TRA) como alternativa de tratamento em bebês portadores de fissura: relato de caso clínico. Revista Odontológica de Araçatuba, v. 24, n. 2, p. 52-55, ago./dez. 2003.

HERMOSILLO, V. H., QUINTERO, L. E., GUERRERO, N. D. et al. The implementation and preliminary evaluation of an ART strategy in Mexico - a country example. J. Appl. Oral Sci. 2009; 17 (Sp. Issue): 114-21.

HOLMGREN, C. J., ROUX, D., DOMÉJEAN, S. Minimal intervention dentistry: part 5. Atraumatic restorative treatment (ART) - a minimum intervention and minimally invasive approach for the management of dental caries. British Dental Journal. 2013; 214: 11-8. 
KANNO, Mauro Teruo. Tratamento restaurador atraumático (ART): uma Alternativa em saúde pública. Monografia (Especialização) - Universidade Estadual de Campinas, Faculdade de Odontologia de Piracicaba. / Mauro Teruo Kanno. -Piracicaba, SP: [s.n.], 2004. $45 f$.

KIKWILU, E. N., FRENCKEN, J. E., MULDER, J. et al. Dental practitioners' attitudes, subjective norms and intentions to practice Atraumatic Restorative Treatment (ART) in Tanzania. J. Appl. Oral Sci. 2009; 17 (2): 97-102.

Lima DC, Saliba NA, Moimaz SAS. Tratamento restaurador atraumático e sua utilização em saúde pública. RGO. 2008;56(1):75-9

LUZ, P. B. Avaliação de duas técnicas restauradoras de mínima intervenção em lesões cariosas profundas de molares decíduos. 2009. 55 f. Dissertação (Mestrado) _ Faculdade de Odontologia, Universidade Federal do Rio Grande do Sul, Porto Alegre, 2009.

MARTINS, Isabela Mascaro. Tratamento Restaurador Atraumático em Odontopediatria: Revisão de Literatura/ Isabela Mascaro Martins. Monografia apresentada ao curso de Especialização Lato Sensu da FACSETE - Faculdade Sete Lagoas, como requisito parcial para conclusão do Curso de Odontopediatria. $28 \mathrm{f}$. 2016.

MASSONI, Andreza Cristina de Lima Targino; PESSOA Caroline Pereira; OLIVEIRA Andressa Feitosa Bezerra de. Tratamento restaurador atraumático e sua aplicação na saúde pública. Revista de Odontologia da UNESP. 2006; 35(3): 201207.

MENEZES, V. A. et al. Percepção dos cirurgiões-dentistas da cidade de Caruaru/PE sobre o tratamento restaurador atraumático. Pesq Bras Odontoped Clin Integr, João Pessoa, v. 9, n. 1, p. 87-93, jan./abr. 2009.

MICKENAUTSCH, S., FRENCKEN, J. E., VAN'T HOTF, M. A. Atraumatic Restorative Treatment and dental anxiety in outpatients attending public oral health clinics in South Africa. J. Public Health Dent. 2007; 67: 179-84.

MONNERAT FA, Souza CIM, Monnerat, LBA. Tratamento restaurador atraumático. Uma técnica que podemos confiar? Rev. bras. Odontol. 2013; 70(1): 33-6

MONNERAT, Antônio Fernando; SOUZA, Maria Isabel de Castro de e MONNERAT, Aline Borges Luiz. Tratamento Restaurador Atraumático. Uma técnica que podemos confiar? Rev. Bras. Odontol. [online]. 2013, vol.70, n.1, pp. 33-36. ISSN 19843747. 
MYAKI, S. I. et al. Infiltração marginal em restaurações com cimento de ionômero de vidro para a técnica do tratamento restaurador atraumático. Rev. Odontol. UNESP, São Paulo, v. 29, n. 1/2, p. 105-112, 2000.

NAVARRO, Maria Fidela de Lima; LEAL, Soraya Coelho; MOLINA, Gustavo Fabián e VILLENA, Rita Sarmiento. Tratamento Restaurador Atraumático: atualidades e perspectivas. Rev. Assoc. Paul. Cir. Dent. [online]. 2015, vol.69, n.3, pp. 289-301. ISSN 0004-5276.

NUNES, O. B. C. et al. Avaliação clínica do tratamento restaurador atraumático (ART) em crianças assentadas do movimento sem-terra. Rev. Fac. Odontol. Lins, Piracicaba, v. 15, n. 1, p. 23-31, 2003.

PHANTUMVANIT, P., et al. WHO Global Consultation on Public Health Intervention against Early Childhood Caries. Community Dent Oral Epidemiol., v.46, p. 280287, 2018.

RAGGIO, D. Tratamento restaurador atraumático. 2004. Disponível em: $<<$ http://solutions.3m.com.br/wps/portal/3M/pt_BR/3M>>. Acesso em: 10 junho 2010.

RAGGIO, Daniela Prócida; BONIFÁCIO, Clarissa Calil; IMPARATO, José Carlos Pettorossi. Tratamento restaurador Atraumático (ART): realidades e perspectivas - São Paulo: Santos, 2011. 150p.: il.

RIOS, L. E.; ESSADO, R. E. P.; FREIRE, M. C. M. Tratamento restaurador atraumático: conhecimento e atitudes de cirurgiões-dentistas do serviço público de GoiâniaGO. Rev. Odontol. UNESP, São Paulo, v. 35, n. 1, p. 75-80, 2006.

SAKAMOTO, C. M.; MOIMAZ, S. A. S. Tratamento restaurador atraumático. Revista Paulista de Odontologia, São Paulo, ano XXIII, n.5, p. 42-45, set./out. 2001.

SANTOS, C.D.G. A, et al. Perda precoce de molares decíduos em crianças atendidas na Faculdade de Odontologia da Universidade Federal da Bahia. Odontol. Clín. Cient, v.12, n.3, 2013.

VENTIN, D. et al. Topografia de restaurações realizadas através do tratamento restaurador atraumático (ART): estudo piloto in vivo. Pesq Bras Odontoped Clin Integr, João Pessoa, v. 7, n. 3, p. 285-290, set./dez. 2007. 


\title{
CAPITULO VIII \\ HALL TECHNIQUE: TRATAMENTO DE MIINIMA INTERVENÇÃO EM LESÕES DE CÁRIE EM MOLARES DECIDUOS
}

\author{
DOI: 10.51859/AMPLLA.EPC757.1121-8
}

\author{
Wendel Chaves Carvalho ${ }^{1}$ \\ Caroline Rodrigues Thomes ${ }^{2}$ \\ Antônio Fabrício Alves Ferreira ${ }^{3}$ \\ Silvia Milena Martins ${ }^{4}$ \\ Dara Lourenna Silva da Nóbrega ${ }^{5}$ \\ Allana da Silva e Silva Dias ${ }^{6}$
}

\begin{abstract}
${ }^{1}$ Graduando do curso de Odontologia. Faculdade Pitágoras de São Luís - MA.
2 Graduanda do curso de Odontologia. Universidade Federal do Espírito Santo - ES.

${ }^{3}$ Graduando do curso de Odontologia. Faculdade Pitágoras de São Luís - MA.

${ }^{4}$ Graduanda do curso de Odontologia. Universidade Potiguar de Caicó-RN.

${ }^{5}$ Graduanda do curso de Odontologia. Faculdade Pitágoras de São Luís - MA.

${ }^{6}$ Doutora e mestre em Odontologia pela UFMA; Especialista em Odontopediatria; Professora do curso de Odontologia da Faculdade Pitágoras e Uninassau.
\end{abstract}

\section{RESUMO}

O objetivo desse trabalho foi fazer uma revisão de literatura sobre Hall technique, a respeito da sua história até a sua aplicabilidade a lesões de cárie em dentes decíduos. Foi realizada uma pesquisa qualitativa e descritiva, através de uma revisão bibliográfica de artigos selecionados nas bases de dados PubMed, SciELO e Google acadêmico, utilizando os descritores: "Cárie Precoce", "Coroa de aço", e "Hall Technique". Foram incluídos artigos publicados nos últimos 10 anos, os quais estavam disponíveis na íntegra, nos idiomas de português e inglês. A Hall technique consiste em um procedimento conservador em molares decíduos, não se enquadrando a todos os dentes, apenas molares decíduos. Essa técnica é baseada no conceito biológico da doença cárie, na qual é cimentado uma coroa metálica, pré-formada, sobre a lesão, criando assim uma barreira entre o meio oral e sobre a mesma. Ela é indicada em odontopediatria, principalmente em crianças menos colaboradoras a tratamento convencionais, justamente por ser uma técnica menos traumática, o acaba contribuindo em menor crise de ansiedade ao paciente infantil. Em suma, a Hall technique demonstra ser uma técnica de sucesso e opção para opção para a reabilitação de dentes decíduos, devolvendo a função mastigatória e funcional da criança, diminuindo chances de retratamento da lesão cárie, quando comparada a tratamento convencional decorrentes de falhas.

Palavras-chave: Dente Decíduo. Cárie Dentária. Odontopediatria. 


\section{INTRODUÇÃO}

A doença cárie continua sendo um dos principais problemas de saúde pública, além de constituir um dos principais motivos de intervenções odontológicas. Ela costuma ser observada desde a primeira infância até a fase adulta, atingindo diferentes idades. A sua prevalência é alta, principalmente em crianças em idade pré-escolar, atingindo números de até 600 milhões em todo o mundo (LARANJO, et al.,2017; GROSS, et al., 2018; PITTS, et al 2019). De acordo com a Declaração de Bangkok, (2019) essa doença é capaz de proporcionar grandes impactos na qualidade de vida da criança, seja interferindo no crescimento, no desenvolvimento e nas relações sociais.

A cárie é uma doença que se apresenta como crônica, localizada e multifatorial, desenvolvendo-se a partir de um desequilíbrio do processo de mineralização e desmineralização com a perda de minerais dentários, seja em nível microscópico ou submicroscópico, podendo até chegar a estágios com a presença de sinais e sintomas clínicos bem definidos como cavidades dentárias, que variam em extensão e profundidade (DEJEAN et al., 2009). Fatores como taxa de secreção de saliva, acesso ao flúor, dieta, higiene oral, condição de caráter socioeconômico, conhecimento e educação a respeito de saúde oral apontam o caráter multifatorial da cárie (FEJERSKOV; KIDD, 2008).

O atendimento odontológico em odontopediatria pode ser visto como desafiador devido ao medo, ansiedade ou até mesmo considerando tratamentos odontológicos anteriores relacionados à dor. Nesse sentido, há necessidade de novas condutas, tratamentos que visem minimizar esses de transtornos às crianças. Atualmente, o método de remoção total do tecido cariado, seguido de uma restauração, já não é mais a melhor opção, sendo substituído por alternativas mais conservadoras e biológicas perante o controle do biofilme e do espaço cariogênico, o que geralmente facilita o atendimento à criança (HESSE, et al.,2016; INNES et al., 2017).

Com objetivo de tratar a doença cárie de forma menos invasiva e evitar impactos negativos à saúde mental da criança, Hall technique surge como uma boa opção e eficiência para reabilitar lesões de cárie em dentes decíduos posteriores. Assim, ela é considerada uma boa opção de um tratamento de mínima intervenção, com grandes 
vantagens em questão da aceitação, praticidade, menor tempo de cadeira, além de evitar a extração precoce (SANTAMARÍA, INNES, 2018).

Por essa técnica, uma coroa metálica pré-fabricada é cimentada sobre a lesão, criando uma barreira entre o meio oral e a superfície dentária, o que impede o desenvolvimento da doença (MICHEL, 2018). Além disso, essa técnica constitui uma alternativa mais conservadora, pois não há necessidade de remoção de tecido cariado ou espessura da dentina, diminuindo o risco de exposição pulpar acidental, o que poderia levar à dor e um tempo de cadeira a mais à criança (CARLOS, et al.,2016).

Acreditando nessa filosofia, esse estudo tem como objetivo fazer uma revisão de literatura sobre Hall technique, a respeito da sua história até a sua aplicabilidade a lesões de cárie em dentes decíduos.

Foi realizada uma pesquisa qualitativa e descritiva, através de uma revisão bibliográfica de artigos selecionados nas bases de dados PubMed, SciELO, Google acadêmico, utilizando os descritores: "Cárie precoce", "Coroa de Aço" e "Hall technique". Foram incluídos artigos publicados nos últimos 10 anos, os quais estavam disponíveis na íntegra, nos idiomas de português e inglês. O estudo incluiu estudos clínicos, relatos de casos, revisões da literatura (monografias, teses e dissertações) e capítulos de livros e excluiu estudos in vitro, estudos com animais e editoriais.

\section{CONTEXTO HISTÓRICO E DEFINIÇÃO DA TÉCNICA}

As primeiras coroas de aço confeccionadas para dentes decíduos foram descritas no ano de 1950 por Engel e por Humphrey, para serem usadas como uma forma de reabilitação para molares decíduos que apresentavam grande perdas de estruturas, sendo ainda utilizada para dentes submetidos ao tratamento pulpar. Sua utilização se justificava por apresentarem uma maior taxa de sucesso, quando comparadas com o tratamento realizado com restaurações de amálgama (ZANOLA, et al., 2018; MICHEL, 2018).

Essas coroas apresentam algumas limitações para uso em odontopediatria, pois, é necessária a realização de anestesia, a preparação do dente, adaptação da coroa, modificações em relação à anatomia, resultando em um protocolo clínico demorado. Diante desses fatos, houve uma necessidade de usar outras formas de abordagem para 
as lesões de cárie em dentes decíduos, como restaurações com resina composta ou com cimento de ionômero de vidro (GILCHRIST et al., 2012; MICHEL, 2018).

Surgiu então, na Escócia, nos anos de 2000, a Hall technique ou técnica de Hall (HT). Nessa técnica são utilizados novos modelos de coroas pré-fabricadas, as quais apresentam novos aspectos, melhor eficiência, anatomia e são maleáveis a possíveis alterações, ajustes para simplificar o procedimento de instalação (INNES, et al.,2017; MICHEL, 2018).

A técnica consiste em um procedimento conservador realizado em dentes molares decíduos (MIDANI, et al., 2019). Zanola et al. 20018), confirmada como uma opção de tratamento preferencial para os mesmos, justamente porque quando presente nesses dentes, a doença cárie acomete múltiplas superfícies. Assim, considerase que essa abordagem tem como objetivo evitar à progressão da lesão de cárie através da cimentação de uma coroa metálica inox pré-formada com CIV (Cimento de lonômero de Vidro), sem que haja remoção de tecido cariado, realização de preparo ou anestesia (SANTAMARÍA; INNES, 2018).

A técnica pode ser realizada em apenas duas consultas. Na primeira colocam-se separadores ortodônticos entre os espaços interproximais presentes entre o elemento dental a ser reabilitado. Esses elásticos permanecem entre três a sete dias, para permitir a criação de um espaço, de forma a facilitar a instalação das coroas, sem nenhuma interferência com o dente adjacente. Na segunda consulta, após esse período, é selecionado o tamanho da coroa correspondente ao dente, sendo cimentada com ionômero de vidro, justamente por ser um material que apresenta como vantagem a libertação de flúor promovendo um efeito bacteriostático e pela sua adesão quimicamente ao esmalte e à dentina, sendo ainda cimentada sem ter feito nenhum tipo de preparo e anestesia (HESSE et al.,2016; HERI, et al 2016; MICHEL, 2018). A imagem abaixo é um exemplo da técnica Hall. 
Figuras 1,2 e 3: I) Dentes com separadores ortodônticos; II) Espaço criado após remoção do separador ortodôntico; III) Coroa instalada sobre o elemento dentário.
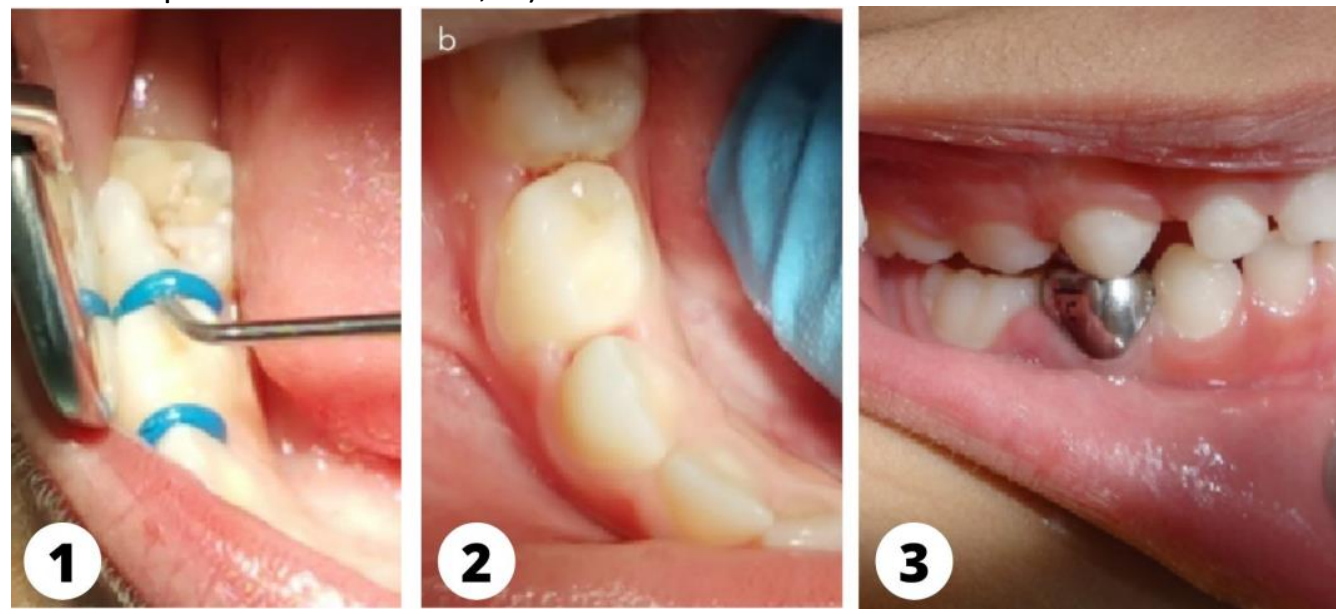

Fonte: (GHAITH, HUSSEIN, 2017).

Segundo Santamaria e Inês (2018), essa forma de tratamento surgiu de serviços prestados em áreas de grandes índices de cárie, onde apresentavam baixa aceitação ao tratamento convencional por questões de dor. Assim, como forma de felicitar o tratamento, contribuiu para o desenvolvimento de uma técnica simplificada, sem anestesia, preparo ou remoção da cárie, e a de certa forma apresentou resultados finais semelhantes quando comparada as técnicas de instalação de coroas (convencional e Técnica de Hall) (IMPARATO, 2017).

Por essas considerações, HT mostra ser uma técnica minimamente invasiva devido à forma de controle de lesões de cárie quebrando o paradigma da remoção total do tecido cariado, o que acaba enfraquecendo o dente e, até mesmo, pode gerar uma possível exposição pulpar (GROSS, et al.2018). A implantação da coroa sobre a superfície do elemento dental vai funcionar como uma camada de blindagem, como um escudo de maneira que a cárie seja revertida, sem progressão, impedindo assim o contato com fluidos orais, alimentos e microrganismos que poderiam acarretar seu desenvolvimento. (ZANOLA, et al., 2018).

Diante desse selamento, a lesão cariogênica ativa se transforma em uma lesão inativa, impedindo sua ampliação à região sensitiva do dente, favorecendo o equilíbrio a favor da polpa, evitando possíveis inflamações irreversíveis (INNES, et al.,2017). A coroa deve permanecer sobre o dente até o período de esfoliação natural do dente (ZANOLA, et al., 2018). 
BOYD et. al (2017), mostra em seu estudo relatos de taxas de sucesso em crianças que receberam tratamento utilizando a técnica de hall na Nova Zelândia, apresentando pequena falhas (cerca de 6\%) quando comparadas com grupos tratados com restauração convencional (32\%). Já em outros autores enfatiza a sobrevida semelhante às técnicas convencionais (Gross, et al 2018). Innes et al. (2017), afirmou o sucesso da técnica, na qual foi monitorado por 1 ano, demonstrando efetividade igual ou até melhor que os matérias comparadores, além da redução de caso de dor e processo de infecção, contribuindo aos atendimentos.

\section{INDICAÇÕES E CONTRAINDICAÇÕES}

Hall technique é uma técnica indicada em odontopediatria, principalmente em crianças menos colaboradoras em tratamentos convencionais, justamente por ser uma técnica menos traumática, o que acaba contribuindo em menor crise de ansiedade ao paciente infantil. Entretanto, a técnica não está indicada para todos os casos clínicos, é de suma importância a seleção correta de casos, sendo assim um fator importante para o sucesso da conduta e tratamento. Serão demostradas as inúmeras indicações do seu uso, assim como suas contraindicações mencionada pela literatura (HARIRI et al., 2016; INNES et al., 2017).

Tabela 1: Indicações da técnica de Hall para dentes decíduos.

Molares decíduos, sem sintomatologia com cárie em oclusal, interproximais ou múltiplas (Cavitadas ou não, ativas ou inativas)

Lesões de carie profundas sem envolvimento pulpar, ICDAS: 5,6.

Dentes com ampla destruição coronária onde não há tecido remanescente suficiente para suportar as forças oclusais durante a mastigação.

Crianças com alto índice de cárie e ansiosas.

Tabela 2: Contraindicações da técnica Hall

Dentes com diagnostico pulpar: Pulpite irreversível; Necrose; Periodontite periapical aguda ou crónica; Abcesso agudo ou crónico e lesões de carie atingindo a polpa.

Dentes sem suporte remanescente, impossibilidade de restaurar.

Criança imunodeprimida.

Presença de fratura radicular, ou dentes próximos ao período de esfoliação.

Não há colaboração da criança, risco de deglutição ou endocardite bacteriana. 


\section{VANTAGENS E DESVANTAGENS}

Essa abordagem biológica traz ótimos resultados e são características de vantagens ao procedimento tais como: a técnica não exige utilização de muitos materiais odontológicos, (INNES, 2017) é uma técnica rápida, sem necessidade de preparo, remoção do tecido cariado ou anestesia, sendo pregado como um procedimento simples, não invasivo, menos traumático, qualidades necessárias para o atendimento pediátrico (HARIRI, et al., 2016).

Apresenta altas taxas de sucessos quando utilizada, diminuindo retratamento relacionado a falhas ao tratamento convencional, podendo ser realizada em outros ambientes com falta de instalações e infraestrutura, o que contribui para promoção de saúde em lugares de difícil acesso a saúde bucal CARLOS et al., 2016; INNES, et al.,2017). Além disso, ela possui uma boa aceitação, quando comparado com tratamento convencional, mostram ser uma opção positiva e aceitável aos pais (INNES, et al.,2017).

Apesar de ser uma técnica existente a mais de 20 anos, ainda existem muitas restrições entre a comunidade de cirurgiões-dentistas como a forma de tratamento e utilização, principalmente as desvantagens da técnica como: dificuldade na aquisição das coroas (importadas), custo alto das coroas, estética e o aumento da dimensão vertical de oclusão (DVO) devido à ausência do preparo remanescente (ZANOLA et al., 2017)

Segundo Zanola et al. (2017), o aumento da DVO não deve ser algo a ser considerado como uma desvantagem da técnica, visto que é algo transitório, pois a coroa consegue se adaptar ao espaço. Além de não ocasionar à articulação, já que a criança consegue se adaptar a essas mudanças devido à musculatura estar em desenvolvimento, desaparecendo em semanas essa mordida unilateral, sem danos aos dentes permanentes (CARLOS, et al., 2016).

É de suma importância frisar que nem sempre a instalação da coroa resulta em uma sobreoclusão, visto que às vezes a cimentação é capaz de devolver a oclusão que estava deficiente. Para medidas de segurança deve-se evitar o aumento nessa discrepância é importante selecionar o tamanho correto da coroa em relação ao antagonista., recomenda a seleção de coroa inferior a 1,5mm como uma medida de limite (HARIRI, et al., 2016). 


\section{CONSIDERAÇÕES FINAIS}

A hall technique mostra ser uma técnica de sucesso e opção para opção para a reabilitação de dentes molares decíduos, devolvendo a função mastigatória e funcional da criança, diminuindo chances de retratamento da lesão cárie, quando comparada a tratamento convencional decorrentes de falhas.

Essa técnica torna-se uma excelente opção de escolha justamente devido a sua simplicidade de execução por questões mínima de matérias, ausência de brocas e anestesia local, o que contribui em um atendimento rápido e menos doloroso, reduzindo menor transtornos psicológicos a criança.

\section{REFERÊNCIAS}

BOYD, D. H.; PAGE, L. F.; THOMSON, W. M. (2017). The Hall Technique and conventional restorative treatment in New Zealand children's primary oral health care - clinical outcomes at two years. International Journal of Paediatric Dentistry, 28(2), 180-188. doi:10.1111/ipd.12324

CARLOS, Al. P. et al. Tratamento restaurador segundo a hall technique - Relato de caso em paciente infantil. Journal of Biodentistry and Biomaterials, v.6, n.2, 2016.

DEJEAN, K. S. et al. Lesão de cárie oculta: um estudo de diagnóstico e prevalência. Clínica e Pesquisa em Odontologia - UNITAU, v.1, n.1, p. 7-13, 2009.

FEJERSKOV, O.; KIDD, E. A. M. Dental caries: the disease and its clinical management. Oxford, Blackwell Munksgaard. 2008. 480p.

GHAITH, B; HUSSEIN, I. The Hall Technique in paediatric dentistry: a review of the literature and an "All Hall" case report with a 24 month follow up. Stoma. Edu. J., v.4, n.3, p. $208-217,2017$.

GILCHRIST, F. et al. Impact of the hall technique for preformed metal crown placement on undergraduate paediatric dentistry experience. European Journal of Dental Education, 2012.

GROSS, D. J. et al. Hall technique in pediatric patients: case study and clinicalradiographic follow-up. Rev. Bras. Odontol., v. 75, 2018.

HARIRI, M. et al. The Hall Technique: A Non-conventional Method for Managing Carious Primary Molars. Dentistry, v. 6, 2016. 
HESSE, D. et al. Atraumatic Restorative Treatment compared to the Hall Technique for occluso-proximal cavities in primary molars: study protocol for a randomized controlled trial. Trials, v.17, .169, 2016.

IMPARATO, J. C. P. Odontopediatria clínica - integrada e atual - anuário 03. 1a edição, Editora: Napoleão, 2017.

INNES, N. P. T. et al. The Hall Technique 10 years on: Questions and answers. British Dental Journal, v.222, n.6, 2017.

LARANJO, E. et al. A cárie precoce da infância: uma atualização. Rev. Port. Med. Geral. Fam., v. 33, p-426-429, 2017.

LUDWIG, K. H. et al. The success of stainless-steel crowns placed with the Hall technique: a retrospective study. The Journal of the American Dental Association, v. 145, n. 12, p. 1248-1253, 2014.

MIDANI, R. et al. Midani Success rates of preformed metal crowns placed with the modified and standard hall technique in a paediatric dentistry setting. wileyonlinelibrary.com/journal/ipd. Int J Paediatr Dent, v.29, p. 550 - 556, 2019.

MICHEL, Q. A técnica de Hall em odontopediatria, Trabalho apresentado à Universidade Fernando Pessoa, como parte dos requisitos para obtenção do grau de Mestre em Medicina Dentária. 2018.

NUNES, V. H.; PEROSA, G. B. (2017). Cárie dentária em crianças de 5 anos: fatores sociodemográficos, lócus de controle e atitudes parentais. Ciência \& Saúde Coletiva, v. 22, n.1, p. 191-200, 2017.

PITTS, N. et al. Early childhood caries: iapd Bangkok declaration. Int. J. Paediatr. Dent., v. 29: 384-386. 2019.

SANTAMARÍA, R; INNES N. Sealing Carious Tissue in Primary Teeth Using Crowns: The Hall Technique. chwendicke F, Frencken J, Innes N (eds): Caries Excavation: Evolution of Treating Cavitated Carious Lesions. Monogr. Oral Sci. Basel, Karger, 2018, v. 27, p. 113-123, 2018.

ZANOLA, M. M.O. et al. Hall Technique: você sabe o que é? Relato de caso. VER. ASSOC. PAUL. CIR. DENT., v.72, n.4, p. 624-30, 2018. 


\title{
CAPITULO IX
}

\section{TRATAMENTO DE DENTES ACOMETIDOS POR AMELOGÊNESE IMPERFEITA: RELATO DE CASO}

DOI: 10.51859/AMPLLA.EPC757.1121-9

\author{
Jeferson Luis de Oliveira Stroparo ${ }^{1}$ \\ Geraldo Fernando Stroparo ${ }^{2}$ \\ Jonathan Fernando de Oliveira Stroparo ${ }^{3}$ \\ Sabrina Cunha da Fonseca ${ }^{4}$
}

${ }^{1}$ Doutorando em Odontologia. Universidade Positivo - UP
${ }^{2}$ Graduado em Odontologia. Prática clínica privada.
${ }^{3}$ Graduado em Odontologia. Prática cínica privada
${ }^{4}$ Mestre em odontologia clínica. Universidade Positivo - UP

\section{RESUMO}

O objetivo desse artigo foi relatar o tratamento de um paciente com amelogênese imperfeita, nos elementos 44 e 45, por meio de restaurações estéticas com resina composta. Relato de caso: Paciente de 24 anos de idade, gênero feminino, apresentouse ao consultório particular a procura de tratamento devido a sensibilidade e tratamento estético para os elementos 44 e 45 . Após anamnese e exame clínico, foi diagnosticada a amelogênese imperfeita. 0 tratamento de escolha foi a realização de restaurações estéticas com resina composta nesses elementos dentários a fim diminuir a sensibilidade e também melhorar a estética. Foi realizado profilaxia com taça de borracha e escova de robson na sequência foi realizado o forramento com cimento ionômero de vidro fotoativavel para evitar sensibilidade e foi utilizado ácido fosfórico $37 \%$ para o condicionamento ácido e foi utilizado sistema Adesivo Universal, foram feitas as restaurações dos elementos dentários 44 e 45 com resina composta. A paciente relatou que após o procedimento não sentiu mais sensibilidade. Concluiu-se que as restaurações estéticas podem ser o tratamento de primeira escolha para alguns casos de amelogênese imperfeita, gerando um resultado satisfatório, tanto na estética quanto na função, com o paciente podendo se alimentar tranquilamente sem sensibilidade dental.

Palavra-chave: Amelogenese impefeita, esmalte dentário, diagnóstico. 


\section{INTRODUÇãO}

Quando falamos da formação do esmalte dentário, podemos ver no trabalho de SIMMER e FINCHAM. (1995), que a amelogênese é concluída antes da erupção do dente na cavidade bucal. O esmalte maduro é formado de cristais de hidroxiapatita de cálcio, os ameloblastos, células formadoras de esmalte, secretam a matriz orgânica e regulam a mineralização do esmalte por meio de vários mecanismos. Segundo PARRY et al. (2013), estes mecanismos seriam a secreção de proteínas da matriz, que vão atuar como moduladores potenciais do crescimento destes cristais, controle do transporte espacial da secreção de proteases para degradar sequencialmente a matriz de proteína da matriz que atuam como moduladores potenciais do crescimento do cristal, controle tempo espacial da secreção de proteases para degradar sequencialmente a matriz proteínas, e a remoção de proteínas degradadas da matriz do esmalte e controle do transporte de íons minerais para acomodar o crescimento do cristal secundário durante o estágio de maturação do desenvolvimento do esmalte.

A falha na amelogênese se apresenta clinicamente como amelogênese imperfeita (AI), podendo afetar tanto a dentição decídua quanto a permanente. Sabese que esse defeito na estrutura é considerada uma doença hereditária que ocorre durante a odontogênese (BERALDO et al., 2015; PARRY et al., 2013; REDDY et al. 2019).

Ela apresenta um grupo de condições e desenvolvimento de origem genômica, podendo afetar alguns elementos dentários ou quase todos os elementos, temos uma classificação que seria Al hipoplásico, o qual o volume do esmalte está diminuído, Al hipomineralizado, caracterizado por graus variáveis de mineralização incompleta da matriz do esmalte, normalmente com um volume da matriz do esmalte quase normal antes das alterações pós-eruptivas e falha prematura (BERALDO et al., 2015; PARRY et al., 2013). É válido acrescentar no impacto psicológico negativo que esta patologia gera nos indivíduos afetados e em suas famílias, sendo de extrema importância o tratamento odontológico (BERALDO et al., 2015; PARRY et al., 2013; REDDY et al. 2019).

Os problemas clínicos estão principalmente associados a uma estética não satisfatória, sensibilidade nos dentes, dificuldade na mastigação, perda de substância dentária devido a lascamento e atrito, sendo que os pacientes têm um maior risco de cárie dentária, e quando acomete vários elementos dentários a relação oclusal destes é 
aberta e a dimensão vertical oclusal diminuída, por isso a importância de tratar pacientes com estas alterações, pois pode trazer a este não só um problema quanto a estética mas também uma função, e principalmente saúde psicossocial (METE et al., 2012; REDDY et al. 2019).

Portanto o objetivo deste trabalho é relatar o tratamento de elementos dentários acometido por Al e também e relatar os resultados imediatos após o tratamento.

\section{RELATO DE CASO}

Paciente do sexo feminino, 24 anos procurou atendimento odontológico em consultório privado por queixa de sensibilidade em vários elementos dentários.

No exame clínico foi observado defeito no esmalte nos elementos 44 e 45 , os quais também possuem exposição radicular (Figura 1A, 1B). A paciente relatou que sentia muita sensibilidade e que a estética destes elementos a incomodava.

O plano de tratamento sugerido foi realizar restaurações estéticas destes elementos, a fim diminuir a sensibilidade e também melhorar a estética. $O$ que foi aceito e realizado.

Foi realizado profilaxia com taça de borracha (Microdont, São Paulo, Brasil) e escova de robson (Microdont, São Paulo, Brasil), na sequencia foi realizado o forramento com cimento ionômero de vidro fotoativavel Ionoseal (Voco, Porto Alegre, Brasil), para evitar sensibilidade e foi utilizado ácido fosfórico 37\% Condac (FGM, Joinville, Santa Catarina, Brasil) para condicionar o esmalte (Figura 1C). Após o condicionamento ácido foi utilizado sistema Adesivo Ambar Universal (FGM, Joinville, Santa Catarina, Brasil) e feito as restaurações dos elementos dentários 44 e 45 com resina composta Z100 A2 (3M, Sumaré, São Paulo, Brasil), (Figura 1D). 
Figura 1- A e 1- B) Pode-se observar os elementos dentários 44 e 45 com defeitos no esmalte em toda coroa, e na região cervical; 1 -C) Realizado forramento com Cimento lonômero de Vidro Fotoativavel e condicionamento do esmalte; 1-D) Realizadas restaurações com resina composta $\mathrm{A} 2$ nos elementos dentários 44 e 45.
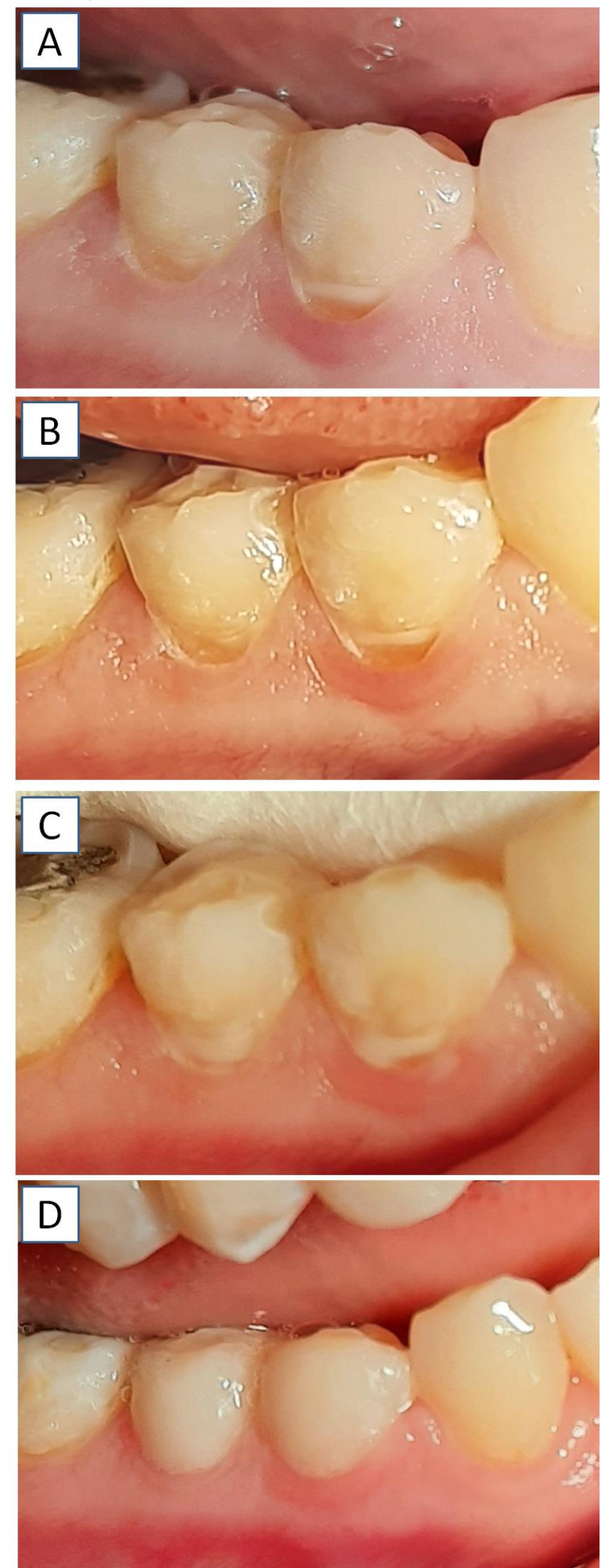

Fonte: própria autoria. 
A paciente relatou que após o procedimento não sentiu mais sensibilidade e pode ingerir comidas e bebidas sem sentir desconforto, além de relatar que gostou muito da nova estética dental.

\section{DISCUSSÃO}

Segundo BERALDO et al. (2015) A Al envolve condições genéticas, que afetam a estrutura e a aparência do esmalte de alguns ou de todos os elementos dentários do indivíduo, não tendo referência com a cronologia da erupção, podendo ter também associação com alterações bioquímicas ou morfológicas.

Alguns autores relatam que dois tipos de Al, sendo que a Al hipocalcificada apresenta a formação da matriz na espessura normal, porém a calcificação é deficiente, e o esmalte é mole, o que acarreta dentes que erupcionam de tamanho normal, mas com a função sofrem rapidamente abrasão, gerando desgastes oclusais e incisais, ocasionando dentes de aspecto quadrangular e cúspides baixas e não definidas, (BERALDO et al., 2015; WHITE e PHAROAH, 2007), algo semelhante ao encontrado nos elementos dentários do presente relato .

Entretanto na Al hipomaturada o esmalte é mais fino e duro, e não tão suscetível a abrasão e cárie, apresentando coroas normais, e manchas de descoloração, branca, marrom e amarela opaca, sendo que esse esmalte mais macio que o normal tende a lascar (BERALDO et al., 2015; WHITE e PHAROAH, 2007).

Contudo a prevalência pode variar dependendo da região, sendo que nos Estados Unidos, a prevalência varia de 1 a cada 12.000 ou 14.000, em Israel de 1 a cada 8000, na Turquia de 1 a cada 232, e na Argentina de 1 a cada 1000 indivíduos, sendo que este último é um pais vizinho ao Brasil, país onde foi realizado este caso clinico, contudo, a prevalência global da doença é de menos de 0,5\% da população (BERALDO et al., 2015; GADHIA et al., 2012; NG e MESSER, 2009; POULSEN et al., 2008).

O tratamento depende da gravidade da alteração, dos fatores como idade, nível socioeconômico, saúde do paciente e também o planejamento, sendo essencial diagnosticar, classificar e realizar o tratamento adequado (BERALDO et al., 2015, SANTOS et al., 2015)

A alteração deve receber o adequado acompanhamento por parte do cirurgião dentista com intervalos pequenos entre as consultas, devido ao risco de desgaste e 
perda de estrutura de esmalte dental. (BERALDO et al., 2015; MARSILLAC et al., 2009; SANTOS et al., 2015).

Dentre os tratamentos que podem ser realizados se incluem a correta limpeza dos dentes, aplicação tópica de verniz fluoretado e selantes ionoméricos quando devidamente indicados (BERALDO et al., 2015; MARSILLAC et al., 2009).

Em casos mais complexos e extremos, os tratamentos incluem desde exodontias múltiplas, placas de restabelecimento de dimensão vertical, e tratamentos para controle de sensibilidade dentaria e restaurações estéticas, (BERALDO et al., 2015) assim como relatado neste trabalho.

Outros autores também relatam a confecção de próteses fixas parciais ou unitárias, coroas metalocerâmicas e também restaurações diretas e indiretas em resina como opções de tratamento para reabilitação de pacientes com amelogênese imperfeita (AZEVEDO et a., 2013; YAMAGUTI, ACEVEDO, PAULA, 2006).

Contudo é importante destacar que o tratamento deve ser o mais conservador possível, sendo resinas compostas geralmente o tratamento de primeira escolha, assim como o relatado neste trabalho, mas outras alternativas como próteses fixas também podem ser utilizadas, pois são alternativas mais conservadoras que exodontias e próteses totais ou removíveis por exemplo (AZEVEDO et al., 2013; YAMAGUTI, ACEVEDO, PAULA, 2006).

Portanto durante o tratamento odontológico desta condição o cirurgião dentista deve estar atento a restaurar a estética, a função adequada e também prevenir a sensibilidade dentária, contudo o profissional deve sempre estar atento de como esta condição pode afetar a autoconfiança do paciente (BORDE et al., 2018).

\section{CONSIDERACÕES FINAIS}

Concluiu-se que as restaurações estéticas podem ser o tratamento de primeira escolha para alguns casos de amelogênese imperfeita, gerando um resultado satisfatório, tanto na estética quanto na função, com o paciente podendo se alimentar tranquilamente sem sensibilidade dental 


\section{REFERÊNCIAS}

Beraldo, C., B., S.; Silva, B., J., A.; Valerio, C., S.; Mazzieiro, E., T.; Manzi, F., R.; Cardoso C., A., A. Amelogênese imperfeita: relato de caso clínico. Revista da Faculdade de Odontologia, Passo Fundo, v. 20, n. 1, p. 101-104, 2015.

GADHIA, K.; MCDONALD, S.; ARKUTU, N.; MALIK, K. Amelogenesis imperfecta: an introduction. British Dental Journal, v. 212 n. 8, p. 377-379, 2012.

MARSILLAC, M., W., S.; BATISTA, A., M., R.; OLIVEIRA. J; ROCHA, M., J., C. Alterações na Amelogênese e suas implicações clínicas: relatos de casos. Revista da Faculdade de Odontologia de Porto Alegre, v. 50, n. 1, p. 9-15, 2009

METE, J., J.; DANGE, S., P.; KHALIKAR, A., N.; VAIDYA, S., P. Functional and esthetic rehabilitation of mutilated dentition associated with amelogenesis imperfecta. The Journal of Indian Prosthodontic Society, v. 12, n. 2, p. 94-100, 2012.

NG, F., K.; MESSER, L., B. Dental management of amelogenesis imperfecta patients: a primer on genotype-phenotype correlations. Pediatric Dentistry Journal, v. 31, n. 1, p. 20-30, 2009.

Parry, D., A.; Poulter, J., A.; Logan, C., V.; Brookes, S. ,J.; Jafri, H.; Ferguson, C., H.; et al. Identification of mutations in SLC24A4, encoding a potassium-dependent sodium/calcium exchanger, as a cause of amelogenesis imperfecta. American Journal of Human Genetics, v. 92, n. 2, p. 307-312, 2013.

POULSEN, S.; GJORUP, H.; HAUBEK, D.; HAUKALI, G.; HINTZE, H.; LOVSCHALL, H.; et al. Amelogenesis imperfect a systematic literature review of associated dental and oro-facial abnormalities and their impact on patients. Acta Odontologica Scandinavica, v. 66, n. 4, p. 193-99, 2008.

REDDY, P.; ARAVELLI, S.; GOUD, S.; MALATHI, L. Amelogenesis Imperfecta with Nephrocalcinosis: A Rare Association in Siblings. The Cureus Journal of Medical Science, v. 11, n. 7, p. e5060, 2019.

SANTOS, C., T., D; PICINI, C.; CZLUSNIAK, G., D.; ALVES, F., B., T. Anomalias do esmalte dentário - revisão de literatura. ARCHIVES OF HEALTH INVESTIGATION, v. 3, n. 4, 24 nov. 2014.

SIMMER, J., P.; FINCHAM, A., G. Molecular mechanisms of dental enamel formation. Critical Reviews in Oral Biology \& Medicine, v. 6, n. 2, p, 84-108, 1995.

WHITE, S., C.; PHAROAH, M., J. Radiologia Oral Fundamentos e Interpretação. 5. ed. Rio de Janeiro: Elsevier; 2007. 


\title{
CAPITULO $\mathrm{X}$ \\ PROCEDIMENTOS RESTAURADORES EM DENTES COM TRATAMENTO ENDODÔNTICO
}

\author{
DOI: $10.51859 /$ AMPLLA.EPC757.1121-10
}

\author{
Isabele Cristina Alves Costa ${ }^{1}$ \\ Elane Lima Da Silva ${ }^{1}$ \\ Wesley De Souza Pereira ${ }^{2}$ \\ Cíntia Veríssimo De Freitas ${ }^{1}$ \\ Karla Geovanna Ribeiro Brígido ${ }^{3}$ \\ Jandenilson Alves Brígido ${ }^{3}$
}

\begin{abstract}
${ }^{1}$ Graduanda do curso de odontologia do Centro Universitário Fametro - UNIFAMETRO
${ }^{2}$ Graduando do curso de odontologia do Centro Universitário Fametro - UNIFAMETRO

${ }^{3}$ Docente do curso de odontologia do Centro Universitário Fametro - UNIFAMETRO
\end{abstract}

\section{RESUMO}

O tratamento endodôntico tem como objetivo eliminar microrganismos do canal radicular, enquanto a odontologia restauradora tem a finalidade de recuperar a forma, textura, cor e função, deixando-o similar ao dente hígido. O objetivo desta revisão foi descrever e distinguir os métodos para restabelecer dentes desvitalizados. A pesquisa foi realizada na base de dados das plataformas PubMed, EBSCO e BVS, após aplicados os critérios de inclusão e exclusão, foram selecionados 15 artigos para elaboração deste estudo. As restaurações podem ser realizadas com abordagem direta ou indireta, de forma alternativa e conservadora. Salienta-se, que a qualidade da restauração influencia diretamente no prognóstico do tratamento endodôntico. Ademais, é importante ressaltar, que se faz necessário uma avaliação individualizada, como princípios biomecânicos, carga mastigatória e requisito estético. O êxito do tratamento pode ser comprometido pela perda de estrutura residual e tem como principal falha, a fratura decorrente de cárie secundária ou fratura composta. A seleção dos biomateriais, pinos, núcleos, preparo, tipo de cerâmica, resina composta e propriedade dos materiais são etapas extremamente relevantes no protocolo de reabilitação. Portanto, com o desenvolvimento de novos materiais e métodos restauradores, para uma viável restauração, é necessário determinar requisitos mínimos mecânicos, como estrutura remanescente, material e técnica, com o intuito de adquirir efetividade, adaptação, resistência e longevidade.

Palavras-chave: Restauração dental. Dentes sem vitalidade. Endodontia. 


\section{INTRODUÇÃO}

A terapia endodôntica é realizada quando ocorre um comprometimento da polpa dentária decorrente de uma coroa extensamente destruída em consequência de cáries ou traumas dentários, que promove uma reação inflamatória ou necrose da polpa. Nesse procedimento clínico, as propriedades biomecânicas e estrutura do elemento dentário não vital ficam comprometidas, comparada ao dente vital (ASLAN et al., 2018; DE CARVALHO et al., 2018). A preservação da estrutura dental é de fundamental importância para uma longevidade do tratamento, por estar diretamente atribuída à resistência a fraturas e redução da ocorrência de falhas (MOROTOMI et al., 2019; SOARES et al., 2018).

O material restaurador usado na reabilitação do dente sem vitalidade, proporciona capacidade de dissipar as forças durante a mastigação, diminui o deflexionamento, proporciona estabilidade a longo prazo, sinergismo integrado de adesão entre os materiais restauradores e a estrutura dentária, retenção, suporte e resistência mecânica semelhante ao dente saudável, pois intensifica e reforça a estrutura dental remanescente. Além disso, é importante ressaltar que a quantidade de esmalte e dentina hígido remanescente é um fator primordial na possibilidade da restauração de um dente (GHEORGHIU et al., 2019; MONDELLI et al., 2019; SUKSAPHAR et al., 2018).

A reabilitação de um dente requer uma abordagem interdisciplinar, que envolve diferentes métodos e técnicas para restabelecer a harmonia estética e função, na qual consiste na realização direta ou indireta do procedimento clínico e utilização de sistemas de retenção adicional, denominado pinos de fibra fabricados. São indicados para reconstruir um dente ou pino de metal fundido, usados para retenção dentro da raiz também denominados intraradicular, restaurações com resina composta adesiva, coroa total de porcelana fundida em metal, denominada metalocerâmica ou porcelana pura, conhecida como metalfree, obtidas por meio do desenho assistido por computador / manufatura assistida por computador, popularmente conhecido como sistema tecnológico CAD-CAM (CHISNOIU et al., 2019; FERRARI et al., 2017; PULCINI et al., 2019).

Os dentes tratados endodonticamente tornam-se frágeis, e após o procedimento ficam mais predispostos a fragmentação ou outras complicações, incluindo 
recontaminação. Diante disso, a remoção da polpa coronária e radicular dos dentes, que após o tratamento tornam-se permanentemente desvitalizados, podem ser prejudicados se forem restaurados de maneira inapropriada. A causa mais prevalente na ocorrência de falhas ao reconstituir o sistema estomatognático, é a fratura, pois são forças resultantes ao aplicar uma determinada força sobre um material, também intitulada resistência mecânica, que está diretamente relacionado à quantidade e a condição da dentina saudável residual. Além disso, há uma alteração da cor da estrutura do esmalte dental, decorrente da coloração do material obturador (CHISNOIU et al., 2019; MOUSSA; APARICIO, 2019).

Dessa forma, este estudo teve como objetivo identificar a melhor opção de tratamento para reabilitação de dentes não vitais, por meio de uma revisão de literatura.

\section{REFERENCIAL TEÓRICO}

\subsection{CONDIÇÃO DOS DENTES QUE SÃO SUBMETIDOS AO TRATAMENTO DE ENDODÔNTICO}

Comumente, os elementos que precisam passar por tratamento endodôntico, são dentes que estão acometidos de processos cariosos, fraturas ou lesões. Dentes que possuem tratamento endodôntico apresentam maior fragilidade na sua estrutura em decorrência da redução de umidade da dentina, perda de tecido dentário devido ao processo carioso, extensão de fratura, preparo para o acesso endodôntico, instrumentação dos canais radiculares e o preparo final para cavidade (DE CARVALHO et al., 2018).

Segundo Chisnoiu et al. (2019), a principal causa de falha de uma restauração em um dente não vital é a fratura, tendo uma direta relação com a resistência mecânica e uma correlação com o que resta de dentina saudável. Outro fator importante o qual está relacionado às fraturas, é a diminuição da hidratação da dentina, essa condição acaba criando uma predisposição a falhas.

A fim de alcançar o sucesso de uma restauração duradoura, é necessário que ocorra a preservação de dentina residual, com o intuito de proporcionar uma maior longevidade e resistência a fraturas. Deste modo, é necessário executar uma 
intervenção minimamente invasiva sempre que possível, pois a escolha da restauração após a endodontia irá resultar de uma série de fatores como estética, função, anatomia e a quantidade de remanescente dentário. Um bom planejamento na escolha do melhor método restaurador afeta de forma positiva ou negativa a longevidade do dente tratado (SOARES et al., 2018).

\subsection{MÉTODOS DIRETOS E INDIRETOS DE RESTAURAÇÕES}

Com o avanço da odontologia restauradora, o desenvolvimento de materiais e técnicas adesivas vem aumentando a utilização de restaurações diretas utilizando resina composta. Quando o dente a ser reabilitado ainda possui uma quantidade satisfatória de remanescente e um preparo cavitário realizado de forma menos invasiva, a restauração utilizando compósitos de resina podem ser uma escolha adequada (HILTON et al., 2020).

Dessa maneira, quanto menor é a fratura dentária ou o desgaste estrutural pela doença cárie, maior são as chances de durabilidade da restauração, porém, a manutenção da cor e do brilho da resina independe do tamanho do reparo. Uma das maiores desvantagens do uso deste material nos dentes anteriores é a alteração de cor que a resina pode sofrer com o passar do tempo, por se tratar de uma área estética, esta modificação é um dos pontos negativos apontados pelos pacientes (VAJANI et al., 2020).

A restauração de dentes posteriores feita com resina composta requer um pouco mais de cuidado, por se tratar de elementos que exercem uma maior força durante a mastigação, quaisquer mudanças estruturais que afetem a sua integridade podem ter um grande impacto no seu desempenho mastigatório. Uma correta técnica aliado de um protocolo bem executado pelo profissional é de extrema importância. A grande vantagem deste tratamento é a rapidez do procedimento, baixo custo e o potencial de se alcançar um bom resultado estético (RODRIGUES et al., 2020).

Devido algumas limitações que a técnica direta pode apresentar em dente posterior, uma alternativa viável é a técnica indireta. Esse tipo de restauração é indicado para dentes que possuem uma perda de tecido dental maior, neste tipo de caso a técnica direta não será capaz de suprir as necessidades funcionais e mecânicas. A restauração indireta pode ser confeccionada com resina composta ou cerâmica. $\mathrm{O}$ uso das resinas compostas vem aumentando sua frequência, pela questão econômica, por causa do 
tempo de confecção e custo ser menor comparado aos das cerâmicas (ALVANFOROUSH et al., 2017).

Com o desenvolvimento contínuo dos sistemas adesivos, as resinas compostas e as cerâmicas surgem como um ótimo método restaurador para casos de Inlay ou Onlay. A restauração tipo inlay/onlay tem como principal indicação cavidades extensas e possui contra indicação para pacientes com hábitos para funcionais (DAHER et al., 2021).

\subsection{PINO INTRACANAL}

Os pinos intra-radiculares são utilizados quando existe uma grande destruição coronária devido a extensas lesões cariosas, fraturas dentárias, amplas restaurações e necessidade ou não de elementos protéticos. Sua principal indicação é quando a estrutura dentária coronal é incapaz de suportar o material restaurador. Eles possuem a vantagem de proporcionar uma distribuição mais uniforme das cargas mastigatórias e retém o tipo de restauração de que será escolhida. Atualmente o mercado disponibiliza pinos de diferentes materiais: metálicos, cerâmicos e reforçados por fibras (GHEORGHIU et al., 2019).

Para se fazer uso de um pino intrarradicular é necessário fazer uma avaliação criteriosa e avaliar uma série de fatores como: quantidade de estrutura dentária íntegra, oclusão, localização e estética, que irão influenciar diretamente na escolha do melhor material. Incisivos, caninos e pré-molares recebem cargas laterais ou de cisalhamento, e os molares recebem cargas verticais. Dentes anteriores geralmente são indicados pinos pré-fabricados por se tratar de uma área estética, e frequentemente o escolhido é a fibra de vidro. Os pinos fundidos são usualmente selecionados para os molares, por se tratar de dentes que recebem um alto estresse mastigatório (CHISNOIU et al., 2019).

Os núcleos metálicos fundidos necessitam no mínimo $1 \mathrm{~mm}$ de remanescente coronário para sua confecção e são combinados com coroas protéticas para a reabilitação. Os retentores pré-fabricados precisam de no mínimo $2 \mathrm{~mm}$ de estrutura da porção coronal, podendo ser combinados no processo restaurador com resina composta ou prótese fixa. A escolha de um bom cimento, controle de umidade, fotopolimerização adequada e a correta execução do procedimento pelo profissional, é essencial para a fixação dos pinos. Um protocolo bem executado, aliado a condições favoráveis dos dentes, contribuem para a sua conservação (ASLAN et al., 2018). 
O uso de pinos pode sofrer limitações devido às alterações na raiz, calcificações radiculares, alteração no formato e diâmetro das raízes. Além do mais, durante o processo de preparo das raízes pode levar ao risco de perfurações e fraturas. Nesses casos, uma alternativa que está sendo utilizada é a coroa do tipo Endocrown (ELASHMAWY et al., 2020).

\subsection{COROAS PROTÉTICAS}

Quando há um comprometimento grande da porção coronária dos dentes, em muitos casos chegando a níveis subgengivais, restaurações com resina composta não é o melhor tratamento a ser usado, as coroas totais de porcelana fundida em metal (metalocerâmicas) ou porcelanas puras (metalfree) são as mais indicadas. A coroa do tipo metal free é frequentemente usada em dentes anteriores, pelo fato de possuir uma alta resistência, translucidez e durabilidade. A principal contraindicação das coroas de porcelana pura é os hábitos para funcionais. Próteses fixas que possuem a combinação de metal com porcelana são indicadas para esse tipo de paciente (FERRARI et al., 2017).

A coroa adesiva do tipo endocrown surge como uma técnica alternativa para molares tratados endodonticamente, que possuem destruição de suas estruturas, restrições anatômicas para os usos de pinos e limitação interoclusal. É uma coroa parcial com cobertura oclusal que pode ser confeccionada em resina composta ou cerâmica. Esse tipo de restauração é caracterizado por possuir uma retenção através das paredes internas da câmara pulpar e são cimentadas com cimentos resinosos. Esta técnica proporciona uma preservação da estrutura dentária, devido ao fato de não precisar realizar preparos nos condutos. As contraindicações principais para a endocrown são: câmara pulpar inferior a 3 milímetros, margem cervical inferior a 2 milímetros e quando a adesão não pode ser certificada (KANAT et al., 2018; LIN et al., 2020).

\section{METODOLOGIA}

Inicialmente foram realizados estudos a partir de acervos virtuais, reunindo artigos encontrados em diferentes bases de dados. Após pesquisa preliminar os estudos foram elencados e categorizados de acordo com sua relevância e relação com o tema estudado. 
A definição dos descritores foi feita com fundamentação na plataforma DeCS (Descritores em Ciências da Saúde) onde ficaram estabelecidos os seguintes descritores: "Restoration", "Non-vital tooth" e "Endodontics", que foram agregados por meio do operador boleano "and" e aplicados nas bases de dados PubMed, EBSCO e BVS. Foram utilizados como critério de inclusão: artigos completos, nos idiomas inglês e português, publicados nos últimos cinco anos. Por outro lado, foram descartadas produções do tipo editorial, resumo e que não estavam de acordo com o tema.

Um fichamento foi elaborado para a organização das publicações contendo as seguintes informações: autor principal; ano; local do estudo; tipo de estudo; amostra; objetivos e principais achados.

\section{RESULTADOS E DISCUSSÃO}

Após a aplicação dos critérios de elegibilidade foram selecionados um total de 15 artigos (Tabela 1), dos quais 1 foi ensaio clínico prospectivo, 1 revisão crítica, 3 revisões sistemáticas, 1 relato de caso, 1 estudo de simulação, 3 Estudos in vitro, 3 estudos transversais e 2 ensaios clínicos controlados.

Tabela 1. Artigos selecionados na busca eletrônica.

\begin{tabular}{|c|c|c|c|c|}
\hline AUTOR/ANO & $\begin{array}{l}\text { TIPO DE } \\
\text { ESTUDO }\end{array}$ & OBJETIVOS & AMOSTRA & PRINCIPAIS ACHADOS \\
\hline $\begin{array}{l}\text { DAHER et al., } \\
2021\end{array}$ & $\begin{array}{l}\text { Ensaio in } \\
\text { vitro }\end{array}$ & $\begin{array}{l}\text { Avaliar a resistência } \\
\text { de molares } \\
\text { tratados } \\
\text { endodonticamente } \\
\text { às fraturas em } \\
\text { cavidades MOD, } \\
\text { com restaurações } \\
\text { com anéis, onlay e } \\
\text { inlay. }\end{array}$ & 70 molares & $\begin{array}{l}\text { Os anéis de reforço } \\
\text { apresentaram resistência } \\
\text { semelhante às onlays e inlays, } \\
\text { possuindo fraturas reparáveis. }\end{array}$ \\
\hline $\begin{array}{l}\text { RODRIGUES et } \\
\text { al., } 2020\end{array}$ & $\begin{array}{c}\text { Estudo } \\
\text { clínico } \\
\text { transversal }\end{array}$ & $\begin{array}{l}\text { Avaliar a perda de } \\
\text { estruturas } \\
\text { dentárias e se este } \\
\text { fator compromete } \\
\text { a força } \\
\text { mastigatória de } \\
\text { molares. }\end{array}$ & $\begin{array}{c}3 \text { pacientes } \\
\text { com } 9,10 \text { e } \\
12 \text { anos de } \\
\text { idade }\end{array}$ & $\begin{array}{l}\text { Quando a dor é removida a força } \\
\text { de mordida é maior, aumentando } \\
\text { assim a possibilidade de fratura, já } \\
\text { que o dente está estruturalmente } \\
\text { menos resistente, então torna-se } \\
\text { necessário a restauração endo- } \\
\text { dôntica. A condição da polpa pode } \\
\text { ser o fator mais relevante da força } \\
\text { de mordida e não a perda de } \\
\text { estrutura dental. }\end{array}$ \\
\hline
\end{tabular}




\begin{tabular}{|c|c|c|c|c|}
\hline AUTOR/ANO & $\begin{array}{l}\text { TIPO DE } \\
\text { ESTUDO }\end{array}$ & OBJETIVOS & AMOSTRA & PRINCIPAIS ACHADOS \\
\hline LIN et al., 2020 & $\begin{array}{l}\text { Estudo de } \\
\text { simulação }\end{array}$ & $\begin{array}{l}\text { Avaliar molares } \\
\text { tratados } \\
\text { endodonticamente } \\
\text { e restaurados com } \\
\text { endocrown ou com } \\
\text { pinos e analisar as } \\
\text { tensões em sua } \\
\text { porção radicular. }\end{array}$ & 1 molar & $\begin{array}{l}\text { Os molares que foram } \\
\text { restaurados com endocrown } \\
\text { apresentaram maior } \\
\text { resistência à fratura do que os } \\
\text { dentes com pinos, visto que os } \\
\text { dentes possuíam uma coroa } \\
\text { extensamente destruída, } \\
\text { podendo ser explicado pela } \\
\text { diminuição das tensões na } \\
\text { parede interna do canal } \\
\text { radicular. }\end{array}$ \\
\hline $\begin{array}{l}\text { ELASHMAWY et } \\
\text { al., } 2020\end{array}$ & $\begin{array}{l}\text { Estudo in } \\
\text { vitro }\end{array}$ & $\begin{array}{c}\text { Avaliar se a carga a } \\
\text { fadiga influencia na } \\
\text { resistência de } \\
\text { molares com } \\
\text { restaurações } \\
\text { endocrowns e } \\
\text { tratados } \\
\text { endodonticamente. }\end{array}$ & $\begin{array}{l}40 \text { primeiros } \\
\text { molares } \\
\text { inferiores }\end{array}$ & $\begin{array}{l}\text { A cerâmica é um material } \\
\text { adequado para escolha de } \\
\text { restaurações endocrowns, } \\
\text { sendo a polifiltrada bem } \\
\text { adequada, pois ainda possui a } \\
\text { capacidade de ser restaurada } \\
\text { em caso de falha. As cerâmicas } \\
\text { reforçadas com dissilicato de } \\
\text { lítio apresentam alta } \\
\text { resistência mecânica sendo } \\
\text { uma excelente opção para } \\
\text { restaurações endocrowns. }\end{array}$ \\
\hline $\begin{array}{l}\text { HILTON et al., } \\
2020\end{array}$ & $\begin{array}{l}\text { Estudo } \\
\text { clínico } \\
\text { transversal }\end{array}$ & $\begin{array}{l}\text { Analisar dentes } \\
\text { posteriores } \\
\text { fissurados e } \\
\text { identificar qual a } \\
\text { melhor forma de } \\
\text { tratá-los. }\end{array}$ & $\begin{array}{c}2858 \\
\text { pacientes } \\
\text { participaram } \\
\text { da pesquisa }\end{array}$ & $\begin{array}{l}\text { Muitos fatores influenciam na } \\
\text { decisão de restaurar ou apenas } \\
\text { acompanhar um dente, fatores } \\
\text { como; cáries, quantidade de } \\
\text { estrutura remanescente ou } \\
\text { fissuras visíveis. Um dente } \\
\text { trincado deve ser tratado com } \\
\text { a colocação de uma } \\
\text { restauração, sendo a de } \\
\text { escolha uma coroa completa. }\end{array}$ \\
\hline $\begin{array}{l}\text { VAJANI et al., } \\
2020\end{array}$ & $\begin{array}{c}\text { Revisão } \\
\text { sistemática }\end{array}$ & $\begin{array}{l}\text { Avaliar se a } \\
\text { restauração direta } \\
\text { apresenta bons } \\
\text { resultados clínicos } \\
\text { na reabilitação de } \\
\text { dentes } \\
\text { desgastados. }\end{array}$ & $\begin{array}{l}1472 \\
\text { estudos }\end{array}$ & $\begin{array}{l}\text { Faltaram evidências para } \\
\text { afirmar qual o melhor método } \\
\text { restaurador de dentes } \\
\text { desgastados, porém a } \\
\text { restauração de resina } \\
\text { composta direta mostra-se } \\
\text { minimamente invasiva, e as } \\
\text { taxas de sucesso clínico da } \\
\text { resina composta híbrida direta } \\
\text { a curto e médio prazo são } \\
\text { positivos, isso aprova o seu uso } \\
\text { para a restauração de dentes } \\
\text { desgastados. }\end{array}$ \\
\hline
\end{tabular}




\begin{tabular}{|c|c|c|c|c|}
\hline AUTOR/ANO & $\begin{array}{l}\text { TIPO DE } \\
\text { ESTUDO }\end{array}$ & OBJETIVOS & AMOSTRA & PRINCIPAIS ACHADOS \\
\hline $\begin{array}{l}\text { PULCINI et al., } \\
2019\end{array}$ & $\begin{array}{l}\text { Relato de } \\
\text { caso clínico }\end{array}$ & $\begin{array}{l}\text { Apresentar o } \\
\text { tratamento } \\
\text { restaurador de um } \\
\text { pré-molar superior } \\
\text { cariado e sem } \\
\text { vitalidade }\end{array}$ & $\begin{array}{l}\text { Paciente } \\
\text { feminino } 45 \\
\text { anos de } \\
\text { idade }\end{array}$ & $\begin{array}{l}\text { As propriedades dos materiais } \\
\text { são muito importantes para a } \\
\text { reabilitação estética e e } \\
\text { funcional é necessário ter uma } \\
\text { translucidez adequada, } \\
\text { facilidade da fresagem, } \\
\text { cimentação simples com } \\
\text { adesivos os cimentos comuns. } \\
\text { O sistema CAD-CAM } \\
\text { apresenta-se confiável para } \\
\text { reabilitações protéticas }\end{array}$ \\
\hline $\begin{array}{l}\text { CHISNOIU et al., } \\
2019\end{array}$ & $\begin{array}{l}\text { Estudo } \\
\text { clínico } \\
\text { transversal }\end{array}$ & $\begin{array}{l}\text { Analisar qual a } \\
\text { preferência dos } \\
\text { dentistas nas } \\
\text { técnicas de } \\
\text { reconstrução de } \\
\text { dentes não vitais. }\end{array}$ & 35 dentistas & $\begin{array}{l}\text { Os pinos e os núcleos fundidos } \\
\text { são as reconstruções mais } \\
\text { utilizadas para dentes tratados } \\
\text { endodon-ticamente. }\end{array}$ \\
\hline $\begin{array}{l}\text { MONDELLI et } \\
\text { al., } 2019\end{array}$ & $\begin{array}{l}\text { Estudo } \\
\text { clínico } \\
\text { controlado }\end{array}$ & $\begin{array}{l}\text { Avaliar a } \\
\text { resistência a } \\
\text { fraturas do efeito } \\
\text { chanfrado em } \\
\text { restaurações classe } \\
\text { II em dentes } \\
\text { posteriores do tipo } \\
\text { MOD. }\end{array}$ & $\begin{array}{l}90 \text { pré- } \\
\text { molares }\end{array}$ & $\begin{array}{l}\text { O chanfro preparado no ângulo } \\
\text { cavo-superficial aumentou a } \\
\text { resistência às fraturas de } \\
\text { dentes com ou sem } \\
\text { tratamento endodôntico }\end{array}$ \\
\hline $\begin{array}{l}\text { CARVALHO et } \\
\text { al., } 2018\end{array}$ & $\begin{array}{l}\text { Revisão } \\
\text { crítica }\end{array}$ & $\begin{array}{l}\text { Apresentar o } \\
\text { conhecimento } \\
\text { atual sobre os } \\
\text { adesivos utilizados } \\
\text { nas restaurações } \\
\text { de dentes tratados } \\
\text { endodonticamente, } \\
\text { com grandes e } \\
\text { pequenas perdas } \\
\text { das estruturas } \\
\text { dentárias. }\end{array}$ & 103 estudos & $\begin{array}{l}\text { O grupo do pino moldado } \\
\text { exibe resistência à fratura } \\
\text { significativamente maior do } \\
\text { que o grupo pós-fibra de vidro. } \\
\text { O estudo fornece evidências de } \\
\text { que os pinos não são } \\
\text { necessários para reter coroas / } \\
\text { endocrowns e que eles podem } \\
\text { estar até associados a taxas de } \\
\text { falhas. }\end{array}$ \\
\hline $\begin{array}{l}\text { ASLAN et al., } \\
2018\end{array}$ & $\begin{array}{l}\text { Estudo } \\
\text { clínico } \\
\text { controlado }\end{array}$ & $\begin{array}{l}\text { Avaliar } \\
\text { restaurações feitas } \\
\text { em dentes tratados } \\
\text { endodonticamente } \\
\text { por diferentes } \\
\text { técnicas e } \\
\text { comparar sua } \\
\text { resistência à } \\
\text { fratura. }\end{array}$ & $\begin{array}{l}105 \text { pré- } \\
\text { molares }\end{array}$ & $\begin{array}{l}\text { Os grupos } \\
\text { submetidos ao tratamentários } \\
\text { com pino de fibra } \\
\text { apresentaram } \\
\text { resistência que os dentes } \\
\text { restaurados apenas com resina } \\
\text { composta, porém não houve } \\
\text { diferença significativa entre os } \\
\text { pinos de } 10 \text { e } 5 \mathrm{~mm} \text { de } \\
\text { comprimento em termos de } \\
\text { resistência à fratura. }\end{array}$ \\
\hline
\end{tabular}




\begin{tabular}{|c|c|c|c|c|}
\hline AUTOR/ANO & $\begin{array}{l}\text { TIPO DE } \\
\text { ESTUDO }\end{array}$ & OBJETIVOS & AMOSTRA & PRINCIPAIS ACHADOS \\
\hline $\begin{array}{l}\text { KANAT et al., } \\
2018\end{array}$ & $\begin{array}{l}\text { Estudo in } \\
\text { vitro }\end{array}$ & $\begin{array}{c}\text { Analisar a } \\
\text { resistência às } \\
\text { fraturas de dentes } \\
\text { com diferentes } \\
\text { profundidades de } \\
\text { preparo. }\end{array}$ & $\begin{array}{c}100 \text { incisivos } \\
\text { centrais }\end{array}$ & $\begin{array}{l}\text { A profundidade do preparo } \\
\text { apresentou grande relevância } \\
\text { na resistência às fraturas } \\
\text { principalmente em } \\
\text { restaurações endocrowns. } \\
\text { materiais cerâmicos de } \\
\text { zircônia apresentaram maiores } \\
\text { valores de resistência à fratura, } \\
\text { e feldspática menores. }\end{array}$ \\
\hline $\begin{array}{l}\text { SUKSAPHAR et } \\
\text { al., } 2018\end{array}$ & $\begin{array}{c}\text { Revisão } \\
\text { sistemática }\end{array}$ & $\begin{array}{l}\text { Investigar a taxa de } \\
\text { sucesso contra } \\
\text { fraturas de dentes } \\
\text { tratados } \\
\text { endodonticamente } \\
\text { com coroas ou } \\
\text { restaurações de } \\
\text { resina composta. }\end{array}$ & $\begin{array}{c}366 \text { estudos } \\
\text { relevantes }\end{array}$ & $\begin{array}{l}\text { Ambos métodos de } \\
\text { reabilitação coronária } \\
\text { demonstram sucesso em mais } \\
\text { de } 90 \% \text { dos casos, } \\
\text { principalmente em pequenos } \\
\text { períodos entre } 12 \text { a } 36 \text { meses. } \\
\text { Os pré molares apresentaram } \\
\text { taxas de sucesso maiores que } \\
\text { os molares, isso pode ser } \\
\text { explicado pela diferença da } \\
\text { carga oclusal. }\end{array}$ \\
\hline $\begin{array}{l}\text { Ferrari et al., } \\
2017\end{array}$ & $\begin{array}{c}\text { Ensaio } \\
\text { clínico } \\
\text { prospectivo }\end{array}$ & $\begin{array}{c}\text { Comparar o } \\
\text { desempenho } \\
\text { clínico de } 7 \text { anos do } \\
\text { tratamento com } \\
\text { pino de fibra e } \\
\text { coroas unitárias } \\
\text { com as próteses } \\
\text { fixas. }\end{array}$ & $\begin{array}{c}120 \\
\text { pacientes }\end{array}$ & $\begin{array}{l}\text { As taxas de sobrevida global } \\
\text { apresentaram-se satisfatórias } \\
\text { com } 7 \text { anos nas regiões } \\
\text { posteriores restauradas com } \\
\text { pinos de fibra, coroas unitárias } \\
\text { ou próteses fixas. Dentes } \\
\text { anteriores apresentaram } \\
\text { maiores taxas de falha. A perda } \\
\text { de tecido duro é um fator que } \\
\text { pode comprometer o sucesso } \\
\text { do tratamento. }\end{array}$ \\
\hline $\begin{array}{l}\text { ALVANFOROUSH } \\
\text { et al., } 2017\end{array}$ & $\begin{array}{c}\text { Revisão } \\
\text { sistemática }\end{array}$ & $\begin{array}{l}\text { Comparar o } \\
\text { sucesso clínico das } \\
\text { restaurações em } \\
\text { dentes posteriores } \\
\text { em um período } \\
\text { mínimo de } 24 \\
\text { meses. }\end{array}$ & 70 artigos & $\begin{array}{l}\text { As principais razões para falha } \\
\text { das restaurações, tanto dos } \\
\text { períodos de } 1992 \text { a } 2005 \text { e de } \\
2006 \text { a } 2016 \text { foram cárie } \\
\text { secundária e fratura composta. } \\
\text { Na última década foram } \\
\text { notadas as falhas devido a } \\
\text { necessidade de tratamento } \\
\text { endodôntico e fraturas } \\
\text { dentárias. }\end{array}$ \\
\hline
\end{tabular}

Fonte: Autoria própria.

Os elementos dentais acometidos por processos cariosos, lesões ou fraturas e ainda, pelo tratamento endodôntico em si, apresentam-se com sua estrutura alterada em relação à dentes vitais, fragilizando suas propriedades físicas. $O$ procedimento tem 
como resultado alterações na microestrutura da dentina, e boa parte das fraturas ocorridas após a realização da endodontia são decorrentes da perda de estrutura dentária durante o acesso, instrumentação e preenchimento do canal (SOARES et al., 2018).

Um dos principais fatores que devemos considerar será a qualidade da dentina remanescente. A perda da polpa gera uma diminuição considerável no nível de hidratação da dentina, diminuindo suas propriedades mecânicas e ocasionando um ambiente propício a fraturas (SOARES et al., 2018). De acordo com Alvanforoush (2017), temos como principais causadores de falha dos tratamentos restauradores a fratura dentária, necessidade de tratamento endodôntico e a presença de cárie secundária.

O sucesso da restauração inicia-se pela qualidade do procedimento endodôntico utilizado, o qual deve ser realizado de forma minimamente invasiva, preservando o máximo de estrutura dental possível. A partir disso, a escolha do material adequado a cada caso, levando em consideração fatores estéticos, físico-químicos, como biocompatibilidade, função e anatomia, irão influenciar no sucesso da restauração (SOARES et al., 2018).

Para os dentes que se apresentem com pouca ou moderada perda tecidual, é recomendado o uso de restauração em resina composta, devido à grande durabilidade da técnica. Já para dentes que apresentem uma destruição mais severa de sua estrutura, pode-se também fazer uso de incrementos de resina, devido ao avanço de sua performance clínica, entretanto, opta-se mais comumente por coroas cerâmicas, muitas vezes associadas à instalação de pinos, sendo preferíveis os pinos de fibra de vidro para restaurações em dentes anteriores e em área estética, e pinos fundidos em dentes posteriores, que possuem maior carga mastigatória (SUKSAPHAR et al., 2018; ALVANFOROUSH et al., 2017).

\section{CONSIDERACÕES FINAIS}

Com o desenvolvimento de novos materiais e alternativas restauradoras, para uma viável restauração é necessário determinar requisitos mínimos mecânicos, como estrutura remanescente, material e técnica, com o intuito de adquirir efetividade, adaptação, resistência e longevidade. Cada paciente deve receber um tratamento individualizado de acordo com as suas necessidades. 


\section{REFERÊNCIAS}

ALVANFOROUSH, N. et al. Comparison between published clinical success of direct resin composite restorations in vital posterior teeth in 1995-2005 and 2006-2016 periods. Aust Dent J, v. 62, n. 2, p. 132-145, 2017.

ASLAN, T. et al. Evaluation of fracture resistance in root canal-treated teeth restored using different techniques. Nigerian Journal of Clinical Practice, v. 21, n. 6, p. 795-800, 2018.

CHISNOIU, A. et al. Dentists' perspectives on the reconstruction possibilities of a nonvital tooth. Medicine and Pharmacy Reports, v. 92, n. 4, p. 387-392, 2019.

DAHER, R. et al. Fracture strength of non-invasively reinforced MOD cavities on endodontically treated teeth. Odontology, v. 109, n. 2, p. 368-375, 2021.

DE CARVALHO, M. A. et al. Current options concerning the endodontically-treated teeth restoration with the adhesive approach. Brazilian Oral Research, v. 32, p. 147158, 2018.

ELASHMAWY, Y. et al. Influence of fatigue loading on fracture resistance of endodontically treated teeth restored with endocrowns. J Prosthodont Rest, v. 65, n.1, p. 78-85, 2021.

FERRARI, M. et al. Post-Retained Single Crowns versus Fixed Dental Prostheses: A 7-Year Prospective Clinical Study. Journal of Dental Research, v. 96, n. 13, p. 1490-1497, 2017.

GHEORGHIU, I. M. et al. The use of endodontic posts in odontal restorations of non-vital teeth. ORL.ro, v. 3, n. 44, p. 36, 2019.

HILTON, T. J. et al. Recommended treatment of cracked teeth: Results from the National Dental Practice-Based Research Network. J Prosthet Dent, v. 123, n. 1, p. 71-78, 2020.

KANAT-ERTÜRK, B. et al. Fracture strengths of endocrown restorations fabricated with different preparation depths and CAD/CAM materials. Dental Materials Journal, v. 37, n. 2, p. 256-265, 2018.

LIN, J. et al. Effect of different restorative crown design and materials on stress distribution in endodontically treated molars: a finite element analysis study. BMC Oral Health, v. 20, n. 1, p 226, 2020.

MONDELLI, J. et al. Assessment of a conservative approach for restoration of extensively destroyed posterior teeth. Journal of Applied Oral Science, v. 27, p. 1-7, 2019.

MOROTOMI, T.; WASHIO, A.; KITAMURA, C. Current and future options for dental pulp therapy. Japanese Dental Science Review, v. 55, n. 1, p. 5-11, 2019. 
MOUSSA, D. G.; APARICIO, C. Present and future of tissue engineering scaffolds for dentin-pulp complex regeneration. Journal of Tissue Engineering and Regenerative Medicine, v. 13, n. 1, p. 58-75, 2019.

PULCINI, M. G. et al. Single tooth prosthetic restoration through surgical crown lengthening, conservative therapies and cad-cam milled restoration in lithiumdisilicate: A case report. Acta Stomatologica Croatica, v. 53, n. 4, p. 371-378, 2019.

RODRIGUES, M. P. et al. Direct resin composite restoration of endodontically-treated permanent molars in adolescents: bite force and patient-specific finite element analysis. J Appl Oral Sci, 2020.

SOARES, C. J. et al. How biomechanics can affect the endodontic treated teeth and their restorative procedures? Brazilian Oral Research, v. 32, p. 169-183, 2018.

SUKSAPHAR, W. et al. Survival Rates from Fracture of Endodontically Treated Premolars Restored with Full-coverage Crowns or Direct Resin Composite Restorations: A Retrospective Study. Journal of Endodontics, v. 44, n. 2, p. 233-238, 2018.

VAJANI, D. et al. Direct Composite Resin for the Management of Tooth Wear: A Systematic Review. Clin Cosmet Investig Dent, v. 12, p.465-475, 2020. 


\title{
CAPITULO XI \\ MATERIAIS CERÂMICOS APLICADOS EM ODONTOLOGIA
}

DOI: 10.51859/AMPLLA.EPC757.1121-11

\author{
Rafaela Alves Castro ${ }^{1}$ \\ Geórgia Moura de Souza Martins ${ }^{1}$ \\ Mauro Wilker Cruz de Azevedo ${ }^{2}$ \\ Karla Geovanna Ribeiro Brígido ${ }^{3}$ \\ Jandenilson Alves Brígido ${ }^{3}$
}

\begin{abstract}
${ }^{1}$ Graduanda do curso de Odontologia - Centro Universitário Fametro - UNIFAMETRO
${ }^{2}$ Graduando do curso de Odontologia - Centro Universitário Fametro - UNIFAMETRO

${ }^{3}$ Docente do curso de Odontologia - Centro Universitário Fametro - UNIFAMETRO
\end{abstract}

\section{RESUMO}

Nas últimas décadas houve uma crescente busca por procedimentos estéticos no consultório odontológico, em que os pacientes almejam uma perfeita harmonia do sorriso. Dessa forma, o crescimento das preocupações relacionadas à estética do paciente, levou a popularização dos materiais cerâmicos odontológicos. O objetivo do presente trabalho foi fornecer uma visão geral das cerâmicas contemporâneas mais comuns em odontologia, abordando seus benefícios e limitações. Trata-se de uma revisão de literatura narrativa, em que foram realizadas buscas bibliográficas no PubMed e EBSCOhost, publicadas nos últimos 5 anos, sendo selecionados 16 artigos para esta revisão. As restaurações cerâmicas foram aperfeiçoadas, visando a biocompatibilidade, durabilidade e a desenvoltura estética do paciente. As microestruturas, propriedades e composições dos materiais cerâmicos apontam indicações clínicas de inúmeras classes de cerâmicas odontológicas. Algumas características desvantajosas impedem o amplo uso por sua baixa tenacidade à fratura, uma vez que quando são usadas em próteses fixas extensas, apresentam imensa ameaça de sofrerem lascamento. Diante desse contexto, as cerâmicas contemporâneas mais comuns utilizadas em odontologia são a zircônia e o dissilicato de lítio, apresentando grandes propriedades estéticas. Faz-se necessário conhecer suas características e detalhes técnicos para saber quando indicar, pois cada tipo de material cerâmico tem suas próprias vantagens e limitações, sendo responsabilidade do clínico orientar o paciente sobre qual material atenderá às suas necessidades funcionais e estéticas.

Palavras-chave: Porcelana odontológica. Cerâmica. Odontologia. 


\section{INTRODUÇÃO}

No início do século XVII a porcelana surgiu no continente Europeu, e logo após a cerâmica foi introduzida na odontologia, substituindo as dentaduras de marfim. 0 primeiro conjunto completo de dentaduras em porcelana foi criado em 1774 e em 1886 foram introduzidas na odontologia as inlays, onlays e coroas de porcelana, resultando na criação de restaurações de cerâmica funcionais e também estéticas (ZHANG et al., 2017).

Nas últimas décadas, observa-se a crescente busca por procedimentos estéticos no consultório odontológico, em que os pacientes almejam uma perfeita harmonia do sorriso, atentando-se para o tamanho dos dentes, sua forma e coloração, passando a procurar por tratamentos restauradores minimamente invasivos, em que se tenha pouco ou nenhum desgaste dentário, como a busca por facetas e coroas cerâmicas (WIERICHS et al., 2021).

$\mathrm{Na}$ odontologia moderna, estamos cercados por uma infinidade de materiais restauradores cerâmicos, que estão disponíveis no mercado odontológico, fazendo com que o processo de escolha desses materiais seja mais desafiador para o cirurgiãodentista restaurador. Assim, o crescimento das preocupações relacionadas à estética do paciente, levou a popularização dos materiais cerâmicos odontológicos (MOSHAVERINIA, 2020).

A cerâmica odontológica é o material mais semelhante ao tecido dentário natural, e possui ampla durabilidade, rigidez, resistência e propriedades estéticas. Apresenta, ainda, capacidade de reproduzir fenômenos ópticos observados na estrutura dental como a fluorescência, opalescência, translucidez e opacidade (SAHIN et al., 2019).

É evidenciado a importância de conhecer os parâmetros que direcionam à escolha da cerâmica, como a localização da restauração em anterior ou posterior; o desenho clínico; forças oclusais esperadas; translucidez, combinando assim, os fatores que determinarão uma boa escolha que suprirá a necessidade estética e funcional do elemento reabilitado (MOSHAVERINIA, 2020).

Uma das cerâmicas mais utilizadas na odontologia é a zircônia, que foi descoberta pelos ortopedistas e tempos depois passou a ser estudada pelos cirurgiões- 
dentistas, que explanaram suas vantagens como material protético em odontologia, sendo hoje a principal cerâmica usada para substituir a maioria das restaurações metalocerâmicas (DE MENDONÇA et al., 2017).

Com o aumento das buscas por restaurações cada vez mais estéticas, a utilização do sistema baseado em zircônia de fabricação auxiliada por computador CAD/CAM se tornou uma excelente alternativa ao sistema metalocerâmica, pois, além de proporcionar restaurações totalmente livres de metais, apresentam boas propriedades mecânicas, sem causar danos à saúde gengival, evitando inflamações e retrações de partes moles. Dentre as principais desvantagens das restaurações à base de zircônia está a alta prevalência de lascamentos de material de estratificação (TEICHMANN et al., 2018).

A porcelana dentária é bastante utilizada para realizar restaurações metalocerâmica e cerâmica pura, por suas ótimas qualidades em biocompatibilidade. A restauração com cerâmica pura, em coping de zircônia, executada por CAD/CAM sobreposta à porcelana estratificada, vem sendo abundantemente utilizada, apresentando a mesma igualdade de resistência mecânica quando comparada às porcelanas que são fundidas com coroas em metal (NAKAMURA et al., 2019).

Apesar da ótima performance de onlays e coroas de metal, devido a sua aparência não muito convidativa, faz com que o paciente não deseje optar por esse procedimento na hora de escolhê-los. Nos últimos anos, todas as restaurações de cerâmica se tornaram muito comuns e usadas corriqueiramente nos consultórios odontológicos. Cerâmicas contemporâneas vêm sendo utilizadas constantemente para a restauração dos dentes com inlays, onlays, coroas ou inclusive podendo-se utilizar próteses parcialmente fixas (ABDUO et al., 2018).

Somando-se ainda, deve ser levada em consideração a longevidade de uma cerâmica pura, que se baseia pela sua resistência e durabilidade do complexo de adesão entre três componentes: a superfície do dente, cimento resinoso e material cerâmico. Assim, é formada uma alta resistência de união entre o dente e a cerâmica, quando é cimentada por um material resinoso (KARAGOZ-YILDIRAK; GOZNELI, 2020).

Contudo, a presença de diferentes fases na composição da cerâmica, aliado aos processos de fabricação proporcionou ao dentista uma variedade de materiais de escolha, como cerâmicas vítreas e cerâmicas policristalinas, sendo a zircônia e o 
dissilicato de lítio os mais utilizados (MOSHAVERINIA, 2020). Dessa forma, o objetivo desse trabalho foi fornecer uma visão geral das cerâmicas contemporâneas mais comuns utilizadas em odontologia, abordando seus benefícios e limitações.

\section{METODOLOGIA}

Este estudo apresenta uma revisão de literatura narrativa, em que foram realizadas buscas bibliográficas no portal eletrônico PubMed e base de dados Ebsco Host, utilizando os descritores "Dental Porcelain"; "Dental Ceramic"; "All-Ceramic"; "Dentistry", associados ao operador booleano "AND".

Os critérios de inclusão para esta revisão foram: estudos publicados nos últimos cinco anos; estudos disponíveis na íntegra; estudos de língua portuguesa e inglesa; estudos clínicos, retrospectivos, in vitro, transversais, comparativos, analíticos, observacional, qualitativo, quantitativo, relatos de caso; e revisões sistemáticas. Já os critérios de exclusão foram: revisões narrativas, teses, dissertações, monografias; artigos duplicados e estudos não pertinentes ao tema.

\section{RESULTADOS E DISCUSSÃO}

Após buscas bibliográficas, gerou-se um total de 305 publicações, distribuídas pela PubMed (165), EBSCOHost (136) e busca manual nas referências dos artigos (4), em que foi efetuada a leitura de títulos e resumos, sendo selecionados 23 estudos. Assim, foi realizada a leitura dos artigos na íntegra e com base nos critérios de elegibilidade estabelecidos, excluiu-se 7 e foram selecionados 16 artigos para compor este estudo (Figura 1). 
Figura 1 - Fluxograma dos artigos encontrados.

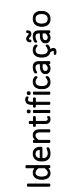

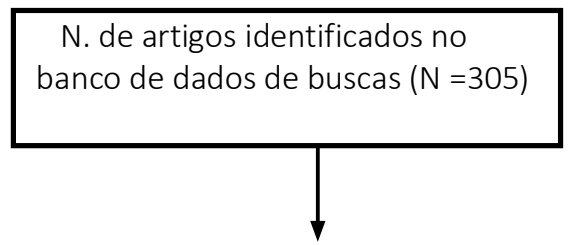

$\frac{2 \pi}{\stackrel{w}{N}}$

N. de artigos excluídos após leitura de títulos e resumos ( $\mathrm{N}$ $=282$ )

$\frac{0}{0}$
$\frac{\pi}{0}$
$\frac{0}{\overline{0}}$
$\frac{0}{00}$
$\frac{0}{w}$

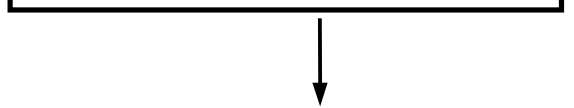

N. de artigos em texto completo avaliados para elegibilidade $(\mathrm{N}=23)$

꼬ำ

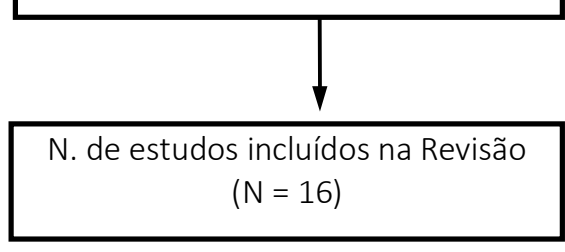

N. de artigos em texto completo excluídos $(\mathrm{N}=$ 7)

Fonte: Autoria própria.

Dos 16 estudos selecionados, 8 são estudos in vitro, 4 revisões sistemáticas, 3 estudos prospectivos e 1 estudo retrospectivo, publicados entre os anos de 2016 e 2021 (Tabela 1).

Tabela 1 - Artigos selecionados para revisão de literatura

\begin{tabular}{|c|c|c|}
\hline $\begin{array}{l}\text { AUTOR PRINCIPAL / } \\
\text { ANO }\end{array}$ & TIPO DE ESTUDO & OBJETIVO/TEMÁTICA \\
\hline WIERICHS et al., 2021 & $\begin{array}{l}\text { Estudo de Coorte } \\
\text { Prospectivo } \\
\text { Multicêntrico }\end{array}$ & $\begin{array}{l}\text { Analisar os fatores associados ao sucesso das coroas } \\
\text { totais de cerâmica. }\end{array}$ \\
\hline $\begin{array}{l}\text { BRANDEBURSK et al., } \\
2020\end{array}$ & Estudo in vitro & $\begin{array}{l}\text { Analisar a resistência a cavacos de diferentes estruturas } \\
\text { cerâmicas (monolítica, bicamada e tri-camada). }\end{array}$ \\
\hline $\begin{array}{l}\text { KARAGOZ-YILDIRAK, } \\
2020\end{array}$ & Estudo In vitro & $\begin{array}{l}\text { Avaliar a eficiência de um laser Er:YAG para descolagem, } \\
\text { e as alterações nos valores de resistência de recolocação } \\
\text { de facetas de cerâmica pura, que foram removidas após } \\
\text { a aplicação do laser. }\end{array}$ \\
\hline MOSHAVERINIA, 2020 & $\begin{array}{l}\text { Revisão } \\
\text { sistemática }\end{array}$ & $\begin{array}{l}\text { Fornecer um guia de tomada de decisões para ajudar o } \\
\text { dentista restaurador a escolher o material em cada } \\
\text { situação clínica. }\end{array}$ \\
\hline
\end{tabular}


As cerâmicas odontológicas podem ser amplamente divididas em duas categorias principais com base em sua composição: cerâmicas de vidro, que possui uma fase cristalina, dentro de uma matriz de vidro e pode ser atacada com ácido fluorídrico; e cerâmicas policristalinas, que não contêm uma matriz de vidro e, portanto, não podem ser atacadas com ácido fluorídrico (BUTT et al., 2019).

As restaurações metalocerâmicas policristalinas têm sido usadas com frequência na odontologia protética por muitos anos, devido à sua alta resistência à fratura. No entanto, as restaurações de cerâmica com subestrutura de metal são negativas na aparência estética, especialmente quando usada em restaurações anteriores, em virtude da sua maior refletividade de luz (SAHIN et al., 2019).

Já as cerâmicas de matriz de vidro são utilizadas em diferentes tipos de restaurações dentárias por causa de suas propriedades melhoradas: resistência relativamente alta, translucidez, biocompatibilidade e capacidade de ligação adesiva. Elas são reforçadas por cargas de policristais ou estruturas cristalinas, como a leucita, dissilicato de lítio e alumina (BUTT et al., 2019; KARAGOZ-YILDIRAK; GOZNELI, 2020).

As restaurações cerâmicas são aperfeiçoadas visando a biocompatibilidade, durabilidade e a desenvoltura estética do paciente. As microestruturas, propriedades e composições dos materiais cerâmicos apontam indicações clínicas de inúmeras classes de cerâmicas odontológicas. Outros fatores que podem influenciar na hora de decisão do material são os projetos de restauração, tensões residuais, espessura da camada, forma do dente e condições de contato com o dente (ZHANG et al, 2017).

Algumas características desvantajosas impedem o amplo uso das cerâmicas odontológicas, como a sua baixa tenacidade à fratura, que é quase 10 vezes menor do que a tenacidade dos metais. Isto expressa que, quando são usadas em próteses fixas, apresentam imensa ameaça de sofrerem lascamento. Outra situação desagradável relacionada a esse tipo de restauração, é o alto poder de desgastar o esmalte do dente antagonista, especialmente se sua superfície se encontrar rugosa, e se o paciente apresentar alguns hábitos parafuncionais, como por exemplo o bruxismo (WIERICHS et al., 2021).

A dimensão, os métodos e as condições de lascamento, têm influenciado a determinação de substituir ou reparar de forma completa a restauração, acarretando, maiores problemas e custos financeiros para o paciente. Para se ter uma menor chance 
de acontecer uma fragmentação, é necessário deixar a maior distância entre as estruturas. Além de permitir que o contato oclusal ocorra a pelo menos $0,5 \mathrm{~mm}$ da borda de uma restauração por cerâmica, pode ser o suficiente para que o lascamento seja dominado, o que pode colaborar para que o cirurgião-dentista escolha o material restaurador correto (BRANDEBURSKI et al., 2020).

As cerâmicas mais utilizadas na odontologia são divididas em vítreas (feldspáticas, leucita e dissilicato de lítio), aluminizadas (óxido de alumínio) e zircônia. Apesar da grande disponibilidade de biomateriais cerâmico-cerâmicas no mercado, a experiência clínica tem destacado dois materiais que conseguem atender os princípios mecânicos, estéticos e com facilidade de processamento, são eles: dissilicato de lítio e a zircônia (BUTT et al., 2019; CETIK; VINCENT; ATASH, 2018).

$\mathrm{Na}$ busca por restaurações com maior longevidade uma abordagem minimamente invasiva é essencial, dessa forma a utilização da cerâmica de dissilicato de lítio tem se mostrado uma boa alternativa para situações de erosão, abrasão, correção de dentes mal posicionados ou diastemas (IMBURGIA; CORTELLINI; VALENTI, 2019).

O dissilicato de lítio, cerâmica do grupo de vitrocerâmicas, imita a estética e a força da estrutura dental. Quanto à estética, em $70 \%$ de sua fase cristalina o material de vidro exclusivo refrata a luz naturalmente, assim, as próteses dentárias feitas com essa cerâmica possuem destaque, devido às boas características (GARBOZA, et al., 2016). Quanto à mecânica, possui um reforço estrutural superior, possuindo maior resistência à flexão do que outras cerâmicas associadas, como a feldspática tradicional ou a cerâmica de vidro com leucita. O dissilicato de lítio possui destaque na confecção de próteses usinadas para coroas unitárias, facetas e lentes de contato, graças ao uso do sistema CAD/CAM (ALVES et al., 2016; GARBOZA et al., 2016).

A zircônia é um dos materiais cerâmicos mais utilizados na odontologia, e conhecer suas características e propriedades torna-se necessário para saber quando usá-la em reabilitações dentárias unitárias, parciais ou totais. Em sua característica física não apresenta fase vítrea como às cerâmicas a base de lítio, apresentam somente a fase cristalina, isso determina sua adesividade ao cimento resinoso. Apresenta três fases cristalinas muito distintas, e essas diferenças podem resultar em diferentes propriedades mecânicas como: resistência à flexão, módulo e dureza (MENDONÇA et al., 2017). A cerâmica de zircônia possui elasticidade muito parecida ao aço inoxidável, 
mas é superior quando se trata de biocompatibilidade. Ademais, a atenuação da retenção de placas melhora significativamente a saúde gengival, logo após a utilização de zircônia.

Atualmente, é possível que existam cerca de 50 cerâmicas diferentes de zircônia no mercado odontológico, e por muitas vezes, acabam acarretando em uma dificuldade ao escolher a ideal para cada tratamento (MOSHAVERINIA, 2020). O uso da zircônia melhora a estética, porém apresenta uma alta taxa de lascamento da cerâmica de estratificação. A falha mais comum encontrada em coroas de zircônia é a perda de retenção, que pode ocorrer devido a um erro na retenção da preparação dentária ou na posição na ligação adesiva da resina com a zircônia. Em busca de diminuir esse erro, existem protocolos a seguir, que resultam na combinação de abrasão de leve partículas de ar contendo primer e cimento resinoso (BUTT et al., 2019).

Quando comparamos o dissilicato de lítio e a zircônia, próteses restauradoras com dissilicato de lítio são confeccionadas em menor tempo. Além disso, estudos mostraram que as coroas feitas com dissilicato de lítio em uma configuração anatômica monolítica, são resistentes à fadiga. Em contrapartida, as de zircônia são altamente suscetíveis à carga cíclica em movimento bucal, com falhas precoces no seu folheado (GARBOZA, et al., 2016).

\section{CONSIDERACÕES FINAIS}

As cerâmicas contemporâneas mais comuns utilizadas em odontologia são a zircônia e o dissilicato de lítio, e ambas possuem grandes propriedades estéticas, porém, faz-se necessário conhecer suas características e propriedades para saber quando indicar. Cada tipo de material cerâmico tem suas próprias vantagens e limitações, sendo responsabilidade do clínico orientar o paciente sobre qual material atenderá às suas necessidades funcionais e estéticas.

\section{REFERÊNCIAS}

ABDUO, Jaafar; SAMBROOK, Raelene Jo. Longevity of ceramic onlays: a systematic review. Journal of Esthetic and Restorative Dentistry, [S.L.], v. 30, n. 3, p. 193215, 20 abr. 2018. 
ALVES, M. F. R. P. et al. Propriedades de dissilicato de lítio reforçado com $\mathrm{ZrO}_{2}(3 \mathrm{~mol} \%$ Y2O3), CBECiMat, 2016.

BRANDEBURSKI, Suzane Boa Nova; DELLA BONA, Alvaro. Quantitative and qualitative analyses of ceramic chipping. Journal of The Mechanical Behavior of Biomedical Materials, v. 110, p. 103928, 2020.

BUTT, Kasim et al. Demystifying Modern Dental Ceramics. Primary dental journal, v. 8, n. 3, p. 28-33, 2019.

CETIK, Sibel; VINCENT, Marion; ATASH, Ramin. Effect of cosmetic ceramics on fracture toughness of all-ceramic restorations. Journal of Dentistry (Tehran, Iran), v. 15, n. 3, p. 137, 2018.

DE MENDONÇA, Beatriz Curvello et al. Estudo da composição e caracterização dos cristais de zircônias Y-TZP para Odontologia. Revista Brasileira de Odontologia, v. 74, n. 1, p. 2, 2017.

GARBOZA, Celso Sebastião et al. Influence of surface treatments and adhesive systems on lithium disilicate microshear bond strength. Brazilian Dental Journal, v. 27, p. 458-462, 2016.

IMBURGIA, Mario; CORTELLINI, Davide; VALENTI, Marco. Minimally invasive vertical preparation design for ceramic veneers: a multicenter retrospective follow-up clinical study of 265 lithium disilicate veneers. Int J Esthet Dent, v. 14, n. 3, p. 286-298, 2019.

KARAGOZ-YILDIRAK, Merve; GOZNELI, Rifat. Evaluation of rebonding strengths of leucite and lithium disilicate veneers debonded with an Er: YAG laser. Lasers in medical science, v. 35, n. 4, p. 853-860, 2020.

MOSHAVERINIA, Alireza. Review of the Modern Dental Ceramic Restorative Materials for Esthetic Dentistry in the Minimally Invasive Age. Dental Clinics of North America, v. 64, n. 4, p. 621-631, 2020.

NAKAMURA, Yoshiharu; YAMAMOTO, Takatsugu; SHIGETA, Yuko; OGAWA, Takumi. In vitro investigation of human enamel wear by dental porcelain. Bio-Medical Materials and Engineering, v. 30, n. 4, p. 365-374, 18 set. 2019.

ŞAHIN, Volkan et al. The effect of repetitive firings on the color of an alumina ceramic system with varying ceramic shade and thickness. Journal of Esthetic and Restorative Dentistry, v. 31, n. 5, p. 471-477, 2019.

TEICHMANN, Maren et al. Ten-year survival and chipping rates and clinical quality grading of zirconia-based fixed dental prostheses. Clinical oral investigations, v. 22, n. 8, p. 2905-2915, 2018. 
WIERICHS, R. J. et al. A prospective, multi-center, practice-based cohort study on allceramic crowns. Dental Materials, 2021.

ZARONE, Fernando et al. Fourteen-year evaluation of posterior zirconia-based threeunit fixed dental prostheses: A Prospective clinical study of all ceramic prosthesis. Journal of Dentistry, v. 101, p. 103419, 2020.

ZHANG, Yu; KELLY, J. Robert. Dental Ceramics for Restoration and Metal Veneering. Dental Clinics of North America, v. 61, n. 4, p. 797-819, out. 2017. 


\title{
CAPITULO XII
}

\section{REABILITAÇÃO DENTAL, FACETAS INDIRETAS, COROA TOTAL SOBRE DENTE E IMPLANTE: RELATO DE CASO}

\author{
DOI: 10.51859/AMPLLA.EPC757.1121-12
}

\author{
Sabrina Cunha da Fonseca ${ }^{1}$ \\ Wagner Augusto Domingues ${ }^{2}$ \\ Vagner Vicente Martins ${ }^{3}$ \\ Celso Yamashita ${ }^{4}$ \\ Fernando Henrique Ruppel Osternack ${ }^{5}$
}

\footnotetext{
${ }^{1}$ Doutoranda em Biologia celular e molecular. Programa de pós graduação da Universidade Federal do Paraná.

${ }^{2}$ Graduado em odontologia. Universidade Positivo.

${ }^{3}$ Graduado em odontologia. Universidade Positivo.

${ }^{4}$ Doutor em Dentística Restauradora. Universidade de São Paulo

${ }^{5}$ Doutor em Odontologia/Dentística. Pontifícia Universidade Católica do Paraná
}

\section{RESUMO}

Introdução: A cada dia aumenta a procura pela estética nos consultórios odontológicos um dos materiais que atende bem os requisitos para a estética são os materiais cerâmicos, estes possuem uma excelente biocompatibilidade,estabilidade de cor, baixa condutividade, resistência ao desgaste e tem propriedades físicas e mecânicas adequadas (LOPES et al., 201. DE OLIVEIRA et al., 2018). O objetivo deste trabalho é apresentar um caso clínico o qual engloba uma reabilitação de10 elementos dentre estes possui faceta, coroa sobre dente e coroa sobre implante, com cerâmica feldspatica. Caso clinico: neste trabalho há um relato de caso de reabilitação protética com cerâmica feldspatica em 10 elementos sendo estas facetas, coroas sobre dente e coroa sobre implante. Conclusão:As técnicas utilizadas, preparos para facetas, coroas sobre dentes e coroa sobre implante foram apropriadas para este caso, e juntamente com o material de cerâmica feldspatica trouxeram uma satisfação ao paciente quanto a estética e função.

Palavras-Chave: Facetas dentárias. Laminado cerâmico. Coroa dentária. 


\section{INTRODUÇÃO}

Atualmente se tem uma grande procura pela estética bucal nos consultórios odontológicos, com finalidade de corrigir fraturas, alteração de forma, posicionamento do elemento dentário, e coloração. Um dos pré-requisitos para se ter sucesso é entender as expectativas do seu paciente, explicar as limitações de seu tratamento, realizar o planejamento reverso, fotografias iniciais, enceramento diagnóstico e mockup (LOPES et al., 2015; DE OLIVEIRA et al., 2018; FURTADO et al.,2019).

Com a facilidade da informação, os pacientes chegam ao consultório odontológico buscando um tratamento com um menor tempo de atendimento e uma maior durabilidade. Um material que supre todas estas exigências seriam os laminados cerâmicos. Este apresenta uma estética satisfatória, uma excelente biocompatibilidade, estabilidade de cor, baixa condutividade, resistência ao desgaste e tem propriedades físicas e mecânicas adequadas (DE OLIVEIRA et al., 2018; FURTADO et al.,2019).

Segundo GOMES et al., 2008, as cerâmicas odontológicas são compostas por elementos metálicos (alumínio, cálcio, lítio, magnésio, potássio, sódio, lantânio, estanho, titânio e zircônio) e substâncias não metálicas (silício, boro, flúor e oxigênio), são caracterizadas por duas fases: uma fase cristalina circundada por uma fase vítrea. A matriz vitrosa é composta por uma cadeia básica de óxido de silício (SiO4), sendo que a proporção Si: O está relacionadacom a viscosidade e expansão térmica da porcelana. Já a quantidade e natureza da fase cristalina ditam as propriedades mecânicas e ópticas. Além disso, a formulação da porcelana deve ser feita de modo a apresentar propriedades, como fundibilidade, moldabilidade, injetabilidade, usinabilidade, cor, opacidade, translucidez, resistência à abrasão, resistência e tenacidade à fratura. Podese classificar as cerâmicas dentais pelas fases, a fase cristalina em feldspatica reforçada por leucita, aluminizada, com alto conteúdo de alumina, de zircônia e espinélio infiltrada por vidro, a fase cerâmica vítrea e alumina densamente sinterizada.

Nesta reabilitação iremos utilizar a cerâmica feldspatica, tanto nos preparos das facetas como nas coroas sobre dente e sobre implantes. Aporcelana feldspática é definida como um vidro, composta por feldspato de potássio ( $\mathrm{K} 2$ O. Al2 O3.6SiO2) e pequenas adições de quartzo ( $\mathrm{SiO} 2)$, sendo que em altas temperaturas, o feldspato decompõe-se numa fase vítrea com estrutura amorfa e numa fase cristalina constituída 
de leucita (KAISi2 O6 ou K2 O. Al2 O3 .4SiO2). Pode ser classificada de acordo com sua temperatura de fusão em: porcelana de alta fusão (>1300 ำ), média fusão (1101-

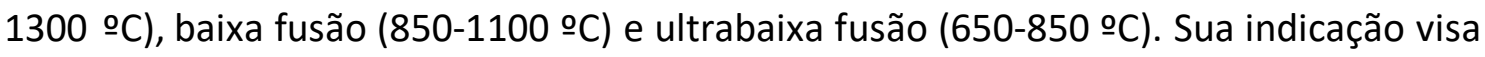
à confecção de coroas de jaqueta de diversos tipos (camada de opaco, corpo de dentina, dentina gengival, overlay de esmalte e esmalte incisal), restaurações metalocerâmicas e totalmente cerâmicas com baixo conteúdo de leucita (coroas, inlays, onlays e facetas laminadas) (GOMES et al., 2008; DE OLIVEIRA et al., 2018).

O objetivo deste trabalho é apresentar um caso clinico o qual engloba uma reabilitação de 10 elementos dentre estes possui faceta, coroa sobre dente e coroa sobre implante, com cerâmica feldspatica.

\section{CASO CLÍNICO}

Paciente S.C.F.L, 37 anos, gênero masculino, compareceu a clínica integrada de odontologia da universidade positivo, com a queixa principal de melhorar a estética dental, devido a tabagismo. O paciente assinou o termo de compromisso permitindo a divulgação cientifica das fotografias e exames radiográficos. Ao realizar o exame clínico foi visto que o além da estética, devido à manchamento e ao escurecimento dental (Escala Vita $A 3,5$ ), necessitava de uma adequação ao meio bucal, pois possuía cálculo supra- gengival em regiam de incisivos inferiores, cárie na distal do elemento 25 , e restaurações inadequadas na palatina, classe $\mathrm{V}$ dos elementos $11,12,21$ e 22 . Coroa sobre implante na região do elemento 24 . A sondagem clinica não apresentou nenhuma alteração, mas seu sorriso foi classificado como sorriso gengivoso.

\subsection{PROCEDIMENTOS PRÉVIOS A REABILITAÇÃO PROTÉTICA}

Inicialmente foi realizado uma profilaxia, raspagem, alisamento e polimento supra- gengival, para a adequação do meio bucal. Na sequência foi executado clareamento com peróxido de hidrogênio a 35\% (Whitness HP), em três seções de 45 minutos.

Na parte restauradora foi removido a cárie na distal do elemento 25 com broca diamantada esférica 1013 , e multilaminada $n^{\circ} 06$, na sequência a restauração com a técnica de incrementos (resina TPH D A2). 
Foi realizada a troca das restaurações dos elementos 11, 12,21 e 22 quese apresentavam inadequadas na face palatina, classe $V$, a remoção da resina foi realizada com a broca 1013, para na sequência a restauração com a técnicade incrementos (resina TPH D A2).

Após foi realizada a moldagem da arcada superior e inferior para planejamento da cirurgia de gengivoplastia e osteoplastia, com a confeç̧ão de placa de silicone de 1 milímetro como guia cirúrgico, com a variação de 1 a 3 milímetros a cima do contorno gengival seguindo a estética para a harmonia do sorriso. Para então a realização do procedimento cirúrgico.

\subsection{PLANEJAMENTO REVERSO DA REABILITAÇÃO PROTÉTICA}

Após 90 dias do procedimento cirúrgico foi realizado moldagem para enceramento diagnóstico, e a partir deste planejamento, foi feito um molde com silicone de adição (Variotime) pesado e leve do enceramento, chamado demockup, para servir como guia para o preparo dos dentes e também para a confecção dos provisórios com resina bisacrílica (Structur $2 \mathrm{SC}$ ) na cor A2 segundo a escala Vita. Foi realizada a instalação dos provisórios no paciente e após seu consentimento, deu-se início aos preparos.

Figura 1 - Foto antes dos procedimentos estéticos
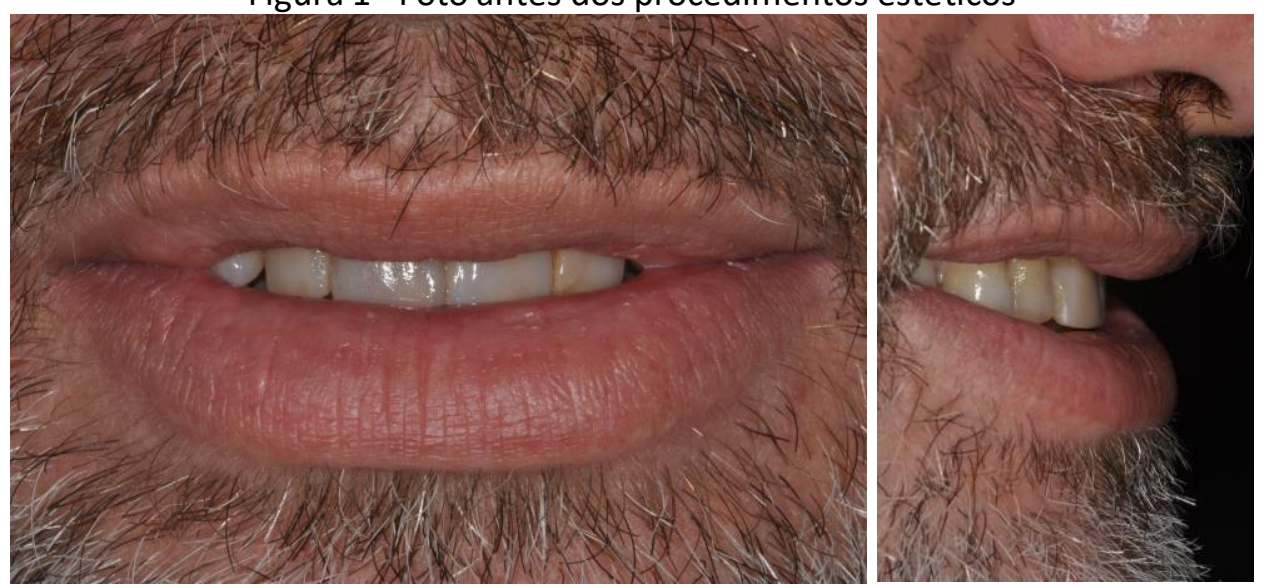

Fonte: Autoria própria. 
Figura 2. (A) Foto intra-bucal, (B) enceramento diagnóstico

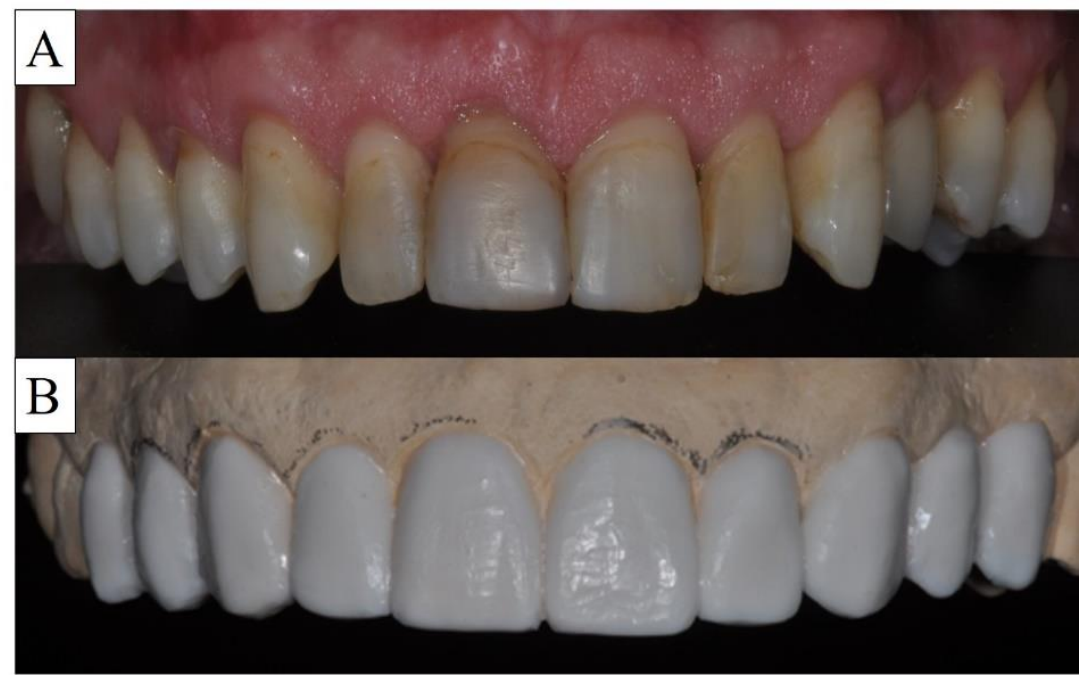

Fonte: Autoria própria.

Figura 3 - Confeç̧ão de mockup.

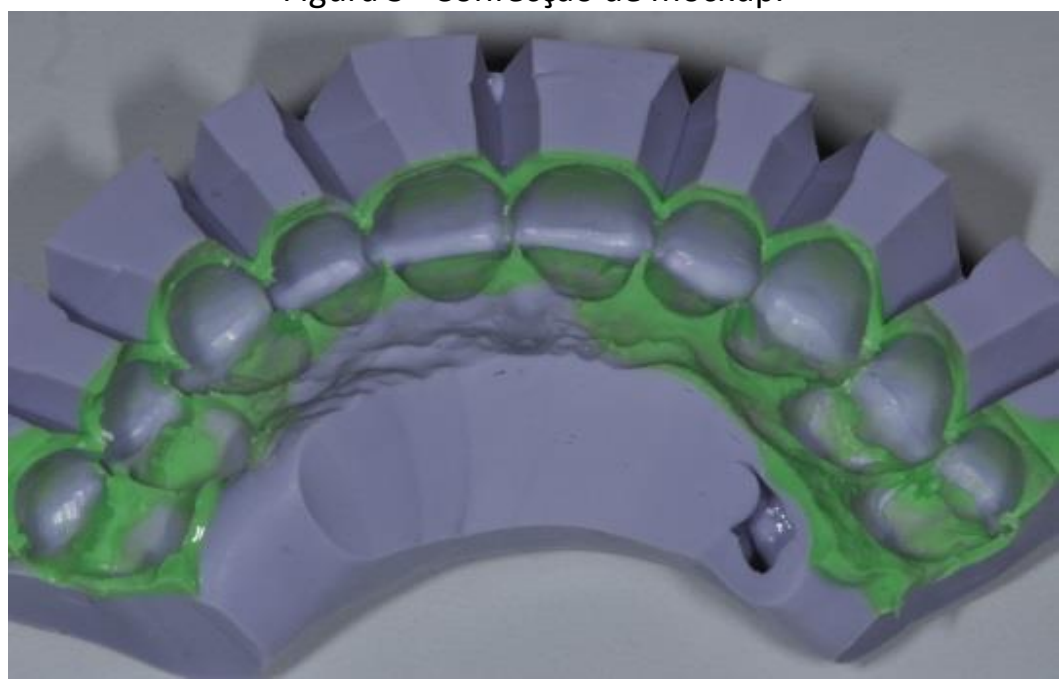

Fonte: Autoria própria.

Com o mockup servindo como guia, foi realizado nos elementos: 11, 21 duas canaletas na mesial e na distal, com a broca 2135 , com a profundidade de $1,2 \mathrm{~mm}$ e depois uma complementar estas canaletas servem como guia para a inclinação correta do preparo que seria aproximadamente de $10^{\circ}$. Após este procedimento, foi realizada a união destas canaletas, e na região cervical foi utilizando a técnica de chanfro. Na incisal foi realizado um desgaste de 1,2 a $2 \mathrm{~mm}$, e na palatina foi utilizada a broca 3118 . Realizando o acabamento final com a broca 2135 F (CONCEIÇÃO et al., 2005). 
Figura 4- (A) Instalação do mockup, (B) realização dos preparos, (C) Preparos finalizados sobre o mockup

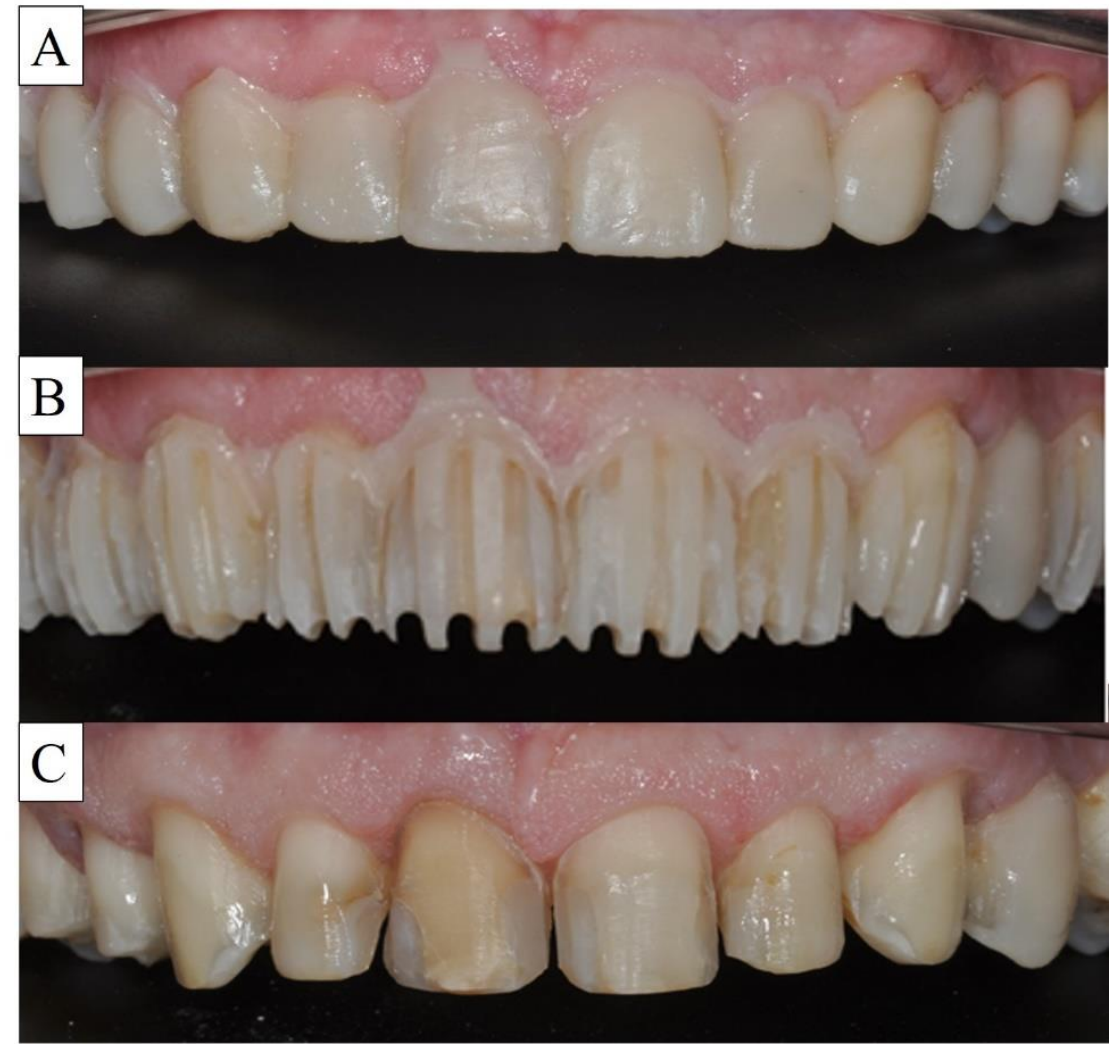

Fonte: Autoria própria.

Nos elementos $12,13,14,15,22,23$ e 25 foi realizado o preparo inicial com duas canaletas na mesial e na distal, com a broca 2135 , com a profundidade de 0,5 a $0,7 \mathrm{~mm}$ e depois uma complementar estas canaletas servem como guia para a inclinação correta do preparo que seria aproximadamente de $10^{\circ}$. Após este procedimento, foi realizada a união destas canaletas, e na região cervical foi utilizando a técnica de chanfro. $\mathrm{Na}$ incisal foi realizado um desgaste de 1,2 a $2 \mathrm{~mm}$. Realizando o acabamento finalcom a broca 2135 F (CONCEIÇÃO et al., 2005).

Sobre o pilar cônico do implante (24) foi instalado o trasnfer (pilar conico), para dar início ao procedimento de moldagem. Foi colocado o fio retrator \#000, e em seguida o fio \#00 (Ultrapack), umedecido com liquido hemostático (Hemostop), para então manipular o material de moldagem com silicone de adição (Variotime). O material pesado foi manipulado e carregado na moldeira e o material leve é injetado diretamente sobre os dentes iniciando na cervical e proximal concomitantemente a remoção do fio \#00 com o auxílio de uma pinça, recobrindo todas as superfícies dos dentes, para posteriormente recobrir com o material pesado que está posicionado na moldeira 
(CONCEIÇÃOet al., 2005). Foi realizado também a moldagem da arcada inferior com alginato (Hydrogum), assim encaminhado ao laboratório para a confecção dos elementos protéticos.

Em outra etapa foi realizada a prova dos elementos cerâmicos feldspáticas confeccionados e do munhão estético sobre o pilar do elemento 24 , para então a cimentação das peças. Inicialmente foi colocado o fio retrator \#000 (Ultrapack) umedecido com liquido hemostático (Hemostop). Para então realizar o condicionamento das peças protéticas com ácido fluorídrico $10 \%$ por 2 minutos, as peças são lavadas com água abundante e secada com ar, para aplicação do silano deixando agir por 1 minuto, em seguida secagem com ar. Nos elementos dentários é aplicado ácido fosfórico $37 \%$ por 15 segundos, os elementos são lavados com água abundante pelo mesmo tempo da aplicação, é aplicado o primer, em seguida volatiza com aplicação de ar por 30 segundos, para então aplicar o adesivo e fotoativar por 10 segundos.

Após o preparo das peças e dos elementos dentários o cimento resinoso (all cem venner) foi manipulado para aplicar sobre as peças de maneira uniforme, assim levando elas sobre os elementos dentários, removendo os excessos, para então fotoativar por 60 segundos em cada face. Removendo-se o fio retrator e realizado os ajustes oclusais.

Figura 5- Foto da instalação das coroas e facetas definitivas

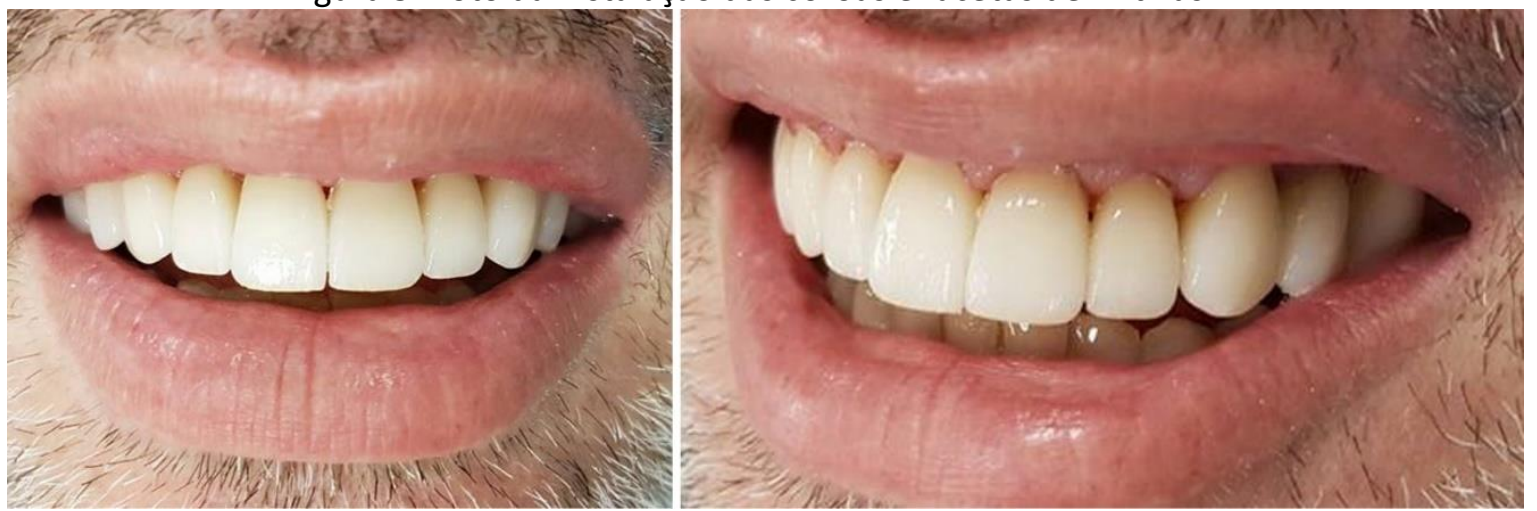

Fonte: Autoria própria.

\section{DISCUSSÃO}

Atualmente a estética é utilizada como algo harmônico, agradável aos olhos, quando se tem alteração nos dentes anteriores, seja a falta deles ou inadequadas restaurações, cria-se esta aparência desagradável que leva a pessoa a perder sua 
confiança. Para poder recuperar esta confiança necessitamos "imitar" a estética natural dos dentes que seria: a luz incidente é refletida, disperso e transmitida. Esta é influenciada pela textura da superfíciee a espessura do dente. Para alcançar uma combinação perfeita do dente a ser substituído, translucidez também deve ser considerado, enquanto a seleção adequada de sombra, sem a qual a seleção de cores não está concluída. Uma das soluções que vem sendo tomada com sucesso é a substituição pela porcelana feldspática odontológica, pois esta manipula a luz de uma forma favorável, com características estéticas desejáveis (SRAVANTHI et al., 2015; DE OLIVEIRA et al., 2018; AHID et al., 2021).

Segundo DOS SANTOS et al., 2020, a vantagem de utilizar as cerâmicas feldspáticas convencionais, seria que esta possui uma estética favorável, tem uma estabilidade química, seu coeficiente de expansão térmica é próximo à do dente, possui uma menor condutividade térmica, baixa temperatura de fusão, alta resistência à compressão, de 350 a $450 \mathrm{Mpa}$, compatibilidade biológica, além da resistência ao desgaste.

Neste caso clinico utilizamos a cerâmica feldspática em toda a reabilitação protética, pois segundo PEIXOTO et al., 2015, as restaurações indiretas são recomendadas em reabilitação oral quando há grande perda de estrutura dentaria.

Segundo AGUSTÍN-PANADERO,2016, o tratamento com próteses fixas dentárias, continua sendo uma das opções mais comuns aplicadas na odontologia, e oferece assim um longo prazo de sobrevivência clínica. Para que possamos ter um grande sucesso em nosso trabalho necessitamos seguir alguns critérios que seria manter a saúde pulpar e tecidos periodontais (PEIXOTO et al.,2015; PEGORARO, 2004; FURTADO et al.,2019; Ahid et al., 2021).

\section{CONCLUSÃO}

As técnicas utilizadas, preparos para facetas, coroas sobre dentes e coroa sobre implante foram apropriadas para este caso, e juntamente com o material de cerâmica feldspatica trouxeram uma satisfação ao paciente quanto a estética e função. 


\section{REFERÊNCIAS}

COSTA A.K., KELLY R.D., FLEMING G.J., BORGES A.L., ADDISON O. Laminated ceramics with elastic interfaces: a mechanical advantage? J Dent. ;43(3):33541. 2015.

LI R.W., CHOW T.W., Matinlinna J.P.Ceramic dental biomaterials and CAD/CAM technology: state of the art. J Prosthodont Res. 58(4):208-16. 2014.

GOMES E. A., ASSUNÇÃO W. G., ROCHA E. P., SANTOS P. H. Ceramic in dentistry: current situation. Cerâmica.54(331):319-25. São Paulo July/Sept. 2008.

CONCEIÇÃO E.N., et al. Restaurações estéticas: compósitos cerâmicas e implantes.Porto Alegre:Artmed,2005

LOPES C. C., RODRIGUES R.B., SILVA A.L., SIMAMOTO JÚNIOR P.C., SOARES C.J., NOVAIS V.R.Degree of Conversion and Mechanical Properties of Resin Cements Cured Through Different All-Ceramic Systems. Braz Dent J. 2015 Oct;26(5):4849.

SRAVANTHI Y., RAMANI Y.V., RATHOD A.M., RAM S.M., TURAKHIA H. The comparative evaluation of the translucency of crowns fabricated with three different allceramic materials: an in vitro study. J Clin Diagn Res. 2015 Feb;9(2):ZC30-4.

PEIXOTO R.F., DE AGUIAR C.R., JACOB E.S., MACEDO A.P., DE MATTOS M.DAG., ANTUNES R.P. Influence of Temporary Cements on the Bond Strength of SelfAdhesive Cement to the Metal Coronal Substrate. Braz Dent J. ;26(6):637-41. 2015.

PEGORARO LF. Capítulo 3. Preparo de Dentes com Finalidade Protética.Prótese fixa. 1st ed. São Paulo: Artes Médicas; p. 45-67. 2004.

AGUSTÍN-PANADERO R., SOLÁ-RUÍZ M.F., CHUST C., FERREIROA A. Fixed dental prostheses with vertical tooth preparations without finish lines: A report of two patients. J Prosthet Dent.;115(5):520-6. 2016.

DE OLIVEIRA LIMA, A. L., GOMES, R. T. B., FULA, V. M. B. F., BARBOSA FILHO, W. R., DE CASTRO FIGUEIRÊDO, B., AMARAL, Â. L. C. \& VANDERLEI, A. D. Reabilitação estética com laminados cerâmicos para fechamento de diastemas: Relato de Caso. Revista da AcBO-ISSN 2316-7262, 8(1). 2018.

AHID, B. D. A. R. N., ABREU-PEREIRA, C. A., AHID, V. P., FERRO, A. C., PEREIRA, A. L. G., CASANOVAS, R. C., \& AHID, F. J. M. O sistema CEREC na confecção de prótese parcial fixa em cerâmica: Relato de caso clínico. Research, Society and Development, 10(6), 2021.

FURTADO, D. C., MELO, E. L. DE, GOMES, M. A. DE L., PONTES, K. T., NEVES, J. L. DAS, CANTO, C. A. DE S., ASSIS, C. P. P. DE, \& BRAZ, R. A importância da reabilitação 
oral estética na alteração de forma e cor dos dentes: relato de caso clínico. Archives of health investigation, 7(12). 2019.

DOS SANTOS, L. R., \& ALVES, C. M. C. Cerâmicas odontológicas na confecção de facetas laminadas: qual a melhor escolha?. VITTALLE-Revista de Ciências da Saúde, 32(3), 257-265. 2020. 


\title{
CAPITULO XIII \\ O USO DE ALINHADORES ESTÉTICOS PARA TRATAMENTO ORTODÔNTICO
}

\author{
DOI: 10.51859/AMPLLA.EPC757.1121-13
}

\author{
Laise Brito Ribeiro de Assunção ${ }^{1}$ \\ Wendel Chaves Carvalho ${ }^{2}$ \\ Roberta Beatriz Rodrigues Turim ${ }^{3}$ \\ Guilherme Barros Aragão ${ }^{4}$ \\ Caroline Rodrigues Thomes ${ }^{5}$ \\ Mariana Almeida Mello Proença de Freitas ${ }^{6}$
}

\begin{abstract}
${ }^{1}$ Graduanda do curso de Odontologia. Faculdade Pitágoras de São Luís - MA
${ }^{2}$ Graduando do curso de Odontologia. Faculdade Pitágoras de São Luís - MA

${ }^{3}$ Graduanda em Odontologia, Faculdade Paulo Picanço, Fortaleza, Ceará

${ }^{4}$ Graduando em Odontologia, Faculdade Paulo Picanço, Fortaleza, Ceará

${ }^{5}$ Graduanda do curso de Odontologia. Universidade Federal do Espírito Santo - ES

${ }^{6}$ Cirurgiã-Dentista. Mestre e Doutora em Odontologia. Especialista em Dentística Restauradora e Ortodontia. Professora do Curso de Odontologia da Faculdade Pitágoras, São Luís - MA.
\end{abstract}

\section{RESUMO}

A proposta desse estudo foi descrever o modo de funcionamento dos alinhadores estéticos; apresentar as vantagens e desvantagens do seu uso e apresentar as suas limitações por meio de uma revisão de literatura de cunho qualitativa descritiva. Realizou-se uma pesquisa nas seguintes bases de dados: Google Acadêmico, PubMed, LILACS, Periódicos Capes, selecionando-se artigos em português e inglês, para obtenção de dados. Os alinhadores são placas plásticas finas e transparentes que se encaixam sobre a superfície vestibular, lingual/palatina e oclusal dos dentes. Esses aparelhos são descartáveis e praticamente indetectáveis a cerca de dois metros de distância. O número de alinhadores por paciente depende da quantidade de etapas necessárias para completar o tratamento. Apresentamse como métodos que podem ajudar a tratar uma grande variedade de casos, sejam problemas ortodônticos simples, apinhamentos, encerramento de diastemas ou tratamentos mais complexos. Por serem transparentes, removíveis e confortáveis, podem ser utilizados diariamente sem dificuldade, o que facilita a sua aceitação. Apesar dos sistemas de alinhadores ortodônticos estéticos serem considerados uma evolução no âmbito da ortodontia, ainda existem limitações como em casos de tratamento ortodônticos em que seja essencial extrações de dentes pré-molares. Constatou-se que os avanços na qualidade dos materiais do alinhador, acessórios e sistemas complementares, na utilização de sistemas digitais de processamento dos dados iniciais, bem como no planejamento tridimensional virtual expandiram a gama de possibilidades do tratamento ortodôntico com aparelhos invisíveis e removíveis aplicados a diversos problemas ortodônticos, dependendo da complexidade.

Palavras-chave: Odontologia. Ortodontia Corretiva. Terapêutica. 


\section{INTRODUÇÃO}

As más oclusões dentais são consideradas um problema de saúde pública em razão da sua elevada prevalência. Independentemente de haver a possibilidade de tratamento, esse defeito interfere no bem-estar e na saúde dos indivíduos afetados. Dessa forma, o mal posicionamento dos dentes dificulta a higiene pois facilita o acúmulo de biofilme no local, aumentando as chances de desenvolver a doença cárie e doenças periodontais. O tratamento ortodôntico promove inúmeros benefícios e dentre os principais estão: corrigir e melhorar o posicionamento dos dentes e facilitar a higienização. Hoje no mercado odontológico, o que se tem de mais estético na ortodontia são os bráquetes estéticos, bráquetes linguais e os alinhadores invisíveis (MARQUES et al., 2005; PEREIRA et al., 2014).

Os avanços na ortodontia proporcionado pelos alinhadores invisíveis, atualmente são dependentes da evolução nos materiais ortodônticos modernos. Sistemas como o Invisalign ${ }^{\circledR}$ tem demonstrado uma diminuição do tempo de tratamento e de cadeira, além do próprio desconforto e o favorecimento da estética durante a terapêutica. Além de que, esses materiais e sistemas podem oferecer ao ortodontista e ao paciente uma nova possibilidade de tratamento, devido à melhor a imagem virtual que permite reproduzir a situação clínica atual, propondo assim uma melhor intervenção e aumentando a eficiência dos alinhadores e o resultado final (DIAS, 2018). Assim, os objetivos específicos do trabalho foram: descrever o modo de funcionamento dos alinhadores estéticos; apresentar as vantagens e desvantagens do uso dos alinhadores estéticos e apresentar as limitações dos alinhadores estéticos.

Para a realização dessa revisão de literatura de cunho qualitativa descritiva, realizou-se uma pesquisa nas seguintes bases de dados: Google Acadêmico, PubMed, LILACS, Periódicos Capes, selecionando-se artigos em português e inglês, para obtenção de dados. Foram utilizados seguintes descritores: alinhadores, estética, ortodontia, alinhamento e suas variações para a língua inglesa. Os critérios de inclusão foram: revisões de literatura, artigos que possuem publicação completa e que possuem relevância com o tema proposto. Já os critérios de exclusão artigos sem metodologia definida e estudos clínicos. 


\section{REVISÃO BIBLIOGRÁFICA}

\subsection{EVOLUÇ̃̃O DO APARELHO REMOVÍVEL}

Sabe-se que a eficiência de tratamentos ortodônticos com bráquetes metálicos convencionais está consolidada. A bandagem de todos os dentes foi substituída pela colagem direta de bráquetes. Em seguida surgiram os bráquetes linguais, bráquetes em policarbonato e cerâmicos e alinhadores removíveis. Esses dispositivos ganharam a preferência dos pacientes, principalmente os adultos que, em razão da maior exigência estética, relutam muitas vezes em utilizar aparelhos metálicos fixos (RUSSELL, 2005; NOBLE et al., 2009; GIANCOTTI et al., 2006; BOYD, 2007).

Não é nova a ideia de um aparelho removível para reposicionar os dentes de forma incremental. Apesar disso, só foi lançada em 1997, quando Align Technologies desenvolveu o sistema Invisalign ${ }^{\circledR}$, tornando este tipo de tratamento mais vastamente utilizado. Invisalign ${ }^{\circledR}$ é um método "invisível" de tratamento ortodôntico que usa uma quantidade de "alinhadores" removíveis, criados por computador, para posicionar corretamente os dentes. O OrthoClear $^{\circledR}$, lançado em 2005, utiliza uma tecnologia parecida. Além da estética, o sistema oferece outras vantagens quando comparado aos aparelhos fixos convencionais: facilidade de uso, conforto, praticidade de atendimento e facilidade na higiene bucal (WONG, 2002; MACNAMARA et al., 2003; JOFFE, 2003).

Em 1997, o sistema Invisalign ${ }^{\circledR}$ (Align Technology, Inc, Santa Clara, Califórnia) associou a tecnologia de CAD-CAM às expectativas de estética do paciente. Atualmente, é o mais divulgado dos alinhadores, provavelmente pela possibilidade de produção a partir de um único molde, da ótima precisão e do valido suporte prestado aos ortodontistas. Dentro desse contexto, a ortodontia invisível é considerada um dos maiores desenvolvimentos na tecnologia de tratamento clínico ortodôntico no século XXI. Desde o início houve significativas melhorias por meio de novas tecnologias, como reconstrução tridimensional (3D), engenharia moderna, design assistido por computador e fabricação assistida por computador (WONG, 2002; FALTIN et al., 2003; Ll et al., 2016). 


\subsection{FUNCIONAMENTO DOS ALINHADORES}

Os alinhadores são placas plásticas finas $(0,75 \mathrm{~mm})$ e transparentes que se encaixam sobre a superfície vestibular, lingual/palatina e oclusal dos dentes. Esses aparelhos são descartáveis e praticamente indetectáveis a cerca de dois metros de distância, incluindo a facilidade de uso, melhor higiene e uma característica inovadora, a qual, pelo fato de o paciente visualizar e acompanhar o seu ClinCheck, observando toda a evolução do tratamento, raramente causa insatisfações em relação ao que foi planejado (GIANCOTTI et al., 2006; TAVARES, 2016).

Com a tecnologia desenvolvida recentemente, é possível, realizar de forma mais precisa e eficiente os tratamentos ortodônticos com alinhadores estéticos. Estes podem ser classificados em dois tipos. O primeiro tipo é representado pelo uso de alinhadores sequenciais, onde realizam-se vários set-up virtuais, com a finalidade de atingir os objetivos finais. Esta configuração final do tratamento é alcançada através de modernos softwares, mostrando todas as etapas da movimentação dentária a partir do estado inicial para o estado final. Por sequência, é realizada uma série de alinhadores, que movem os dentes de acordo com as fases projetadas do movimento. Cada placa alinhadora movimenta o dente $0,33 \mathrm{~mm}$ e realiza rotações de 20 por placa. 0 número de alinhadores por paciente, depende da quantidade de etapas necessárias para completar o tratamento (BOYD et al., 2000). Nos Estados Unidos (EUA), os moldes são digitalizados e a versão 3D dos arcos e da oclusão do paciente permite reproduzir as correções, virtualmente, fazendo o uso do CAD (Computer Aided Design), conforme o que foi planejado pelo ortodontista. Este tem a capacidade de visualizar os modelos 'virtuais', a correção da má oclusão, movimento por movimento, por meio de um programa de conexão com a Internet chamado 'ClinCheck. O tratamento do paciente pode ser revisado alinhador-a-alinhador e as correções feitas antes do plano de tratamento ser validado. Podem-se utilizar attachments para maior retenção dos alinhadores durante a correção da curva de Spee, para extrusão, rotação, translação e controle de torque. Assim, a troca dos alinhadores a cada duas semanas é conveniente e causa menor sensibilidade (BOLLEN et al., 2003; JOFFE, 2003; CLEMENTS et al.,2003; BOYD, 2007; TAVARES, 2016). Os alinhadores devem ser removidos durante as refeições e a higiene bucal deve ser feita com escova e dentifrício. O paciente deve usá-los, ao 
menos, 20 horas/dia. Para a contenção pós-tratamento, pode-se utilizar o último alinhador no arco superior e uma contenção $3 \times 3$ no arco mandibular. Se comparados ao tratamento com aparelhos fixos convencionais, os alinhadores mostraram causar menos impactos negativos na vida dos pacientes durante a primeira semana de uso. No entanto, no período pós-tratamento ocorreu uma maior quantidade de recidivas (KUNCIO et al., 2007; MILLER et al., 2007; PHAN, 2007).

\section{VANTAGENS E DESVANTAGENS DOS ALINHADORES ESTÉTICOS}

\subsection{VANTAGENS DOS ALINHADORES ESTÉTICOS}

Os alinhadores ortodônticos estéticos são bastante discretos uma vez que são constituídos por um material transparente, o que apresenta uma vantagem relativamente aos bráquetes metálicos quando visualizados por vestibular. Esta característica possibilita uma redução das limitações a nível social permitindo, por exemplo, que os pacientes sorriam com uma maior confiança. O fato desses aparelhos serem removíveis permite que eles sejam retirados durante as refeições e as atividades físicas, na utilização de instrumentos musicais de sopro e, além disso, facilitam a fonética no decorrer de alguns discursos profissionais e permitem uma melhor higienização tanto dos alinhadores como dos dentes (ACAR et al., 2014; JOFEE, 2003).

Ao efetuar tratamentos ortodônticos com aparelhos ortodônticos fixos, é recomendado a remoção do mesmo aquando da realização de exames complementares de diagnóstico como ressonâncias magnéticas. No caso dos alinhadores ortodônticos, 0 procedimento torna-se mais fácil pelo fato de que esses aparelhos são removíveis. No caso de atletas de esportes de contato, estes aparelhos são procurados pois, podem servir de contenção durante as atividades físicas, evitando por vezes traumas que possam ocorrer. Ao mesmo tempo, durante as refeições, não há o risco de retenção dos alimentos no aparelho, o que proporciona uma melhor higiene e um menor risco de aparecimento de cáries e de gengivite (NAIK; CHAVAN, 2010; JOFFE, 2003; MILLER et al., 2007; URZAL; FERREIRA, 2017).

Apresentam-se como métodos que podem ajudar a tratar uma grande variedade, quer de problemas ortodônticos simples quer apinhamentos e encerramento de diastemas ou tratamentos mais complexos. Por serem transparentes, removíveis e 
confortáveis, podem ser utilizados diariamente sem dificuldade, o que facilita a sua aceitação. Esses tipos de alinhadores a princípio foram inicialmente indicados para doentes que anteriormente já realizaram tratamento ortodôntico e apresentavam recidivas (MORO et al., 2017; LAPUENTE, 2017). A utilização destes alinhadores permite ao paciente visualizar de uma melhor forma o progresso do tratamento, através dos alinhadores transparentes que transparecem uma percepção real dos resultados. Dentro desse aspecto, nota-se ainda a possibilidade de ver o resultado final no programa eletrônico, aumentando de certa maneira a motivação dos pacientes, pois os mesmos passam a acompanhar mais atentamente a evolução e o sucesso do tratamento. Esse tipo de aparelhos é menos suscetível a causar lesões, nomeadamente na mucosa ou na língua, comparativamente aos aparelhos ortodônticos fixos, o que faz com que o paciente tenha menos consultas de urgência. Além disso, quando estas lesões estão presentes apresentam uma gravidade menor do que quando ocorrem em aparelhos ortodônticos fixos (BOYD, 2001; MILLER et al., 2007). Um outro benefício proveniente deste tratamento é o fato dele ter uma prevalência de reabsorção radicular bastante baixa ou inexistente no final do tratamento ortodôntico (). Além disso, é possível a realização de clareamento dentário no decorrer do tratamento com o uso desses alinhadores ortodônticos, uma vez que este sistema não engloba o uso de bráquetes. Posto isto, este procedimento dispensa as convencionais moldeiras de clareamento. Nesse sentido, os alinhadores ortodônticos invisíveis permitem a redução do tempo de cadeira a que o paciente está sujeito por consulta, uma vez que os alinhadores já estão prontos devido ao planeamento prévio ao tratamento. $O$ último alinhador pode servir como aparelho de contenção (PEREIRA et al., 2014; KRIEGER et al., 2013; URZAL; FERREIRA, 2017).

É de se salientar o fato e a importância de a contenção estar inserida no plano tratamento e ser indispensável ao sucesso do mesmo. Além disso, é de se referir que o uso deste tipo de alinhadores não apresenta nenhum registo de atividade citotóxica em estudos in vitro, realizados por Eliades et al., (2009), que utilizaram um modelo padrão para avaliar a citotoxicidade de materiais, demonstrando que nos aparelhos convencionais de níquel-titânio pode ocorrer corrosão devido à sua permanente ligação com a saliva e assim haver a libertação de compostos tóxicos como o níquel. Assim, este 
composto pode gerar reações de hipersensibilidade e alergias na mucosa e na pele do paciente (NEVES et al., 2012; LAPUENTE, 2017).

\subsection{DESVANTAGENS DOS ALINHADORES ESTÉTIICOS}

A incapacidade de o cirurgião-dentista controlar o tratamento completo, é apresentada como desvantagem, levando em consideração a impossibilidade de alteração dos alinhadores visto que os mesmos são geralmente recebidos na sua totalidade no início do tratamento. Por esse motivo, é fundamental a automotivação do paciente para o sucesso do tratamento. Uma vez que se trata de um aparelho removível que deve ser retirado durante as refeições, a probabilidade de o paciente perder 0 alinhador é mais alta. Um outro inconveniente é o fato de ter de se enviar todos os documentos e modelos para a própria marca e ainda aguardar a recepção dos alinhadores, visto que todo este processo atrasa o início do tratamento (DJEU et al., 2005; SRIVASTAVA et al., 2017).

Segundo Kuncio et al., (2007), que demonstrava as alterações dentárias após o uso da contenção, houve uma maior recidiva nos pacientes tratados com alinhadores do que com pacientes tratados com aparelhos fixos convencionais. Além disso, o marketing desta marca é bastante persuasivo, ilude os pacientes que este sistema é capaz de tratar todos os tipos de maloclusões, o que é um aspeto falso. Uma outra desvantagem além das citadas anteriormente é o fato de não se poder realizar nenhum outro tipo de tratamento que possa alterar a anatomia dos dentes ou a sua posição, uma vez que todos os alinhadores recebidos são estudados e fabricados segundo as únicas impressões recebidas no início do tratamento. Por este motivo, todas as alterações realizadas a este nível iriam exigir novas impressões e respectivas goteiras (NEVES et al., 2012; PEREIRA et al., 2014).

Disfagia e aumento do fluxo alimentar também são mais comuns em pacientes que utilizam os alinhadores ortodônticos estéticos. Além disso, o elevado custo do sistema também se apresenta como um inconveniente deste tratamento, assim como a prescrição da técnica que é geralmente utilizada apenas por cirurgiões-dentistas previamente cadastrados após a realização de um curso ministrado pela empresa proprietária da técnica. Embora esses alinhadores ortodônticos estejam em processo constante de evolução cínica mediante a existência de novas tecnologias, ainda existem 
algumas limitações nesses sistemas ortodônticos (NEVES et al., 2012; SRIVASTAVA et al., 2017). Dentro desse contexto, no próximo capítulo serão apresentadas as limitações encontradas provenientes do uso desses tipos de aparelhos ortodônticos conforme as suas indicações descritas anteriormente.

\section{LIMITAÇÕES DOS ALINHADORES ESTÉTIICOS}

Apesar dos sistemas de alinhadores ortodônticos estéticos serem considerados uma evolução no âmbito da ortodontia, ainda existem limitações, como por exemplo, em casos de tratamento ortodônticos em que seja essencial extrações de dentes prémolares e incisivos inferiores. Outras situações limitantes são os casos com sobremordida acentuada, dentes impactados, pacientes com predominância de problemas de ordem periodontal, arcadas com inúmeras perdas dentárias, elementos dentários com coroas clínicas curtas e quando há existência de discrepâncias entre a oclusão cêntrica e a relação cêntrica (ROTHIER; VILELA, 2010; MADOTTI et al., 2014; TAKEHARA; CASA; CARVALHO, 2013; MALTAGLIATI; BRÁQUETES, 2013; GIMENEZ; BRANT, 2013).

Os alinhadores ortodônticos estéticos são incapazes de executar o movimento de rotação em alguns dentes que apresentam a anatomia muito arredondada, como por exemplo alguns pré-molares inferiores, uma vez que se torna difícil a fixação do alinhador a esta anatomia dentária. Entretanto, essa limitação foi ultrapassada com o advento dos attachments. Algumas das outras limitações existentes descritas na literatura no tratamento ortodôntico com alinhadores estéticos Invisalign ${ }^{\circledR}$ são representadas pelo controle do torque, principalmente em dentes posteriores, enquanto nos dentes anteriores essa dificuldade geralmente é contornada por meio dos Power Ridges, ranhuras presentes nos alinhadores de uso em dentes incisivos com o objetivo de controle da raiz que se encontra em movimento (ROTHIER, 2013; SRIVASTAVA et al., 2017).

Há pouco controle dos movimentos precisos dos elementos dentários realizados pelos alinhadores estéticos Invisalign ${ }^{\circledR}$, levando em consideração que são aparelhos removíveis. Isso ocorre principalmente nos seguintes tipos de movimentos ortodônticos: extrusão, verticalização, rotação e fechamento de espaços com paralelismo radicular após a realização das extrações. A terapêutica dos casos 
caracterizados por mordida aberta anterior também tem obtido sucesso limitado com o uso desses alinhadores estéticos, tendo como uma possível explicação o fato de que ainda persiste uma falta de mecânica interarcos. Assim, mesmo que haja um certo grau de extrusão anterior, geralmente não ocorre o suficiente para que seja alcançado um trespasse vertical ideal (JOFEE, 2003; PHAN; LING, 2007). Além disso, uma outra limitação encontra-se pautada em relação ao tempo adicional significativo na integração de mudanças posteriormente ao planejamento ortodôntico inicial. É necessária a documentação complementar, além de um novo planejamento contendo movimentos em sequência para cada respectivo elemento dentário desde o princípio até a finalização do tratamento, o que acaba demandando em média até dois meses adicionais. Más oclusões como apinhamentos e espaços superiores a 5 milímetros ( $\mathrm{mm}$ ), dentes com a presença de giroversões superiores a 20으, discrepâncias esqueléticas anteroposteriores superiores a $2 \mathrm{~mm}$, inclinações dentárias superiores a 45 을 dificilmente conseguem ser tratadas por meio do uso dos alinhadores ortodônticos estéticos Invisalign ${ }^{\circledR}$ (PHAN; LING, 2007; BRAGA, 2015; ROTHIER; VILELA, 2010; MADOTTI et al., 2014; CALHEIROS; BRAGA, 2014; ROTHIER, 2013).

Com base nas informações descritas anteriormente, pode-se perceber que os alinhadores estéticos são uma alternativa a ser usada com sucesso na ortodontia em casos que necessitam proporcionar estética e conforto ao paciente, além de reduzir o tempo de cadeira e favorecer uma boa higiene bucal. Por se tratar de uma técnica removível, entretanto, não é indicada para todo tipo de caso ortodôntico. Assim, esses alinhadores ortodônticos estéticos são utilizados principalmente para o tratamento de casos simples a moderados de alinhamento dentário.

\section{CONSIDERACÕES FINAIS}

O profissional deve possuir um extenso conhecimento acerca das vantagens e desvantagens do sistema e o próprio paciente deve estar motivado e atuar de forma colaborativa. Constata-se que os resultados do tratamento com os alinhadores dependem da experiência do clínico, da seleção de casos e da adesão do paciente. Sugere-se que mais estudos possam ser realizados abordando essa temática buscando promover maiores esclarecimentos e popularizar este tipo de tratamento entre os ortodontistas, encorajando, inclusive, os profissionais a se atualizarem sobre 
tecnologias virtuais e escaneamentos que se encontram disponíveis no mercado odontológico.

\section{REFERÊNCIAS}

ACAR, Y. et al. How Efficient are Clear Aligners? Clear aligners vs Traditional Orthodontic Treatment: Systematic Review. Turkish Journal of Orthodontics, v.27, n.3, p. 106 - 110, 2014.

BOLLEN, A. M. et al. Activation time and material stiffness of sequential removable orthodontic appliance. Part 1: Ability to complete treatment. American Journal of Orthodontics Dentofacial Orthopedics, v.124, n.5, p. 496-501, 2003.

BOYD, R. L. Complex orthodontic treatment using a new protocol for the invisalign appliance. Journal of Clinical Oncology, n.9, p. 525 - 547, 2007.

BOYD, R. L. et al. The Invisalign system in adult orthodontics: mild crowding and space closure. Journal of Clinical Orthodontics, v. 34, p. 203-213, 2000.

BOYD, R. L.; MILLER, R. J.; VLASKALIC, V. The Invisalign System in adult orthodontics: mild crowding and space closure cases. Journal of Clinical Orthodontics, v.34, n.4, p. 203-12, 2000.

BOYD, R. L.; V. V. Three-dimentional diagnosis and orthodontic treatment of complex malocclusions with the Invisalign appliance. Seminars in Orthodontics, v.7, n.4, p. $274-293,2001$.

CALHEIROS, A.; BRAGA, C. C. Eficácia do tratamento ortodôntico com sistema Invisalign. Ortodontia SPO, v.47, n.1, p. $67-73,2014$.

CLEMENTS, K. M. et al. Activation time and material stiffness of sequential removable orthodontic appliance. Part 2: Dental improvements. American Journal of Orthodontics Dentofacial Orthopedics, v.124, n.5, p. 502-508, 2003.

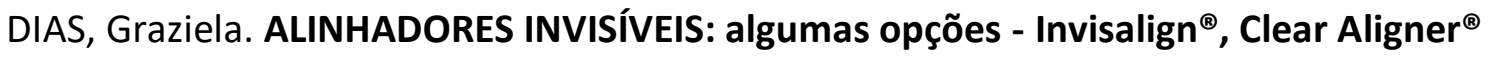
e Essix ${ }^{\circledR}$ Clear Aligner. Orientador: Jean Christian Moreira Benetti. 2018. 42 p. Monografia (Especialista em Ortodontia) - Faculdade de Sete Lagoas - MG, [S. I.], 2018.

DJEU, G. et al. Outcome assessment of Invisalign and Traditional orthodontic treatment compared with the American Board of Orthodontics objective Grading system. American Journal of Orthodontics and Dentofacial Orthopedics, v.128, n.3, p. $292-298,2005$.

FALTIN, R. M. et al. Efficiency, three-dimension.al planning and prediction of the orthodontic treatment with the Invisalign ${ }^{\circledR}$ System: case report. Revista Clínica de Ortodontia Dental Press. v.2 n.2. p.61-71., 2003. 
GIANCOTTI, A; GRECO, M.; MAMPIERI, G. Extraction treatment using invisalign technique. Progress in Orthodontics, v.7, n.1, p. 32-43, 2006.

GIMENEZ, C. M. M.; BRANT, J. Ortodontia e estética: a opção dos alinhadores para a prática clínica cotidiana. Revista Clínica de Ortodontia Dental Press, v.12, n.4, p. $18-23,2013$.

JOFFE, L. Features section: Current products and practice invisalign: Early experiences. Journal of Orthodontics, v.30, n.4, p. $348-352,2003$.

JOFFE, L. Invisalign: early experiences. Journal of Orthodontics, v.30, n.4, p. 348-352, 2003.

KOKICH, V.G. Entrevista (URIAS D.; CHAVES K.; ROSA R.O., CORREA J). Revista Dental Press de Ortodontia e Ortopedia Facial Maringá, v.11.n.6, p.19-23, 2006.

KRIEGER, E. et al. Apical root resorption during orthodontic treatment with aligners? A retrospective radiometric study. Head and Face Medicine, v.9, n.1, 2013.

KUNCIO, D. et al. Post containment results of traditional orthodontic treatment and Invisalign compared using the American Board of Orthodontics objective classification system. The Angle Orthodontist, v.77, n.5, p. 864-869, 2007.

LAPUENTE, P. D. V. A ortodontia invisível, um novo desafio. Instituto Universitário de Ciências da Saúde, 2017.

MADOTTI, V. et al. Aparelhos removíveis em adultos: avaliação perceptiva do sistema invisalign ${ }^{\circledR}$. Orthodontic Science and Practice, v.7, n.25, p. $21-26,2014$.

MALTAGLIATI, L. A. Bráquetes estéticos - considerações clínicas. Revista Clínica de Ortodontia, v.5, n.3, p. $89-95,2006$.

MARQUES, L. S. et al. Malocclusion prevalence and orthodontic treatment need in 1014-year-old school children in Belo Horizonte, Minas Gerais State, Brazil: a psychosocial focus. Cadernos de Saúde Pública, v.21, n.4, p. 1099-1106, 2005.

MCKENNA, S. Invisalign: technology of mythology? Journal of the Massachusetts Dental Society, v.50, n.2, p. $8-9,2001$.

MCNAMARA, J. et al. Invisible Retainers. Journal of Clinical Orthodontics, v.19, n.8, p. $570-578,1985$.

MILLER, K. B. et al. A comparison of treatment impacts between Invisalign aligner and fixed appliance therapy during the First week of treatment. American Journal of Orthodontics and Dentofacial Orthopedics, v.131, n.3, 2007.

MORO, A. et al. Ortodontia Lingual x Alinhadores Removíveis: Lingual Orthodontics $x$ Removable Aligners: Whens to use. Orthodontic Science and Practice, v.10, n.39, p.104-130, 2017. 
NAIK, V.R.; CHAVAN, P. Invisalign: The Invisible braces. Journal of Contemporary Dentistry, v.1, n.2, p. $54-57,2010$.

NEVES, C. P. T. et al. Sistema Invisalign: Uma alternativa ortodôntica estética. Pós em Revista, p. $314-321,2012$.

NOBLE, J. Future practice plans of orthodontic residents in the United States. American Journal of Orthodontics Dentofacial Orthopedics, v.135, n.3, p. 357-360, 2009.

PEREIRA, D. Ortodontia Plástica: conceito e diferentes sistemas, 2014, p. 1-8.

PHAN, X.; LING, P. H. Clinical limitations of invisalign. Journal of the Canadian Dental Association, v.73, n.3, p. 263-266, 2007.

PROFFIT, W.R.; FIELDS, J.R.H.W. Ortodontia Contemporânea. 3ed. Rio de Janeiro: Guanabara Koogan, 2002. 751p.

ROTHIER, E. K. C. Afinal, o que podemos esperar do sistema Invisalign? Revista Clínica de Ortodontia Dental Press, v.12, n.6, p. 6-14, 2013.

ROTHIER, E. K. C.; VILELA, O. V. Invisalign: uma alternativa estética para movimentação dentária. Orthodontic Science and Practice, v.3, n.11, p. 268 - 272, 2010.

RUSSELL, J. S. Aesthetic Orthodontic brackets. Journal of Orthodontics, v.32 p.146-163, 2005.

SRIVASTAVA, R. et al. Sequential Removal Orthodontics: An Alternative Approach. International Journal of Contemporary Medicine Surgery and Radiology, v.2, n.1, p. $32-36,2017$.

TAKEHARA, E. C.; CASA, M. A.; CARVALHO, L. S. Plano de tratamento virtual na ortodontia. Orthodontic Science and Practice, v.6, n.23, v.346-352, 2013.

TAVARES, S.W.; FONSECA JUNIOR, G. Revista Clínica de Ortodontia Dental Press, v.15, n.4, p. 89-98, 2016.

TURPIN, D. L. Clinical trials needed to answer questions about Invisalign. American Journal of Orthodontics Dentofacial Orthopedics, v.127, n.2, p. 157-158, 2005.

URZAL, V.; FERREIRA, A. P. Analysis of Invisalign system in what concerns it's advantages and limitations. Revista de Ortodontia, p. $28-39,2011$.

VANARSDALL, L.R.; MUSICH, D.R. Ortodontia em adultos: Diagnóstico e tratamento. In: GRABER, T.M.; VANARSDALL, L.R. Ortodontia: Principios e técnicas atuais. 2.ed. Rio de Janeiro: Guanabara Koogan, 1996. Cap.14. p. 697-778.

WHITEHOUSE, J.A. Everyday uses of adult orthodontics Dent Today. Dentistry Today, v.23. n.9. p.116-120. 2004. 
WONG, B.H. Invisalign A to Z. American Journal of Orthodontics Dentofacial Orthopedics, v.121, n.5, p. 540 - 541, 2002.

ZACHARISSON, B.U. Ortodontia e Periodontia. In. LINDHE J. Tratado de Periodontia e Implantologia Oral. 5ed. Rio de Janeiro: Guanabara Koogan, 2010. 


\title{
CAPITULO XIV \\ REABILITAÇÃO ESTÉTICO-FUNCIONAL EM ODONTOPEDIATRIA
}

\author{
DOI: 10.51859/AMPLLA.EPC757.1121-14
}

\author{
Rafaela Alves Castro ${ }^{1}$ \\ Lucas Andeilson dos Santos Matos ${ }^{2}$ \\ Larysse Dias do Nascimento ${ }^{1}$ \\ Maria Emily de Sousa Guedes ${ }^{1}$ \\ Karla Geovanna Ribeiro Brígido ${ }^{3}$ \\ Jandenilson Alves Brígido ${ }^{3}$
}

\begin{abstract}
${ }^{1}$ Graduanda do Curso de Odontologia - Centro Universitário Fametro - UNIFAMETRO
${ }^{2}$ Graduando do Curso de Odontologia - Centro Universitário Fametro - UNIFAMETRO

${ }^{3}$ Docente do Curso de Odontologia - Centro Universitário Fametro - UNIFAMETRO
\end{abstract}

\section{RESUMO}

O acompanhamento em odontopediatria tem ganhado mais notoriedade e importância na atualidade, focando fortemente na prevenção e promoção em saúde bucal desses pacientes. Alguns fatores predispõem doenças bucais no público infantil, que afetam diretamente a funcionalidade e estética da criança. $O$ objetivo do trabalho foi avaliar a previsibilidade da reabilitação estético-funcional em odontopediatria. Trata-se de uma revisão de literatura, em que foram realizadas buscas bibliográficas no PubMed e EBSCOhost. Assim, após leitura dos artigos na íntegra, foram selecionados 18 para esta revisão. Além de restabelecer a função e a estética, a reabilitação oral visa abranger o paciente como um todo, incluindo seu bem-estar psicológico. Além disso, melhora a dieta alimentar da criança, pois a ausência dentária de um ou mais elementos, acarreta em uma mastigação e ingestão deficiente. É notória a diversidade de tratamentos reabilitadores para crianças que possuem alterações estético-funcionais, desde alternativas como a reabilitação por próteses implantossuportadas, próteses totais e/ou parciais removíveis, até técnicas conservadoras como a utilização facetas e coroas dentárias. Desta forma, a reabilitação oral protética pode ser um importante mediador para a melhora da saúde como um todo, promovendo desde benefícios estéticos, com a possibilidade de um sorriso harmônico, melhora da autoestima e convívio social, como também contribui para a fonação e restabelece a função mastigatória, auxiliando diretamente na nutrição da criança e a implementação de uma dieta mais rica.

Palavras-chave: Estética. Criança. Reabilitação oral. 


\section{INTRODUÇÃO}

O acompanhamento em odontopediatria tem ganhado mais notoriedade e importância na atualidade, focando fortemente na prevenção e promoção em saúde bucal de crianças. Alguns fatores predispõem doenças bucais no público infantil, como a dieta, a condição socioeconômica, as crenças, a genética, o acesso à saúde e as informações necessárias para a correta higienização oral, que afetam diretamente a funcionalidade e estética (ESSVEIN et al., 2019).

Os dentes são essenciais e participam efetivamente da fala e mastigação, proporcionando não só estética, como também a função. A perda prematura da dentição, seja decídua ou permanente, acarreta numa série de problemas bucais, com disfunções na dicção, mastigação, oclusão e comprometimento dos movimentos da língua. Em consequência, pode-se desenvolver possíveis deficiências nutricionais, pois com a ausência desses elementos a mastigação também poderá ser afetada (PINTO et al., 2016).

A dieta está diretamente associada à doença cárie, e uma das causas é a ingestão de alimentos açucarados e carboidratos, ocasionando o acúmulo de biofilme, que quando associada à não higienização bucal eficiente, tornará um meio propício para as bactérias responsáveis pelo processo da cárie, fator de agravamento da doença (KANTOVITZ et al., 2016).

Apesar da implementação de flúor nos cremes dentais, águas e de todos os procedimentos odontológicos existentes para sua prevenção e regressão, a cárie dentária ainda se torna bastante comum na maioria da população, o que a torna um problema de saúde pública, ocorrendo a perda de dentes de forma prematura, seja pelo não incentivo e participação evolutiva dos pais, ou pelo incorreto cuidado bucal domiciliar (MOHDNOR et al., 2019).

Desde a infância, a estética facial torna-se um ponto bastante relevante ao que se refere à aceitação, pois, a partir desse período são criados vínculos afetivos e não se sentir parte de um grupo interfere diretamente na interação social. Dessa forma, quando uma criança passa pelo processo de perda prematura dentária, pode contribuir com a não interação social, influenciando na saúde emocional (PINTO et al., 2016). 
Essas crianças chegam ao consultório odontológico queixando-se aos pais ou responsáveis acerca do constrangimento sofrido por sua aparência em locais frequentados diariamente, principalmente na escola. A reabilitação oral pode devolver a função e estética do paciente, tornando-se uma importante aliada para o bem-estar psicossocial da criança, melhorando assim seu convívio entre as demais (ESSVEIN et al., 2019).

Além da cárie, outros fatores que podem desencadear sequelas orais em crianças são as alterações genéticas. Dentre as principais, a displasia ectodérmica, que advém do desenvolvimento embrionário, repercute no desenvolvimento das características craniofaciais, podendo causar hipoplasia maxilar, prognatismo mandibular e altura facial inferior reduzida. Já na mucosa oral, ocorrem modificações dentárias que incluem a carência congênita dos dentes, podendo manifestar-se em anodontia ou hipodontia, ocasionando a deficiência da crista alveolar e quando presentes, os dentes anteriores apresentam formato cônico e taurodontismo (TABORDA et al., 2018).

A síndrome Christ-Siemens-Touraine ou comumente conhecida como displasia ectodérmica anidrótica, possui origem recessiva e apresenta características dentárias como a hipodontia, oligodontia, e mais raramente anodontia, presente em cerca de $1 \%$ dos casos relatados. Pode causar o subdesenvolvimento das cristas alveolares, diminuição da dimensão vertical de oclusão e diminuição do fluxo salivar (KILIC et al., 2017; RETNAKUMARI et al., 2016).

Para Triches et al. (2017) a reabilitação oral tem como seu principal objetivo o restabelecimento da função mastigatória, deglutição e fonética da criança, que a longo prazo trará grandes benefícios ao paciente. Concomitantemente, esta também promoverá a melhora psicossocial do paciente odontopediátrico e contribuirá diretamente para seu desenvolvimento e convívio social.

Nesse sentido, a reabilitação oral pode ser um importante mediador no restabelecimento estético-funcional do paciente, por meio de próteses dentárias totais e parciais removíveis, além da reabilitação por meio de facetas e coroas dentárias, garantindo qualidade de vida e condições específicas para reconstituir a função e estética (ALNUAIMI; MANSOOR, 2019). Diante desse contexto, o objetivo do estudo foi identificar as opções de reabilitação estético-funcional em odontopediatria. 


\section{METODOLOGIA}

Este estudo apresenta uma revisão de literatura, em que foram realizadas buscas bibliográficas nos portais eletrônicos PubMed/Medline, EBSCOHost e busca manual nas referências dos artigos encontrados, utilizando as palavras-chave "Dental Prosthesis", "Children", "Oral Rehabilitation", além dos termos relacionados em português.

Os critérios de inclusão para esta revisão foram: a) estudos publicados nos últimos cinco anos; b) estudos disponíveis na íntegra; c) estudos de língua portuguesa e inglesa; d) estudos clínicos, relatos de caso, transversais, comparativos, analíticos, observacional, qualitativo, quantitativo; e e) estudos que atendessem à questão norteadora acerca da reabilitação estético-funcional em odontopediatria. Já os critérios de exclusão foram: a) artigos de revisão, teses, dissertações, monografias; b) artigos duplicados; c) estudos não pertinentes ao tema.

\section{RESULTADOS E DISCUSSÃO}

Após buscas bibliográficas, gerou-se um total de 76 publicações, distribuídas pela PubMed (52), EBSCOHost (14), Busca Manual (10), em que foi efetuada a leitura de títulos e resumos, sendo selecionados 25 artigos. Assim, foi realizada a leitura dos artigos na íntegra e com base nos critérios de elegibilidade estabelecidos, excluiu-se 7 e foram selecionados 18 artigos para compor este estudo, demonstrados na Figura 1 e Tabela 1. 
Figura 1. Fluxograma dos artigos encontrados.



N. de artigos identificados no banco de dados + busca Manual $(\mathrm{N}=76)$

웛

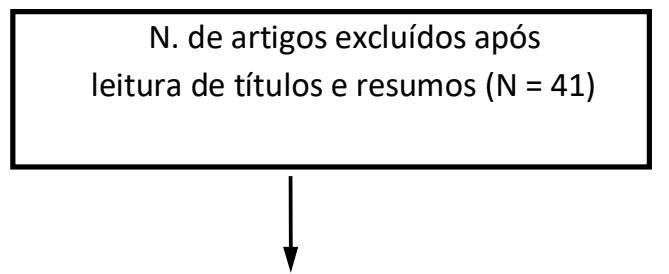

$\frac{\text { 을 }}{\frac{7}{0}}$

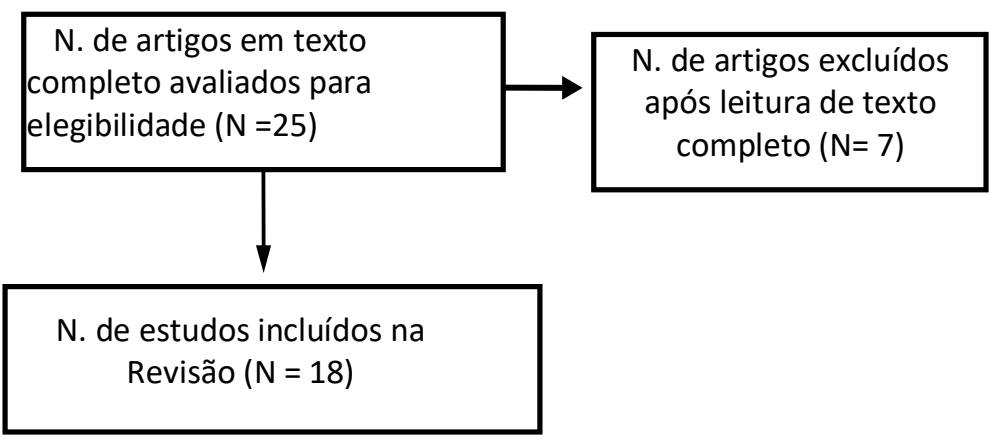

Fonte: Autoria própria.

Tabela 1. Artigos selecionados para revisão de literatura

\begin{tabular}{|c|c|c|}
\hline AUTOR PRINCIPAL/ANO & TIPO DE ESTUDO & OBJETIVO/TEMÁTICA \\
\hline DURSUN, 2016 & $\begin{array}{l}\text { Relato de caso } \\
\text { clínico }\end{array}$ & $\begin{array}{l}\text { Relatar o estudo de caso de } 15 \text { anos de dois } \\
\text { irmãos afetados pela forma hipocalcificada de } \\
\text { IA hereditária. }\end{array}$ \\
\hline KANTOVITZ et al., 2016 & $\begin{array}{l}\text { Relato de caso } \\
\text { clínico }\end{array}$ & $\begin{array}{l}\text { Reabilitação protética devido a perdas } \\
\text { prematuras dos elementos dentários de uma } \\
\text { criança com alto índice de risco de cárie. }\end{array}$ \\
\hline MAROULAKOS et al., 2016 & $\begin{array}{l}\text { Relato de caso } \\
\text { clínico }\end{array}$ & $\begin{array}{l}\text { Considerar diferentes pontos nos casos } \\
\text { clínicos abordados, buscando uma forma de } \\
\text { um tratamento individualizado e de forma } \\
\text { simples, e que tenham resultados } \\
\text { satisfatórios. }\end{array}$ \\
\hline PINTO et al., 2016 & $\begin{array}{l}\text { Relato de caso } \\
\text { clínico }\end{array}$ & $\begin{array}{l}\text { Acompanhamento de } 6 \text { anos de um } \\
\text { tratamento reabilitador não invasivo em uma } \\
\text { criança com displasia ectodérmica. }\end{array}$ \\
\hline
\end{tabular}




\begin{tabular}{|c|c|c|}
\hline AUTOR PRINCIPAL/ANO & TIPO DE ESTUDO & OBJETIVO/TEMÁTICA \\
\hline MOHD NOR et al., 2019 & Estudo seccional & $\begin{array}{c}\text { Avaliar os índices de cáries em crianças da } \\
\text { Malásia, e investigar e avaliar os fatores } \\
\text { determinantes da doença nestes grupos. }\end{array}$ \\
\hline OU-YANG, 2019 & Relato de caso & $\begin{array}{c}\text { Este relato de caso apresenta a reabilitação } \\
\text { protética oral precoce de } 2 \text { irmãs gêmeas } \\
\text { com displasia ectodérmica e hipodontia } \\
\text { severa na dentição decídua. }\end{array}$ \\
\hline RAJAN et al., 2019 & Relato de caso \\
clinico & $\begin{array}{c}\text { Paciente de cinco anos de idade com displasia } \\
\text { ectodérmica, e a inserção de um tratamento } \\
\text { de implantes dentários, após uma não } \\
\text { adaptação a outros meios de reabilitação } \\
\text { estético-funcional. }\end{array}$ \\
\hline ALRASHDI et al., 2020 & Relato de caso \\
clínico & $\begin{array}{c}\text { Relatar os objetivos, tratamento e problemas } \\
\text { encontrados no tratamento de crianças DGI-II } \\
\text { da mesma família, usando dois diferentes } \\
\text { abordagens de tratamento, uma na dentição } \\
\text { decídua e outra na dentição mista inicial. }\end{array}$ \\
\hline
\end{tabular}

Fonte: Autoria própria.

Além de restabelecer a função e a estética, a reabilitação oral visa abranger o paciente como um todo, incluindo seu bem-estar psicológico, revelando tamanha importância de um trabalho multidisciplinar capaz de englobar várias especialidades com um único objetivo, que é reconstituir as funções orais e sociais do paciente infantil (ALNUAIMI; MANSOOR, 2019).

O tratamento multidisciplinar é essencial, para isso os profissionais envolvidos devem trabalhar em conjunto, atentando-se a todas as fases de desenvolvimento dentário e esquelético da criança, portanto, a equipe multiprofissional deve considerar todas as opções de tratamento e planejar juntos a melhor técnica a ser realizada (KNOBLOCH et al., 2018).

Ademais, a multidisciplinariedade em casos de reabilitação oral em crianças é indispensável para um resultado satisfatório, geralmente o trabalho do cirurgiãodentista é realizado com acompanhamento de fonoaudiólogos e psicólogos, especialidades que ajudam diretamente na adaptação ao novo comum do paciente (TRICHES et al., 2017).

A estética e os fatores psicológicos têm correlação notória, durante a infância poderá gerar uma insatisfação, que a longo prazo poderá atrapalhar o seu 
desenvolvimento escolar, e prejudicar a maturidade mental do mesmo. Sob outra perspectiva, a aceitação ao tratamento reabilitador estético-funcional se torna menos facilitada, uma vez que, crianças são pouco contribuintes, no geral a vida social consegue ser restabelecida, trazendo bem-estar e prazer a esses pacientes (PINTO et al., 2016).

Esse fator pode ser observado no estudo de Retnakumari et al. (2016), em que foi relatado um caso raro de anodontia associada a displasia ectodérmica anidrótica em um paciente de 5 anos, sua principal queixa era estética, que a deixava receosa ao ir para escola, assim, após sua reabilitação oral com prótese total foi notória a resposta positiva ao tratamento e a mesma foi inserida com sucesso no meio escolar.

Além de afetar a aparência, existe a possibilidade da criança estar sujeita a uma má nutrição devido a dificuldade na ingestão de alguns alimentos, resultante da ausência de um ou mais elementos dentários. A deglutição de alguns grupos alimentares se torna comprometida, fazendo com que o indivíduo evite consumi-los devido a mastigação deficiente (KANTOVITZ et al., 2016).

Pinto et al. (2016) apresentaram um caso clínico, referente a uma criança de 6 anos com displasia ectodérmica hipoidrótica, que possuía grande dificuldade de deglutição e ingestão de alimentos com aspectos mais duros ou fibrosos, como tratamento realizou-se a restauração de dentes superiores e a confecção de prótese parcial removível inferior, constatando-se após seis meses de acompanhamento um aumento de peso considerável, resultando em uma função mastigatória melhorada que contribuiu diretamente para a nutrição da criança e implementação de uma dieta mais rica.

A reabilitação oral de crianças com displasia ectodérmica também pode ser obtida através das próteses dentárias, sejam totais ou parciais. As próteses totais são produzidas por meio de moldagem anatômica com silicona de condensação, em seguida moldagem funcional com pasta zinco-enólica, registros no plano de cera, registro intermaxilar, seguido de prova de dentes e prova final da prótese. Por consequência dos rebordos alveolares reduzidos, podem apresentar instabilidade na prótese, portanto recomenda-se a utilização de creme fixador, bem como saliva artificial para lubrificação bucal (KNOBLOCH et al.,2018).

Já em outros casos da displasia ectodérmica, faz-se necessária a reabilitação oral através de próteses parciais removíveis, onde sua confecção inicia-se por moldagem 
anatômica com alginato, seguida da moldagem funcional com material elástico de poliéter e medições das dimensões verticais. Em seguida, os dentes são fixados em cera e a prótese acrilizada, apoios circunferenciais em dentes disponíveis são indicados para uma melhor adaptação da prótese (MAROULAKOS et al., 2016).

A reabilitação por meio de próteses removíveis pode ser realizada a partir dos 3 anos completos de idade da criança, porém esse tipo de reabilitação inclui algumas limitações, como episódios de vômitos ao inserir a prótese, ingestão inicial apenas de alimentos moles, dificuldade de uso em público. Além disso, a troca das próteses devem ser feitas periodicamente acompanhando o crescimento craniofacial desses pacientes (DALLEDONE et al., 2017).

A reabilitação oral de crianças com ausências dentárias é uma questão que levanta opiniões divergentes na literatura, alguns estudos apontam que a reabilitação por implantes dentários em pacientes em desenvolvimento, podem causar efeitos adversos no crescimento craniofacial e repercussões negativas na estética e função, portanto é indicada apenas a partir dos 15 anos de idade (KILIC et al., 2017). Ao contrário de outros autores que sugerem a colocação do implante dentário a partir dos 3 anos completos da criança, para que ao decorrer dos anos, ele consiga melhorar sua autoestima e convívio social, porém ressaltam algumas complicações do procedimento a ser realizado nesta fase de desenvolvimento, como o imperfeito crescimento craniofacial (RAJAN et al., 2019).

Para Taborda et al. (2018), crianças com displasia ectodérmica que estão na primeira infância de 0 a 6 anos não se recomenda a reabilitação oral por meio de implantes dentários, pois os mesmos não acompanham o crescimento craniofacial da criança, comportando-se como anquilose dentária em posição infraoclusal. Pode ainda ocorrer complicações como limitação do desenvolvimento dos ossos basais, luxação, exposição do implante e comprometimento estético-funcional.

Já no estudo clínico de Knobloch et al. (2018), com um paciente de nove anos, portador de displasia ectodérmica, foi obtido sucesso no caso apresentado, através da reabilitação utilizando uma prótese dentária sobre implantes. Com a instalação dos implantes foi possível retardar o processo de reabsorção óssea, estabelecendo altura e largura alveolar para a sustentação da prótese implanto-suportada. 
Taborda et al. (2018) relatam em seu estudo que a idade cronológica do paciente nem sempre coincidirá com a maturação óssea, mas por meio de radiografias de punho pode-se analisar a idade esquelética do paciente. Este fato corrobora com o artigo de Dalledone et al. (2017), onde os autores ressaltam a importância da avaliação esquelética, principalmente para o planejamento de implantes dentários em crianças.

Além disso, com a ausência dentária a retenção e estabilidade fornecidas pela crista alveolar podem ser comprometidas em prótese removíveis convencionais, deste modo, os implantes podem restabelecer esse importante elemento para reabilitação oral, porém, é necessário o correto planejamento e a discussão do caso, avaliando se resultados positivos superam os riscos (KNOBLOCH et al., 2018).

Em contrapartida, a reabilitação estético-funcional em alguns pacientes com defeitos na formação dentária pode ser obtida por meio de alternativas menos invasivas, que possuem mais variações de tratamento e uma aceitação maior dos estudos por usar técnicas mais conservadoras, como a restauração de resina composta direta e indireta, facetas, coroas cerâmicas, dentre outros (DURSUN et al., 2016).

\section{CONSIDERACÕES FINAIS}

Diante do exposto é notória a diversidade de tratamentos reabilitadores para crianças que possuem alterações estético-funcionais, desde alternativas como a reabilitação por próteses implantossuportadas, próteses totais e/ou parciais removíveis, até técnicas conservadoras como a utilização facetas e coroas dentárias.

Desta forma, a reabilitação oral protética, pode ser um importante mediador para a melhora da saúde como um todo, promovendo desde benefícios estéticos, com a possibilidade de um sorriso harmônico, melhora da autoestima e convívio social, como também contribui para a fonação e restabelece a função mastigatória, auxiliando diretamente na nutrição da criança e a implementação de uma dieta mais rica.

\section{REFERÊNCIAS}

ALNUAIMI, R; MANSOOR, M. Prosthetic rehabilitation with fixed prosthesis of a 5-yearold child with Hypohidrotic Ectodermal Dysplasia and Oligodontia: a case report. Journal of medical case reports, v. 13, n. 1, p. 1-6, 2019. 
ALRASHDI, Murad et al. Full Mouth Rehabilitation of Two Siblings with Dentinogenesis Imperfecta Type II Using Different Treatment Modalities. International Journal of Environmental Research and Public Health, v. 17, n. 19, p. 7029, 2020.

CHEN, A. Y.; CHEN, K. Dental treatment considerations for a pediatric patient with incontinentia pigmenti (Bloch-Sulzberger syndrome). European journal of dentistry, v. 11, n. 02, p. 264-267, 2017.

DALLEDONE, M. et al. Oral rehabilitation with removable dental prosthesis in a six-yearold patient with hypohidrotic ectodermal dysplasia. RSBO Revista Sul-Brasileira de Odontologia, v. 14, n. 1, p. 44-49, 2017.

DURSUN, E. et al. Management of amelogenesis imperfecta: a 15-year case history of two siblings. Operative dentistry, v. 41, n. 6, p. 567-577, 2016.

ESSVEIN, G. et al. Atendimento odontológico na primeira infância no Brasil: da política pública à evidência. Revista de Saúde Pública, v. 53, 2019.

FOUCHER, F.; MAINJOT, A. K. Polymer-Infiltrated-Ceramic-Network, CAD/CAM Restorations for Oral Rehabilitation of Pediatric Patients with X-Linked Ectodermal Dysplasia. International Journal of Prosthodontics, v. 31, n. 6, 2018.

KANTOVITZ, K. R. et al. A Clinical Report of Functional and Esthetic Oral Rehabilitation in a High-caries-risk Child: One-year follow-up. Brazilian Dental Science, v. 19, n. 1, p. 125-128, 2016.

KILIC, S. et al. Six-Year Survival of a Mini Dental Implant-Retained Overdenture in a Child with Ectodermal Dysplasia. Journal of Prosthodontics, v. 26, n. 1, p. 70-74, 2017.

KNOBLOCH, L. A. et al. Early implant placement for a patient with ectodermal dysplasia: Thirteen years of clinical care. The Journal of prosthetic dentistry, v. 119, n. 5, p. 702-709, 2018.

MAROULAKOS, G. et al. Removable partial dentures vs overdentures in children with ectodermal dysplasia: two case reports. European archives of paediatric dentistry, v. 17, n. 3, p. 205-210, 2016.

MOHD NOR, N. A. et al. The prevalence of enamel and dentine caries lesions and their determinant factors among children living in fluoridated and non-fluoridated areas. Community dental health, v. 36, n. 3, p. 229-236, 2019.

OU-YANG, L. W.; LI, T. Y.; TSAI, A. I. Early prosthodontic intervention on two three-yearold twin girls with ectodermal dysplasia. European journal of paediatric dentistry, v. 20, n. 2, p. 139-142, 2019.

PINTO, A. S. B. et al. Prosthetic management of a child with hypohidrotic ectodermal dysplasia: 6-year follow-up. Case reports in dentistry, v. 2016, 2016.

RAJAN, G. Implant Supported Oral Rehabilitation in a 5-Year-old ectodermal dysplasia patient. Clinical Dentistry (0974-3979), v. 13, n. 10, 2019. 
RETNAKUMARI, N. et al. Christ siemens touraine syndrome: A rare case report. Journal of Indian Society of Pedodontics and Preventive Dentistry, v. 34, n. 2, p. 185, 2016.

TABORDA, E. C. et al. Reabilitação oral com prótese total em pacientes infantis com displasia ectodérmica-relato de caso clínico. RSBO, v. 15, n. 1, p. 41-09, 2018.

TRICHES, T. C. et al. Implant-supported oral rehabilitation in child with Ectodermal dysplasia-4-year follow-up. The Bulletin of Tokyo Dental College, v. 58, n. 1, p. 49-56, 2017. 


\title{
CAPITULO XV
}

\section{TRANSPLANTE DENTÁRIO AUTÓGENO: UMA ABORDAGEM NA ODONTOPEDIATRIA}

DOI: $10.51859 /$ AMPLLA.EPC757.1121-15

\author{
Antonio Gonçalves Oliveira Neto ${ }^{1}$ \\ Elisama de Oliveira Mendes ${ }^{1}$ \\ Haylla Freitas Vieira ${ }^{1}$ \\ Mylleny Estrela Bandeira ${ }^{1}$ \\ Cristiane de Oliveira Pinto ${ }^{1}$ \\ Alfredo Carlos Rodrigues Feitosa ${ }^{2}$
}

\begin{abstract}
Graduando do curso de Odontologia. Faculdade Pitágoras de Imperatriz - MA
${ }^{2}$ Orientador e Professor Titular em Odontologia do Departamento de Clínica Odontológica da Universidade Federal do Espirito Santo (UFES)
\end{abstract}

\section{RESUMO}

Os transplantes dentários autógenos são substituições de dentes perdidos ou ausentes por outros elementos dentários do mesmo paciente que são avulsionados dos seus locais de origem. O objetivo do presente trabalho é relatar a evolução histórica, as indicações e critérios para sucesso clínico, as contraindicações e complicações, bem como, as técnicas e cuidados cirúrgicos, além das vantagens desses procedimentos no público infantil junto à especialidade da Odontopediatria. Trata-se de uma revisão bibliográfica através de buscas em bases de dados eletrônicas como: PubMed e Google Scholar, com artigos publicados entre os anos 2005 a 2021, tanto em português quanto em inglês, utilizando-se os seguintes descritores: "Dental Autotransplant", Young Patients" e "Pediatric Dentistry". O transplante dentário autógeno é uma solução confiável disponível na Odontopediatria, pois apoia os dentes circunvizinhos, estimulando a formação natural de osso, restaurando o sorriso e garantido o bem-estar do paciente. Normalmente, o transplante autógeno ocorre em terceiros molares para o lugar dos primeiros ou segundos molares; de pré-molares para o lugar de incisivos e de caninos impactados para sua posição funcional. Para o sucesso do procedimento são necessários vários fatores, entre eles: técnica cirúrgica adequada, mínimo trauma na região, grau de desenvolvimento radicular do dente selecionado, ausência de carga mastigatória precoce e um acompanhamento clínico e radiográfico.

Palavras-chave: Autotransplante, Paciente jovem, Odontopediatria. 


\section{INTRODUÇÃO}

O transplante dental autógeno (TDA) é a transferência de um dente com vitalidade ou tratado endodonticamente do seu local de origem para outro sítio, sendo necessário que esse elemento pertença ao mesmo indivíduo para ser considerado autógeno (CRUZ, 2021. Et al)

Os procedimentos de transplantes autógenos foram inicialmente descritos por Harland Apfel em 1950, para os terceiros molares na substituição dos primeiros e segundos molares. As causas mais comuns para a substituição são: cáries extensas, complicações periapicais, aplasias de pré-molares, fraturas corono radiculares, indicações ortodônticas, dentes impactados que não podem erupcionar dentro de uma oclusão funcional, dentes supranumerários, finalidades estéticas e motivos econômicos (BARBIERI et al., 2008).

Esses transplantes são realizados há mais de 40 anos nos países escandinavos, permitindo uma elevada taxa de sucesso na população destes países, sendo procedimentos rotineiros e com protocolos bem estabelecidos nos serviços odontológicos (SANTOS et al., 2013).

O transplante dental pode ser realizado pela técnica convencional ou imediata em uma única etapa, que consiste em realizar a extração do dente a ser transplantado e o preparo da cavidade óssea alveolar para o qual esse dente será transferido ou pela técnica mediata, em duas etapas, na qual o alvéolo cirúrgico é preparado na primeira etapa. Após um período inicial de cicatrização de aproximadamente 14 dias, realiza-se, na segunda etapa, a exodontia e o transplante. O sucesso do procedimento depende de uma série de fatores, tais como técnicas cirúrgicas adequadas, mínimo trauma na região, grau de desenvolvimento radicular do dente selecionado, ausência de carga mastigatória precoce e um acompanhamento clínico e radiográfico. É importante que o dente a ser transplantado apresente de dois terços a três quartos do comprimento radicular, e a rizogênese esteja incompleta, para que o término da rizogênese aconteça no leito receptor. O alvéolo receptor não deve apresentar evidência de lesão inflamatória aguda. É imprescindível, também, que o paciente apresente boa saúde sistêmica, para evitar comprometimento imunológico e cicatricial (BARBIERI et al., 2008). 
Em situações que ocorram perda dentária permanente precoce em crianças, seja por trauma, cárie, agenesia ou por outras causas, a reabilitação oral por implante ou prótese fixa não é indicada mediante sua fase de crescimento e desenvolvimento, tendo então a indicação do autotransplante dentário. Dessa forma, o presente capitulo intitulado transplante dentário autógeno: uma abordagem na Odontopediatria, tem como objetivo central relatar a evolução histórica, indicações e critérios para sucesso clinico, contraindicações complicações, técnicas e cuidados cirúrgicos, além das vantagens desse procedimento no público infantil.

\section{METODOLOGIA}

Para a revisão bibliográfica foram utilizadas as ferramentas de busca nas bases de dados PubMed e Google Scholar, através dos descritores "Dental Autotransplant", Young Patients" e "Pediatric Dentistry", para levantamento de estudos voltado ao objetivo do tema proposto. Através da leitura dos resumos e títulos, foram selecionados 14 artigos nos idiomas inglês e português, sem data limite de publicação. Foram incluídos relatos de casos, estudo retrospectivo descritivo, revisão integrada e sistemática, e os critérios de exclusão foram editoriais e capítulos de livros.

\section{REVISÃO BIBLIOGRÁFICA}

As crianças são indivíduos bem ativos e, infelizmente, às vezes sofrem acidentes e perdem os dentes permanentes. Perder um incisivo central permanente e ter um espaço vazio pode ser desesperador para os pais. Diante da necessidade do pleno crescimento craniofacial, os implantes dentários só podem ser implantados após esse desenvolvimento. Nessas situações, o autotransplante dentário é uma boa indicação em abordagem na Odontopediatria, visto que esse procedimento realizado com dentes em rizogênese incompleta tem melhor prognóstico, possibilita o desenvolvimento do osso alveolar, além de ter altas taxas de sucesso na literatura (AQUINO et al, 2019).

\subsection{EVOLUÇÃO HISTÓRICA}

Ao longo da história da civilização, a existência de toda uma dentição é considerada de grande valor por razões funcionais e estéticas. Isso levou as pessoas em todo o mundo a substituir os dentes perdidos em várias épocas, o que acabou levando 
à invenção e ao uso de implantes dentários. Ao longo do processo de evolução do implante, na história antiga, era comum substituir dentes perdidos por dentes de animais ou de outros povos (SMITH, 2019).

Até a descoberta do sucesso clínico de implantes dentários, verificado atualmente, foram várias as tentativas e experimentos no decorrer da história que não obtiveram sucesso, pois eram bastante suscetíveis à rejeição, sendo fabricados com compostos que poderiam facilmente ser encapsulados, causando infecções e atrapalhando a reconstituição das funções bucais, como a mastigação (VITAL ODONTO, 2020).

Alguns pesquisadores, durante o século XVIII, começaram com o uso do ouro e ligas em experimentos para fazer implantes dentários, onde não foi verificado eficiência. Logo após, em 1886, um médico instalou uma coroa de porcelana em um disco de platina, que também não produziu resultados bons a longo prazo. Já em 1952, um médico ortopédico aproximou-se da eficiência, descobriu as características especiais necessárias para uma fusão bem-sucedida ao relacionar um cilindro de titânio fundido junto ao osso do fémur de um coelho durante um estudo na cura e na regeneração do osso, supondo que esse material poderia ser utilizado para implante dentários (SMITH, 2019).

Os implantes dentários de titânio surgiram na Suécia em 1965 e foram concebidos por Branemark. Ele descobriu que o titânio, ao contrário de outros materiais, poderia promover a óssea integração, onde elevou a taxa de sucesso dos implantes dentários para 95\% (VITAL ODONTO, 2020).

A história dos implantes anda em constante evolução. Os transplantes dentários autógenos, que corresponde a substituição de um dente perdido ou ausente por outro elemento dentário do mesmo paciente que é avulsionado do seu local de origem, foi documentado pela primeira vez por Hale, onde até os dias atuais os princípios dessa técnica cirúrgica são praticamente os mesmos. No Brasil, desde a década de 1980, Roldi e sua equipe transdisciplinar realizam transplantes autógenos, acumulando centenas de casos (PEIXOTO et al., 2013).

Atualmente, é uma solução disponível que pode confiadamente apoiar os dentes circunvizinhos e estimular a formação natural de osso, podem restaurar o sorriso e a confiança total de um indivíduo. Normalmente, o transplante autógeno ocorre dos 
terceiros molares para o lugar dos primeiros ou segundos molares; de pré-molares para o lugar de incisivos e de caninos impactados para sua posição funcional (CRUZ et al., 2021; SMITH, 2019).

\subsection{INDICAÇÕES E CRITÉRIOS PARA SUCESSO CLÍNICO}

Existem diversas situações que o transplante dental autógeno pode ser indicado na Odontopediatria. Entre as mais comuns são na área estética, visto ser uma região mais exposta aos traumas e acidentes, quando o dente está ausente por problemas congênitos como a agenesia ou por perda dentária precoce por cárie. Outras situações também são prováveis, como erupção atípica de caninos, reabsorção radicular, grandes lesões endodônticas, fraturas da raiz cervical, processos patológicos como periodontite localizada e dentes inclusos ou mal posicionados, são causas suficientes para que o procedimento possa ser indicado (CONTE et al., 2019).

Alguns critérios são importantes para o sucesso desta técnica. As dimensões mésio-distal e ápico-coronal do dente a ser transportado devem ser compatíveis com o local receptor e, portanto, ter um tamanho proporcional. Todas as dimensões da área receptora devem ter suporte ósseo alveolar suficiente, com tecido queratinizado adequado, para estabilizar os dentes transplantados (CONTE et al., 2019).

O sítio receptor deve estar livre de infecção aguda e inflamação crônica, seja doença periodontal ou periapical, além de ser necessário que a exodontia do dente condenado seja realizada de maneira atraumática. O sucesso da operação depende da integridade da membrana periodontal ou folículo dentário, de fatores relacionados à criança como paciente, sem descompensação sistêmica, e seu responsável, pois podem supervisionar para que a criança tenha boas condições de higiene bucal e faça o acompanhamento sempre que solicitado (AQUINO et al., 2019; PEIXOTO et al., 2013).

Outro fator básico é a curta duração do dente a ser transplantado fora do alvéolo e o meio de armazenamento que ele ficará, que deve ser úmido, conter glicose, íons Ca e Mg, ter pressão osmótica e valor de pH compatíveis. O meio de cultura deve ser capaz de manter e / ou fornecer metabólitos para células do ligamento periodontal, sendo os mais ideais as soluções salinas balanceadas de Hank e ViaSpan. Porém, devido as questões econômicas e sua disponibilidade, o soro fisiológico é o meio de armazenamento mais comum (PEIXOTO et al., 2013). 
O comprimento radicular ideal no momento do autotransplante é de $2 / 3$ a $3 / 4$ da raiz formada, com forame apical aberto, pois favorece a revascularização pulpar para que não seja necessário o tratamento endodôntico. A técnica cirúrgica envolvendo dentes com menos de dois terços da formação da raiz pode causar grande trauma e pode afetar o desenvolvimento da raiz, podendo ocasionar uma falha no processo de maturação. Ademais, a existência de uma raiz suficientemente longa protege o transplante, caso não ocorra o desenvolvimento radicular no pós-operatório (AQUINO et al., 2019; CRUZ et al., 2021).

O transplante dentário em rizogênese incompleta tem melhor prognóstico, pois a solução líquida na superfície do sítio receptor contém íons, aminoácidos, peptídeos e diversos mediadores celulares, que irão nutrir e estimular os fenômenos de proliferação e reparo. Dessa forma, visando que o autotransplante pode obter melhor resultado antes da formação completa dentária, quando for realizado em área estética (anterior), é ideal que a idade da criança seja até os 12 anos, e na região posterior até os 16 anos, pois o processo de formação da raiz do dente está finalizando nesta idade. Em paciente jovem, os terceiros molares têm se mostrado uma excelente escolha de dentes doadores para o autotransplante na parte posterior da mandíbula e maxila, pois se desenvolvem tardiamente em comparação com outros elementos, e seus ápices ficam abertos até cerca de 18 anos de idade (AQUINO et al., 2019).

Vale lembrar que dentes de ápices fechados também podem ser usados, pois não impedem o potencial de regeneração pulpar, porém, o tratamento endodôntico costuma ser necessário (AQUINO et al., 2019). Em um estudo (KALLU et al., 2005) onde houve 273 transplantes autógenos realizados, dos 58 casos notificados de reabsorção, a maior porcentagem foi de dentes transplantados após completa formação da raiz e o menor número foi de casos com rizogênese incompleta.

O exame radiográfico é fundamental para a seleção e indicação da cirurgia, permite a análise de estruturas não identificadas durante o exame clínico, bem como determina o estágio de formação da raiz, o diâmetro mésio-distal do dente a ser transplantado e as possíveis patologias no sítio cirúrgico (CRUZ et al., 2021). 


\subsection{CONTRAINDICAÇÕES E COMPLICAÇÕES}

O procedimento está contraindicado nos casos em que os pacientes pediátricos apresentem infecções e/ou doenças periodontais nos dentes a serem transplantados, pois deverá ser realizado previamente o tratamento das condições desfavoráveis. Inviabiliza o procedimento também, os casos em que a morfologia radicular é complexa e quando houver a necessidade de odontossecção. Por outro lado, não pode ser realizado o procedimento, os dentes que possuem dimensões maiores do que a área receptora, havendo falta de espaço adequado na região (CONTE et al., 2019).

Torna-se contraindicado também, quando houver possibilidade de tratamento conservador ou tracionamento ortodôntico, não ser possível estabilizar o dente no leito receptor, condições de má higiene bucal, descompensação sistêmica da criança, ausência de um dente doador adequado ou osso insuficiente no local do receptor (AQUINO et al., 2019).

As complicações possíveis de acontecer com o procedimento são perda do elemento transplantado, anquilose, reabsorção radicular, necrose pulpar, perda de inserção do transplante, cáries, fratura de raiz, falha na cicatrização inicial, bolsa periodontal e mobilidade (AQUINO et al., 2019; CONTE et al., 2019). A imagem do exame complementar (Figura 1) mostra uns dos principais fatores que influência para a taxa de insucesso do transplante, a reabsorção e crescimento incompleto da raiz. Isso acontece devido a danos à raiz durante a extração embora todo o cuidado tenha sido prestado, ou trauma oclusal no momento da transplantação. 
Figura 1: Pré-molar transplantado mostrando reabsorção radicular externa, obliteração pulpar e formação de raiz incompleta.

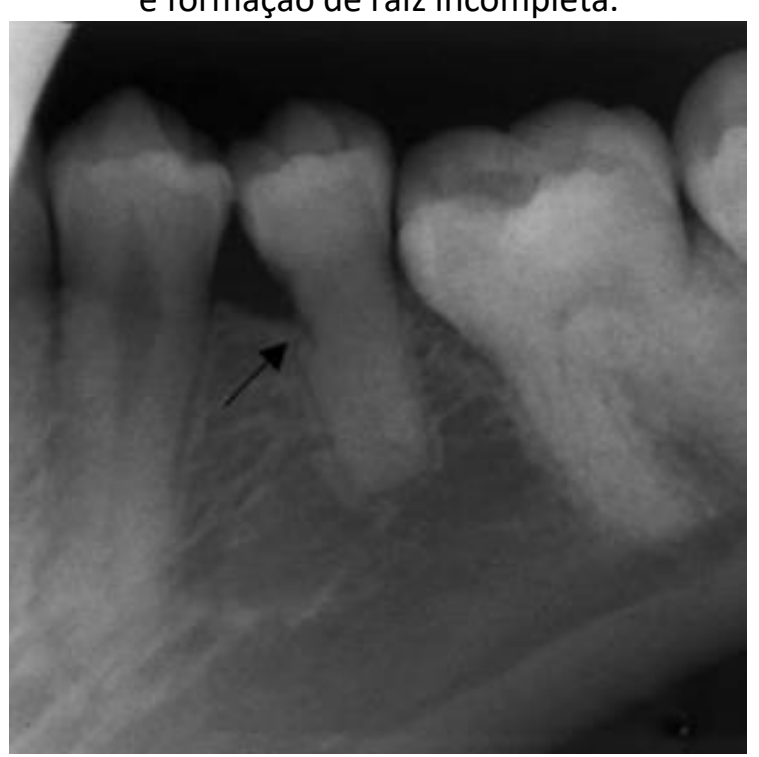

Fonte: (KALLU et al., 2005).

\subsection{TÉCNICAS E CUIDADOS CIRÚRGICOS}

O transplante dental pode ser realizado em uma única etapa pela técnica convencional ou imediata, que consiste em realizar a extração do dente a ser transplantado e a preparação da cavidade óssea alveolar que receberá o dente. Outra opção é a técnica mediata ou tardia, em duas etapas, na qual o alvéolo cirúrgico é preparado na primeira etapa e, após um período inicial de cicatrização de aproximadamente 14 dias, realiza-se a exodontia e o transplante na segunda etapa. 0 período de duas semanas pode melhorar o prognóstico, permitindo que o leito receptor forneça mais nutrientes ao cemento do dente a ser transplantado e às células do ligamento periodontal. (PEIXOTO et al., 2013).

O procedimento deve ser realizado com atenção e cuidados, o dente condenado deve ser removido com o mínimo trauma cirúrgico para que o leito receptor possa ser preparado, sendo cuidadosamente curetado e irrigado com solução fisiológica à $0,9 \%$ e, se necessário, realizado preparos com broca cirúrgica em alta rotação sob irrigação constante para melhor adaptação. Então, o dente deve ser inserido deixando-o em infra oclusão e, posteriormente, feito sutura e confecção da contenção (CONTE et al., 2019).

O tempo de contenção é projetado para estabilizar o dente transplantado em seu leito receptor e facilitar o processo de restauração. As técnicas semirrígidas ou flexíveis são usadas com sucesso porque permitem o movimento fisiológico do dente no 
alvéolo receptor, promovendo a ligação inicial das fibras em vez de uma união óssea entre o dente e o alvéolo, o que levaria a complicações como anquilose (PEIXOTO et al., 2013).

Os testes necessários para o acompanhamento são de mobilidade dental, vitalidade pulpar, profundidade de sondagem, nível clínico de inserção e teste de percussão. Sendo então, feito avaliações periodontal, oclusal e radiográfica para o melhor prognóstico (CONTE, et al., 2019).

O teste de sensibilidade pulpar é utilizado para avaliar a revascularização da polpa e a reinserção das fibras periodontais, sendo o teste eficaz somente três a quatro meses após o transplante, embora esse período possa ser mais longo. Portanto, a falta de sensibilidade no teste não significa que haja necrose pulpar, é necessário aguardar até que algum sinal clínico-radiográfico (como: escurecimento coronário, fístula, reabsorção radicular, lesão periapical, entre outros) exija a endodontia do dente transplantado (PEIXOTO et al., 2013).

A profundidade de sondagem e a presença de recessão gengival devem ser medidas em milímetros para melhor prognóstico. A perda de inserção gengival após transplantes de dentes em crianças, com rizogênese incompleta, é rara, pois a cicatrização do ligamento periodontal pode ser evidenciada pela formação da lâmina dura, observada após cerca de um mês da cirurgia (PEIXOTO et al., 2013).

No caso clínico publicado por ARAÚJO (2021), paciente de 10 anos sofreu um acidente e perdeu o incisivo central trazendo grandes consequências ao seu sorriso, observado na imagem A (Figura 2). O Dr. Maurício Araújo realizou o autotransplante de um pré-molar para a região do incisivo central superior como mostra a imagem B (Figura 2), e após cicatrização, na imagem C (Figura 2) observa-se reanatomização com resina composta. Com isso, pode-se verificar a melhora na estética, com tecido saudável e tratamento duradouro. 
Figura 2: Transplante dentário autógeno de um pré-molar para a região do incisivo central superior.

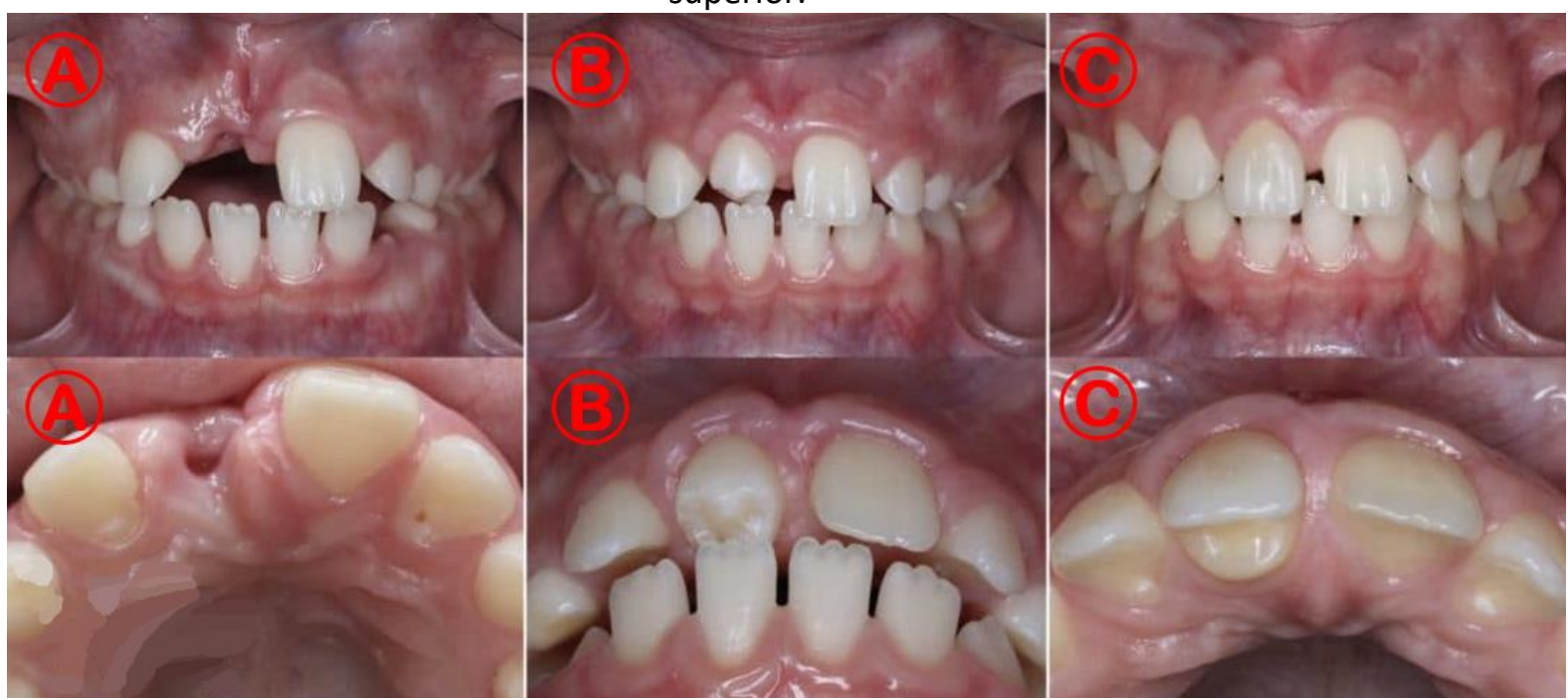

Fonte: (ARAÚJO, 2021).

\subsection{VANTAGENS DO TRANSPLANTE DENTÁRIO AUTÓGENO}

O autotransplante na abordagem pediátrica fornece várias vantagens, dentre elas, a redução do custo se comparado a outros meios de reabilitação oral, tornando-o uma opção de tratamento a todas as camadas sociais. Diante das crianças estarem em constante crescimento e, consequentemente, desenvolvimento craniofacial, a reabilitação com implante ou prótese fixa não é indicada. Dessa forma, o transplante dentário autógeno evita que a criança sofra com o uso de próteses temporárias (CONTE et al., 2019).

É uma boa opção a ser realizado nesses pacientes que estão em fase de crescimento, pois mantém a viabilidade do ligamento periodontal, pode ser realizado a movimentação com aparelhos ortodônticos (o que não é permitido em um implante dentário, e resulta em um posicionamento do dente auto transplantado após o total crescimento da criança), além de poder manter a estrutura óssea alveolar, recuperando o espaço do dente perdido, possibilitando o desenvolvimento do osso alveolar na área receptora e evitando alterações no desenvolvimento da maxila e da mandíbula. Sendo então, um procedimento seguro e favorável para crianças que perderam os dentes precocemente (CRUZ et al., 2021). 


\section{CONSIDERAÇÕES FINAIS}

O transplante dentário autógeno apresenta-se, portanto, como uma boa alternativa terapêutica para reabilitação oral em pacientes pediátricos. Além de ser um procedimento de baixo custo, quando corretamente indicado, o índice de sucesso é grande e permite devolver as características estéticas e funcionais ao paciente. Os transplantes de dentes em rizogênese têm um prognóstico melhor, pois os líquidos presentes na superfície do sítio receptor contêm íons, aminoácidos, peptídeos e vários mediadores celulares que irão nutrir e estimular fenômenos proliferativos e reparadores.

Estudos vêm sendo realizados, confirmando que o transplante dental autógeno é um procedimento seguro, rápido e economicamente viável e que, a depender de uma associação de uma boa técnica cirúrgica, atenção e habilidade do cirurgião e da cooperação do paciente, o prognóstico é favorável. Sendo assim, o transplante dental autógeno é considerado uma alternativa viável para a reabilitação oral de pacientes pediátricos na substituição de dentes perdidos.

\section{REFERÊNCIAS}

AQUINO, L. E. DO N. et al. Transplante dental autógeno. Revista Odontológica do Brasil Central, v. 28, n. 84, p. 26-29, 2019.

ARAÚJO. Autotransplante Dentário. Mauricio Araújo clinica odontológica, 2020. Disponivel em: <https://clinicamauricioaraujo.com.br/transplante-dentarioautogeno-ou-autotransplante-dentario/>. Acesso em: 20 de jul. de 2021.

BARBIERI, A. A. et al. Cirurgia de transplante autógeno pela técnica imediata TT Autogenous transplantation surgery through the immediate technique. Revista de Cirurgia e Traumatologia Buco-Maxilo-Facial, v. 8, n. 3, p. 35-40, 2008.

CONSOLARO, A. et al. Transplantes dentários autógenos: uma solução para casos ortodônticos e uma casuística brasileira. Revista Dental Press de Ortodontia e Ortopedia Facial, v. 13, n. 2, p. 23-28, 2008.

CONTE, P. C.; JARDIM, L. T. Caso Clínico Transplante dentário autógeno : revisão de literatura e relato de caso clínico. p. 273-278, 2019.

CRUZ, A. I. et al. Transplante autógeno em dentes posteriores: Revisão Integrativa. Research, Society and Development,v. 10, n. 3, p. 1-9, 2021. 
KALLU, R. et al. Tooth transplantations: A descriptive retrospective study. International Journal of Oral and Maxillofacial Surgery, v. 34, n. 7, p. 745-755, 2005.

LISBOA, U. DE. Faculdade Medicina Dentária Taxa de sobrevivência e sucesso do autotransplante dentário Revisão sistemática Ana Lúcia Apolinário Barata Dissertação Mestrado Integrado em Medicina Dentária Universidade de Lisboa Faculdade Medicina Dentária Taxa de sobreviv. 2020.

PEIXOTO, A. C.; MELO, A. R.; SANTOS, T. DE S. Transplante dentário: Atualização da literatura e relato de caso. Revista de Cirurgia e Traumatologia Buco-MaxiloFacial, v. 5458, n. 2, p. 75-80, 2013.

REBOUÇAS, D. S. et al. Autotransplante Dentário: Uma Opção Reabilitadora E Viável Ao Sus. Journal of Dentistry \& Public Health, v. 6, n. 1, 2015.

SANTOS, L. C. S. et al. Transplante dental autógeno como alternativa para reabilitação oral: relato de caso. Uningá Review, v. 14, n. 1, p. 49-57, 2013.

SILVA, R. M. et al. Conhecimento de estudantes de Odontologia sobre autotransplante dentário. Research, Society and Development. v.9 , n. 7, p. 1-16, 2020.

SMITH, Y. História de implantes dentais. News medical life sciences, 2019. Disponivel em: $\quad<$ https://www.news-medical.net/health/History-of-Dental-Implants(Portuguese).aspx>. Acesso em: 20 de jul. de 2021.

VITAL ODONTO. Um pouco de história sobre o implantes dentário. Vital odontontologia integrada, $2020 . \quad$ Disponivel em: <https://www.vitalodontoimplantes.com.br/artigo/um-pouco-de-historiasobre-o-implante-dentario/27/>. Acesso em: 20 de jul. de 2021. 


\title{
CAPITULO XVI \\ LESÕES BUCAIS DE TECIDOS MOLES COMUNS NA PRIMEIRA INFÂNCIA
}

DOI: 10.51859/AMPLLA.EPC757.1121-16

\author{
Wendel Chaves Carvalho ${ }^{1}$ \\ Dara Lourenna Silva da Nóbrega ${ }^{2}$ \\ Alícia de Fátima Mendes Pereira ${ }^{3}$ \\ Gabryella Bezerra Silva ${ }^{4}$ \\ lanca Danielle Penha Viana ${ }^{5}$ \\ Luana Martins Cantanhede ${ }^{6}$
}

\begin{abstract}
${ }^{1}$ Graduando do curso de Odontologia. Faculdade Pitágoras de São Luís - MA
${ }^{2}$ Graduanda do curso de Odontologia. Faculdade Pitágoras de São Luís - MA

3 Graduanda do curso de Odontologia. Faculdade Pitágoras de São Luís - MA

${ }^{4}$ Cirurgiã-Dentista. Faculdade Pitágoras de São Luís - MA

${ }^{5}$ Cirurgiã-Dentista. Faculdade Pitágoras de São Luís - MA

${ }^{6}$ Cirurgiã-Dentista. Especialista em Odontopediatria e Educação à Distância. Mestre e Doutora em Odontologia. Professora do curso de Odontologia da Faculdade Pitágoras e Centro Universitário UNDB.
\end{abstract}

\section{RESUMO}

A primeira infância pode ser definida como o período que abrange desde o nascimento até os seis anos completos de vida da criança. $O$ atendimento odontológico precoce na infância denominado geralmente de "Odontologia para bebês" é considerado de suma necessidade e importância, porém, esse fato ainda não é tão visível e rotineiro. Este estudo é uma revisão bibliográfica e tem como objetivo demonstra as principais lesões bucais de tecidos moles mais comuns na primeira infância. Foram incluídos artigos em português, inglês e espanhol, disponíveis nas bases de dados PubMed, Google Acadêmico, Scielo e Periódicos Capes. Serão incluídos artigos publicados sem data limite de publicação, utilizando os descritores: Patologia bucal, tecido mole oral, criança, mucosa bucal, odontopediatria. Doenças acometendo a cavidade bucal de crianças tem se tornado cada vez mais comum, principalmente na primeira infância. Os principais estudos mencionam que a prevalência das alterações na cavidade oral de crianças entre 0 a 3 anos evidenciam as alterações mais prevalentes durante esse período, são: Hematoma de erupção, Pérolas de Epstein, Lesões orais provenientes da varicela, Doença de riga-fede e Glossite migratória benigna, implicando em riscos à saúde da criança. É de suma importância diagnosticar precocemente essas alterações para que se possa estabelecer o sucesso do tratamento, ainda tendo como finalidade conscientizar os pais a respeito e tranquilizá-los.

Palavras-chave: Tecido mole oral. Patologia bucal. Criança. Odontopediatria. 


\section{INTRODUÇÃO}

A cavidade oral é considerada um complexo habitat microbiano e porta de entrada para fungos, bactérias, vírus e diversos outros microrganismos, capazes de se manifestar clinicamente através de infecções, refletindo diretamente assim na saúde geral. Nessa perspectiva, a manutenção de uma boa saúde bucal torna-se importante desde os primeiros dias de nossa vida, desempenhando funções fundamentais na fala, mastigação respiração, salivação e deglutição (GLORIA, 2011; MEDRADO, et al., 2020).

A primeira infância pode ser definida como o período que abrange desde o nascimento até os seis anos completos de vida da criança. Durante esse período, a boca apresenta constante crescimento e desenvolvimento, além de diversos processos fisiológicos próprios, alterações ou até mesmo o surgimento de doenças infecciosas que são capazes de se manifestarem clinicamente como lesões orais, na maioria das vezes em regiões de mucosa oral e nos tecidos gengivais (MEDRADO et al., 2020).

Atualmente $\mathrm{o}$ atendimento odontológico precoce na infância denominado geralmente de "Odontologia para bebês" é considerado de suma necessidade e importância, porém, esse fato ainda não é tão visível e rotineiro. Essa área tem como finalidade diagnosticar possíveis alterações da cavidade oral na primeira infância, além disso, visa conscientizar, por meio de ações educativas, os pais acerca de hábitos de higiene oral, práticas de alimentação saudável, assim como sobre a instalação e remoção de hábitos deletérios e o desenvolvimento da cronologia de erupção do bebê (BARBOSA, 2015; SANTOS; BARRETO, 2019).

A participação do profissional Odontopediatra durante esse período é crucial, salientando a respeito da importância do conhecimento do cirurgião-dentista no diagnóstico de lesões orais, diferenciando o fisiológico do patológico, dessa forma, este profissional é responsável por ter contato direto e examinar alterações a respeito sobre a saúde oral da criança (HADDAD et al., 2009).

É de suma importância diagnosticar precocemente essas alterações para que se possa estabelecer o sucesso do tratamento. Os principais estudos mencionam que a prevalência das alterações na cavidade oral de crianças entre 0 a 3 anos evidenciam as alterações mais prevalentes durante esse período, como: os nódulos de Bohn, pérolas de Epstein, língua geográfica, Anquiloglossia, Gengivite e Candidíase, sendo 
manifestações que geralmente não necessitam de biópsias para a confirmação (LIMARIVERA et al., 2016). Motisuki et al (2005), por meio de um estudo de levantamento bibliográfico realizado sobre as bases de dados científicas, no período entre (1990 a 2005), também sobre alterações bucais na infância, descreveu como as lesões mais prevalentes na infância, a mucocele, a infecção primária pelo vírus herpes simples (HSV), a úlcera aftosa e a língua geográfica.

Infelizmente ainda existem poucos estudos sobre alterações bucais na infância, sendo mais comum informações acerca de dados com faixas etárias mais abrangentes, incluindo os jovens (KNIEST et al., 2001; PIAZZETA, 2010; LIMA-RIVERA, et al., 2016). Pensando nisso, é de suma relevância mais estudos que abranjam essas temáticas. Nessa perspectiva, o presente estudo tem como objetivo descrever as principais lesões bucais de tecidos moles mais comuns na primeira infância, de forma características dos seus aspectos etiológicos e clínicos, de modo a elucidar o dentista acerca da importância do seu papel em fornecer um diagnóstico precoce, correto, assim como esclarecer os tratamentos, evitando a evolução do quadro e levando a uma menor preocupação da família.

\section{METODOLOGIA}

O seguinte trabalho será uma revisão bibliográfica sobre lesões bucais de tecidos moles comuns na primeira infância, nas quais as pesquisas serão fundamentadas através de buscas de artigos em português, inglês e espanhol, disponíveis nas bases de dados PubMed, Google Acadêmico, Scielo e Periódicos Capes. Serão incluídos artigos publicados sem data limite de publicação.

Os descritores utilizados para a pesquisa serão: Patologia bucal, tecido mole oral, criança, mucosa bucal, odontopediatria, indexados no decs. A seleção dos estudos para a realização desta pesquisa será feita a partir dos títulos e resumos.

Os critérios de inclusão que nortearão a busca serão trabalhos que possuam relevância e relação com a pesquisa que será realizada, que tratem da temática de lesões orais comuns em crianças. A pesquisa incluirá estudos clínicos, relatos de casos, estudos comparativos, observacionais e literatura cinza (monografias, teses e dissertações). Serão excluídos estudos com animais, e laboratoriais. Aqueles estudos 
que abordam lesões em jovens e adultos como tema principal também serão descartados da pesquisa.

Será realizada a leitura na íntegra dos estudos pesquisados, e será feita a extração de dados dos mesmos contendo o autor do estudo, data, tamanho da amostra, tipo de estudo e fator comparativo. A partir desses dados, será elaborada uma revisão de literatura referente a "Lesões bucais de tecidos moles comuns na primeira infância".

\section{REVISÃO BIBLIOGRÁFICA}

\subsection{HEMATOMA DE ERUPÇÃO}

A erupção dentária é considerada como um dos processos que se referem ao desenvolvimento e as mudanças que ocorrem no sistema imunológico do bebê. Dessa maneira, ela engloba um dos momentos mais aguardados por todos os pais em relação a cavidade oral da criança, sendo ainda mais preocupantes para os mesmos, visto que essa fase geralmente é acompanhada por diversos incômodos ao infanto, além da própria preocupação em relação a possibilidade do contato com objetos que lhe chegam à boca, sendo mais fácil a sua deglutição, podendo gerar problemas de risco a saúde da criança (CASAGRANDE, 2011; CARNEIRO, 2017; PINHEIRO, 2020)

Normalmente o primeiro dente decíduo do bebê irrompe por volta dos 6 meses de vida, acompanhado da presença de alguns sinais e sintomas, como: febre, salivação excessiva, febre, distúrbios gastrointestinais, perda de peso decorrente da falta de apetite e mudanças no comportamento da criança; como agitação, choro e distúrbios do sono (CARNEIRO, 2017).

Essas manifestações têm sido desencadeadas conforme sugere-se a existência de uma complexa interação entre células inflamatórias, proteínas da matriz do esmalte e imunoglobulina E (IgE). Dessa maneira, a presença de IgE nos tecidos em torno do dente em erupção resulta em reação de hipersensibilidade, o que pode ocasionar a sintomatologia sistêmica, caracterizada pela febre (VASQUES et al., 2010). O conhecimento acerca do tempo normal de erupção do dente, que pode variar da vida intrauterina até os 30 meses, possui fundamental importância clínica no diagnóstico de várias condições locais e sistêmicas que podem afetar este processo, tendo como exemplo o hematoma de erupção (CASTRO et al., 2019). 
O hematoma de erupção é definido como um dos cistos odontogênicos, ocorrendo mais comumente nas regiões entre dentes e ossos maxilares, sendo classificado como o segundo tipo mais comum de cisto dentígero, com localização extraóssea. Sua patogênese é desconhecida, mas, aparentemente ele se origina por conta de acúmulo de exsudato entre o epitélio reduzido do órgão de esmalte e a coroa do dente, se manifesta tanto na dentição decídua e permanente, sendo mais comum em meninos quando presente na primeira infância (ALMEIDA et al., 2015). Alguns estudos correlacionam a presença desse tipo de hematoma de erupção como uns dos sinais da erupção dentaria, sendo ainda visto como uma alteração que dificulta o processo, podendo se manifestar tanto na erupção decíduo quanto na permanente (NEVILLE et al., 2004). A imagem abaixo é um exemplo da lesão quando presente.

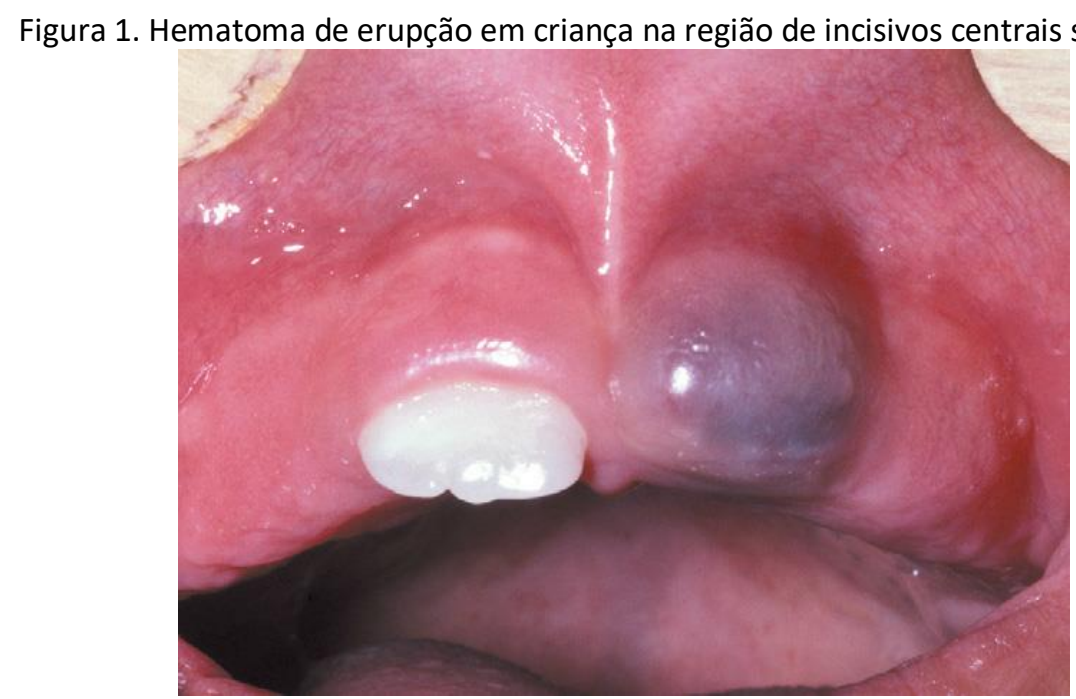

Fonte: (SCHITINI,2019).

Clinicamente, as lesões de cistos dentígero se apresenta como uma tumefação mole, com aspectos translucida, circunscrita, unilocular, bolhoso, flutuante sobre o dente, podendo conter apenas líquidos, ou pigmento hemoglobínico (sangue), quando o interior da cavidade cística que circunda o dente teve algum trauma, apresenta coloração de cor violácea ou azul escuro, lembrando um hematoma, sendo assim denominado "hematoma de erupção". De vista radiográfica observa uma área radiotransparente, sobre a coroa de um dente em erupção. O diagnóstico se baseia através o exame clinico e radiográfico (NEVILLE et al.,2004; GUEDES-PINTO, 2010; SANTOS, et al., 2011; CASAGRANDE, 2011; ALMEIDA, et al., 2015). 
Para Neville et al., (2004) e Laskaris (2000), esse cisto é uma variação em tecido mole do cisto dentígero, interligado a um dente que está em fase de erupção, sendo ocasionado devido a separação do folículo dentário ao redor da coroa do dente em erupção que está inserido dentro do tecido mole sobre o osso alveolar, sendo comum sua manifestação em incisivos, podendo também se apresentar em molares e caninos quando referido a decíduos. Já em permanentes é mais comum em as áreas de dentes inclusos como terceiros molares inferiores e caninos superiores, embora também sejam encontrados com certa frequência, na região de segundos pré-molares inferiores e de terceiros molares superiores (CASAGRANDE, 2011; SANTOS, et al., (2011)

Vale ressaltar que o atraso no processo de erupção não está associado somente a essa alteração, existe mais fatores interligados a esse problema tais como: alterações locais, sistêmicas, hipotireoidismo, desnutrição, ausência de dentes, supranumerários, traumatismos dento alveolares, e a presença de alguns tumores e cistos (VALENTINE, et al., 2007).

Em questão do tratamento, normalmente os estudos mencionam que não há necessidade de intervenção quando associado a dentição decídua, isso porque em geral a lesão rompe, ou desaparece, conforme o processo de erupção na cavidade bucal, entretanto em casos onde há forte relatos de dores, incomodo, necessita de tratamento, sendo indicado a marsupialização (drenagem local), ou ulectomia, sendo utilizado principalmente quando não ocorre a erupção de forma espontânea do dente, tendo como finalidade drenar o fluido cístico e facilitar a exposição da coroa na cavidade bucal, sendo importante antes um diagnóstico critico com exames clínico e radiográfico da região antes da tomada da decisão (GUEDES-PINTO, 1997; NEVILLE et al., 2004; ALMEIDA, et al., 2015).

\subsection{PÉROLAS DE EPSTEIN}

As pérolas de Epstein são descritas como pequenas elevações de colorações esbranquiçadas, geralmente distribuídas na região do palato duro comumente com maior dispersão na junção palato duro-palato mole, retidos ao longo de uma linha de efusão do recém-nascido, como demonstra a figura 2. Sua etiologia não é totalmente esclarecida, mas, infere-se que elas podem derivar de restos epiteliais de glândulas salivares palatinas em desenvolvimento, podendo também serem vistas ao longo das 
superfícies vestibulares e linguais dos rebordos maxilares e mandibulares e consideradas como resquícios de tecidos mucosos glandulares (EPSTEIN, 1880). Ainda conforme Neville (2004), esses tipos de lesões são considerados como cistos queratinizados localizados na região da rafe média palatina e estão presentes em grande maioria dos bebês recém-nascidos, tendo uma prevalência de $80 \%$, enquanto os nódulos de Bohn constituem elevações esbranquiçadas, dispersas no palato duro, que geralmente se encontram em maioria na junção palato duro/ palato mole e indicam serem derivadas de restos epiteliais de glândulas salivares palatinas em desenvolvimento (PENIDO; FONSECA, 2003).

As alterações presentes na mucosa oral de bebês em sua maioria possuem apresentações benignas e não requerem nenhum tipo de tratamento específico (BALDANI; LOPES; SCHEIDT, 2001). A conduta terapêutica na apresentação das pérolas de Epstein-Barr deve ser a observação juntamente com o acompanhamento do desenvolvimento que costuma ser involutivo, além de aconselhar aos pais sobre a realização de massagem digital suave. A tendência da alteração é o desaparecimento em algumas semanas, todavia, quando o seu volume é exagerado recomenda-se realizar a marsupialização (NEVILLE et al., 2004).

Figura 2. Pérolas de Epstein-Barr localizadas na mucosa oral da região supero-anterior de criança.

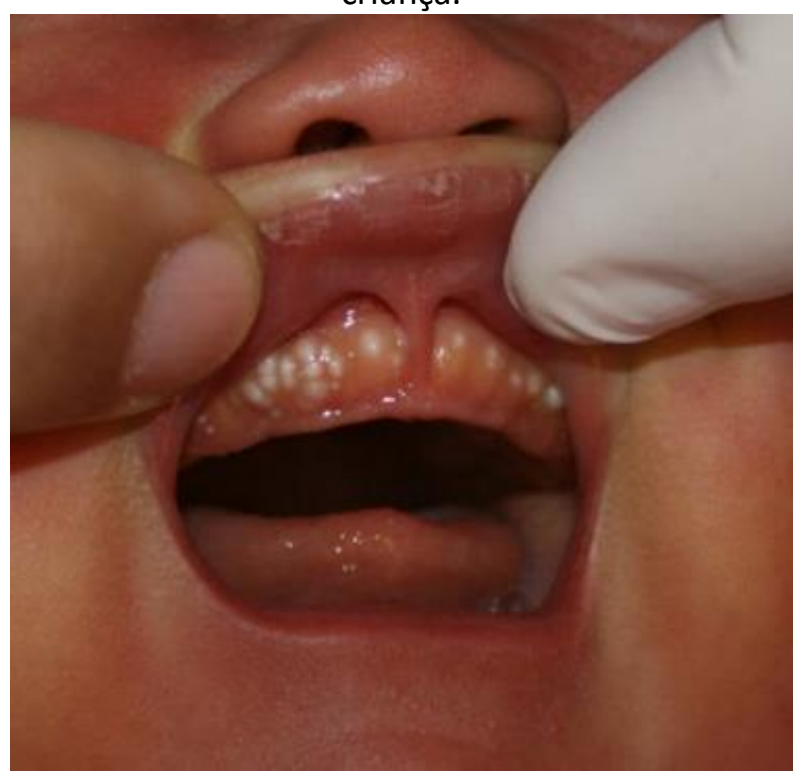

Fonte: (LESSA, 2015). 


\subsection{LESÕES ORAIS PROVENIENTES DA VARICELA}

A infecção primária do vírus varicela em crianças saudáveis é geralmente uma doença leve e autolimitada. (MAPLE et al., 2015) e quando um indivíduo susceptível é exposto ao vírus, este sofre, inicialmente uma replicação primária, iniciando 3 a 4 dias após a exposição, que ocorre nos gânglios linfáticos regionais e na orofaringe (ARNOLD et al., 2016; LAM et al., 2010).

As lesões cutâneas da varicela são perceptíveis em várias fases de cicatrização por meio de pequenas úlceras na área da cavidade oral e amígdalas, que podem causar dores ou não. Assim, pode haver apenas manifestação de prurido ou este pode ser concomitante com as úlceras. As manifestações orais da doença (enantema) podem, frequentemente, preceder a erupção cutânea (exantema) por 1 a 3 dias. Em crianças, a doença geralmente não é precedida por sintomas prodrômicos, sendo o primeiro sinal o enantema ou as manchas na cavidade oral. (LUCA et al., 2015).

As lesões que envolvem a mucosa oral podem aparecer como pequenas vesículas que se rompem, deixando estas úlceras com margem eritematosa e geralmente não são dolorosas, como mostra a figura 3 (VRANJAC, 2005). Além disso, geralmente a lesão mais precoce é representada por uma pequena vesícula que se apresenta em menor número somente na parede faríngea posterior, ou numerosas aparecendo na mucosa oral, gengiva, língua e em outras cavidades (WALTER; FERELLE; ISSÁO, 1997).

O diagnóstico dessa doença é a partir de exame clínico através da constatação dos primeiros sintomas prodrômicos típicos, seguidos de exantema e enantema característicos (LUCA et al., 2015), enquanto a confirmação obtida por intermédio laboratorial pode ser realizada através da demonstração da presença de antígenos virais específicos em amostras de pele, por imunofluorescência ou por PCR, sendo que estes métodos de diagnóstico são altamente sensíveis e rápidos. (LAM et al., 2010).

O diagnóstico diferencial da varicela é constituído pela pitiríase liquenóide, picadas de artrópodes, vírus do herpes simplex (HSV) e impetigo. (LEFEBVRE et al., 2010). Já a terapêutica da condição em indivíduos com maior risco de varicela grave, são muitas vezes administrados medicamentos antivirais, tais como aciclovir, ou imunoglobulinas ou específicos como profilaxia após suspeita de exposição. (ARNOLD et al., 2016). 
Figura 3. Lesões orais provenientes de um quadro de varicela em criança.

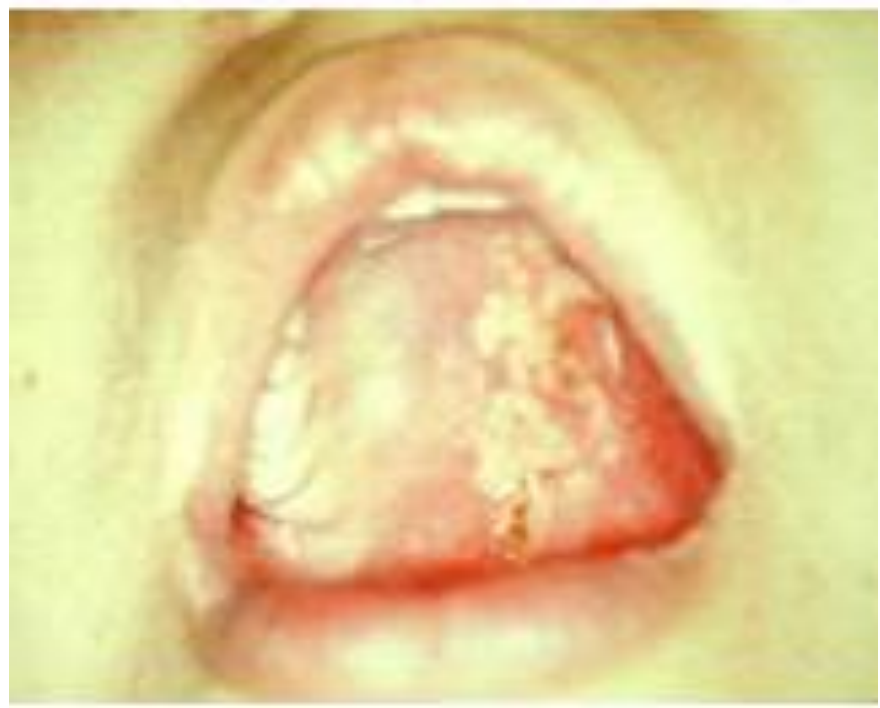

Fonte: CONSTANTINO; MIZIARA, 2008).

\subsection{DOENCSA DE RIGA-FEDE}

A lesão de Riga-Fede é uma ulceração traumática e pode estar associada a dentes natais ou neonatais (CEYHAN et al., 2009). Ela é tipicamente de ordem benigna e progride devido ao mecanismo traumático repetitivo (SOUZA et al., 2011), podendo aumentar e desencadear a formação de uma massa fibrosa com aparência de granuloma ulcerativo (COSTACURTA; MATURO; DOCIMOR, 2012). que pode causar danos na sucção do leite e na própria alimentação, colocando o recém-nascido em risco de deficiências nutricionais (SOCIEDADE BRASILEIRA DE PEDIATRIA, 2006). A sua etiologia ainda é de causa desconhecida, podendo estar ou não associada a hereditariedade ou até mesmo atrelada a alguma síndrome (JANINE; FERREIRA; MATHEUS, 2003; SENANAYAKE; KARUNARATNE, 2014).

Esse tipo de lesão pode ser caracterizada como uma ulceração crônica na mucosa oral causada pelo trauma persistente de um dente (CAMPOS-MUÑOZ et al., 2006). Ela se localiza, na maioria das vezes, na região ventral da língua, podendo acometer outras regiões como mucosa jugal, palato, dorso da língua, lábio e gengiva e clinicamente se apresenta como uma lesão ulcerativa bem delimitada com bordas elevadas e endurecidas, presença de exsudato, área cruenta e placa branca coalescente, como demonstra a figura 4 (CEYHAN et al., 2009).

Como muitas vezes pode se assemelhar a algumas doenças orais benignas e malignas, o diagnóstico diferencial da doença de Riga-Fede é importante. Apesar de 
inúmeros relatos terem sugerido a realização da biópsia prévia ao tratamento da doença de Riga-Fede, este procedimento raramente é necessário e deve ser indicado apenas para as lesões que não cicatrizam, mesmo após a remoção dos dentes (TAGHI; MOTAMEDI, 2009).

Os tratamentos para a doença de Riga-Fede dividem-se em duas alternativas: desgaste da borda incisal e acompanhamento no caso desse elemento não possuir grande mobilidade e fazer parte da dentição decídua normal, ou a exodontia do elemento quando esse dente possuir grande grau de mobilidade, podendo ser aspirado e quando está causando injúria para a criança e/ou genitora (SLAYTON, 2000).

Figura 4. Lesão oral em ventre de língua proveniente do quadro de doença de Riga-Fede.

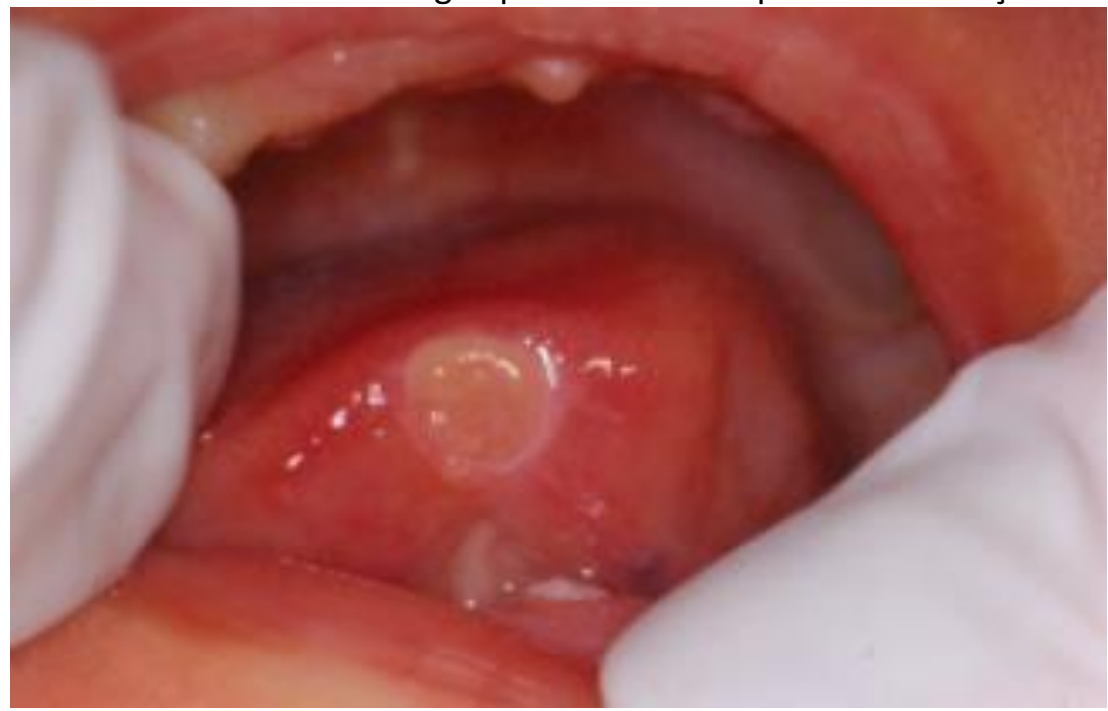

Fonte: (LEMOS, et al.,2009).

\subsection{GLOSSITE MIGRATÓRIA BENIGNA}

A glossite migratória benigna, popularmente conhecida como língua geográfica é uma patologia que afeta o dorso da língua e sua principal características são lesões variadas em tamanho, cor, formam uma imagem semelhante a um mapa geográfico. Sua etiologia é atrelada a alergias, fatores psicológicos, alterações genéticas, fatores hereditários e fatores genéticos e sua predileção é por crianças (CARVALHO et al., 2010).

Clinicamente é manifestada como placas eritematosas irregulares que representam a perda da papila filiforme, normalmente apresentam-se circunscritas, circulares, com bordas delimitadas, ou pelo menos em parte, por uma linha branco- 
amarelada ligeiramente saliente ou plana e bem definida. Semelhante a (Figura 5). (CARVALHO et al., 2010).

Figura 5. Língua geográfica no dorso da lingual da criança.

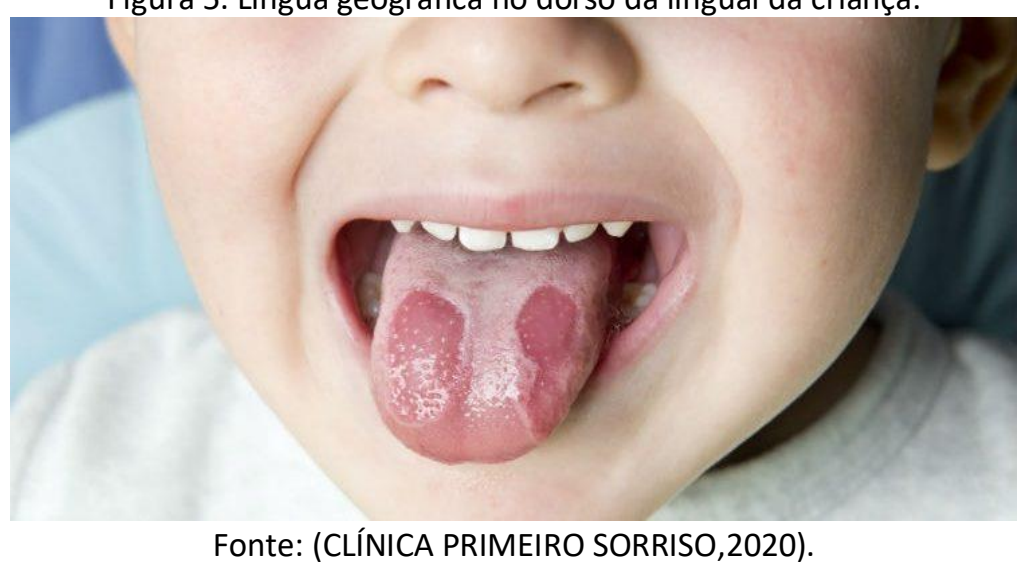

Sua sintomatologia é caracterizada por período de irritação e remissão, durante o qual as lesões se curam sem desenvolvimento residual de cicatrizes, no período das exacerbações, as lesões podem ser seguidas de desconfortos orais, queimações, sensação de corpo estranho, ou dor no ouvido, mas na maioria dos casos os pacientes são assintomáticos (PEREIRA, et al.,2002; ASSIMAKOPOULOS,2002). De acordo com Carvalho et al. (2010), sua prevalência é de $2 \%$ da população mundial, no Brasil especialmente na paraíba, sua frequência foi de 3,7\%. Já Crespo et al. (2005), afirma que sua prevalência pode variar entre 0,60 a 9,8\%.

O diagnostico pode ser feito através de exames clínicos, biopsias e históricos coerentes com lesões crônicas, migratórias e macroscópicas no epitélio da língua que alteram de tamanho, cor e posição. Testes de rotina laboratoriais, incluindo contagem completa do sangue, taxa de sedimentação. Por se tratar de patologia benigna, e sem maiores consequências, não há necessidade de tratamento específico. Se faz necessário apenas o controle do estresse. Quando há presença de sintomatologia dolorosa relatada pelo paciente, nesses casos para um melhor resultado, os estudos indicam o uso de corticóide tópico e creme bucais com anestésico. Outros autores reiteram que evitar comidas quentes ou apimentadas na região da lesão contribui no sucesso do tratamento (FONSENCA, 1997; ASSIMAKOPOULOS,2002). 


\section{CONSIDERAÇÕES FINAIS}

Doenças acometendo a cavidade bucal de crianças tem se tornado cada vez mais comum, principalmente na primeira infância. Tornando-se necessário o conhecimento das causas das lesões bucais e como proceder diante da manifestação de cada uma.

Dentro desse contexto, a literatura ainda carece de trabalhos que retratem a respeito sobre este assunto. Desta forma, o desenvolvimento deste presente estudo possibilitou um vasto conhecimento sobre as principais lesões bucais acometidas na primeira infância, tais como suas características clínicas e formas de tratamento, sendo de suma importância para que o cirurgião dentista consiga realizar um correto diagnóstico e consequentemente planejar o tratamento ou prevenção mais indicado de acordo com o caso, ainda tendo como finalidade conscientizar os pais a respeito e tranquilizá-los.

\section{REFERÊNCIAS}

ALMEIDA, L.H.S.D. Hematomas de erupção: relato de três casos clínicos em bebês. RFO UPF vol.20 no.2 Passo Fundo Mai./Ago. 2015

Arnold N, Messaoudi I. Herpes Zoster and the Search for an Effective Vaccine. Clin Exp Immunol. 2016 May 10. doi: 10.1111/cei.12809

ASSIMAKOPOULOS D, Patrikakos G, Fotika C, Elisaf M. Benign Migratory Glossitis or Geographic Tongue: An Enigmatic Oral Lesion, The American Journal of Medicine, 2002, Vol 113.

\section{BARBOSA, A. F. G. PREVALÊNCIA DE ALTERAÇÕES BUCAIS EM BEBÊS DE 0 A 36 MESES DA BEBÊ CLÍNICA DA FACULDADE DE ODONTOLOGIA DE ARAÇATUBA - UNESP. Trabalho de Conclusão de Curso como parte dos requisitos para a obtenção do título de Bacharel em Odontologia da Faculdade de Odontologia de Araçatuba, Universidade Estadual Paulista "Júlio de Mesquita Filho". 2015.}

BALDANI, M. H.; LOPES, C. M. L.; SCHEIDT, W. A. Prevalência de alterações bucais em crianças atendidas nas clínicas de bebês públicas de Ponta Grossa - PR, Brasil. Pesq Odontol Bras, São Paulo, v. 15, n. 4, p. 302-307, 2001.

CARVALHO, Fabiola; Trigueiro, Mariana; MANGUEIRA, Dayane. Glossite migratória benigna ou língua geográfica: relato de caso clínico, IJD, Int. j. dent. vol.9 no.3 Recife Jul./Set. 2010. 
CASAGRANDE. V. D.O. CISTO DE ERUPÇÃO OU HEMATOMA DE ERUPÇÃO. Monografia apresentada para obtenção do título de Especialista em Odontopediatria ao Departamento de Estomatologia, Setor de Ciências da Saúde, Universidade Federal do Paraná. 2011.

Castro, C. R. S. Baixo peso ao nascer e atraso na erupção de dentes decíduos em crianças. Rev. Bras. Saúde Mater. Infant., Recife, 19 (3): 711-721 jul. / set., 2019

CRESPO, MRR, Pozo PP, Garcia RR. Epidemiology of the most common oral mucosal diseases in children. Med Oral Patol Oral Cir Bucal, 2005,10(5):376-387.

CONSTANTINO, G.T.L; MIZIARA, I.D. Lesões de Cavidade Oral.2008

CLÍNICA PRIMEIRO SORRISO, Língua geográfica, Causas, sintomas e tratamentos.2020 dispo: https://www.clinicaprimeirosorriso.com.br/lingua-geografica-causassintomas-e-tratamentos/

EPSTEIN A. Ueber epithelperlen in der mundhöle neugeborener kinder. Z Heilkd, Tempsky; 1880 apud Jorgenson RJ. Intraoral fi ndings and anomalies in neonates. Pediatrics 1982; 69:577-82

FONSECA, A.C. Língua geográfica [dissertação], São Paulo: Centro de especialização em fonoaudiologia clínica (CEFAC); 1997.

GLORIA, VFV. Relações entre condições bucais e saúde geral. Trabalho de conclusão de curso apresentado ao curso de Especialização em Atenção Básica em Saúde da Familia/Agora, Universidade Federal de Minas Gerais, para obtenção do Certificado de Especialista, Eunápolis-BA, p.6-28, 2011.

GUEDES-PINTO, A. C. Odontopediatria. $6^{\circ}$ ed. São Paulo, Ed. Santos, 1997. Cap. 2, p. 1734.

GUEDES-PINTO, A. C. Odontopediatria. $8^{\circ}$ ed. São Paulo: Ed. Santos, 2010. Cap. 23, p. 381-395.

HADDAD, A. E. et al. Semiologia aplicada à Odontopediatria e à Hebiatria. In CRIVELLO JR., O. Fundamentos de Odontologia: Odontopediatria. São Paulo: Santos, 2009, cap. 6, p. 111-132.

KNIEST, G.; STRAMANDINOLI, R. T.; ÁVILA, L. F. C.; IZIDORO, A. C. S. Frequência das lesões bucais diagnosticadas no Centro de Especialidades Odontológicas de Tubarão (SC). RSBO, Joinville, v. 8, n. 1, p. 13-18, 2001

Lam J. Characterizing Viral Exanthems. Pediatr Health. 2010;4(6):623635 
LASKARIS, G. Atlas Colorido de Doenças Bucais da Infância e da Adolescência. São Paulo: Ed. Santos, 2000. Cap.10, p 98-103.

Lefebvre N, Camuset G, Bui E, Christmann D, Hansmann Y. Koplik Spots: A Clinical Sign with Epidemiological Implications for Measles Control. Dermatology 2010;220:280-281 DOI: 10.1159/000277122

LEMOS, L. V. F. M. et al., Dentes natal e neonatal. einstein. 2009; 7(1 Pt 1):112-3

LESSA, C. Doenças bucais em crianças e bebês - Região bucomaxilofacial.2015. Dispo: bucomaxilofacial.com.br/2015/01/doencas-bucais-em-criancas-e-bebes.html

LIMA-RIVERA, Luciana Monti et al. Prevalência de lesões bucais em crianças de $\mathbf{6}$ a 12 anos. SALUSVITA, Bauru, v. 35, n. 3, p. 411- 422, 2016.

LUCA M, Vâţă A, A. St. Luca, Dorobăţ C, Brănişteanu D. New perspectives in the diagnosis and the treatment of childhood febrile exanthemas. Rev. Med. Chir. Soc. Med. Nat., Iaşi 2015; vol. 119, no. 2

MAPLE P. Application of Oral Fluid Assays in Support of Mumps, Rubella and Varicella Control Programs. Vaccines 2015, 3, 988-1003; doi:10.3390/vaccines3040988

MEDRADO, A.R.A.P. et al. Manifestações bucais de doenças infecciosas na infância. 2020.

Dispo: https://www.isaude.com.br/noticias/detalhe/noticia/manifestacoes-bucais-dedoencas-infecciosas-na-infancia/.

MELO, D.S.D. Estudo da prevalência de cistos nos maxilares diagnosticados no laboratório de patologia bucal da universidade estadual de feira de santana, no período de 2006 a 2017. 2018.

NEVILLE, B. W.; DAMM, D. D.; ALLEN, C. M.; BOUQUOT, J. E. Patologia Oral \& Maxilofacial. $2^{\circ}$ ed. Rio de Janeiro: Ed. Guanabara-Koogan, 2004. Cap. 15. p. 565616.

PADOVANI, M. C. R. L. Prevalência de manifestações bucais em tecidos moles na primeira infância. 2008. 73 f. Dissertação (Mestrado em Odontologia), Universidade Cruzeiro do Sul, São Paulo, 2008.

PENIDO, C.V. S.R; FONSECA, M.S. Cistos da Cavidade Bucal de Recémnascidos. JBP - Rev Ibero-am Odontopediatr Odontol Bebê 2003; 6(34):526-31

Pereira JV, Forte FDS, Ely MR, Sampaio MCC. Alterações linguais em crianças do Estado da Paraíba. Rev. bras. ciênc. saúde, 2002, 6(2):157-162.

PENIDO, C.V. S.R; FONSECA, M.S. Cistos da Cavidade Bucal de Recémnascidos. JBP - Rev Ibero-am Odontopediatr Odontol Bebê 2003; 6(34):526-31 
SANTOS, G.C.B.D; BARRETO, M.A.C. Atendimento precoce na primeira infância - uma revisão de literatura. 2019.2 Dispo: http://openrit.grupotiradentes.com:8080/xmlui/handle/set/2233

SANTOS, M.E.S.M. Cisto dentígero em criança - um caso peculiar tratado por descompressão. Rev. Cir. Traumatol. Buco-Maxilo-Fac., Camaragibe v.11, n.3, p. 21-28, jul./set. 2011.

SCHITINI, N. Patologia Oral (Cistos Odontogênicos) Mind Map on CISTO DE ERUPÇÃO. 2019.

ZZETA, C. M. Lesões bucais e do complexo maxilomandibular em crianças e adolescentes: estudo retrospectivo de 15 anos. 2010, 91 f. Dissertação Mestrado em Odontologia, área de concentração em Saúde Bucal durante a Infância e Adolescência), Universidade Federal do Paraná, Setor de Ciências da Saúde, 2010.

VALENTINE, F. F., CARVALHO, P. L.; CANDELÁRIA, F. L. A. Estudo dos Fatores que Alteram a Cronologia de Erupção Dentária. Rev Virt Odontol. 2007; vol.1(3), p. 18-23.

VASQUES, Evamiris de França Landim et al. Manifestações relacionadas à erupção dentária na primeira infância: percepção e conduta de pais. RFO UPF [online]. 2010, vol.15, n.2, pp. 124-128. ISSN 1413-4012.

VRANJAC, Alexandre. Surto de varicela em creches e escolas da Direção Regional de Saúde XXII, junho de 2005. Rev Saúde Pública 2005;39(4):687-90

WALTER, L.R.F. Com o futuro nas mãos. Rev ABO Nac 1993; 1(3):146- 50. WALTER, L.R.F.; FERELLE, A.; ISSAO, M. Odontologia para o bebê: Odontopediatria do nascimento aos 3 anos. São Paulo: Artes Médicas, 1997. Cap.1, p.1-5. 


\title{
CAPITULO XVII \\ MANEJO DAANSIEDADE NA CLINIICA DE ODONTOPEDIATRIA
}

\author{
DOI: 10.51859/AMPLLA.EPC757.1121-17
}

\author{
Bianca de Matos Venâncio ${ }^{1}$ \\ Victor Bruno Bessa da Silva ${ }^{2}$ \\ Jéssica da Silva Rodrigues ${ }^{1}$ \\ Julyanna Arruda Brígido ${ }^{3}$ \\ Karla Geovanna Ribeiro Brígido 4 \\ Jandenilson Alves Brígido 4
}

\begin{abstract}
${ }^{1}$ Graduanda do Curso de Odontologia - Centro Universitário Fametro - UNIFAMETRO
2 Graduando do Curso de Odontologia - Centro Universitário Fametro - UNIFAMETRO

${ }^{3}$ Psicóloga - Centro Universitário Maurício de Nassau - UNINASSAU

${ }^{4}$ Docente do Curso de Odontologia - Centro Universitário Fametro - UNIFAMETRO
\end{abstract}

\section{RESUMO}

A adequada assistência ao paciente pediátrico constitui-se como fator determinante para a condução do tratamento em odontopediatria. O atendimento odontológico é frequentemente associado a dor, o que pode gerar ansiedade em infantes. A ansiedade da criança pode reduzir a eficácia do tratamento odontológico, ao comprometer o comportamento da criança e a relação do paciente com o dentista, tornando-se fundamental que o cirurgião-dentista conheça técnicas de manejo da ansiedade infantil, para que possa propor uma assistência odontológica satisfatória. $\mathrm{O}$ objetivo do estudo foi avaliar as ferramentas disponíveis que possam influenciar no manejo da ansiedade na clínica de odontopediatria. Trata-se de uma revisão integrativa, em que se buscou publicações de 2016 a 2021, a partir dos descritores MESH "Behavior", "Pediatric Dentistry", "Child" e "Dental Anxiety", nos bancos de dados PUBMED e EBSCO e na base de dados LILACS, restando 27 estudos qualificados para inclusão no presente estudo. Os estudos evidenciam que o conjunto de técnicas alternativas associadas às técnicas convencionais proporcionam redução na ansiedade do paciente pediátrico no âmbito odontológico. As técnicas de observação, simulação e aprendizagem mostram resultados positivos quanto à diminuição da ansiedade dos pacientes estudados, mas diminuem apenas a percepção da dor durante o atendimento clínico. Portanto, as ferramentas criadas para facilitar o manejo da ansiedade na clínica infantil, são de suma importância para maior eficiência e eficácia do tratamento odontopediátrico, tornando o atendimento mais humanizado, mais tranquilo e menos traumatizante.

Palavras-chave: Odontopediatria. Manejo. Ansiedade. 


\section{INTRODUÇÃO}

A viabilidade da realização do procedimento clínico está relacionada com a cooperação do paciente, de tal forma que o desenvolvimento de estresse e ansiedade gerados pelo tratamento, dificulta a atuação do profissional. Sendo assim, preparo psicológico das crianças visa minimizar o desconforto causado ao longo do atendimento e o controle comportamental do paciente passa a ser uma das etapas mais importantes do atendimento (MORAES et al., 2004; SANTOS et al., 2012).

A existência e desenvolvimento de métodos para o controle da ansiedade constam como um conjunto de técnicas que podem ser empregadas isoladamente ou de forma conjunta. Além disso, o controle da ansiedade objetiva o desenvolvimento de habilidades que possam ser úteis para enfrentar os medos relacionados ao âmbito odontológico. Tais medos, comuns da faixa etária infantil, podem prolongar-se ao decorrer da vida adulta (ADAIR et al., 2004).

A evolução da tecnologia proporcionou melhorias em amplos aspectos da odontologia. A inserção de distrações audiovisuais como os óculos de realidade virtual pôde agregar o conjunto de técnicas usadas para controle da ansiedade (PALAZ; PALAZ; AKAL, 2020).

A condução do paciente pediátrico é estabelecida entre a cooperação do dentista, pais e pacientes, ou seja, para a aplicação das técnicas de redução de ansiedade é necessário conhecer o estado emocional do paciente (SOUZA et al., 2020). Dessa forma, é essencial que os profissionais que atenderão crianças possam saber o manejo mais adequado para controle da ansiedade, pois influencia diretamente na eficácia do tratamento.

Com o desenvolvimento de novas medidas que possam agregar ao atendimento individualizado, há maior possibilidade de um atendimento efetivo, frente às necessidades de cada indivíduo, promovendo maior conforto ao paciente nas visitas odontológicas (ONUR et al, 2020). Logo, a produção de conteúdo de pesquisa voltados para a área de manuseio da ansiedade pediátrica busca otimização do atendimento frente aos novos achados clínicos de aplicabilidade das técnicas comportamentais (ALBUQUERQUE $C$ et al, 2010). Desse modo, o presente trabalho científico buscou enfatizar a importância das técnicas de distrações e a busca por inovações na área do 
tratamento infantil na odontologia moderna, a partir de uma revisão de literatura narrativa.

\section{METODOLOGIA}

Para a composição do presente estudo, fez-se necessário responder a indagação "Como diminuir o grau de ansiedade dos infantes na clínica odontológica?". Dessa forma, escolheu-se a revisão de literatura narrativa como o tipo de estudo a ser seguido.

Com o objetivo de determinar ferramentas de manejo da ansiedade, buscou-se estudos nos bancos de dados PUBMED e EBSCO e na base de dados LILACS, com o uso dos descritores "Behavior", "Pediatric Dentistry", "Child" and "Dental Anxiety", obtendo-se inicialmente 404 estudos (PUBMED $(n=45)$; EBSCO $(n=298)$ e LILACS $(n=$ 61)). Buscou-se artigos publicados nos últimos 6 anos, disponíveis em texto completo, que após leitura de títulos e resumos e exclusão dos duplicados, restaram 40 estudos. Por fim, leu-se na íntegra os estudos selecionados, sendo selecionados 27 artigos que se adequaram ao objetivo desta pesquisa.

\section{RESULTADOS E DISCUSSÃO}

No âmbito da odontopediatria, o controle da ansiedade infantil consiste num fator fundamental na condução do tratamento. Sendo assim, o conhecimento e o desenvolvimento de técnicas que possam contrapor quaisquer vivências negativas e adquiridas são essenciais para um bom atendimento odontológico (GUEDES PINTO, 2010). Para facilitar o entendimento, as técnicas de manejo de ansiedade apresentadas nos artigos selecionados para a confecção do presente estudo foram dispostas em tópicos de acordo com o tipo de abordagem utilizado.

\subsection{MANEJO DA ANSIEDADE ODONTOPEDIÁTRICA A PARTIR DE MÉTODOS DE OBSERVAÇÃO, SIMULAÇÃO E APRENDIZAGEM}

Tell-show-do (TSD) é uma técnica baseada no princípio da teoria da aprendizagem que consiste primeiramente na explicação e depois na demonstração do procedimento odontológico para o paciente pediátrico, previamente ao tratamento odontológico (WRIGHT; STIGERS, 2011; AMERICAN ACADEMY OF PEDIATRIC DENTISTRY, 2020). Já Experiential learning (EL) é um método de instrução que tem se mostrado 
efetivo no gerenciamento comportamental pelo qual o conhecimento é obtido, por meio do envolvimento em atividades práticas ou simulações (KOLB, 2014). Nesse contexto, Zhu et al. (2020) produziram um estudo com amostra de 988 crianças de 7 a 8 anos de idade, que foram divididas em 2 grupos: um grupo exposto à técnica EL e outro submetido à TSD. Os pacientes que foram sujeitos à técnica EL apresentaram menor escore de ansiedade na Children's Fear Survey Schedule-Dental Subscale (CFSS-DS), menor prevalência de ansiedade odontológica elevada e maior redução da média da pressão arterial sistólica, apesar de ter maiores valores médios dessa pressão. Foi observado também, menor aumento da pressão arterial diastólica e maior média da frequência de pulso, em relação ao grupo submetido à TSD.

Atualmente, o microscópio operatório ( $\mathrm{MO}$ ) pode ser projetado em uma tela de modo que o paciente possa observar o procedimento, configurando-se como uma distração visual. Sayed et al. (2016) utilizou o MO juntamente com a TSD em 90 crianças de 7 a 9 anos, obtendo redução significativa da ansiedade, em comparação à primeira e segunda consulta, além de ter obtido menos movimentação e mais colaboração dos pacientes.

Modeling é uma técnica de aprendizagem a partir da observação, permitindo que o paciente exerça o comportamento modelo observado (WRIGHT; STIGERS, 2011). Essa técnica foi considerada efetiva na redução da ansiedade de crianças durante atendimento de profissionais da saúde, de acordo com vários estudos. Modeling pode ser aplicado de forma presencial (live modeling) (LM), com a observação do procedimento odontológico realizado em outro paciente em tempo real, ou de forma assíncrona, a partir da apresentação de vídeos filmados (film modeling) (FM) do procedimento odontológico a ser realizado (KLEIN, 2011).

Vishwakarma et al (2017) modificou a técnica TSD para tell-play-do (TPD), substituindo a demonstração do procedimento pela simulação do tratamento pelo próprio infante, a partir de instrumentais odontológicos de brinquedo e um cartoon como paciente. Nesse contexto, comparou-se a Frequência Cardíaca (FC) de pacientes submetidos à técnica TPD com a de infantes que utilizaram a técnica LM. O resultado demonstrou que as crianças do grupo submetido à técnica TPD apresentaram valores significativamente menores de FC antes e depois do atendimento. Setiwan, Elsari e Augustiani (2020) correlacionaram a FM, a simulação de LM e a intervenção integral, 
obtendo menores escore na Facial Image Scale Score Mean (FISSM), antes e depois do procedimento odontológico em 64 crianças de 3 a 6 anos.

Crianças com deficiências graves podem ser particularmente mais ansiosas do que outras durante o tratamento odontológico. Para mitigar a ansiedade de um paciente de 5 anos de idade com síndrome de Down, McMullen et al. (2017) constataram resultados significativos com o uso diário, com participação dos pais e da criança, de um pacote de tratamento odontológico, 10 dias antes do atendimento odontopediátrico. Nesse contexto, o pacote de tratamento odontológico permitiu que o infante se acostumasse com os sons dos equipamentos utilizados na odontopediatria, o que reduziu sua ansiedade durante o atendimento odontológico.

\subsection{MANEJO DA ANSIEDADE ODONTOPEDIÁTRICA A PARTIR DE DISTRAÇÃO AUDIOVISUAL}

De acordo com Palaz, Palaz e Akal (2020), o uso de óculos de realidade 3D demonstrou eficácia na redução da sensação dolorosa em crianças submetidas a extração dentária. Custódio et al. (2020), Shetty et al. (2019), Hashemi, Nezhad e Telenbianpour (2021), ratificam a efetividade do uso de óculos de realidade virtual, pois proporcionou redução da dor e melhora comportamental em crianças durante o atendimento odontológico. Também, Shetty et al. (2019) demonstraram redução significativa nos níveis de cortisol salivar nas crianças que foram expostas ao método de distração visual.

Por outro lado, Custódio et al. (2021) aponta que a utilização de distração comóculos audiovisual não acarretou em controle da ansiedade, melhora comportamental ou mudança na percepção dolorosa. Conforme a pesquisa de Kamel, Awahba e Talaat (2017), apesar do uso de imagens relacionadas ao contexto dental não interferirem no nível da ansiedade, houve melhora no comportamento dos pacientes com a visualização de imagens aleatórias de cunho positivo. Palaz, Palaz e Akal (2020) também demonstram que não houve redução significativa nos valores de ansiedade com o uso de óculos de realidade de vídeo 3D.

Segundo Mobarek, Khalil e Talaat (2019), a exposição exacerbada a conteúdo de viés violento está relacionada com problemas comportamentais de crianças de 5 a 8 anos de idades, durante consultas odontológicas. Contudo, não se aponta influência 
direta da exposição a telas eletrônicas no nível de ansiedade dos infantes. Chatuverdi et al. (2016) reafirma a veracidade da redução de ansiedade em crianças que utilizaram óculos de distração audiovisual em procedimentos de restauração, em procedimentos de endodontia e profilaxia, em comparação com crianças que não utilizaram métodos de distração. Em 40 crianças de 6 a 10 anos de idade, divididas em dois grupos, com escore 3 e 4 de ansiedade na escala de classificação comportamental de FRANKL, apontou-se redução significativa do grau de ansiedade a partir da utilização do índice Wong-Baker Faces Pain Rating Scale (WBFPRS), da Visual Analog Scale e do oxímetro de pulso, entre o grupo exposto a distração com óculos audiovisual e o grupo não exposto.

Em outro estudo, 56 crianças que utilizaram os óculos i-theatre ${ }^{\mathrm{TM}}$ para distração audiovisual, obtiveram-se escores menores na Modified Venham's Clinical Ratings of Anxiety and Cooperative Behaviour Scale (MVARS). Em contrapartida, o grupo de controle apresentou aumento significativo na frequência cardíaca durante a administração da anestesia local, diferente do grupo teste que não apresentou mudanças significativas (AL-KHOTANIA; BELLO; CHRISTIDIS, 2016). Em crianças sem deficiência mental, porém com necessidades especiais de saúde, a utilização de distração audiovisual em procedimentos restauradores apresentou eficácia no que diz respeito ao controle da sensação dolorosa. Entretanto, a distração audiovisual não apresenta a capacidade de substituir completamente os métodos convencionais de administração comportamental (BAGATTONI et al., 2017).

\subsection{MANEJO DA ANSIEDADE ODONTOPEDIÁTRICA A PARTIR DE ABORDAGENS LÚDICAS}

O estudo feito por Souza et al. (2020), analisaram as emoções encontradas em 74 crianças de 4 a 10 anos de idade durante o atendimento clínico infantil, e demonstrou que houve diminuição de emoções negativas antes e depois de atividades lúdicas durante o atendimento odontológico. No entanto, a quantificação do sentimento de ansiedade permaneceu constante em todos os momentos avaliados. A SALPED (Servicios y Actividades Lúdico-Educativas del Postgrado en Estomatologia Pediátrica) desenvolveu um projeto em que os pais, os pacientes pediátricos e o cirurgião-dentista pudessem interagir em uma brinquedoteca antes do atendimento odontológico. Desse modo, é possível estabelecer mais confiança na relação entre dentista, paciente e pais. 
Esse projeto foi avaliado como positivo por $95 \%$ dos participantes e considerado como um suporte satisfatório aos infantes por $85-90 \%$ dos pais.

Outro estudo com amostra de 62 crianças de 4 a 6 anos de idade, técnicas de distração como a utilização de um espelho de mão, brinquedos e histórias infantis, não reduziram significativamente a ansiedade dos infantes. Contudo, o uso do espelho de mão como ferramenta de cooperação, contribuiu para a melhora no atendimento a partir da segunda visita ao dentista. Além disso, foi evidenciado que fatores como a faixa etária, ansiedade e comportamento durante os procedimentos, influenciam a prática de procedimentos odontológicos (RANK et al., 2017). Em estudo de Vasconcellos, Imparato e Rezende (2017), utilizou-se a técnica quadro de incentivos, em que o paciente pediátrico ganha recompensas ao seguir as regras estipuladas, e observou-se diminuição nos níveis de ansiedade.

Conforme Charowski (2021), a companhia de cães não constituiu uma estratégia tão eficaz em estudo randomizado com amostra de 47 crianças de 6 a 10 anos de idade. Apesar disso, os níveis de desconforto, a resposta fisiológica e o comportamento, reduziram significativamente no grupo experimental quando o isolamento dentário foi reposicionado de acordo com a escala de Houpt. Além disso, registrou-se no grupo teste maiores escores na escala comportamental de Frankl, quando o isolamento dentário foi reposicionado e ao completar a aplicação de selante no segundo lado. No entanto, os dois grupos obtiveram avaliações semelhantes do dentista, não tendo disparidade significativa nas respostas fisiológicas ou na escala FACES, e a ansiedade basal foi similar.

Susilo et al. (2018) introduziram o uso de livros pop-up de teor educacional como método para o manejo da ansiedade, em estudo randomizado com amostra 42 crianças portadoras de deficiência auditiva de faixa etária de 7 a 9 anos, a fim de avaliar o impacto do uso de livros pop-up educacional, tendo como resultado redução significante da frequência respiratória. O estudo apontou a eficácia do livro pop-up como estratégia educacional para proporcionar diminuição nos níveis de ansiedade em crianças portadoras de deficiência auditiva.

Segundo Onur et al (2020), o psicológico do paciente a ser tratado pode ser entendido por meio de desenhos que mostravam a projeção do nível de ansiedade, 
sendo um método fácil e barato, que pode ser utilizado para avaliar o grau de ansiedade durante a consulta odontológica.

Kamel, Awahba e Talaat (2017) dividiram 60 crianças saudáveis com faixa etária de 4 a 6 anos de idade em dois grupos aleatoriamente: grupo experimental (grupo 1) e grupo controle (grupo 2). Antes do atendimento odontológico, os pacientes do grupo 1 visualizaram imagens positivas e agradáveis do ambiente odontológico e os infantes do grupo 2 observaram imagens neutras de desenhos animados não odontológicos, seguindo a indicação da faixa etária do paciente. O intuito da exposição das imagens é fazer com que haja uma associação entre as imagens positivas com a odontologia, no entanto, o estudo evidenciou que não houve diferenças significativas da ansiedade entre os dois grupos.

A respiração com bolhas é um método de respiração profunda que é comumente utilizado para o gerenciamento de dor em crianças (JACOBS; PRICE; POPENHAGEN, 2014). Sridhar et al. (2019) selecionou 66 crianças de 7 a 11 anos de idade, divididas aleatoriamente em dois grupos, no qual o grupo de intervenção foi treinado com exercícios de respirações com bolhas, com intuito de avaliar o efeito do exercício durante o atendimento odontológico. $O$ estudo resultou na diminuição significativa da percepção da dor pelas crianças, que formaram o grupo de intervenção, sendo utilizada como ferramenta de avaliação as escalas Faces Legs Activity Cry and Consolability (FLACC) e WBFPRS. O comparativo na percepção de dor pela WBFPRS e FLACC apresentou valores significativos análogos. Por outro lado, a pesquisa demonstrou também que não houve diferença significativa da ansiedade tanto no grupo controle como no de intervenção.

\subsection{MANEJO DA ANSIEDADE ODONTOPEDIÁTRICA A PARTIR DA ESCOLHA DE TÉCNICAS ODONTOLÓGICAS E FARMACOLÓGICAS}

Apesar dos métodos farmacológicos não serem a primeira escolha na redução da ansiedade do paciente infantil, o desenvolvimento e estudo dessas estratégias mostram uma melhora significativa na condução do tratamento. Nesse contexto, o estudo realizado por Shanmugaavel et al. (2016) teve como objetivo verificar as mudanças comportamentais e o grau de ansiedade de crianças, a partir da administração de midazolam. Dividiu-se crianças de 4 a 7 anos em dois grupos: Grupo 
A, exposto a sedação intranasal, e Grupo B, exposto a sedação sublingual. Os resultados apontaram que durante os procedimentos houve diminuição da ansiedade desde o início até 20 minutos após a administração de midazolam no grupo submetido à sedação intranasal e no grupo tratado com sedação sublingual, evidenciadas pela VENHAM's Clinical Anxiety Rating Scale. Não apontaram diferença significativa entre os grupos no nível de cortisol salivar antes e depois da administração de midalozam e também evidenciou que não houve correlação significativa entre a diminuição da ansiedade clínica e a diferença no nível de cortisol salivar.

O estudo realizado por Villa-Sierra et al. (2019), com 32 crianças de 4 a 11 anos de idade, avaliou os efeitos da ansiedade no tratamento de remoção de cárie, comparando o método tradicional, o qual utiliza uma de colher de dentina ou broca esférica, e o método Brix 3000, que consiste na utilização de um gel com atividade enzimática. O método convencional para remoção de cárie mostrou-se menos ansiogênico do que o do Brix 3000. Além disso, constatou-se que o gênero feminino apresentou maior grau de ansiedade com a utilização do Brix 3000 para remoção de cárie em comparativo com o gênero masculino.

Aldosari et al (2019) comparou o medo e a ansiedade diante o atendimento odontológico de uma amostra de 98 de crianças de 5 a 12 anos de idade divididas em grupo controle e grupo submetido à anestesia geral para prática odontológica. Tal estudo observou taxas de ansiedade e medo extremamente significativamente maiores nos infantes expostos à anestesia geral do que o grupo controle. Além disso, apesar de ambos grupos apresentarem correlação de Pearson positiva com escores das escalas CFSS-DS e Modified Child Dental Anxiety Scale (MCDASf), os infantes submetidos à anestesia geral tiveram maior correlação do que o grupo controle.

\subsection{OUTROS MÉTODOS DE MANEJO DA ANSIEDADE ODONTOPEDIÁTRICA}

A inovação dos métodos de distrações possibilitou a associação das técnicas tradicionais com o surgimento de novos métodos. Desse modo, o método de acupressão é indicado para crianças, pois consiste em uma terapia de origem natural onde não é feito o uso das agulhas. Tal método promove a estimulação da pele através da pressão dos dedos. Nesse contexto, essa estratégia mostrou-se eficaz na redução da ansiedade de crianças de 8 a 12 anos nas quais foram realizados procedimentos menos invasivos, 
de acordo com estudo de amostra de 225 infantes dessa faixa etária. Apesar da eficácia, o método sofre variação de acordo com o gênero da criança, visto que o gênero feminino apresenta maior grau de aversão a técnica empregada (AVISA et al., 2018).

\section{CONSIDERACÕES FINAIS}

A ansiedade odontológica é um estado emocional caracterizado por episódios de angústia, nervosismo, medo e exacerbação da dor, tornando o atendimento odontológico menos efetivo e mais traumatizante. Assim, torna-se essencial o manejo da ansiedade na odontopediatria.

As técnicas de observação, simulação e aprendizagem mostram resultados positivos quanto à diminuição da ansiedade dos pacientes estudados. No entanto, diminuem apenas a percepção da dor durante o atendimento clínico, diferentemente do manejo da ansiedade com ferramentas de distração visual. Já as abordagens lúdicas evidenciam tantos pontos positivos quanto pontos negativos no grau de ansiedade dos infantes.

Portanto, foi possível constatar que as ferramentas criadas para facilitar o manejo da ansiedade na clínica infantil, são de suma importância para maior eficiência e eficácia do tratamento odontopediátrico, tornando o atendimento mais humanizado, mais tranquilo e menos traumatizante.

\section{REFERÊNCIAS}

AAPD - American Academy of Pediatric Dentistry. Guideline on behavior guidance for the pediatric dental patient. The Reference Manual of Pediatric Dentistry, Chicago, p 292-310, 2020.

ADAIR, S. M. et al. Survey of behavior management teaching in pediatric dentistry advanced education programs. Pediatr Dent, Chicago, v. 26, n. 2, p 151-8, 2004.

Albuquerque, C. et al. Principais técnicas de controle de comportamento em Odontopediatria. Arquivos em Odontologia, Minas Gerais, v. 46, n. 2, p. $110-$ 115, 2010.

ALDOSSARI, G. S.; ALDOSARI, A. A.; ALASMARI, A. A.; ALDAKHEEL, R. M.; AL-NATSHA, R. R.; ALDOSSARY, M. S. The long-term effect of previous dental treatment under general anaesthesia on children's dental fear and anxiety. International Journal of Paediatric Dentistry, v. 29, n. 2, p. 177-184, 2018. 
AL-KHOTANI, A.; BELLO, L. A.; CHRISTIDIS, N. Effects of audiovisual distraction on children's behaviour during dental treatment: a randomized controlled clinical trial. Acta Odontologica Scandinavica, v. 74, n. 6, p. 494-501, 2016.

AVISA, P. et al. Effectiveness of Acupressure on Dental Anxiety in Children. Pediatr Dent, Chicago, v. 40, n. 3, p. 177-183, 2018.

BAGATTONI, S.; D'ALESSANDRO, G.; SADOTTI, A.; ALKHAMIS, N.; PIANA, G. Effects of audiovisual distraction in children with special healthcare needs during dental restorations: a randomized crossover clinical trial. International Journal of Paediatric Dentistry, v. 28, n. 1, p. 111-120, 11 abr. 2017.

CHAROWSKI, M. et al. A Randomized Controlled Pilot Study Examining Effects of Animal Assisted Therapy in Children Undergoing Sealant Placement. Pediatr Dent, v. 43, n. 1, p. 10-16, 2021.

CHATURVEDI, S. et al. Comparative Evaluation of Anxiety Level during the Conventional Dental Procedures with and without Audiovisual Distraction Eyeglasses in Pediatric Dental Patients. Journal of International Oral Health, v. 8, n. 11, p. 1016-1022, 2016.

CUSTÓDIO, N. B. et al. Effectiveness of Virtual Reality Glasses as a Distraction for Children During Dental Care. Pediatric Dentistry, v. 42, n. 2, p. 93-100, 2020.

CUSTÓDIO, N. B.; CADEMARTORI, M. G.; AZEVEDO, M. S.; MENDES, M. A.; SCHARDOZIM, L. R.; COSTA, L. R. R. S.; GOETTEMS, M. L. Efficacy of audiovisual distraction using eyeglasses during dental care: a randomized clinical trial. Brazilian Oral Research, v. 35, n. 26, 2021.

GUEDES PINTO, A.C. Odontopediatria. São Paulo: Santos. 8 ed. 970p, 2010.

HASHEMI, M. S.; NEZHAD, S. J.; TALEBIANPOUR, S. Effects of Using Music Methods, 3D Glasses and Behavioral Control on Children's Anxiety during Dental Treatment. Journal of Isfahan Dental School, v. 17, n. 1, p. 40-48, 2021.

JACOBS, A., PRICE H.N, POPENHAGEN M.P. Blowing away the pain: a technique for pediatric pain management. Pediatr Dermatol, v. 31, n. 6, p. 757-758, 2014.

JACOBS, A.; PRICE, H. N.; POPENHAGEN, M. P. Blowing Away the Pain: a technique for pediatric pain management. Pediatric Dermatology, v. 31, n. 6, p. 757-758, 2014.

KAMEL, D. O.; A WAHBA, N.; TALAAT, D. M. Comparison between Positive Dental Images and Neutral Images in Managing Anticipatory Anxiety of Children. Journal Of Clinical Pediatric Dentistry, v. 41, n. 2, p. 116-119, 2017.

KLEIN S. B. Learning: Principles and applications. 6 ed. Nova York: Sage Publications, p. 61-67, 2011.

KOLB D. A. Experiential learning: experience as the source of learning and development. 2 ed. Nova Jersey: Pearson FT Press, p. 15, 2014. 
MCMULLEN et al. Using Prediction and Desensitization Techniques to Treat Dental Anxiety: A Case Example. Behavioral Interventions, v. 32, n. 1, p. 91-100, 2017.

MOBAREK, N. H.; KHALIL, A. M.; TALAAT, D. M. Exposure to Electronic Screens and Children's Anxiety and Behavior During Dental Treatment. J Dent Child (Chic), Chicago, v. 86, n. 3, p. 139-144, 2019.

ONUR, S. G; ALTIN, K. T.; YURTSEVEN, B. D.; HAZNEDAROGLU, E.; SANDALLI, N. Children's drawing as a measurement of dental anxiety in paediatric dentistry. Int J Paediatr Dent, p. 666-675, 2020.

PALAZ, Z. H.; PALAZ, E.; AKAL, N. Süt molar diş çekimi sırasında 3D video gözlük kullanımının çocuklarda ağrı ve anksiyete üzerine etkisi. Acta Odontologica Turcica, v. 37, n. 3, p. 71-77, 2020.

RANK, R. C. I. C. et al. Dental Anxiety and Behavior in Young Children Undergoing Different Distraction Techniques. Pesqui. Bras. Odontopediatria Clín. Integr, v. 17, n. 1, p. 1-11, 2017.

SANTOS, J. J. S. de et al. Avaliação da ansiedade dos pais e/ou responsáveis frente ao tratamento odontológico de crianças. Jornada Odontológica dos Acadêmicos da Católica, v. 3, n. 1, nov. 2017.

SAYED, A.; RANNA, V.; PADAWE, D.; TAKATE, V. Effect of the video output of the dental operating microscope on anxiety levels in a pediatric population during restorative procedures. Journal of Indian Society of Pedodontics and Preventive Dentistry, v. 34, n. 1, p. 60, 2016.

SETIAWAN, A. S.; ELSAR, L.; AGUSTIANI, H. Intervention Program on Dental Fear in Sekeloa Kindergarten Bandung Indonesia. Journal Of International Dental and Medical Research, p. 602-606, 2018.

SHANMUGAAVEL, A.; ASOKAN, S.; BABY, J. J.; PRIYA, G.; DEVI, J. G. Comparison of Behavior and Dental Anxiety During Intranasal and Sublingual Midazolam Sedation - A Randomized Controlled Trial. Journal Of Clinical Pediatric Dentistry, v. 40, n. 1, p. 81-87, 2016.

SHETTY, V.; SURESH, L. R.; HEGDE, A. M. Effect of Virtual Reality Distraction on Pain and Anxiety During Dental Treatment in 5 to 8 Year Old Children. Journal of Clinical Pediatric Dentistry, v. 43, n. 2, p. 97-102, 2019.

SINGH, K. A.; MORAES, A. B. A. de; BOVI AMBROSANO, G. M. Medo, ansiedade e controle relacionados ao tratamento odontológico. Pesq Odont Bras, v. 14, n. 2, p. 131136, 2000.

SOUZA, L; NOGUEIRA, F; MARTINS, L; FERREIRA, L; OLIVEIRA, F; CASTRO, A. Behavior and reaction of children to dental care, when submitted to play workshops before and after treatment. Rev Gaúch. Odontol, v. 68, e20200041, p. 1-8, 2020. 
SRIDHAR, S.; SUPRABHA, B. S; SHENOY, R.; SHWETHA, K. T.; RAO, A. Effect of a relaxation training exercise on behavior, anxiety, and pain during buccal infiltration anesthesia in children: randomized clinical trial. International Journal of Paediatric Dentistry, v. 29, n. 5, p. 596-602, 2019.

SUSILO, C. W.; FAUZIAH, E.; RIZAL, M. F.; SUHARSIN, M. Impact of Using an Educational Pop-up Book to Address Dental Anxiety in Hearing Impaired Children. Journal of International Dental and Medical Research, p. 135-138, 2018.

VASCONCELLOS, C; IMPARATO, J. C. P; REZENDE, K. M. Motivation chart as a supporting tool in pediatric dentistry. Rev Gaúch. Odontol, v. 65, n. 03, p. 276-281, 2020.

VILLA SIERRA, L. A. et al. Ansiedad, miedo y comportamiento en odontopediatria utilizando Brix 3000 y método rotatorio para remoción de caries. Duazary, v. 16, n. 2, p. 383-394, 2019.

VISHWAKARMA, A. P. et al. Effectiveness of two different behavioral modification techniques among 5-7-year-old children: A randomized controlled trial. Journal of the Indian Society of Pedodontics \& Preventive Dentistry, v. 35, n. 2, p. 143149, 2017.

WRIGHT, G. Z., STIGERS, J. I. Non-pharmacologic management of children's behaviors. In: DEAN, J. A.; AVERY, D. R., MCDONALD, R. E. McDonald and Avery Dentistry for The Child and Adolescent, p. 30-31, 2011.

ZHU, M. et al. Experiential learning for children's dental anxiety: a cluster randomized trial. BMC Oral Health, v. 20, n. 1, p. 1-8, 2020. 


\title{
CAPITULO XVIII
}

\section{CARACTERISTICAS EPIDEMIOLÓGICAS DE PACIENTES COM FISSURA LABIOPALATINA NÃO SINDRÔMICA}

\author{
DOI: 10.51859/AMPLLA.EPC757.1121-18
}

\author{
Mariana Martins Juglair ${ }^{1}$ \\ Bianca Maria Borges Saliba ${ }^{1}$ \\ Mayra Le Senechal Horta ${ }^{2}$ \\ Jeferson Luis de Oliveira Stroparo ${ }^{3}$ \\ Débora Hautsch Willig ${ }^{4}$ \\ João Armando Brancher ${ }^{5}$ \\ Maria Ângela Naval Machado ${ }^{6}$ \\ Marilisa Carneiro Leão Gabardo ${ }^{7}$
}

\footnotetext{
${ }^{1}$ Graduanda Do Curso De Odontologia. Universidade Positivo - UP

2 Mestre Em Odontologia Clínica. Universidade Positivo - UP

${ }^{3}$ Doutorando Em Odontologia. Universidade Positivo - UP

${ }^{4}$ Mestre Em Odontologia. Universidade Federal Do Paraná - UFPR

${ }^{5}$ Doutor Em Ciências Da Saúde. Universidade Positivo - UP

${ }^{6}$ Doutora Em Clínica Odontológica. Universidade Federal Do Paraná - UFPR

7 Doutora Em Odontologia. Universidade Positivo - UP
}

\section{RESUMO}

O complexo dentofacial é composto de diversas estruturas que frequentemente sofrem alterações no seu desenvolvimento. Alterações congênitas, como as fissuras labiais e/ou palatinas (FL/P), são um exemplo disso. O objetivo do presente estudo foi realizar um levantamento de algumas características epidemiológicas e possíveis associações em pacientes com FL/P não sindrômicas. Tratou-se de um estudo transversal realizado por meio de pesquisa documental junto aos prontuários dos pacientes atendidos no Centro de Atendimento Integral ao Fissurado Labio-Palatal (CAIF), localizado em Curitiba, PR, entre os meses de janeiro de 2018 a dezembro de 2019. Os dados coletados foram: demográficos (sexo e idade), fenótipo da fissura (fissura de lábio isolada, fissura de lábio com palato e fissura de palato isolada) e lateralidade (unilateral ou bilateral). Foram avaliados 227 pacientes. A fissura de palato do tipo completa esteve presente em 115 casos (68,3\%) e unilateralidade em 154 (75,5\%), tendo a completa, maior prevalência em homens. Concluiuse que as $\mathrm{FL} / \mathrm{P}$ unilaterais se apresentaram em maior número, e para os homens prevaleceu a fissura palatina completa. Há necessidade de se compreender os aspectos epidemiológicos relacionados às $\mathrm{FL} / \mathrm{P}$ para que assim sejam desenvolvidas políticas de saúde efetivas, com impacto na melhora da qualidade de vida dos indivíduos.

Palavras-chave: Fenda labial. Fenda palatina. Epidemiologia. Odontologia. 


\section{INTRODUÇ̃̃O}

As anomalias congênitas, sejam de estrutura, função ou metabolismo, presentes no nascimento, são considerados um problema de saúde pública, pois podem levar à invalidez ou à morte. Estima- se que 1 a cada 303 mil nascidos vivos venha a falecer nas quatro primeiras semanas de vida devido a anomalias congênitas (HLONGWA; LEVIN; RISPEL, 2019).

Dentre os locais que podem ser acometidos por essas anomalias está o complexo dentofacial, composto de diversas estruturas que frequentemente sofrem alterações no seu desenvolvimento, dentre elas alterações congênitas como as fissuras labiais e/ou palatinas (FL/P), ou até mesmo alterações no desenvolvimento dentário sejam de número, como as agenesias e dentes supranumerários, ou de forma como as taurodontias (ELLIS, 2000; OZDEMIR; ESELINK, 2018). Para Leslie e Marazita (2013) essas alterações podem se apresentar de maneira isolada, caracterizadas como não sindrômicas, objeto da presente pesquisa, ou acompanhadas por outra alteração, sendo então classificadas como sindrômicas.

Para Sperber (2002) e Mossey et al. (2009), quando ocorre o desenvolvimento craniofacial, o lábio e o palato envolvem uma complexa série de eventos que contemplam migração celular, crescimento, diferenciação e apoptose, nas quais as células da crista neural migram através do tecido mesenquimal; aproximadamente na 4. a semana de desenvolvimento elas participam da formação frontonasal, e por volta da 6. a semana ocorrem as fusões dos processos maxilares com os processos nasais mediais, formando palato primário e lábio superior. Entretanto, antes da conclusão do processo, o pico da divisão das células se torna suscetível a efeitos teratogênicos, podendo ocorre uma falha no processo de fechamento, que se dá por volta da 10.a semana de embriogênese. Howe et al. (2018) sustentam que as FL/P não sindrômicas estão relacionadas a anormalidades no desenvolvimento do filtrum.

De acordo com Küchler et al. (2011) as FL/P ocorrem na proporção de 1 a cada 700 nascidos vivos e podem variar de acordo com aspectos geográficos e étnicos. Aproximadamente $70 \%$ das FL/P são consideradas não sindrômicas ou isoladas, cujos indivíduos afetados não apresentam qualquer outra anomalia estrutural associada, enquanto as $30 \%$ restantes são atribuídas a fissuras sindrômicas (NOPOULOS et al., 
2007; SHI; WEHBY; MURRAY, 2002). No Brasil, estima-se que a incidência de FL/P não sindrômicas seja de 0,99 casos para cada 1000 nascidos (PANAMONTA et al., 2015), sendo observado que os indivíduos de descendência asiática ou de índios americanos apresentam maior incidência dessa alteração, enquanto nos africanos isso se reduz (BEKELE; EKANEM; MEBERATE, 2019; DIXON et al., 2011; NATSUME et al., 1987).

Há algumas classificações para as FL/P, entretanto, a mais utilizada pelos profissionais é a de Spina et al. (1972), que consiste na classificação que tem como base o forame incisivo, em quatro grupos: pré-forame incisivo, transforame incisivo, pósforame incisivo e fissuras raras da face. Há, ainda, uma classificação conforme a localização em: pré-forame incisivo esquerda, direita, mediana ou bilateral, sendo incompletas quando atingem apenas tecidos moles ou completas quando atingem todos os tecidos. As transforame são classificadas em unilaterais ou bilaterais, e as pós-forame também podem ser unilaterais ou bilaterais, incompletas ou completas. Já as fissuras raras são quaisquer outras fissuras faciais que acometem tecido ósseo, muscular ou mucoso que não são incluídas nas classificações anteriores (COSTA; TAKESHITA; FARAH, 2013).

A etiologia e a patogênese exata das FL/P ainda não foram completamente elucidadas, mas sabe-se que há um modelo multifatorial, onde tanto fatores genéticos quanto ambientais estão envolvidos (MOSSEY; LITTE, 2002; MURRAY, 2002). Dentre os ambientais, destacam-se déficit nutricional, uso de inseticidas, consumo de bebidas alcoólicas, tabagismo e uso de medicamentos durante a gestação (NEVES et al., 2016; DEROO et al., 2016; MURRAY, 2002). Também foi relatado que consanguinidade e uso de anticonvulsivantes durante a gravidez podem ter algum envolvimento (BEKELE; EKANEM; MEBERATE, 2019), além de diabetes e obesidade das mães (KOZMA et al., 2019). Outros autores demonstraram relação entre a ocorrência de FL/P e o uso de tabaco pelas mães durante o primeiro trimestre de gestação, sendo o cigarro considerado um dos principais fatores de risco para o desenvolvimento dessas alterações (MOREIRA, 2014).

Outra importante consideração trata dos impactos negativos que as $\mathrm{FL} / \mathrm{P}$ tem na qualidade de vida dos indivíduos afetados (GUILLÉN; PEÑACOBA; ROMERO, 2020). 
Portanto, o objetivo deste trabalho foi realizar um levantamento de algumas características epidemiológicas e possíveis associações em pacientes com FL/P não sindrômicas.

\section{MATERIAIS E MÉTODOS}

Tratou-se de estudo transversal realizado por meio de pesquisa documental junto aos prontuários dos pacientes atendidos no Centro de Atendimento Integral ao Fissurado Labio-Palatal (CAIF), localizado em Curitiba, PR, Brasil, entre os meses de janeiro de 2018 a dezembro de 2019. Os dados coletados foram: demográficos (sexo e idade), fenótipo da fissura (fissura de lábio isolada, fissura de lábio com palato e fissura de palato isolada) e lateralidade (unilateral ou bilateral). Pacientes portadores de alguma síndrome foram excluídos, bem como aqueles sem todas as informações necessárias para a presente pesquisa.

Inicialmente, foram descartados os dados dos indivíduos com FL/P sindrômica. Para a variável quantitativa foi feita análise descritiva, na busca de valores de média, desvio-padrão, mínimo e máximo. Para as variáveis qualitativas foram descritos os valores em frequências absoluta e relativa. Então, o teste de Qui-quadrado foi feito entre as variáveis de desfecho de interesse (presença de fissura e fissura de palato) e o sexo. Foram considerados como diferenças estatisticamente significativas, os resultados $\operatorname{com} \mathrm{p}<0,05$.

Esta pesquisa passou por aprovação de Comitê de Ética de Pesquisa da Universidade Positivo, sob registro n. 3.837.352.

\section{RESULTADOS}

Foram avaliados os prontuários de 321 pacientes. Desses, 94 foram excluídos pelo fato de serem indivíduos sindrômicos ou não terem ao menos uma informação a respeito da fissura presente.

Dos 227 avaliados, a média de idade foi de 32,3 anos ( $D P=11,3$ ), com valores mínimo e máximo de 4 e 59 anos, respectivamente.

Houve um equilíbrio entre os sexos, com a participação de 105 mulheres (46,3\%) e 122 homens $(53,7 \%)$. 
Na Tabela 1 estão descritas as classificações do CID das alterações identificadas nos casos avaliados, distribuídas conforme o sexo. Em seis, das 12 alterações (fenda dos palatos duro e mole com fenda labial unilateral, fenda do palato duro com fenda do palato mole, fenda do palato duro com fenda labial bilateral, fenda do palato duro com fenda labial unilateral, fenda labial com fenda palatina e fenda labial unilateral), houve prevalência entre os homens.

A fissura de palato do tipo completa esteve presente em 115 casos $(68,3 \%)$ e unilateralidade em 154 (75,5\%).

Tabela 1 -Descrição dos dados do CID identificados nos pacientes do CAIF, distribuídos conforme o sexo, Curitiba, Brasil $(n=227)$

\begin{tabular}{lcc}
\hline CID & \multicolumn{2}{c}{ Sexo } \\
\cline { 2 - 3 } & Feminino & Masculino \\
& $\mathbf{n}(\%)$ & $\mathbf{n}(\%)$ \\
\hline Fenda dos palatos duro e mole com fenda labial unilateral & $35(33,3)$ & $51(41,8)$ \\
Fenda dos palatos duro e mole com fenda labial bilateral & $26(24,8)$ & $23(18,9)$ \\
Fenda do palato com fenda labial unilateral, não especificada & $2(1,9)$ & $1(0,8)$ \\
Fenda do palato duro & $3(2,9)$ & $0(0,0)$ \\
Fenda do palato duro com fenda do palato mole & $4(3,8)$ & $5(4,1)$ \\
Fenda do palato duro com fenda labial bilateral & $0(0,0)$ & $3(2,5)$ \\
Fenda do palato duro com fenda labial unilateral & $20(19,0)$ & $22(18,0)$ \\
Fenda do palato mole & $3(2,9)$ & $2(1,6)$ \\
Fenda do palato mole com fenda labial unilateral & $1(1,0)$ & $0(0,0)$ \\
Fenda labial com fenda palatina & $0(0,0)$ & $1(0,8)$ \\
Fenda labial unilateral & $7(6,7)$ & $14(11,5)$ \\
Fenda palatina não especificada & $4(3,8)$ & $0(0,0)$ \\
\hline
\end{tabular}

Fonte: Autoria própria.

Em relação ao fenótipo da fissura, $81,50 \%$ da amostra apresentou fissura de lábio com palato, e as fissuras de lábio e de palato isoladas obtiveram a mesma frequência. Para os sexos houve prevalência para as mulheres da fissura de palato isolada $(66,70 \%)$, e para os homens fissura de lábio isolada e fissura de lábio com palato (66,70\% e 54,59\%, respectivamente).

Com referência às associações realizadas, os dados estão dispostos na Tabela 2. Quando em análise o tipo de fissura de palato, a completa prevaleceu entre os homens, apesar da diferença estatística ser considerada como um borderline $(p=0,055 ; O R=$ 
0,58; IC 95\%: 0,33-1,01), o que representa uma tendência de severidade no sexo masculino. Já a lateralidade não se mostrou diferente entre os sexos $(p=0,335 ; O R=$ 0,73; IC 95\%: 0,38-1,38).

Tabela 2 - Resultados da análise de associação entre tipo de fissura de palato e lateralidade, e sexo.

\begin{tabular}{|c|c|c|c|c|c|c|}
\hline \multirow{2}{*}{ Variável } & \multicolumn{2}{|c|}{ Fissura de palato } & \multirow{2}{*}{$\begin{array}{c}\text { Valor de } \\
\text { p }\end{array}$} & \multicolumn{2}{|c|}{ Lateralidade } & \multirow{2}{*}{$\begin{array}{l}\text { Valor } \\
\text { de } p\end{array}$} \\
\hline & $\begin{array}{c}\text { Completa } \\
\text { n (\%) }\end{array}$ & $\begin{array}{c}\text { Incompleta } \\
\text { n (\%) }\end{array}$ & & $\begin{array}{c}\text { Unilateral } \\
\text { n (\%) }\end{array}$ & $\begin{array}{c}\text { Bilateral } \\
\text { n (\%) }\end{array}$ & \\
\hline \multicolumn{7}{|l|}{ Sexo } \\
\hline Feminino & $\begin{array}{l}65(41,9)^{\mathrm{a}} \\
90(58,1)^{\mathrm{a}}\end{array}$ & $\begin{array}{l}40(55,6)^{a} \\
32(44,4)^{a}\end{array}$ & 0,055 & $\begin{array}{l}65(42,2)^{a} \\
88(57,8)^{a}\end{array}$ & $\begin{array}{l}25(50,0)^{b} \\
25(50,0)^{b}\end{array}$ & 0,335 \\
\hline
\end{tabular}

Nota: Letras diferentes nas linhas indicam diferença estatisticamente significativa (QuiQuadrado, $p<0,05)$.

Fonte: Autoria própria.

\section{DISCUSSÃO}

No presente estudo foram buscadas características epidemiológicas e possíveis associações em pacientes com FL/P não sindrômicas. Os resultados apontaram que houve prevalência de FL/P unilaterais, e diferenças estatisticamente significativas entre os sexos não foram observadas para tipo de fissura e lateralidade, apesar de, na primeira, os homens terem apresentado mais severidade, dada a maior prevalência de fissura palatina completa.

Quanto às variáveis aqui estudadas, o sexo é um fator frequentemente descrito nos estudos desta natureza, sendo apontado como um fator associado aos diferentes desfechos. No presente estudo houve um equilíbrio entre os sexos, com um ligeiro aumento no número de homens e, nestes, a fissura palatina do tipo completa foi superior. Também, para os homens as prevalências foram maiores para as alterações: fenda dos palatos duro e mole com fenda labial unilateral, fenda do palato duro com fenda do palato mole, fenda do palato duro com fenda labial bilateral, fenda do palato duro com fenda labial unilateral, fenda labial com fenda palatina e fenda labial unilateral.

A maioria dos estudos evidencia maior prevalência para o sexo masculino (BEKELE; EKANEM; MEBERATE, 2019; COUTINHO et al., 2009; ESHETE et al., 2017; 
IMPELLIZZERI et al., 2019; MENEZES et al., 2010; NEVES et al., 2016; PONS-BONALS et al., 2017; PRABAKARAN; THILAGAM; REDDY, 2019; ROLLEMBERG et al., 2019). Tolarova e Cervenka (1998) estimaram que $60 \%$ a $80 \%$ dos pacientes com FL/P eram homens na amostra por eles avaliada na Califórnia, Estados Unidos. Algumas pesquisas mostram que a diferença não é estatisticamente significativa, como o caso do presente estudo (CUOZZO et al., 2013; KIANIFAR et al., 2015; PACÁKOVÁ et al., 2016). De modo contrário, Maia et al. (2019), observaram que o sexo feminino era o mais acometido por FL/P. Cautela em relação aos achados deve ser tomada, uma vez que essas diferenças podem ser justificadas pelos tamanhos das amostras.

Em relação ao fenótipo, as fissuras de palato foram mais frequentes entre as mulheres e a fissuras de lábio isolada e de lábio com palato predominaram nos homens, características que corroboram os relatos de conjuntos de dados nacionais e mundiais (ANTOSZEWSKI; FIJAŁKOWSKA, 2016; COUTINHO et al., 2009; CUOZZO et al., 2013; FERRARI-PILONI; BARROS; JESUÍNO, 2021; HLONGWA; LEVIN; RISPEL, 2019; IMPELLIZZERI et al., 2019; MARTELLI et al., 2012; MENEZES et al., 2010; PACÁKOVÁ et al., 2016; PANG; BROYLES; REDETT, 2013). Martelli et al. (2012) constataram que o risco de fissura de lábio em relação à fissura de palato foi de 2,19 vezes maior em homens quando comparados às mulheres; enquanto o risco de fissura de lábio com palato em relação à fissura de palato apenas, foi 2,78 vezes em homens, em comparação às mulheres. Segundo Hlongwa et al. (2019) os homens são mais afetados que as mulheres em uma escala de 2:1 nas fissuras de lábio e de lábio com palato, enquanto as mulheres apresentaram risco maior de fissuras apenas de palato. Umas das teorias para a maior incidência de fissura de palato nas mulheres seria o tempo de fechamento do palato secundário do embrião. Nos homens, a fusão e o fechamento do palato ocorre antes, assim o tempo suscetível a fatores teratogênicos é menor do que nas mulheres (BURDI; SILVEY, 1969).

A distribuição das FL/P entre os fenótipos neste estudo demonstrou maior prevalência de fissuras de lábio com palato, isso corrobora com estudos epidemiológicos de fissuras na África do Sul (HLONGWA; LEVIN; RISPEL, 2019), Etiópia (BEKELE; EKANEM; MEBERATE, 2019), Irã (KIANIFAR et al., 2015), Austrália (LO et al., 2015) e China (FAN et al., 2018). Esses resultados são similares aos estudos nacionais realizados em Pernambuco (COUTINHO et al., 2009), Rio Grande do Sul (MENEZES et al., 2010), Minas 
Gerais (MARTELLI et al., 2012), Alagoas (MONLLEÓ et al., 2015), Mato Grosso (CUOZZO et al., 2013; NEVES et al., 2016) e Goiás (FERRARI-PILONI; BARROS; JESUÍNO, 2021).

Neste estudo a fissura de palato do tipo completa foi a mais frequente, resultado semelhante ao de Coutinho et al. (2009) e Ferrari-Piloni et al. (2021). A maior prevalência da fissura completa em relação à incompleta, está relacionada à maior gravidade e maio demanda por tratamento (FERRARI-PILONI; BARROS; JESUÍNO, 2021). Em relação aos sexos, foi encontrada uma maior prevalência de fissuras completas no sexo masculino, sendo que Martelli et al. (2012) apresentaram resultados diferentes, com maior prevalência no sexo feminino, na razão de 1,77:1 em relação aos homens.

Quanto à lateralidade das fissuras, a literatura apresenta uma maior prevalência de casos de fissuras unilaterais (BEKELE; EKANEM; MEBERATE, 2019; BUNDUKI et al., 2001; COUTINHO et al.; 2009; HLONGWA; LEVIN; RISPEL, 2019; MAIA et al., 2019; MONLLEÓ et al., 2015; PONS-BONALS et al., 2017), o que foi confirmado nesta pesquisa.

As diferenças observadas podem ser justificadas pela complexidade das $\mathrm{FL} / \mathrm{P}$, as quais são multifatoriais, que podem ser causadas por fatores ambientais ou genéticos diversos (OZDEMIR; ESELINK, 2018).

De acordo com Abulezz (2017) as FL/P influenciam negativamente as atividades normais da vida de um bebê, como sucção e fala. Bekele et al. (2019) também relatam outros problemas relacionados, como deficiências auditivas, problemas dentários, crescimento maxilofacial deficiente, o que gera uma série de desafios com impactos na qualidade de vida dos acometidos, conforme também destacado por Guillén et al. (2020).

Dixon et al. (2011) apontam que estas deformidades, em países desenvolvidos, não geram um número elevado de mortes. Entretanto, para Mossey et al. (2009) e Wehby e Cassell (2010) o risco de morbidade e mortalidade pode aumentar em países menos desenvolvidos, pois as FL/P estão associadas a maiores taxas de morbidade em famílias com menor poder socioeconômico, uma vez que todos os procedimentos reconstrutivos e que complementam essas intervenções tais como tratamentos psicológicos, fonoaudiólogos, dentre outros, impõem um alto custo financeiro.

Deste modo, a compreender as características epidemiológicas da doença em diferentes grupos é de suma importância para criar subsídios para desenvolver políticas 
públicas voltadas a estratégias de prevenção, diagnóstico, tratamento e prognóstico para assistir de forma adequada esses indivíduos e suas famílias.

\section{CONSIDERACÕES FINAIS}

Os principais resultados mostraram que houve prevalência de FL/P unilaterais, e não foram observadas diferenças estatisticamente significativas entre os sexos para tipo de fissura e lateralidade. Contudo, os homens apresentaram mais severidade, devido à maior prevalência de fissura palatina completa.

Esta pesquisa realizada no Centro de Atendimento Integral ao Fissurado LabioPalatal (CAIF) mostra a complexidade das FL/P e a importância de estudos epidemiológicos para o planejamento de ações de saúde mais efetivas, não apenas voltadas para o tratamento, mas também para a qualidade de vida destes indivíduos e suas famílias.

\section{REFERÊNCIAS}

ABULEZZ, T. A. Cleft lip and palate: An experience of a developing center in Egypt. Journal of Craniofacial Surgery, v. 28, n. 8, p. e731-e734, 2017.

ANTOSZEWSKI, B.; FIJAŁKOWSKA, M. Prevalence of cleft lip and/or palate in children from Lodz between years 1981-2010. Congenital Anomalies (Kyoto), v. 56, n. 2, p. 60-64, 2016.

BEKELE, K. K.; EKANEM, P. E.; MEBERATE, B. Anatomical patterns of cleft lip and palate deformities among neonates in Mekelle, Tigray, Ethiopia; implication of environmental impact. BMC Pediatrics, [S. I.], v. 19, n. 1, p. 254, 2019.

BUNDUKI, V.; RUANO, R; SAPIENZA, A. D.; HANAOKA, B. Y.; ZUGAIB, M. Diagnóstico prénatal de fenda labial e palatina: experiência de 40 casos. Revista Brasileira de Ginecologia e Obstetrícia, v. 23, n. 9, p. 561-566, 2001.

BURDI, A. R.; SILVEY, R. G. Sexual differences in closure of the human palatal shelves. Cleft Palate Journal, v.6, p. 1-7, 1969.

COSTA, R. R.; TAKESHITA, W. M.; FARAH, G. J. Levantamento epidemiológico de fissuras labiopalatais no município de Maringá e região. Revista da Associação Paulista de Cirurgiões Dentistas, São Paulo, v. 67, n. 1, p. 40-44, 2013. 
COUTINHO, A. L.; LIMA, M. C.; KITAMURA, M. A.; FERREIRA NETO, J.; PEREIRA, R. M. Perfil epidemiológico dos portadores de fissuras orofaciais atendidos em um Centro de Referência do Nordeste do Brasil. Revista Brasileira de Saúde Materno Infantil, v. 9, n. 2, p. 149-156, 2009.

CUOZZO, F. D.; ESPINOSA, M. M.; SILVA, K. T.; BARROS, Y. B.; BANDECA, M. C.; ARANHA, A. M.; BORGES, A. H.; VOLPATO, L. E. Cleft lip and palate in a Brazilian subpopulation. Journal of International Oral Health, v. 5, n. 4, p. 15-20, 2013.

DEROO, L. A.; WILCOX, A. J.; LIE, R. T.; ROMITTI, P. A.; PEDERSEN, D. A.; MUNGER, R. G.; MRENO URIBE, L. M.; WEHBY, G. L. Maternal alcohol binge-drinking in the first trimester and the risk of orofacial clefts in offspring: a large population-based pooling study. European Journal of Epidemiology, v. 31, n. 10, p. 1021-1034, 2016.

DIXON, M. J.; MARAZITA, M. L.; BEATY, T. H.; MURRAY, J. C. Cleft lip and palate: Understanding genetic and environmental influences. Nature Reviews Genetics, v. 12, n. 3, p. 167-178, 2011.

ELLIS, E. Tratamento de pacientes com fissuras orofaciais. In: Peterson, L. J. Cirurgia oral e maxilofacial contemporânea. Rio de Janeiro: Guanabara Koogan, 2000. p. 639661.

ESHETE, M.; BUTALI, A.; DERESSA, W.; RIVERA, K. P.; HAILU, T.; ABATE, F., MOHAMMED, I.; DEMISSIE, Y.; HAILU, A.; DAWSON, D. V.; DERIBEW, M.; GESSESE, M.; GRAVEM, P. E.; MOSSEY, P. Descriptive epidemiology of orofacial clefts in Ethiopia. Journal of Craniofacial Surgery, v. 28, n. 2, p. 334-337, 2017.

FAN, D.; WU, S.; LIU, L.; XIA, Q.; TIAN, G.; WANG, W.; YE, S.; WANG, L.; RAO, J.; YANG, X.; YU, Z.; XIN, L.; LI, S.; DUAN, Z.; ZHANG, T.; WU, S.; GUO, X.; LIU, Z. Prevalence of non-syndromic orofacial clefts: based on $15,094,978$ Chinese perinatal infants. Oncotarget, v. 9, n. 17, p. 13981-13990, 2018.

FERRARI-PILONI, C.; BARROS, L. A. N.; JESUÍNO, F. A. S.; VALLADARES-NETO, J. Prevalence of cleft lip and palate and associated factors in Brazil's Midwest: a single-center study. Brazilian Oral Research, v. 3, p. 1-9, 2021.

GUILLÉN, A. R.; PEÑACOBA, C.; ROMERO, M. Psychological variables in children and adolescents with cleft lip and/or palate. Journal of Clinical Pediatric Dentistry, v. 44, n. 2, p. 116-122, 2020.

HLONGWA, P.; LEVIN, J.; RISPEL, L. C. Epidemiology and clinical profile of individuals with cleft lip and palate utilising specialised academic treatment centres in South Africa. PLoS One, v. 14, n. 5, p. 0215931, 2019.

HOWE, L. J.; LEE, M. K.; SHARP, G. C.; SMITH, G. D.; POURCAIN, B. S. T.; SHAFFER, J. R.; LUDWIG, K. U.; MANGOLD, E., MARAZITA, M. L.; FEINGOLD, E.; ZHUROV, A.; 
STERGIAKOULI, E.; SANDY, J.; RICHMOND, S.; WEINBERG, S. M.; HEMANI, G.; LEWIS, S. J. Investigating the shared genetics of non-syndromic cleft lip/palate and facial morphology. PLoS Genetics, v. 14, n. 8, p. 1007501, 2018.

IMPELLIZZERI, A.; GIANNANTONI, I.; POLIMENI, A.; BARBATO, E.; GALLUCCIO, G. Epidemiological characteristic of orofacial clefts and its associated congenital anomalies: retrospective study. BMC Oral Health, v. 19, n. 1, p. 290, 2019.

KIANIFAR, H.; HASANZADEH, N.; JAHANBIN, A.; EZZAT, A.; KIANIFAR, H. Cleft lip and palate: a 30-year epidemiologic study in north-east of Iran. Iranian Journal of Otorhinolaryngology, v. 27, n. 78, p. 35-41, 2015.

KOHLI, S. S.; KOHLI, V. S. A comprehensive review of the genetic basis of cleft lip and palate. Journal of Oral Maxillofacial Pathology, v. 16, n. 1, p. 64-72, 2012.

KOZMA, A.; RADOI, V.; URSU, R.; BOHALTEA, C. L.; LAZARESCU, H.; CARNICIU, S. Gestational diabetes mellitus and the development of cleft lip / palate in newborns. Acta Endocrinologica (Bucharest), v. 5, n. 1, p. 118-122, 2019.

KÜCHLER, E. C.; MOTTA, L. G.; VIEIRA, A. R.; GRANJEIRO, J. M. Side of dental anomalies and taurodontism as potential clinical markers for cleft subphenotypes. The Cleft Palate-Craniofacial Journal, v. 48, n. 1, p. 103-108, 2011.

LESLIE, E. J.; MARAZITA, M. L. Genetics of cleft lip and cleft palate. Seminars in Medical Genetics, Part C of the American Journal of Medical Genetics, v. 163, n. 4, p. 246-258, 2013.

LITTLE, J.; CARDY, A.; ARSLAN, M. T.; GILMOUR, M.; MOSSEY, P. A. Smoking and orofacial clefts: A United Kingdom-based case-control study. The Cleft Palate-Craniofacial Journal, v. 41, n. 4, p. 381-386, 2004.

LO, J. Y. J.; KILPATRICK, N.; JACOBY, P.; SLACK-SMITH, L. Description of total population hospital admissions for cleft lip and/or palate in Australia. BMC Oral Health, v. 15, p. 156, 2015.

MAIA, L. W.; PINHEIRO, J.; MORAIS, E.; BARBOZA, C. A.; BEZERRA, B.; LEITE, R. Pacientes portadores de fissura labiopalatal: um estudo retrospectivo. Revista de Ciências da Saúde de Nova Esperança, v. 17, n. 1, p. 8-14, 2019.

MANGOLD, E.; LUDWIG, K. U.; NÖTHEN, M. M. Breakthroughs in the genetics of orofacial clefting. Trends in Molecular Medicine, v. 17, n. 12, p. 725-733, 2011.

MONLLEÓ, I. L.; BARROS, A. G.; FONTES, M. I.; ANDRADE, A. K.; BRITO, G. M.; NASCIMENTO, D. L.; GIL-DA-SILVA-LOPES, V. L. Diagnostic implications of associated defects in patients with typical orofacial clefts. Jornal de Pediatria, v. 91, n. 5, p. 485-492, 2015. 
MARTELLI, D. R. B.; MACHADO, R. A.; SWERTS, M. S. O.; RODRIGUES, L. A. M.; AQUINO, S. N.; MARTELLI JÚNIOR, H. Fissuras lábio palatinas não sindrômicas: relação entre sexo e a extensão clínica. Brazilian Journal of Otorhinolaryngology, v. 78, n. 5, p. 116-120, 2012.

MENEZES, L. M. M.; RIZZATTO, S. M. D.; AZEREDO, F.; VARGAS, D. A. Characteristics and distribution of dental anomalies in a Brazilian cleft population. Revista Odonto Ciência, v. 25 n. 2, p. 137-141. 2010.

MOREIRA, H. S. B. Avaliação epidemiológica e investigação de polimorfismos em genes do reparo do DNA na fissura lábio-palatina não sindrômica. Tese (doutorado) Universidade Estadual de Campinas, Faculdade de Odontologia de Piracicaba, Piracicaba, São Paulo; 2014. 137 p.

MOSSEY, P. A.; LITTE, J. Epidemiology of oral clefts: an international perspective. In: WYSZYSNSKI, D. F. (Ed). Cleft lip and palate. From origin to treatment. New York: Oxford Press, 2002. p. 127-158.

MOSSEY, P. A.; LITTLE, J.; MUNGER, R. G.; DIXON, M. J.; SHAW, W. C. Cleft lip and palate. The Lancet, v. 374, n. 9703, p. 1773-1785, 2009.

MURRAY, J. C. Gene/environment cases of cleft lip and/or palate. Clinical Genetics, v. 61, n. 4, p. 248-256, 2002.

NATSUME, N.; SUZUKI, T.; KAWAI, T. The prevalence of cleft lip and palate in the Japanese: their birth prevalence in 40.304 infants born during 1982 . Oral Surgery, Oral Medicine, Oral Pathology, and Oral Radiology, v. 63, n. 4, p. 421423, 1987.

NEVES, A. T. C.; VOlPATO, L. E. R.; ESPINOSA, M. M.; ARANHA, A. M. F.; BORGES, A. H. Environmental factors related to the occurrence of oral clefts in a Brazilian subpopulation. Nigerian Medical Journal, v. 57, n. 3, p. 167-172, 2016.

NOPOULOS, P.; LANGBEHN, D. R.; CANADY, J.; MAGNOTTA, V.; RICHMAN, L. Abnormal brain structure in children with isolated clefts of the lip or palate. Archives of Pediatrics \& Adolescent Medicine, v. 161, n. 8, p. 753-758, 2007.

OZDEMIR, S. A.; ESENLIK, E. Three-dimensional soft-tissue evaluation in patients with cleft lip and palate. Medical Science Monitor, v. 28, n. 24, p. 8608-8620, 2018.

PACÁKOVÁ, D.; ZÁBAVNÍKOVÁ, M.; MIKLOŠOVÁ, M.; KÚKEL'OVÁ, D.; DANKOVČíK, R. Epidemiological study of orofacial clefts among population of eastern slovakia during the period 1996-2013. Central European Journal of Public Health, v. 2, n. 2, p. 128-132, 2016. 
PANAMONTA, V.; PRADUBWONG, S.; PANAMONTA, M.; CHOWCHUEN, B. Global birth prevalence of orofacial clefts: a systematic review. Journal of the Medical Association of Thailand, v. 98, n. 7, p. 11-21, 2015.

PANG, J.; BROYLES, J.; REDETT. R. Cleft lip and palate. Eplasty, v. 13, p. ic25, 2013.

PARANAÍBA, L. M.; MIRANDA, R. T.; MARTELLI, D. R.; BONAN, P. R. F.; ALMEIDA, H.; ORSI JÚNIOR, J. M.; MARTELLI JÚNIOR, H. Cleft lip and palate: series of unusual clinical cases. Brazilian Journal of Otorhinolaryngology, v. 76, n. 5, p. 649-653, 2010.

PONS-BONALS, A.; PONS-BONALS, L.; HIDALGO-MARTÍNEZ, S. M.; SOSA-FERREYRA, C. F. Estudio clínico-epidemiológico en niños con labio paladar hendido en un hospital de segundo nivel. Boletín Médico del Hospital Infantil de México, v. 74, n. 2, p. 107-121, 2017.

PRABAKARAN, S.; THILAGAM, K. K.; REDDY, G. M. M. Profile of cleft lip and cleft palate at a public hospital in southern india. Indian Pediatrics, v. 56, n. 9, p. 753-755, 2019.

ROLLEMBERG, V. E.; PIRES, T. O.; MORAES, G. N.; RIOS, L. R., MACHADO, L. G.; DA-SILVA, M. D.; PARREIRA, D. R. Perfil epidemiológico de pacientes portadores de fissura labiopalatinas em serviço de referência no Distrito Federal. Revista Brasileira de Cirurgia Plástica, v. 34, n. 1, p. 94-100, 2019.

SHI, M.; WEHBY, G. L.; MURRAY, J. C. Review on genetic variants and maternal smoking in the etiology of oral clefts and other birth defects. Birth Defects Research Part C - Embryo Today: Reviews, v. 81, n. 1, p. 16-29, 2008.

SPERBER, G. H. Formation of the primary and secondary palate. In: WYSZYNSKI, D. F. (Ed.). Cleft lip and palate: from origin to treatment. New York: Oxford University Press, 2002. p. 5-24.

SPINA, V.; PSILLAKIS, J. M.; LAPA, F. S.; FERREIRA, M. C. Classificação das fissuras lábiopalatinas. Sugestão de modificação. Revista do Hospital de Clínicas da Faculdade de Medicina da Universidade de São Paulo, v. 27, n. 1, p. 5-6, 1972.

TOLAROVA, M. M.; CERVENKA, J. Classification and birth prevalence of orofacial clefts. American Journal of Medical Genetics, v. 13, n. 75, p. 126-137, 1998.

YILMAZ, N. H.; ÖZBILEN, Ö. E.; ÜSTÜN, T. The prevalence of cleft lip and palate patients: a single-center experience for 17 years. Turkish Journal of Orthodontics, v. 32, n. 3, p. 139-144, 2019.

WEHBY, G. L.; CASSELL, C. H. The impact of orofacial clefts on quality of life and healthcare use and costs. Oral Diseases, v. 16, n. 1, p. 3-10, 2010. 
WORLD HEALTH ORGANIZATION. Human Genetics Programme. Global strategies to reduce the health-care burden of craniofacial anomalies: report of WHO meetings on international collaborative research on craniofacial anomalies. Genebra: World Health Organization, 2002. Disponível em: < https://apps.who.int/iris/bitstream/handle/10665/42594/9241590386.pdf?seq uence=1\&isAllowed=y $>$ Acesso em 12 Jul. 2021. 


\title{
CAPITULO XIX DIAGNÓSTICO DE INFECÇÕES SEXUALMENTE
TRANSMISSIVEIS POR MEIO DE LESÕES ORAIS
}

DOI: 10.51859/AMPLLA.EPC757.1121-19

\author{
Jéssica Vergna Neves ${ }^{1}$ \\ Caroline Travesani Marchezi ${ }^{2}$ \\ Larissa Neves de Angeli ${ }^{3}$ \\ Liliana Aparecida Pimenta de Barros ${ }^{4}$ \\ Tânia Regina Grão-Velloso ${ }^{5}$ \\ Danielle Resende Camisasca ${ }^{6}$
}

1, 2,3 Graduando do curso de Odontologia. Universidade Federal do Espírito Santo - UFES
4, 5, 6 Professoras do Departamento de Clínica Odontológica. Universidade Federal do Espírito Santo - UFES

\section{RESUMO}

Introdução: um dos agravos da Saúde Pública são as Infecções Sexualmente Transmissíveis (ISTs), que apresentam um grande desafio no rastreamento e no tratamento adequado, mostrando poucos estudos epidemiológicos e escassez de pesquisas, principalmente, no que tange as manifestações na cavidade oral. A cavidade bucal sendo um dos sítios das manifestações das ISTs e de fácil acesso pelo indivíduo portador e profissional de saúde, em especial, o cirurgião-dentista, permite a identificação dessas manifestações contribuindo para o processo diagnóstico. Objetivo: Descrever as manifestações orais das ISTs (Gonorreia, Herpes, HIV/Aids, Condiloma acuminado e Sífilis), para contribuir com a identificação dessas infecções, que se mostram de difícil rastreamento. Métodos: foram incluídos 31 artigos científicos, publicados entre os anos de 2005 e 2021, nos idiomas inglês e português e textos de órgãos nacionais e internacionais, que são importantes para o estudo das ISTs, e a busca foi realizada nas bases de dados PubMed, Periódicos Capes e Scielo, usando as palavras chave "sexually transmitted infections", "gonorrhea", "syphilis", "oral manifestations", "hpv", "hiv", "herpesvirus", "hepatitis C" e "oral lichen planus" entre os anos de 2005 e 2021. Conclusão: Os cirurgiões dentistas devem estar atentos às alterações da cavidade bucal, dentre elas, as manifestações orais das doenças sistêmicas, como as ISTs. Dessa forma, ao identificar lesões orais, o cirurgião dentista deve diagnosticar e encaminhar o paciente para tratamento médico, contribuindo com a diminuição da transmissão e auxiliando na condição sanitária da sociedade e na economia.

Palavras-chave: infecções sexualmente transmissíveis. Aids. Sífilis. HPV. Manifestações orais. 


\section{INTRODUÇÃO}

Infeç̧ão Sexualmente Transmissível (IST) ou Doença Sexualmente Transmissível (DST)? Com a finalidade de substituir à expressão DST, a terminologia IST, salienta a capacidade do indivíduo em apresentar e transmitir uma infecção, mesmo sem sinais ou alguma sintomatologia (MINISTÉRIO DA SAÚDE, 2021).

As ISTs representam um dos problemas de Saúde Pública mais comuns em todo o mundo, apresentando grande incidência e difícil acesso ao tratamento necessário. De acordo com o levantamento de 2021 da Organização Mundial da Saúde (OMS), acontecem por ano e no mundo, um total de 376 milhões de casos novos curáveis de ISTs, esses dados demonstram um acentuado prejuízo econômico aos países em desenvolvimento, uma vez que nesses países as ISTs estão entre os principais motivos de procura aos serviços de saúde, representando diretamente um problema na condição sanitária, da sociedade e da economia. No Brasil são registrados um total de 10 a 12 milhões de casos por ano, além de outras estimativas de milhões de casos de IST não curáveis, sendo elas as infecções por Papilomavírus Humano (HPV), pelo Vírus da Imunodeficiência Humana (HIV), Herpes genital e Hepatite B (PINTO et al., 2018; JUNIOR et al., 2019; AN et al., 2008, WHO, 2021).

A transmissão das diversas ISTs pode ocorrer de um indivíduo infectado, por meio de patógenos virais, bacterianos ou outros microrganismos, principalmente, por contato sexual sem uso de preservativos e pelas vias oral, vaginal e anal. A infecção também pode ocorrer de forma vertical, onde a mãe infectada transmite a doença ao filho durante a gestação, no parto ou na amamentação (PETRY et al., 2019; AN et al., 2008).

Devido às dificuldades inerentes aos sistemas de vigilância sanitária, as estimativas para as ISTs não são precisas, o que gera prejuízos à sociedade e ao indivíduo no aspecto socioeconômico, além de interferir na saúde sexual e reprodutiva, quando o tratamento inadequado ou o não tratamento resulta no agravamento da infecção, podendo evoluir, por exemplo, para casos como a Doença Inflamatória Pélvica (DIP), pois os estudos mostram que 10 a $40 \%$ das mulheres não tratadas por gonorreia/clamídia, irão desenvolver essa patologia. Dessas mulheres, $25 \%$ se tornarão inférteis, com aumento de 10 vezes na probabilidade de uma gravidez ectópica, 
podendo levar à morte. Além das infecções congênitas, podem ocorrer cânceres, casos de abortos, prematuridade, natimortos, mortalidade neonatal e elevado risco de transmissão do HIV, podendo ser maior se houver lesões ulceradas (PINTO et al., 2018; JUNIOR et al., 2019).

Além disso, muitas vezes o indivíduo portador de uma IST não reconhece os sinais e sintomas da infecção, como por exemplo no caso das hepatites, retardando assim o seu diagnóstico. Um outro exemplo é a hepatite $C$, que apesar de não possuir manifestação oral específica, possui diversas manifestações hepáticas e extra-hepáticas como a associação com o surgimento de lesões de líquen plano oral. Nesses pacientes com HCV há evolução mais longa, exacerbações repetidas e sintomas agudos do líquen plano, afetando a qualidade de vida do indivíduo (figura 1). A associação da hepatite $C$ com líquen plano pode contribuir para que o diagnóstico da hepatite seja feito por um cirurgião dentista (GHEORGHE et al., 2014).

Outro aspecto mostra uma problemática em relação à notificação compulsória. No Brasil, as ISTs com notificação são o HIV/Aids, inclusive em gestantes e crianças, a sífilis adquirida, congênita e em gestantes e as hepatites virais. Assim, no caso das outras ISTs, a situação epidemiológica e suas complicações são pouco conhecidas devido a condição complexa e de pouca informação, além da falta de estudos de base populacional, dificultando a visão da real problemática (PINTO et al., 2018; JUNIOR et al., 2019; AN et al., 2008; BRASIL, 2020).

A cavidade bucal é um dos sítios das manifestações das ISTs, e é de fácil acesso pelo indivíduo portador e profissional de saúde, em especial, o cirurgião-dentista, sendo assim, a identificação dessas manifestações pode contribuir para o processo diagnóstico dessas infecções. Assim, serão apresentadas as ISTs que podem possuir manifestações orais e será discutido o papel dessas lesões para o diagnóstico, sendo elas: a gonorreia, herpes simples, HIV/Aids, condiloma acuminado e sífilis. 
Figura 1: Líquen plano oral acometendo paciente com hepatite $C$

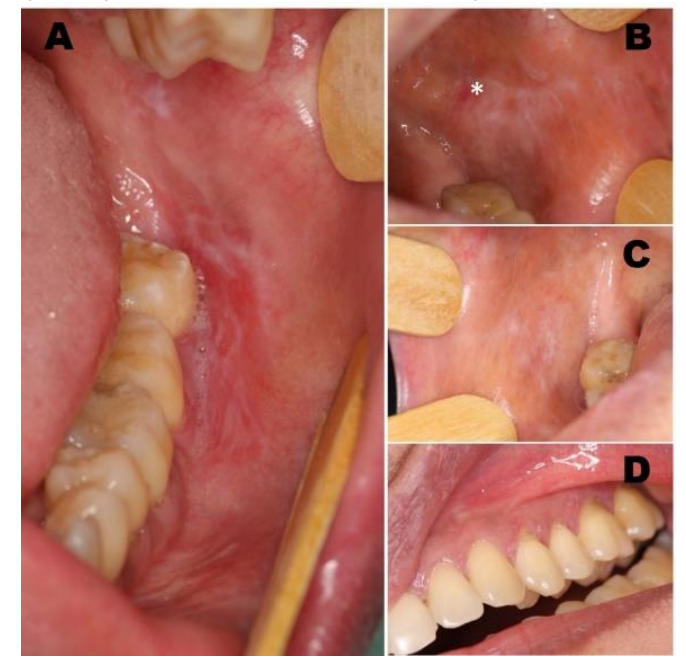

Fonte: Núcleo de Diagnóstico Bucal - NDB/UFES)

O líquen plano oral pode estar associado à Hepatite C. A - líquen plano em fundo de vestíbulo e mucosa jugal de paciente sabidamente portador de Hepatite C. B, C - a localização típica das estriações esbranquiçadas (estrias de Wickham) é na mucosa jugal, bilateralmente, podendo haver áreas avermelhadas $\left({ }^{*}\right)$ ou erosadas. D - também podem ser observadas lesões em outros locais, como a gengiva inserida.

\section{REVISÃO BIBLIOGRÁFICA}

O presente capítulo consiste em uma revisão de literatura e a busca foi realizada nas bases de dados PubMed, Periódicos Capes e Scielo.

De acordo com os critérios de elegibilidade, foram incluídos artigos publicados entre os anos de 2005 e 2021, nos idiomas inglês e português e artigos que apresentassem o tema previamente escolhido. Foram excluídos os artigos que após leitura dos resumos não abrangiam o assunto definido.

Para a busca foram usadas as palavras chave "sexually transmitted infections", "gonorrhea", "syphilis", "oral manifestations", "hpv", "hiv", "herpesvirus", "hepatitis C" e "oral lichen planus". As etapas de busca, triagem, seleção, avaliação dos estudos e extração dos dados foram realizadas por três revisores, de forma independente, avaliando um total de 31 artigos científicos nas bases de dados. Além disso, foram incluídos textos de órgãos nacionais e internacionais, que são importantes para o estudo das ISTs e alguns artigos clássicos amplamente citados nas referências inicialmente incluídas. 


\subsection{GONORREIA}

A gonorreia é uma IST causada pela bactéria Neisseria gonorrhoeae, um diplococo Gram negativo, aeróbio, sem formação de esporos e sensível a maioria dos antissépticos. É uma patologia infectocontagiosa e pandêmica (JUNIOR et al., 2019; LITTLE, 2006).

Acomete os sexos feminino e masculino e, a maior incidência de casos, ocorre entre 15 e 30 anos, podendo ser encontrada em idades inferiores ou muito superiores, com a transmissão durante a relação sexual, por via vaginal, retal ou oral. Existem evidências em estudos epidemiológicos mostrando a influência que as infecções gonocócicas possuem na facilitação da transmissão da infecção pelo HIV (JUNIOR et al., 2019; LITTLE, 2006; DA ROS \&SCHMITT, 2008).

O quadro clínico, em geral, é de infecção da uretra ou do colo uterino, podendo ter propagação para glândulas e órgãos do indivíduo. De forma eventual, pode ocorrer infecção extragenital, levando a patologias como conjuntivite, faringite, oftalmia e anorretite. A infecção pode ser localizada ou sistêmica (JUNIOR et al., 2019).

As manifestações orais são raras, inespecíficas e variadas, podendo apresentar desde um leve eritema até uma ulceração grave com revestimento pseudomembranoso (LITTLE, 2006).

A sintomatologia na população masculina é mais evidente, o que leva ao tratamento precoce, evitando assim que a infecção progrida gravemente, porém não é suficientemente rápido para evitar a transmissão. 0 período de incubação é de 2 a 6 dias. Os sinais e sintomas são de secreção mucopurulenta, além de disúria leve, piorando no período da manhã. Na população feminina, em sua maioria não há sintomatologia até o momento do surgimento de complicações. Quando os sintomas aparecem entre 7 e 21 dias após a infecção, são leves e se caracterizam por dor e queimação ao urinar, sangramento entre os períodos de menstruação e corrimento vaginal purulento. Mesmo com sintomatologia leve, pode-se ter o agravamento da infecção e apresentar um quadro de doença inflamatória pélvica (JUNIOR et al., 2019; DA ROS \&SCHMITT, 2008; LITTLE, 2006).

O desenvolvimento das lesões orais ocorre em geral no período de uma semana após o contato com o indivíduo infectado. A mucosa da orofaringe fica eritematosa e 
com pústulas, podendo haver coceira e queimação, assim o indivíduo fica com limitação na fonação e na alimentação, ou pode apresentar-se assintomático (LITTLE, 2006).

Deve-se obter amostras durante o exame para avaliar a cultura de $N$. gonorrhoeae, sendo a coleta feita por esfregaços endocervicais em mulheres e esfregaço uretral na população masculina. Também é possível avaliar amostras de urina usando a reação em cadeia da ligase. $O$ diagnóstico definitivo deve ser realizado isolando a $N$. gonorrhoeae dos locais de exposição, que podem ser a uretra, endocérvice, a garganta e o reto, utilizando a cultura, e em seguida confirmar com testes bioquímicos, sorológicos, enzimáticos ou de ácido nucléico. Deve-se evitar determinar o diagnóstico de gonorreia quando utilizados métodos isolados que não fazem a cultura do microorganismo, por eles não mostrarem suscetibilidade aos antibióticos (LITTLE, 2006).

A recomendação é que sejam administrados antibióticos específicos por via oral ou intramuscular. Pacientes sem complicações graves não precisam realizar testes para evidenciar a cura, mas os pacientes com sintomas persistentes devem ser testados para determinar se houve resistência antimicrobiana (LITTLE, 2006).

Todos os indivíduos que tiveram relação sexual com o paciente infectado, nos últimos 60 dias, devem ser investigados, diagnosticados e tratados se necessário. 0 paciente infectado deve evitar relações sexuais enquanto o tratamento não estiver concluído (LITTLE, 2006).

Em relação ao tratamento das lesões orais, os pacientes infectados devem ser identificados pelo cirurgião dentista, quando possível, e podem receber o tratamento odontológico poucos dias após o início do tratamento com antibióticos. Deve-se observar com cautela as lesões nos tecidos bucais, faríngeo e perioral, quando encontradas lesões suspeitas em região faríngea deve-se questionar sobre o histórico de ISTs e, caso positivo, encaminhar para um médico infectologista (LITTLE, 2006).

\subsection{HERPES SIMPLES}

O herpes é uma das infecções humanas mais comuns e de curso leve, embora manifestações mais severas possam ocorrer entre neonatos e indivíduos imunocomprometidos, incluindo HIV-positivos e transplantados. Nesses pacientes, as manifestações causadas pelo herpes podem variar de formações vesiculares limitadas 
às regiões orofacial e genital até doença disseminada em pele e mucosas (figura 2) (VARELLA et al., 2005).

O herpes é uma infecção causada por dois vírus da família Herpesviridae e pode afetar a região da boca, principalmente labial, órgãos genitais e áreas próximas. Seres humanos são os únicos hospedeiros nos quais os Herpesviridae se mantêm viáveis sob o aspecto infectivo, por toda a vida do indivíduo (GELLER et al., 2012).

As lesões do herpes oral e genital são decorrentes de infecção pelo vírus herpes simples. O vírus herpes simples tipo 1 (HSV-1) ou herpesvírus humano 1 (HHV-1), é o agente etiológico principal das lesões da região orofacial, enquanto o vírus herpes simples 2 (HSV-2) é a causa principal das lesões na região genital. Entretanto, o HSV-1 pode levar a lesões na região genital e, embora mais raro, o HSV-2 pode ter manifestação na região orofacial. As infecções pelos vírus herpes simples representam as doenças sexualmente transmissíveis mais comuns globalmente, alcançando uma soroprevalência de $80 \%$ em adultos, e apresentam um amplo espectro de acometimento clínico, porém nem sempre a herpes é transmitida sexualmente (GELLER et al., 2012), pode ser transmitida por contato direto com a pele ou com secreções da pessoa infectada.

As manifestações clínicas causadas pelo vírus herpes simples variam do herpes labial comum até encefalites fatais e necrose de órgãos. Essa enorme variabilidade de sintomas clínicos depende da virulência e da resistência da cepa viral à medicação, além do estado imunológico do paciente (VARELLA et al., 2005).

Em 90\% dos casos, a inoculação inicial pelos HSV-1 leva a uma infecção assintomática, detectável apenas por meio da presença de anticorpos. Caso haja sintomatologia, esta é em geral representada por gengivoestomatite com adenopatia regional, balanite, ceratoconjuntivite e herpes cutâneo. O período de incubação dos vírus do gênero Simplexvirus é de 4 a 5 dias (GELLER et al., 2012). A gengivoestomatite herpética primária é uma infecção da cavidade oral, causada pelo HSV-1, que é mais frequente em recém-nascidos e crianças menores de 6 anos. Embora haja relatos, quase nunca é recorrente, a menos que uma doença sistêmica afete a imunidade (SALINAS et al., 2008). O diagnóstico laboratorial para o HSV tem aplicação complementar às manifestações comuns causadas pelo vírus (vesículas orolabiais e genitais), embora seja 
importante para indivíduos imunocomprometidos, transplantados, gestantes, recémnatos e em suspeita de encefalite (VARELLA et al., 2005).

Alguns testes que podem ser feitos para a detecção do Vírus da Herpes são: swab com estudo citológico (método de Tzanck) que trata de um método com baixa especificidade, pois não distingue o HSV de outras espécies de herpesvírus. Reservado para casos atípicos e em pacientes imunocomprometidos. Teste de Cultura viral, onde o material é coletado com um swab a partir de raspado de vesículas dérmicas e semeado em meio de cultura, preferencialmente humano (fibroblastos pulmonares embrionários). A sorologia consiste em uma técnica especialmente indicada quando houver queixas de desconforto genital ou labial recorrente, porém sem presença de lesões e informa principalmente acerca da exposição anterior. Além desses, existe o $P C R$, uma técnica molecular baseada no conhecimento prévio de uma sequência de DNA, característica da espécie que se deseja detectar (GELLER et al., 2012).

O tratamento mais indicado é o farmacológico, pode-se utilizar os medicamentos valaciclovir, aciclovir e famciclovir, classificados como antivirais análogos sintéticos dos nucleosídeos purínicos (guanosina), tendo mecanismo de ação semelhante. Infeç̧ões de mucosa oral pelo HSV podem ser tratadas com aciclovir tópico, oral ou intravenoso. O tratamento deveria ser iniciado ainda na fase prodrômica da doença. (GELLER et al., 2012).

Figura 2: Manifestações do herpes simples recorrente
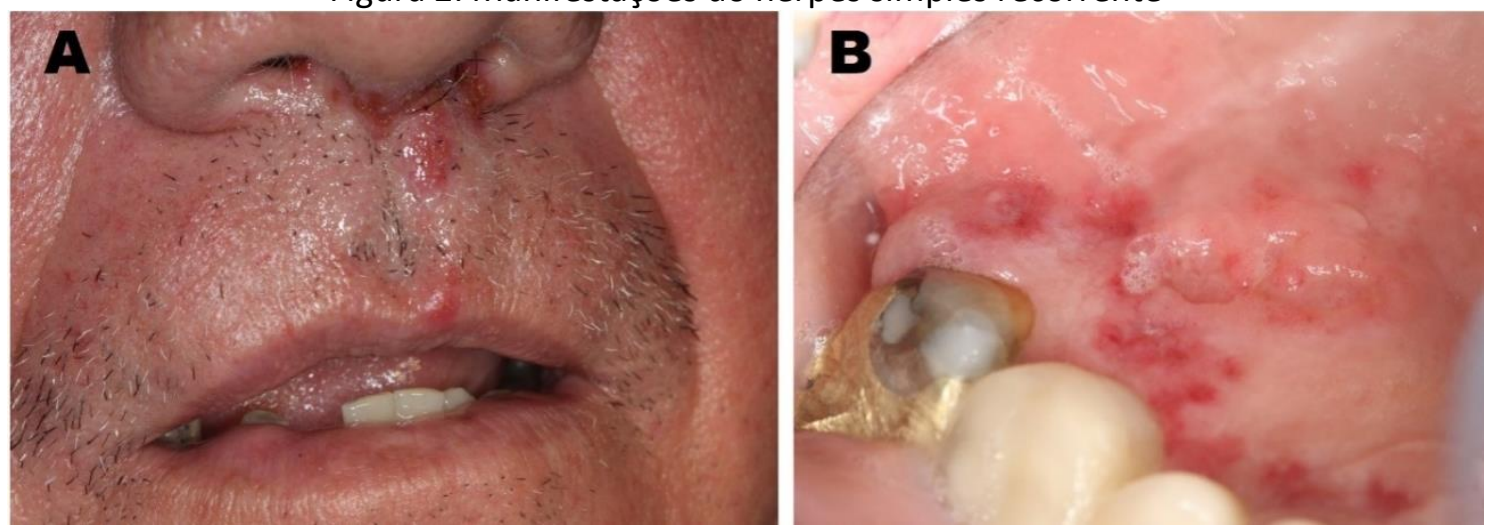

Fonte: Núcleo de Diagnóstico Bucal - NDB/UFES)

A - Paciente apresentando lesões predominantemente em fase de úlcera, em vermelhão do lábio superior, à esquerda do paciente, e em mucosa nasal e pele perinasal. B - Áreas erosadas e avermelhadas, indicando a fase de cicatrização do herpes simples recorrente intraoral, após rompimento das vesículas. O herpes simples dentro da cavidade oral acomete preferencialmente palato duro e gengiva inserida. 


\subsection{HIV/AIDS}

A síndrome da imunodeficiência adquirida (Aids), é causada pelo vírus da imunodeficiência humana (HIV) e é caracterizada pela redução progressiva dos linfócitos T CD4 e enfraquecimento do sistema imunológico infectado. Assim, resultando em algumas doenças, como infecções oportunistas, consideradas como indicadores da Aids (MOTTA et al., 2014).

A transmissão do HIV-1 resulta da exposição do vírus nas superfícies mucosas, por exposição materno-infantil e por inoculação percutânea. A compreensão da transmissão vem de estudos epidemiológicos do HIV, da genética viral e do hospedeiro, dos fatores de risco, análises de comportamento, entre outros. Durante a fase de eclipse, que é uma fase clinicamente silenciosa e que dura cerca de 7 a 21 dias, o vírus se aloja nos linfócitos T CD4 da mucosa, submucosa, pela drenagem linfática e tecidos linfáticos sistêmicos. Assim que o vírus é detectado no plasma sanguíneo, ocorre um aumento exponencial da carga viral como consequência da replicação do vírus nos tecidos linfoides periféricos (SHAW et al., 2012).

As manifestações orais da Aids são os primeiros e mais importantes marcadores clínicos da infeç̧ão pelo HIV, portanto, desempenham um papel importante na sua detecção. Exames como a contagem de linfócitos T CD4 e carga viral são excelentes marcadores laboratoriais, porém, alguns países não possuem disponibilidade de executá-los, sendo os achados orais a principal forma de detecção da doença. Portanto, o cirurgião-dentista possui um importante papel na detecção dessa doença, apesar de classicamente não ser o profissional buscado para o diagnóstico. Contudo, as alterações orais encontradas em pacientes com Aids são primordiais para a detecção da infecção, visto que são oportunistas, não sendo comuns em pacientes imunocompetentes (PAKFRETAT et al., 2015; MOTTA et al., 2014; FILHO et al., 2021).

As lesões podem se desenvolver em até $50 \%$ dos pacientes infectados pelo HIV, de acordo com o nível médio de T CD4, e em até $80 \%$ dos pacientes com Aids (PAKFRETAT et al., 2015). Entre as lesões orais mais encontradas nos pacientes portadores do HIV, podemos citar a candidíase pseudomembranosa, leucoplasia pilosa, periodontite grave, além do sarcoma de kaposi e diversos tipos de infecção, como pelo HSV e HPV (figura 3). Essas lesões podem influenciar na qualidade de vida dos pacientes, 
pois a saúde bucal está relacionada à saúde física e mental, podendo causar disfagia, dificuldade de fala e deglutição e, consequentemente, perda de peso e deterioração clínica (PAKFRETAT et al., 2015; MENEZES et al., 2015).

A infeç̧ão pelo HIV ainda é um grande problema de saúde pública no mundo, visto que muitas pessoas ainda não possuem informação necessária para prevenção e, quando infectados, desconhecem sua condição sorológica. Assim sendo, conhecer as manifestações orais da Aids irá auxiliar o cirurgião-dentista no diagnóstico e acompanhamento dos pacientes (FILHO et al., 2021).

Figura 3: Paciente portando lesões indicativas de HIV/Aids.
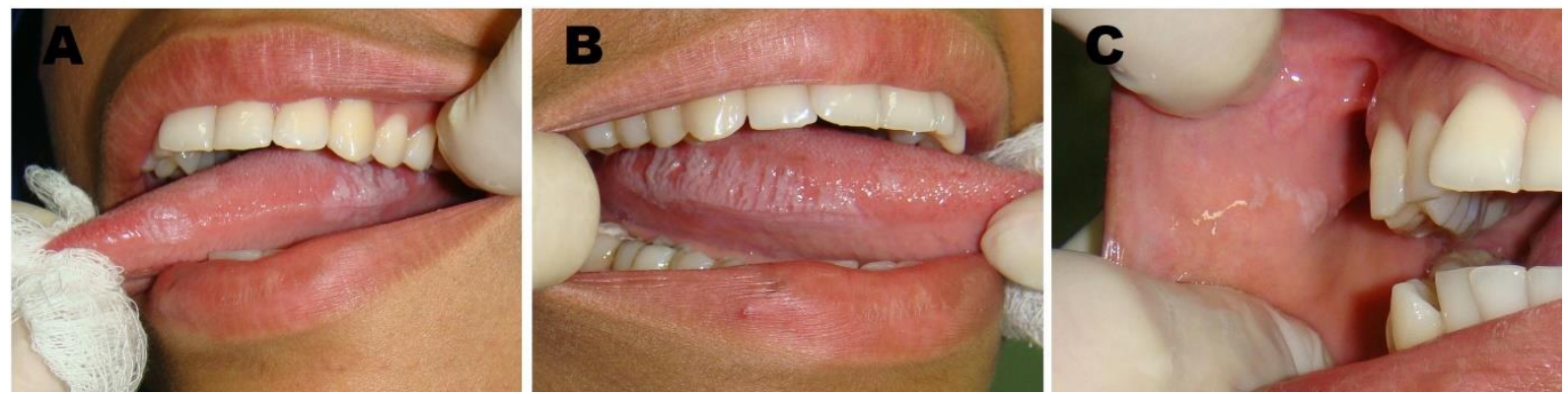

Fonte: Dra. Silvia Paula de Oliveira - Curso de Especialização

em Estomatologia - Odontoclínica Central do Exército - RJ

A, B - placa branca não removível, com estriações verticais, em borda de língua, bilateralmente, com suspeita de leucoplasia pilosa. C - placa branca removível em mucosa jugal, característica de candidíase pseudomembranosa. Além disso, a paciente apresentava aumento de volume inespecífico na região de glândula salivar parótida. Após o exame clínico foi solicitada a sorologia para HIV, o que estabeleceu o diagnóstico.

\subsection{CONDILOMA ACUMINADO}

Existem diversas doenças induzidas pelo papilomavírus humano (HPV) e que possuem manifestação oral, como o papiloma escamoso oral, a verruga vulgar, o condiloma acuminado e a hiperplasia epitelial multifocal (Doença de Heck). Dentre elas, apenas o condiloma acuminado é considerado uma IST induzida pelo HPV, que é a IST mais comum em todo o mundo, com $9 \%$ a $13 \%$ da população global infectada, sendo o condiloma acuminado caracterizado como uma lesão composta por proliferação epitelial, podendo estar localizada nas regiões genital, perianal, oral, laríngea e faríngea (SEM et al.,2018; CLANNER-ENGELSHOFEN et al., 2020; PENNYCOOK et al., 2020).

O DNA do vírus HPV pode permanecer em uma fase latente por vários meses, resultando em um período de incubação de 1 mês a 2 anos, em que o genoma viral, que 
contém oncogenes para codificação de proteínas e estímulo à proliferação celular, promovem a divisão celular das células hospedeiras que aumentam em quantidade, tornando as camadas basal, espinhosa e granulosa da epiderme ou mucosa mais espessas, propiciando a acantose e ao aparecimento macroscópico de proliferações verruciformes, assim o condiloma leva um período de 3 a 4 meses para se formar após a exposição ao vírus (PENNYCOOK et al., 2020).

A transmissão pode ocorrer por meio de relação sexual, sexo oral, autoinoculação -levando a mão à boca - e perinatal, da mãe para o bebê (CHATURVEDI et al., 2020; SEN et al., 2018). É comum em adolescentes e adultos jovens, mas todas as idades são suscetíveis e os fatores de risco conhecidos para a aquisição do HPV apresentam-se em indivíduos que aumentam o número de parceiros sexuais ao longo da vida, com histórico de infecção por clamídia e gonorreia, tabagistas e infectados pelo HIV (CHATURVEDI et al., 2020; PENNYCOOK, et al., 2020).

As lesões orais encontradas são pápulas verrucosas ou papilomatosas, róseas, podendo ser pediculados, e quando exofíticos, possuem aparência de couve-flor. Os locais mais frequentemente envolvidos são a mucosa labial, freio lingual, língua, mucosa bucal, assoalho da boca e palato mole, e pode ainda envolver os ductos excretores das glândulas salivares menores, sendo em sua maioria lesões assintomáticas, porém podem sangrar, tornar-se doloridos ou pruriginosos (figura 4) (COSTA E SILVA et al.,2017; JAISWAL et al., 2014; CHATURVEDI, et al. 2020). As lesões orais podem ocorrer isoladamente, na ausência de lesões anogenitais (CHATURVEDI et al., 2020).

O diagnóstico do condiloma acuminado pode ser estabelecido através de características clínicas, avaliação histopatológica e identificação do genótipo específico do HPV (SEM et al., 2018).

Já o tratamento consiste na excisão das lesões que pode ser realizada por bisturi simples, por criocirurgia, eletrodissecação ou ablação a laser (SEM et al., 2018). A aplicação de ácido 5-aminolevulínico (ALA) com a terapia fotodinâmica é um tratamento emergente para o condiloma acuminado e mostrou-se mais eficaz, simples e com menores taxas de recorrência do que o tratamento com laser de $\mathrm{CO}_{2}$ (PENNYCOOK et al., 2020).

As recorrências são comuns devido à persistência do vírus, especialmente em pessoas com estado imunológico debilitado, assim os pacientes submetidos ao 
tratamento cirúrgico têm taxas de recorrência menores, porém podem ocorrer recidiva em qualquer tipo de terapia (LACEY et al., 2012; SEM et al., 2018). Existem vacinas contra o HPV, sendo elas a bivalente, que protege contra os subtipos de HPV 16 e 18 , e a quadrivalente, que protege contra os vírus 6, 11, 16 e 18, sendo que no Brasil, em 2014, a vacina está no calendário de vacinação de meninas de 9 a 14 anos e meninos de 11 a 14 anos (SILVA et al.,2019, MOURA et al., 2020). Porém, em casos de imunossupressão, homens podem se vacinar até os 26 anos e mulheres até os 45 anos (MINISTÉRIO DA SAÚDE, 2021).

Um assunto importante relacionado ao condiloma acuminado é a sua presença em crianças pois o mesmo pode ser indício de abuso sexual, portanto existe a necessidade de uma avaliação médica e social para determinar se há qualquer evidência ou para estabelecer a origem do vírus, após a conclusão diagnóstica. O abuso sexual de crianças deve ser denunciado ao Conselho Tutelar, e dentistas e médicos são os primeiros profissionais a observar sinais de lesão não acidental ou intencional (PERCINOTO et al., 2014).

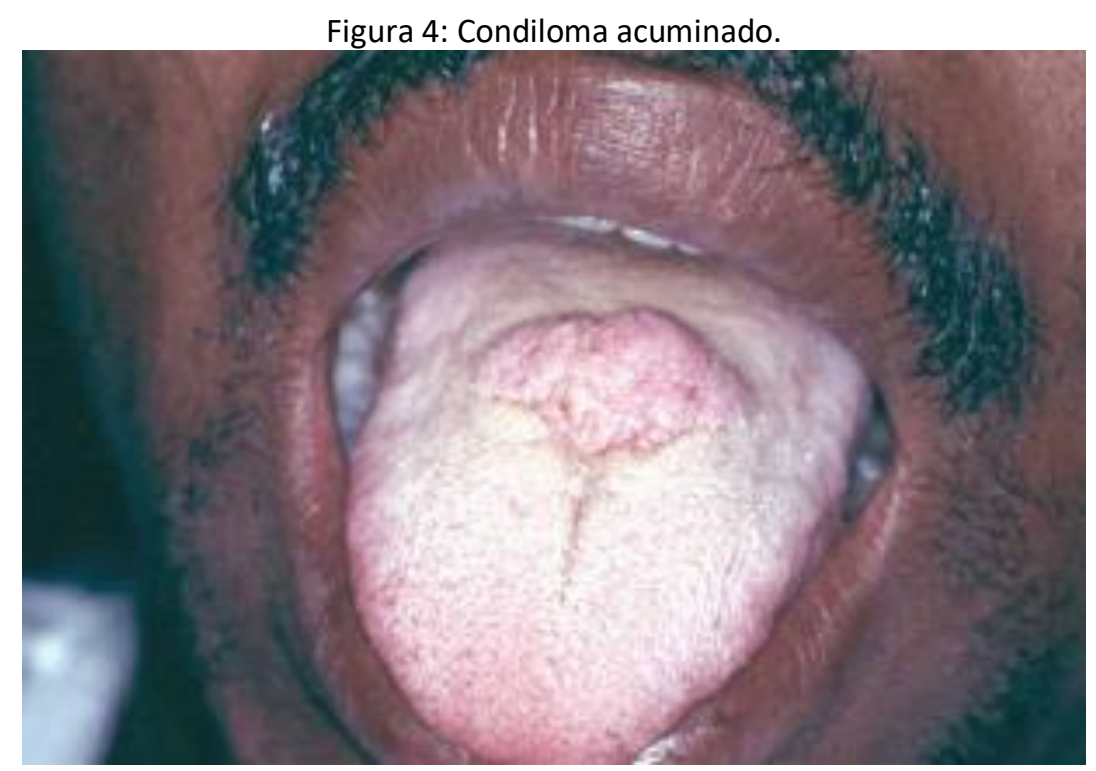

Fonte: Núcleo de Diagnóstico Bucal - NDB/UFES

Observa-se nódulo róseo de base séssil e superfície papilar, assintomático em dorso de língua.

\subsection{SÍFILIS}

A sífilis é uma IST exclusiva do ser humano, causada pela bactéria Treponema pallidum que possui tropismo por vários órgãos e tecidos do corpo causando manifestações clínicas complexas. Apresenta diferentes estágios: sífilis primária, 
secundária, latente, terciária e congênita (MINISTÉRIO DA SAÚDE, 2021; FICARRA et al., 2009). No Brasil em 2019, segundo o sistema de notificação compulsória da sífilis, foram notificados 152.915 casos de sífilis adquirida, 61.127 casos de sífilis em gestantes, 24.130 casos de sífilis congênita e 173 óbitos por sífilis congênita (MINISTÉRIO DA SAÚDE, 2020).

A transmissão da sífilis ocorre por contato sexual através da penetração do $T$. pallidum na mucosa ou feridas de pele e entra na corrente sanguínea, chegando a diversos órgãos, além da transmissão também ocorrer via parenteral (THAKRAR et al., 2018). Vale ressaltar que nos estágios, primário e secundário da infecção, a possibilidade de transmissão é maior (MINISTÉRIO DA SAÚDE, 2021).

A fase primária da sífilis é caracterizada pelo cancro, que ocorre no local de inoculação da bactéria T. pallidum (MARI et al., 2019). O cancro inicia-se como pápula, porém evolui até a formação de uma úlcera endurecida, assintomática, não purulenta, podendo ser única ou múltipla e normalmente regride sem tratamento. O tamanho pode variar de 0,3 a $3 \mathrm{~cm}$, possui as bordas definidas e o surgimento da lesão ocorre entre 10 e 90 dias após o contágio, normalmente no pênis, vulva, vagina, colo uterino, ânus, boca, ou outros locais da pele (MINISTÉRIO DA SAÚDE, 2021; FICARRA et al., 2009).

As lesões orais são visualizadas normalmente com frequência nos lábios, porém outras áreas como a língua, faringe e amígdalas podem ser acometidas (LEÃO et al., 2006).

Após 6 a 8 semanas da resolução das lesões primárias, ocorre a sífilis secundária, devido a disseminação hematogênica e linfática da bactéria causadora da sífilis pelo corpo, havendo a possibilidade de manifestações mucocutâneas e sistêmicas (MARI et al., 2019). Assim, é comum a presença de erupção macular não pruriginosa generalizada ou erupção papuloescamosa na pele, mas em relação ao envolvimento oral, as lesões podem ser múltiplas e sintomáticas como placas ligeiramente elevadas e ocasionalmente ulceradas, que geralmente são ovais e cobertas com uma pseudomembrana cinza ou branca, chamada de placas mucosas ou ainda múltiplas manchas mucosas que podem se unir para dar origem a lesões sinuosas (LIU et al.,2017; MARI et al., 2019). Ocasionalmente, lesões papilares vermelhas, elevadas e firmes com um centro cinza que podem se tornar ulceradas e assim formar lesões infecciosas 
úmidas e planas chamadas de condiloma lata (figura 5) (LEÃO et al., 2006; MATTEI, 2012).

Se a sífilis não for tratada, ocorre a sífilis terciária que é caracterizada por complicações em longo prazo com o envolvimento de órgãos sistêmicos como a pele, o sistema nervoso central, o fígado, o baço, os ossos e outros, com complicações que podem desencadear até mesmo a morte do indivíduo (FICARRA et al., 2009). As complicações orais da sífilis terciária centram-se na formação de goma sifilítica, que se manifesta inicialmente como lesão endurecida, nodular ou ulcerada, que pode causar destruição tecidual com perfuração do palato e formação de fístula oro-nasal (LEÃo et al., 2006).

No período de latência não aparecem sinais e sintomas da infeç̧ão, assim, o diagnóstico nessa fase pode ser feito apenas por meio de um teste sorológico. E a duração é variável, podendo ser interrompida pelo surgimento de sinais e sintomas da forma secundária ou terciária (FICARRA et al.,2009; MINISTÉRIO DA SAÚDE, 2021).

Por fim, na sífilis congênita a bactéria T. pallidum atravessa a placenta após a 16ạ semana de vida intrauterina e dependendo da gravidade, a infecção do feto pode resultar em aborto, natimorto, morte neonatal ou transmissão da doença, com isso pode afetar de forma variável as estruturas faciais (LEÃO et al., 2006; FICARRA et al., 2009). Assim as características iniciais incluem erupção cutânea maculopapular difusa, periostite e rinite. Já as características tardias se manifestam pelo menos 24 meses após o nascimento, através da tríade de Hutchinson, que compreende a ceratite intersticial da córnea, perda auditiva neurossensorial e anomalias dentárias (LEÃO et al.,2006), como os incisivos de Hutchinson e os molares em amora.

O diagnóstico pode ser realizado através de microscopia de campo escuro ou por teste de anticorpo fluorescente direto. Já quanto aos exames sorológicos que contribuem para a elucidação do diagnóstico há os não-treponêmicos como o Estudo Laboratorial de Doenças Venéreas (VDRL) e Teste de Reagina Plasmática Rápido (RPR) que indicam atividade da doença e os treponêmicos, dentre os mesmos, há o Anticorpo Treponêmico Fluorescente (FTA-ABS) e a Hemaglutinação de T. pallidum (TPHA) e o MHA-TP que é uma versão modificada do TPHA. A análise histopatológica é pouca utilizada, porém é um meio para o diagnóstico (FICARRA, et al., 2009), as colorações 
histoquímicas baseadas na prata, como a Warthin-Starry, facilitam a visualização do microorganismo na microscopia óptica.

A penicilina benzatina é considerada a droga de escolha para o tratamento da sífilis em todos os estágios da infecção, sendo a dose recomendada no adulto de 2,4 UI em uma única injeção intramuscular. Porém é necessário repetir este tratamento uma ou duas vezes por semana se a doença estiver numa fase complicada (BINDAKHIL et al., 2021).

Após tratamento os pacientes podem obter a cura sorológica obtida com redução nos exames de anticorpos treponêmicos por um fator> 4 é observada dentro de 6-12 meses ou 12-24 meses respectivamente após a terapia para sífilis precoce e sífilis tardia (BINDAKHIL et al., 2021).

Figura 5: Paciente com lesões em toda a mucosa oral, indicativas de sífilis secundária. Foi solicitada a sorologia, que confirmou o diagnóstico
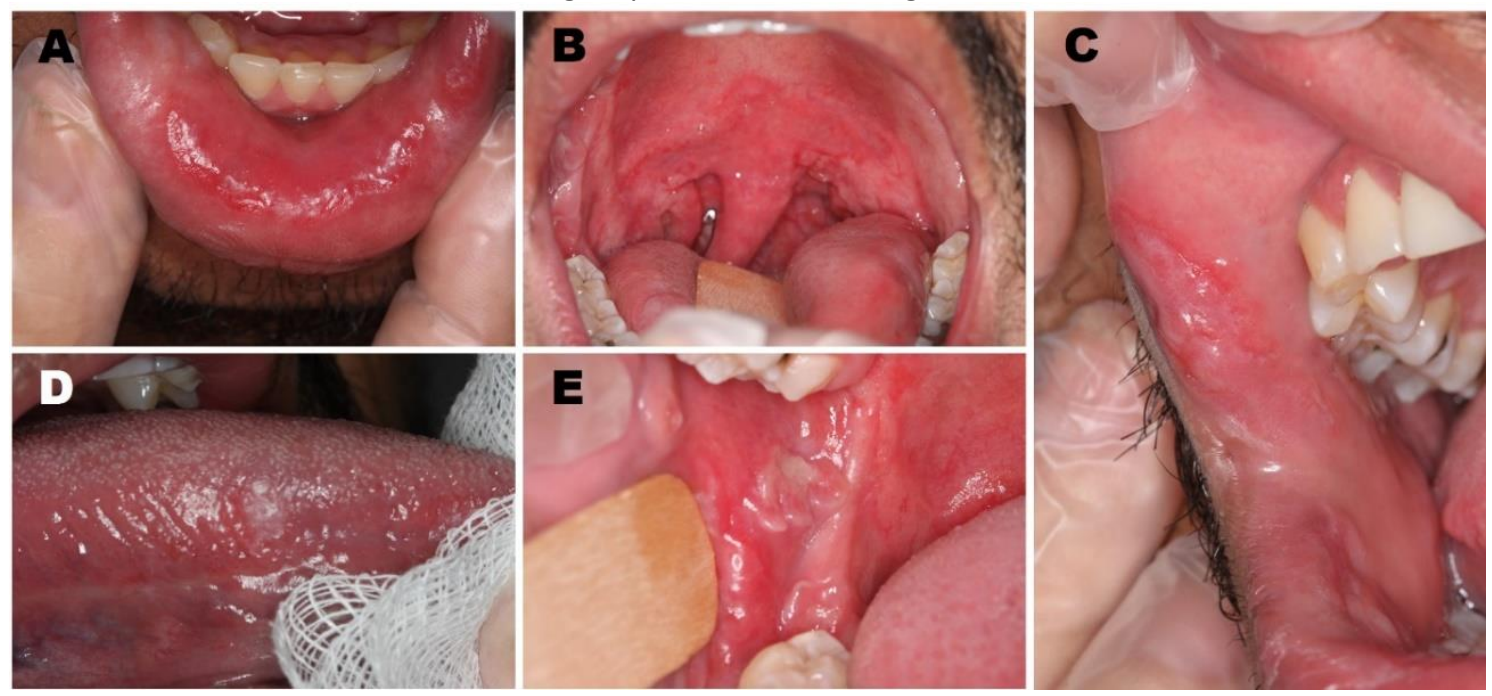

Fonte: Núcleo de Diagnóstico Bucal - NDB/UFES

A, B, C - Lesões máculo papulares em mucosa labial, orofaringe e mucosa retrocomissural. D - Placa mucosa esbranquiçada em borda de língua. E - Lesão exofítica em mucosa jugal.

\section{CONSIDERACÕES FINAIS}

O atendimento odontológico cotidiano envolve muitas variáveis e é comum observar manifestações orais de doenças sistêmicas, o que engloba também as infecções sexualmente transmissíveis. Assim, doenças como gonorreia, herpes, HIV/Aids, condiloma acuminado e sífilis desencadeiam lesões orais específicas, com características próprias e o cirurgião dentista deve estar apto para detectar, levantar hipóteses e diagnosticar tais doenças, pois quanto antes alertar o paciente da forma de 
transmissão e tratamento, melhor a qualidade de vida e menores são as chances de transmissão a outras pessoas.

O cirurgião dentista a partir do momento que suspeita de uma doença sistêmica com manifestação oral pode intervir no processo diagnóstico, seja por meio de biópsia de lesão oral, solicitação de exames sorológicos, atuando em conjunto com os médicos para chegar ao diagnóstico final e conduzir o paciente da melhor forma.

Concluindo, pode-se perceber a importância da contribuição do dentista na saúde geral de um indivíduo e que as ISTs, apesar de existirem há muito tempo, continuam sendo uma realidade no século XXI e assim políticas públicas de saúde são fundamentais para diminuir a disseminação das mesmas.

\section{REFERÊNCIAS}

AN, M. Y. O; CÂMARA, J; SILVA, M. R. A; OLIVEIRA, L.C; BENZAKEN, A. S. DST j. bras. doenças sex. transm. Amazonas, vol. 20, n. 3.4, pág. 161-166, 2008.

BINDAKHIL, M., ALAWI, F., FRANCE K. TANAKA, T. I. PrimarySyphilisofthe Oral Cavity, a RarePresentationof a Re-EmergingDisease. Cureus, vol.13, n.4, abril/2021.

BRASIL. Portaria no 264, de 17 de fevereiro de 2020. DiárioOficial da União, Brasília, 19 fev. 2020. Seção 1, p. 97.

CHATURVEDI, H. T., CHATUREVEDI, C. Oral condylomaacuminatumwithchanges in excretoryductofminorsalivarygland: Anunusual case reportandreviewofliterature. Online onlyarticles - case report, vol. 24. n. 3, pág. 588-589, maio/2020.

CLANNER-ENGELSHOFEN, B. M., MARSELA E., ENGELSBERGER N., GUERTLER A., SCHAUBER J., FRENCH L. E., REINHOLZ M. Condylomataacuminata: A retrospectiveanalysisonclinicalcharacteristicsandtreatmentoptions. Heliyon, vol.6, n. 3, março/2020.

DA ROS, C. T; SCHMITT, C. D. A. S. Global epidemiologyofsexuallytransmitteddiseases. Asian J Androl. Porto Alegre, vol. 10, n. 1, pág. 110-4, julho/2008.

FICARRA, G., CARLOS, R. Syphilis: The RenaissanceofanOldDiseasewith Oral Implications. Head andNeckPathology, vol.3, pág. 195-206, julho/2009.

FILHO, O. J. L. D.; VIANA, E. C.; PESSOA, W. G.; DOMINGOS, P. R. C. Manifestações orais em pacientes imunodeprimidos pelo Vírus da Imunodeficiência Humana (HIV): revisão da literatura. Revista Eletrônica Acervo Saúde, v. 13, n. 2, p. e6034, fevereiro/2021. 
GELleR, M., NETO, M. S., RIBEIRO, M. G, OliVEIRA, L., NALIATO, E.C.O., ABREU, C., SCHECHTMAN, R.C. Herpes Simples: Atualização Clínica, Epidemiológica e Terapêutic. Dst - J Bras Doenças Sex Transm, vol. 24, n. 4, pág. 260-266, 2012.

GHEORGHE, C., MIHAI, L., PARLATESCU, I., TOVARU, S. Associationof Oral LichenPlanuswithChronic C Hepatitis. Reviewofthe Data in Literature. MAEDICA - a JournalofClinical Medicine, vol. 9, n.1, pág. 98-103, março/2014.

JAISWAL, R., PANDEY, M. SHUKLA, M. KUMAR, M. CondylomaAcuminatum da Mucosa Bucal. Ear, e \&ThroatJournal, vol. 93, n. 6, pág. 219-223, 2014.

JUNIOR, W. B; SHIRATSU, R; PINTO, V. Abordagem nas doenças sexualmente transmissíveis. Anais Brasileiros de Dermatologia. São Paulo, vol. 84, n. 2, pág. 151-159, 2009.

LACEY C.J.N., WOODHALL S.C., WIKSTROM A., ROSS J. Europeanguideline for the management ofanogenitalwarts. JournaloftheEuropeanAcademyofDermatologyandVenereology. Vol. 27, n. 3, pág. 263-270, março/2012.

LEÃO, J. C., GUEIROS L. A., PORTER S. R. Oral manifestationsofsyphilis. Clinics, vol 61, n. 2, abril/2006.

LITTLE, J, W. Gonorrhea: update. Oral Surg Oral Med Oral Pathol Oral RadiolEndod.Naples, vol. 101, n. 2, pág. 137-43, fevereiro/2006.

MARI E., NUDO M, PALESE E., COTTICELLI L., COTTICELLI C., ZINO G., COPPOLA R., LELLA F. M. D., ARCARI G., RODIO D. M., PIETROPAOLO C. P., DEVIRGILIIS V., PANASITI V. Além da aparência: uma manifestação incomum de sífilis oral secundária isolada. InternationalJournalofImmunopathologyandPharmacology, janeiro/2019.

MATTEI P. L., BEACHKOFSKY, T. M., GILSON, R. T., WISCO, O. J. Syphilis: A Reemerging Infection - American Family Physician, vol. 86, n. 5, pág. 433-440, setembro de 2012.

MENEZES, T. O. A., RODRIGUES, M.C., NOGUEIRA, B.M.L., MENEZES, S.A.F., SILVA, S. H. M., VALLINOTO, A.C.R. Oral andsystemicmanifestations in HIV-1 patients. Revista da Sociedade Brasileira de Medicina Tropical, v. 48, n. 1, pág. 83-86, fevereiro/2015.

Ministério da Saúde. Boletim Epidemiológico. Sífilis. Secretaria de Vigilância em Saúde, n. Especial, outubro/2020.

Ministério da Saúde. Departamento de Doenças de Condições Crônicas e Infecções Sexualmente Transmissíveis. Infecções Sexualmente Transmissíveis. Disponível em: <http://www.aids.gov.br/pt-br/publico-geral/o-que-sao-ist>. Acesso em: 30 de junho de 2021. 
Ministério da Saúde. Notícias. Saúde. Disponível em: <https://www.gov.br/saude/ptbr/assuntos/noticias/saude-amplia-vacinacao-contra-hpv-para-mulheresimunossuprimidas-com-ate-45-anos>. Acesso em 23 de agosto de 2021.

MOTTA, W. K. S., NÓBREGA, D.R. M., SANTOS, M.G.C., GOMES, D.Q.C., GODOY, G.P. PEREIRA, J.V. Aspectos demográficos e manifestações clínicas bucais de pacientes soropositivos para o HIV/Aids. Revista de Odontologia da Unesp, vol. 43, n. 1, pág. 61-67, janeiro/ 2014.

MOURA, L.L., CODEÇO, C.T.L., MENDES, P. Cobertura da vacina papilomavírus humano (HPV) no Brasil: heterogeneidade espacial e entre coortes etárias. Revista Brasileira de Epidemiologia [online], vol. 24, dezembro, 2020.

PAKFETRAT, Atessa et al. Oral Manifestations of Human Immunodeficiency VirusInfected Patients. IranianJournalOfOtorhinolaryngology, Mashhad, v. 27, n. 1, pág. 43-54, janeiro/2015.

PENNYCOOK, K. B., MCCREADY, T. A.CondylomaAcuminatum. StatPearls - NCBI Bookshelf, agosto/2020.

PERCINOTO, A. C., DANElON, M., CRIVELINI, M. M., CUNHA, R. F., PERCINOTO, C. Condylomaacuminata in thetongueandpalateof a sexuallyabusedchild: a case report. BMC research notes, vol. 7, n. 467, junho/2014.

PETRY, S.; PADILHA, M.I.; KUHNEN, A.E.; MEIRELLES, B.H.S. Saberes de estudantes de enfermagem sobre a prevenção de Infecções Sexualmente Transmissíveis. RevBrasEnferm. Santa Catarina, vol.72, n. 5, pág. 1208-16, 2019.

PINTO, V. M.; BASSO, C. R., BARROS, C. R. S., GUTIERREZ, E. B. Fatores associados às infecções sexualmente transmissíveis: inquérito populacional no município de São Paulo, Brasil. Ciência \& Saúde Coletiva, vol. 23, n. 7, 2018.

SALINAS, M., Yuni, J., MILLAN, I., RONALD, E. Gingivoestomatitis herpética primaria: Conducta odontológica. Acta odontol. venez, Caracas , v. 46, n. 2, p. 219226, junho/ 2008.

SEN, R., SHAH, N., SHEIKH, M. A., CHATTERJEE, R. P. Oral condylomaacuminatum in a 75year-old geriatricpatient. BMJ Case Reports, 2018.

SHAW, G. M.; HUNTER, E. HIV Transmission. Cold Spring Harbor Perspectives In Medicine, vol. 2, n. 11, pág. 006965-006965, outubro/2012.

SILVA, L., OLIVEIRA, M., GALATO, D.Humanpapillomavirusvaccinereceptivity: a systematicreview. Pan American journalofpublichealth, vol. 43, n. 22, fevereiro/2019.

THAKRAR, P., ACLIMANDOS, W., GOLDMEIER, D., SETTERFIELD, J. F. Úlceras orais como apresentação de sífilis secundária. Dermatologia clínica e experimental, vol. 43, n. 8, pág. 868-875, julho/2018. 
VARELlA, R. B., PIRES, I. L., SARAIVA, C. A., GUIMARÃES, A. C. C., GUIMARÃES M. A. A. M.Diagnóstico laboratorial da infecção pelo vírus herpes simples (HSV) em pacientes transplantados e não transplantados. J Bras Patol Med Lab, vol. 41, n. 4, pág. 257-262, agosto/2005.

World Health Organization. Sexuallytransmittedinfections (STIS). Disponível em: $<$ https://www.who.int/news-room/fact-sheets/detail/sexually-transmittedinfections-(stis)>. Acesso em: 23 de agosto de 2021. 


\title{
CAPITULO $x \times$ \\ LASERTERAPIA NA PREVENÇÃO E TRATAMENTO DA
MUCOSITE EM PACIENTES ONCOLÓGICOS
}

DOI: 10.51859/AMPLLA.EPC757.1121-20

\author{
Cândida Calenzani Petri ${ }^{1}$ \\ Caroline Travesani Marchezi ${ }^{2}$ \\ Jéssica Vergna Neves ${ }^{3}$ \\ Lorrana Rodrigues Guimarães 4 \\ Pamela Barbosa dos Santos ${ }^{5}$ \\ Tainã Figueiredo Santos 6 \\ Maria Helena Monteiro de Barros Miotto ${ }^{7}$
}

\begin{abstract}
1, 2, 3, 4, 5, 6 Graduando do curso de Odontologia. Universidade Federal do Espírito Santo - UFES
7 Professora Titular do curso de Odontologia da Universidade Federal do Espírito Santo - UFES, mestre e doutora em saúde coletiva - UFPE. Professora e orientadora dos cursos de Pós-graduação da UFES.
\end{abstract}

\section{RESUMO}

INTRODUÇÃO: Pacientes em terapia antineoplásica podem desenvolver complicações orais, devido terapia destruir também células normais, sendo mais susceptíveis tecidos com renovação rápida, como o epitélio oral. Associada a quimioterapia sistêmica, radioterapia, ou combinação de ambas, e transplante de células-tronco hematopoiéticas, a mucosite oral (MO), pode levar a dor, desconforto, dificuldade de alimentação, maior tempo de internação, custos, limitações e interrupções no tratamento e piora no prognóstico. REVISÃO BIBLIOGRÁFICA: Descreve-se MO como lesões inflamatórias, caracterizadas por eritema e ulceração do revestimento da mucosa oral. Há diversos tipos de laser de baixa intensidade no mercado, que podem ser utilizados das duas seguintes formas: Pontual e Varredura. No método pontual a área irá coincidir com a ponteira do aparelho e no método de varredura a área a ser utilizada corresponde a área da lesão. Para prevenção e tratamento, a laserterapia é realizada através do laser vermelho com 10 a $71 \mathrm{~J} / \mathrm{cm} 2(0,24-2 \mathrm{~J})$ por ponto. Inicia-se no primeiro dia de quimioterapia e mantem-se por 15 dias. Em radioterapia, inicia-se no primeiro dia e mantem-se até 15 dias após última sessão. Nas lesões que surgirem, faz-se associação do laser vermelho e infravermelho - 71 a $142 \mathrm{~J} / \mathrm{cm} 2(2,0-4,0 \mathrm{~J})$ por ponto e aplicações podem ser diárias até completa cicatrização. Lesões de $\mathrm{MO}$ são frequentemente associadas a infecções secundárias, sendo a terapia fotodinâmica um tratamento de escolha. CONSIDERAÇÕES FINAIS: O emprego do laser de baixa potência utilizado no tratamento preventivo e terapêutico da mucosite tem sido eficiente, apresentando efeitos de analgesia desde a primeira aplicação.

Palavras chave: Laserterapia. Mucosite. Tratamento. Odontologia hospitalar. 


\section{INTRODUÇÃO}

Os pacientes em terapia antineoplásica podem desenvolver uma variedade de complicações orais, dependentes do tipo e potência do tratamento. Isso ocorre devido a terapia destruir, além de células neoplásicas, algumas células normais, sendo mais susceptíveis os tecidos com renovação rápida, como o epitélio oral (NEVILLE, 2016).

Uma complicação aguda predominantemente associada a quimioterapia sistêmica é a mucosite, assim como a hemorragia. A radioterapia também pode ocasionar efeitos secundários nos pacientes, como a mucosite dolorosa aguda e a dermatite. Além de algumas consequências crônicas, como: Xerostomia, Hipogeusia (perda do paladar), Osteorradionecrose, Trismo, Dermatite crônica e Anormalidades do desenvolvimento (NEVILLE, 2016).

Tais complicações orais em pacientes oncológicos como a mucosite, podem levar a dor, desconforto, dificuldade de alimentação e consequente deficiência nutricional, aumento no tempo de internação hospitalar, maiores custos, limitações e interrupções no tratamento e piora no prognóstico. Dessa forma, a inclusão do cirurgião dentista na equipe se mostra essencial para a promoção da saúde e bem-estar do paciente oncológico (ELAD et al., 2020).

Em 25 de Setembro de 2008, a Resolução no 82, do Conselho Federal de Odontologia (CFO), reconheceu o exercício pelo cirurgião dentista das seguintes práticas integrativas e complementares à saúde bucal: Acupuntura, Fitoterapia, Terapia Floral, Hipnose, Homeopatia e Laserterapia. (CFO, 2008) Acredita-se no uso do laser como um método menos invasivo na odontologia moderna, e uma excelente opção para o tratamento da mucosite, devido a seus efeitos benéficos para os tecidos, incluindo efeitos antiinflamatórios e analgésicos, ativação da microcirculação, produção de novos capilares, estímulo ao crescimento e à cicatrização (MOREIRA et al., 2020). 


\section{REVISÃO BIBLIOGRÁFICA}

\subsection{MUCOSITE}

\subsubsection{DEFINIÇÃO}

A Mucosite Oral (MO) é descrita como o surgimento de lesões inflamatórias, caracterizadas por eritema e ulceração do revestimento da mucosa oral, embora, possa acometer todo o trato gastrointestinal. Se trata de uma complicação comum da quimioterapia, radioterapia, ou combinação de ambas, e do transplante de célulastronco hematopoiéticas. Em pacientes imunocomprometidos, as ulcerações são susceptíveis a infecções secundárias, podendo resultar em infecções sistêmicas e risco de vida (ELAD et al., 2020; BLAKAJet al., 2019).

\subsubsection{FISIOPATOLOGIA}

As células da mucosa oral possuem alto poder mitótico e como resultado dos tratamentos antineoplásicos são afetadas pelos agentes citotóxicos. Geram radicais livres que agem de forma direta por danos às células, tecidos e vasos, ou de maneira indireta com a ativação de fatores de transcrição, causando as interações bioquímicas que levam aos danos relacionados a mucosite. Assim, a fisiopatologia da mucosite é dividida em algumas fases, inflamatória, epitelial, ulcerativa e curativa, que retratam essas interações e suas consequências (CAILLOT, 2012; SCHIRMER, 2012).

A fase inflamatória acontece quando o tecido epitelial libera o fator de necrose tumoral (TNF-alfa), a interleucina-1 (IL-1) e a interleucina-6 (IL-6), levando inicialmente ao aparecimento de edema intra e extracelular e esbranquiçamento da área afetada. $\mathrm{Na}$ fase epitelial, essas citocinas desempenham determinado aumento da vascularização local, e complexo dano tecidual devido a apoptose das células, gerando áreas eritematosas na mucosa levando a ulceração, decorrente desse processo de aceleração e aumento do desenvolvimento biológico tecidual. Já a fase ulcerativa ocorre quando existe a colonização por microrganismos, onde o tecido ulcerado e os macrófagos ativados resultam na maior secreção das citocinas TNF, IL1b e IL6, que levam a inflamação e sintomatologia dolorosa, e deixam a superfície com aspecto de camadas destacadas, eritematosa e com uma pseudomembrana serofibrinosa. Se essas características não são regeneradas ocorrerá perda do revestimento mucoso, levando a 
sintomatologia dolorosa, possível febre e necessidade de interrupção no tratamento. Essa intensificação das lesões estabelece a fase ulcerativa (CAILLOT, 2012; SCHIRMER, 2012; VAN SEBILLE, 2015).

Pacientes imunocomprometidos ou que realizam tratamento com quimioterapia de forma simultânea, podem estar mais predispostos a infecções e sepse. A quantidade de saliva e sua composição podem dificultar a cicatrização tecidual e aumentar a citotoxicidade (CAILLOT, 2012; SCHIRMER, 2012).

Por último se tem a fase curativa, onde a matriz extracelular prolifera, ocorre a diferenciação epitelial e também a restauração da flora microbiana do local. A mucosa aparecerá normal, mas continua consideravelmente modificada, havendo também a neovascularização residual, e a renovação celular e consecutiva cicatrização da mucosite.Porém, a mucosa fica mais exposta a ataques citotóxicos, apresentando assim um risco elevado para um quadro de mucosite grave no futuro (CAILLOT, 2012; SCHIRMER, 2012).

\subsubsection{SINAIS E SINTOMAS DA MUCOSITE}

A qualidade de vida dos pacientes acometidos com mucosite oral induzida por tratamento de radioterapia ou quimioterapia é extremamente afetada devido aos sinais e sintomas dessa patologia, sendo eles: dificuldade na alimentação e disfagia, prejuízo da fala, desconforto gengival, alteração do paladar, dificuldade de higienizar a cavidade bucal, eritema, ulceração da mucosa que pode causar desidratação e má nutrição, sangramento, xerostomia, hipossalivação, além de dor intensa, e risco elevado de invasão microbiana levando a infecções oportunistas (locais ou sistêmicas) (BLAKAJ, 2019; CAILLOT, 2012; DE SANCTIS,2016; RAPOSO, 2014; SCHIRMER, 2012; VAN SEBILLE, 2015).

Devido a destruição do epitélio oral e a inibição da sua renovação, ocorre uma atrofia epitelial e isso irá contribuir para que ocorra uma adesão e invasão de CandidaAlbicans. Com o aumento da severidade da mucosite oral, pode-se instalar um quadro de febre, infecção e necessidade de nutrição parenteral total. Com o elevado risco de extensão sistêmica da infecção, pode-se chegar a um quadro de sepse, e evoluir para sepse grave ou até choque séptico e assim desencadear a morte. Esses sintomas podem influenciar na eficácia do tratamento, causando reduções de dose na 
quimioterapia e interrupção da radioterapia (BLAKAJ, 2019; CAILLOT, 2012; RAPOSO, 2014; VAN SEBILLE, 2015).

\subsubsection{GRAUS DE MUCOSITE}

A gravidade da mucosite é avaliada por critérios padronizados de classificações validadas. Para realizar a classificação do grau de gravidade da mucosite oral existem algumas escalas de avaliação que podem ser utilizadas. As que parecem ser mais utilizadas pelos profissionais serão descritas a seguir(CAILLOT, 2012; DE SANCTIS,2016).

A mucosite oral é frequentemente avaliada pela graduação da Escala de Toxicidade Oral desenvolvida pela Organização Mundial de Saúde (OMS), frequentemente usada na prática clínica, com intuito de avaliar a condição funcional, dependendo de variáveis objetivas e subjetivas das observações clínicas, como critérios de existência de eritema e ulceração, dor local e capacidade de deglutição. É uma escala de grau 0 a 4, sendo a gradação 0 significado de ausência de alterações; a gradação 1 demonstra a presença de eritema, mas sem necessidade de tratamento e o paciente ainda é capaz de engolir alimentos sólidos; grau 2 possui quadro doloroso com feridas evidentes na mucosa oral, mas sem necessidade de analgésicos e paciente ainda é capaz de ingerir alimentos sólidos; grau 3, paciente com extrema sensibilidade ao engolir alimentos sólidos, e necessidade do uso de analgésicos; grau 4 apresenta a incapacidade de engolir, necessidade de nutrição parenteral total ou alimentação por sonda (BLAKAJ, 2019; FIGUEIREDO, 2013; MOSLEMI, 2016).

Outra escala muito utilizada na avaliação da mucosite oral é a National Cancer Institute $(\mathrm{NCl})$. É uma escala fundamentada na dor e sua intensidade, e nas alterações funcionais como a capacidade de alimentação.Contribuiu para os ensaios clínicos na documentação dos efeitos causados pelas terapias antineoplásicas, e estabelece a gradação iniciando pelo grau 0, representando a ausência da mucosite oral; o grau 1 mostra a presença de úlceras indolores, eritema ou sintomatologia dolorosa leve na ausência de úlceras; grau 2 com eritema doloroso, existência de edema ou úlceras, e ainda é possível a alimentação; grau 3 com eritema doloroso, edema, ou úlceras e sem a capacidade de deglutir alimentos sólidos, com a necessidade de nutrição parenteral; grau 4 com a presença de ulceração grave e a necessidade de nutrição parenteral ou 
intubação profilática; e grau 5 para avaliar os casos que chegam a morte devido à toxicidade (BLAKAJ, 2019; FIGUEIREDO, 2013).

Apesar das variadas escalas para classificação da mucosite oral, não é possível definir uma superioridade entre elas (DE SANCTIS,2016).

\subsubsection{PREVENCÃO}

A laserterapia é utilizada na prevenção da mucosite através do laser vermelho com 10 a 71J/cm2 (0,24 - 2J) por ponto com 78 pontos de aplicação (4 pontos no lábio superior e 4 no lábio inferior, 1 ponto em cada comissura labial, 4 pontos na mucosa labial superior e 4 na inferior, 12 pontos na mucosajugal direita e 12 na esquerda, 4 pontos no palato mole, 12 pontos no dorso da língua, 6 pontos em cada borda lateral da língua, 2 pontos em cada coluna do ventre lingual e 4 pontos no assoalho da língua) em 2 a 3 aplicações por semana. A aplicação do laser deve iniciar no primeiro dia de quimioterapia e mantém por 15 dias, mas em caso de radioterapia, faz início no primeiro dia de radioterapia e mantém até 15 dias após a última sessão (MOREIRA, 2020).

Mas além do laser, existem uma grande variedade de agentes utilizados para prevenção de mucosite oral, dentre eles há a crioterapia, o uso do fator de estimulação de colônia macrófago - granulócito (GM - CSF), glutamina, o Palifermin, medicações antiinflamatórias como a benzidamina no enxágue oral, a clorexidina, a geléia real com cloridrato de benzidamina e lavagens com nistatina, zinco, cuidados nutricionais e de higiene oral, além de consultas odontológicas previamente ao tratamento oncológico para precaução de possíveis danos decorrentes do tratamento (NAMETALA et al., 2020).

\subsubsection{TRATAMENTO}

O tratamento da mucosite consiste em aliviar os sintomas, acelerar o reparo tecidual e controlar eventuais infecções de origem bucal. Assim, muitas substâncias têm sido usadas para diminuir a severidade da mucosite, como analgésicos, vitaminas $A, D$, Zn, enxaguatórios bucais, anestésicos locais, laserterapia, dentre outras, mas sem eficácia absoluta (OLIVEIRA et al., 2018).

Porém o uso do laser atua como antiinflamatório, analgésico e cicatrizante nas lesões possui grande efetividade na redução da severidade da mucosite, promovendo efeitos biológicos e elevando o metabolismo celular com estimulação da atividade mitocondrial (NAMETALA et al., 2020). 
Para utilização do laser no tratamento da mucosite, faz-se sua utilização como se faz na prevenção e que foi citado anteriormente. Porém, nas lesões que surgirem, pode fazer associação do laser vermelho e infravermelho - 71 a 142J/cm2 (2,0 - 4,0J) por ponto e as aplicações podem ser diárias até completa cicatrização da lesão (MOREIRA, 2020).

\subsection{LASERTERAPIA}

\subsubsection{HISTÓRICO}

Um dos grandes avanços na área odontológica foi o desenvolvimento do laser, devido a suas diversas aplicações na área. E o seu desenvolvimento advém de diversos conhecimentos desenvolvidos ao longo dos anos, com a colaboração de diversas pessoas.

Assim, em 1917, baseado nos conceitos de Planck (1890), Albert Einstein formulou a Teoria da Emissão Estimulada de Radiação que analisa os processos nos quais os estados de energia e momento de um gás de átomos atingem o equilíbrio com um campo de radiação térmica (PROCKT et al., 2018; KLEPPNER, 2005).

Townes, em 1954 criou o primeiromasere em 1958, Townes e Schawlow descreveram os princípios do maser para a região visível do espectro eletromagnético, mas foi e Gould no mesmo ano que fez a primeira aplicação com êxito da emissão estimulada de microondas (PINHEIRO et al., 2010; PROCKT et al., 2018).

Já em 1960, Maiman desenvolveu a cristal de rubi que resultou na geração do primeiro raio laser com emissão do espectro vermelho, e em 1961, Javan e colaboradores desenvolveram o laser HeNe (PINHEIRO et al., 2010).

Na Odontologia o primeiro estudo que utilizaram o laser de rubi foi em 1964, onde foi aplicado em tecidos dentais "in vitro", e foi observado que este tipo de laser formava cratera e fusão de esmalte e dentina com alterações de temperatura nos tecidos irradiados. Já "in vivo" foi realizado um estudo em 1965, onde foi aplicado o laser e o paciente não sentiu dor durante o ato operatório e nem depois (PECORA et al., 1999).

Com isso, estudos continuaram a ser realizados, novos tipos de lasers foram sendo inventados e chegamos ao que temos hoje no mercado com suas infinitas aplicabilidades. 


\subsubsection{CARACTERISTICAS DOS LASERS}

\subsubsection{PROPRIEDADES DA LUZ LASER}

Coerência: Fótons de mesmo comprimento de onda, se propagando na mesma direção e vibrando na mesma frequência (MOREIRA et al., 2020).

Direcionalidade ou colimação: Os fótons se propagam em uma única direção, sem divergência significativa (MOREIRA et al., 2020).

Monocromaticidade: A luz a laser é composta de fótons de mesmo comprimento de onda, ou seja, uma única cor (MOREIRA et al., 2020).

\subsubsection{ELEMENTOS CONSTITUINTES DO LASER}

- Meio Ativo:

Sólido: diodo, Er:YAG, Er,Cr:YSGG, Nd:YAG.

Líquido: corantes orgânicos (em desuso).

Gasoso: CO2, He-Ne, Argônio, Criptônio.

- Mecanismo de excitação ou bombeamento: fonte de energia (ex: lâmpada flash).

- Sistema óptico de ressonância: conjunto de espelhos, sendo um totalmente refletor e outro parcialmente refletor (MOREIRA et al., 2020).

\subsubsection{FUNCIONAMENTO DOS LASERS}

O laser é um equipamento que tem funcionamento baseado na absorção de energia, para que a maior parte dos átomos se excitem(elétrons "saltem" para camadas mais distantes do núcleo atômico). Após a absorção de energia, deve haver liberação de luz coerente (CAVALCANTI et al., 2011).

O funcionamento dos três elementos essenciais do equipamento laser: meio ativo,mecanismo de excitação ou bombardeamento e sistema óptico de ressonância, que gera uma emissão de luz que, ao incidirem sobre outras moléculas do meio formam uma reação em cadeia, com a excitação de várias outras moléculas (CAVALCANTI et al., 2011).

Cada tipo de laser produz um comprimento de onda específico, e cada comprimento de onda age de forma específica em cada tecido, sendo essa interação por meios dos processos ópticos de reflexão, transmissão, espalhamento e absorção. Sendo 
que ao incidir no tecido, parte da luz é refletida enão penetra no tecido biológico. Da porção de luz penetrada,parte será absorvida, parte espalhada e a outra parte transmitida. A luz que é transmitida, refletida ou dispersada não tem nenhum efeito, e para que haja efeito no tecido a luz deve ser absorvida (CAVALCANTI et al., 2011).

A absorção da luz do laser depende da quantidade de cromóforo (elemento capaz de absorver os fótons do feixe de laser) presente no tecido e da correspondência entre o comprimento de onda utilizado e as características de absorção daquele cromóforo. A luz absorvida pode causar três efeitos: o fototérmico, o fotoquímico e o fotomecânico (CAVALCANTI et al., 2011).

\subsubsection{TIPOS DE LASERS}

\subsubsection{ALTA INTENSIDADE}

Os lasers de alta intensidade, também chamados de lasers cirúrgicos causam danos aos tecidos através da transformação de energia luminosa em energia térmica (MOREIRA et al., 2020)

- Ação dos lasers de alta intensidade: Lasercirurgia, coagulação, descontaminação (redução microbiana), meltingdentinário e ácido resistência em esmalte.

- Efeitos fototérmicos: Desidratação, coagulação, vaporização, carbonização, descontaminação.

- Efeitos fotoquímicos: Polimerização de resinas compostas.

- Efeitos fotomecânicos: Ablação, disrupção.

- Tipos de laser de alta intensidade: Neodímio (Nd:YAG): 1064 nm; dióxido de Carbono (CO2): 10600 nm; dióxido de Carbono (TEA CO2): 9600 nm; diodo (Ga-Al-As): 808- 920 nm; Argônio (Ar): 514,5 nm e 488 nm, Érbio (Er:YAG): 2940 nm; Érbio, Cromo (Er,Cr:YSGG): $2780 \mathrm{~nm}$ (MOREIRA et al., 2020).

\subsubsection{BAIXA INTENSIDADE}

Terapia de fotobiomodulação (Laserterapia): uso terapêutico da luz absorvida acarretando reações não térmicas, não citotóxica, biológicas por meio de eventos fotoquímicos ou fotofísicos, levando a mudanças fisiológicas (MOREIRA et al., 2020). 
- Tipos de laser de baixa intensidade:

Diodo: Infra-vermelho (720-980nm), Vermelho (Visível) (620-690nm), Diodo: GaAl-As, Ga-As, Ga-In-As).

Hélio-Neônio: Visível (Vermelho) (632,8nm).

- Comprimentos de onda:

Vermelho (620-690nm): ação mais superficial e reparadora.

Infravermelho (720-980nm): ação mais profunda (maior penetração), modulação da inflação (dor, edema) (MOREIRA et al., 2020).

\subsubsection{MÉTODOS TERAPÊUTICOS}

Há diversos tipos de laser de baixa intensidade no mercado, que podem ser utilizados das duas seguintes formas:

Pontual: Ao se realizar a aplicação pontual deve-se lembrar de fazer pontos previamente na área que se deseja tratar, além de utilizar papel filme para proteger a ponteira e evitar contaminação da ponteira e da lesão (RAMIRES; MEJIA, 2012). No método pontual a área irá coincidir com a ponteira do aparelho (MEDEIROS, 2020).

Varredura: No método de varredura a área a ser utilizada corresponde a área da lesão (MEDEIROS, 2020). É realizado uma varredura sobre a área da lesão com uma distância de $1,5 \mathrm{~cm}$, é recomendado realizar uma padronização no movimento de varredura, para que toda área recebe lesão (DIAMANTOPOULOS, 1994). Indicado para ser utilizado em lesões cruentas ou extremamente doloridas, que apresenta dor ao contato com o laser pontual (GARCEZ et al., 2012).

\subsubsection{CONDIÇÕES PARA OBTENÇÃO DE EFEITOS BIOLÓGICOS}

Mecanismo de ação biológico nas células ao se utilizar espectro de luz visível: Permite que ocorra uma fotobiomodulação nas mitocôndrias, levando a transdução e em seguida, irá emitir uma série de sinais para outras regiões da célula, que irá resultar na fotoresposta e em sequência ativará uma série de ações na cadeia respiratórias das mitocôndrias, no núcleo e citoplasma (KARU, 1999).

Mecanismo de ação biológico nas células ao se utilizar um espectro de luz infravermelho: Ao se irradiar um tecido com espectro infravermelho, o mesmo irá causar um estímulo nos canais de cálcio da membrana plasmática, ocorrendo então em 
seguida mudanças na permeabilidade da membrana, gradiente de pressão e temperatura (SMITH, 1991).

Ambas luzes, tem a capacidade de ser absorvida pelo citocromo C oxidase, porfinas e vários componentes da cadeia respiratória, resultando em um aumento da produção de ATP, espécies reativas de oxigênio e radicais superóxidos (KARU, 1987; KARU, 1999; KARU, 2003).

Em seguida, com a ocorrência da fotorecepção nas células, teremos uma série de acontecimentos, incluindo proliferação, síntese de proteínas e fatores de crescimento (SMITH, 1991).

\subsubsection{PARÂMETROS NECESSÁRIOS}

Os parâmetros de modulação adequado é de extrema importância, pois se utilizado de forma incorreta ele pode alterar os efeitos desejados.

Potência: É caracterizado como a quantidade de energia que juntamente com os fótons chegam até o tecido (GARCEZ et al., 2012).

Densidade de Potência: A literatura define como apotência de saída da luz por unidade de área que atinge o tecido, ela pode ser caracterizada por $\mathrm{Mw} / \mathrm{cm}^{2} \mathrm{t}$ (GARCEZ et al., 2012).

Densidade de Energia: É a quantidade de energia que atinge uma unidade de área, é caracterizada por J/cm² (GARCEZ et al., 2012).

Tempo: Variável que deve ser levado em conta ao se adotar um protocolo (GARCEZ et al., 2012).

Comprimento de onda: Ainda não é possível definir qual o melhor comprimento de onda, para cada situação específica (GARCEZ et al., 2012).

Outros parâmetros também devem ser levados em conta, como: modo de emissão de luz (se ela é contínua ou pulsátil), número de pontos e espaço entre os pontos (FERREIRA, 2020), número de sessões, intervalo entre a sessões, área em $\mathrm{cm}^{2}$ (WALT, 2004).

A descrição detalhada dos parâmetros dosimétricos é fundamental para determinação da dose exata na terapia por laser de baixa potência. 


\subsubsection{AÇ̃OO DO LASER SOB LESÕES DE MUCOSITE}

O laser age de diversas formas nos tecidos e entre as ações podemos citar a estimulação da atividade celular, a liberação de fatores de crescimento por macrófagos, proliferação de queratinócitos, aumento da população e degranulação de mastócitos e principalmente a angiogênese. Esses efeitos sobre as lesões aceleram o processo de cicatrização de feridas a redução na duração da inflamação aguda, resultando numa reparação mais rápida (RIBEIRO, 2004 apud KELNER; CASTRO 2007).

O emprego do laser de baixa potência elimina a dor já na primeira aplicação em razão da liberação de ß-endorfina, nas terminações nervosas da lesão, fazendo com que a ulceração se repare de forma mais rápida (GENOVESE, 2000).

Um evento biológico importante a mencionar é a proliferação e maturação epitelial e de fibroblastos, assim como a sua locomoção e transformaçãoem miofibroblastos (FIGUEIREDO, 2013).

\subsubsection{TERAPIA FOTODINÂMICA}

\subsubsection{DEFINICHÃO}

A reação fotodinâmica é dependente da presença de quantidades suficientes de fotossensibilizador representado pelos corantes, ativação pela luz laser e oxigênio. Para a utilização desta reação, o pró-fármaco fotossensibilizador requer uma alta seletividade para o alvo (MORTON et al.,2008).

\subsubsection{VANTAGENS}

Entre as vantagens da PDT, podemos citar o baixo custo, mínimos efeitos colaterais e redução da probabilidade de recorrência como as principais vantagens da terapia, além de simplicidade técnica e ausência de risco de resistência microbiana (EDUARDO et al., 2015).

\subsubsection{FOTOSSENSIBILIZADORES}

Existe uma infinidade de fotossensibilizadores que podem ser divididos em grupos em função de sua estrutura química e origem, como as fenotiazinas (azul de metileno e azul de toluidina), tinturas de ftalocianinas (aluminumdissulfonado, zinco catiônico), porfirinas, clorinas, xantenos (eritrosina) e monoterpenos (azuleno). As hematoporfirinas foram os primeiros a serem descobertos, sendo chamados de 
fotossensibilizadores de primeira geração. Foram utilizados inicialmente como ferramenta no diagnóstico do câncer, em virtude do efeito de fluorescência que apresentava. Os fotossensibilizadores de segunda geração mostraram-se mais efetivos na produção de oxigênio singleto, eram derivados de porfirinas, porfirinas sintéticas e ftalocianinas e a terceira geração era caracterizada pela modificação na incorporação de anticorpos e proteínas receptoras, cujo objetivo era melhorar a seletividade ao tecido (PRAŻMO et al, 2016).

\subsubsection{MECANISMO DE AÇÃO}

O mecanismo de fotossensibilização da PDT consiste na interação da luz com o fotossensibilizador e o oxigênio, gerando radicais livres que induzem severos danos às células microbianas, levando à sua morte. A luz é responsável por excitar o agente fotossensibilizador que interage com moléculas vizinhas através de dois mecanismos. 0 fotossensibilizador no estado excitado pode agir removendo um átomo de hidrogênio de uma molécula do substrato biológico (fosfolipídeos, colesterol, proteínas entre outros)ou transferindo elétrons, gerando íons radicais que tendem a reagir com o oxigênio no estado fundamental (Foote,1991). São formados produtos oxidados responsáveis pela cadeia de radicais livres, como radical superóxido (O2-), peróxido de hidrogênio ( $\mathrm{H} 2 \mathrm{O} 2)$, e radical hidroxila $(\mathrm{OH})$, que são capazes de oxidar uma grande variedade de biomoléculas. O fotossensibilizador no estado excitado pode, ainda, transferir energia ao oxigênio molecular no estado fundamental, produzindo oxigênio singleto. Este é o mecanismo dominante na PDT (BAGNATO, 2008).

Devido à variedade de microrganismos presentes na cavidade oral, as lesões de mucosite oral são frequentemente associadas a infecções, que dificultam a cicatrização (SILVA et al, 2018). Em razão disto, a terapia fotodinâmica é fundamental na descontaminação de infecções secundárias associadas à mucosite, sendo um tratamento de escolha diante destas condições.

\section{CONSIDERAÇÕES FINAIS}

O emprego do laser de baixa potência utilizado no tratamento preventivo e terapêutico da mucosite tem sido eficiente, apresentando efeitos de analgesia desde a primeira aplicação. Por ser considerada uma prática integrativa complementar de saúde 
bucal, teve o reconhecimento do exercício da terapia pelo cirurgião dentista através da resolução no 82 de 2008, emitida pelo Conselho Federal de Odontologia. Entre os principais mecanismos de ação do laser sobre a mucosite, podemos citar a estimulação celular, liberação de fatores de crescimento, proliferação de queratinócitos, mastócitos e indução da angiogênese que aceleram o processo de cicatrização de feridas e reduzem o tempo de duração da inflamação aguda. O método de varredura é escolhido em detrimento do método pontual em casos de lesões cruentas e extremamente dolorosas e entre as principais vantagens do laser, o baixo custo, os mínimos efeitos colaterais, a redução da recorrência e a simplicidade técnica contribuem para o uso difundido da laserterapia no tratamento da mucosite.

\section{REFERÊNCIAS}

NEVILLE, B. W. et al. Patologia oral e maxilofacial. 4. ed. Rio de Janeiro: Elsevier, 2016. $912 \mathrm{p}$.

ELAD, S.; CHENG, K. K. F.; LALLA, R. V. et al. Clinical practice guidelines for the management of mucositis secondary to câncer therapy. Cancer, v. 126, n. 19, p. 4423-4431, 2020. Wiley.

CONSELHO FEDERAL DE ODONTOLOGIA (CFO). Resolução no 82, de setembro de 2008. Reconhece e Regulamenta O Uso Pelo Cirurgião-Dentista de Práticas Integrativas e Complementares À Saúde Bucal. Rio de Janeiro-RJ.

MOREIRA, F. C. L. et al. Manual prático para uso dos lasers na odontologia. Goiânia: CegrafUfg, p. 42, 2020.

BLAKAJ, A.; BONOMI, M.; GAMEZ, M. E. et al. Oral mucositis in headandneckcancer: evidence-based management and review of clinical trial data. Oral Oncology, v. 95, p. 29-34, 2019. Elsevier BV. http://dx.doi.org/10.1016/j.oraloncology.2019.05.013.

NAMETALA, L. L. M.;SANTOS, M. M.; ESTEVES, C. M. S. et al.Prevenção e tratamento da mucosite oral em pacientes submetidos a quimioterapia e radioterapia: o que o cirurgião-dentista precisa saber? - Uma revisão de literatura. CEMOI, RJ, 2020.

OLIVEIRA, E.L.; CABRAL.G.M.P.; GALVÃO, A.K.F.C. et al.Mucosite - uma revisão sistemática. Rev Camp do Sab. v 4, n. 5, out/nov de 2018.

PÉCORA, J.D.; JÚNIOR, A. B. Breve histórico do laser. FORP-USP. Web Masters, 1999.

PINHEIRO, A. L. B., Aplicação do laser na odontologia. Ed. Santos. 1ạ ed., Editora Gen e Santos, 2010. 
PROCKT, A.P.; TAKAHASHI, A.; PAGNONCELLI, R.M. Uso de Terapia com Laser de Baixa Intensidade na Cirurgia Bucomaxilofacial. Rev Port Estomatol Cir Maxilofac, v .49, p. 247-255, 2008.

KLEPPNER, D. Rereading Einstein onradiation. Rev. Bras. Ensino Fís.V. 27, n. 1, Março, 2005.

DIAMANTOPOULOS, C. Bioenergerticsandtissueoptics. In_: Therapeutic lasers: TheoryandPractice (BaxterG.D.,ed.) Edinburg: Churchill Living stone, p.67- 88, 1994.

GARCEZ, A.S.; RIBEIRO, M.S.; NUNEZ, S.C. Laserterapia de baixa Potência: princípios básicos e aplicações clínicas em odontologia. Elsevier, p. 167-178, 2012.

WORLD ASSOCIATION OF LASER THERAPY - WALT. Consensus agree menton the design and conduct of clinical studies with low level laser therapyand light therapy for músculos keletal painan ddisorders. 5th World Congress, in Guarujá, Brasil, p. 761, 2004.

FERREIRA, A. G. A. Aplicação do laser de baixa intensidade no processo de cicatrização de ferida cirúrgica: padronização dos parâmetros dosimétricos. Tese (Dissertação de mestrado) programa de pós-graduação em engenharia mecânica na escola de engenharia da UFMG, p. 42, 2016.

KARU, T.I. Special issue papers photo biological fundamental so flow-power laser. IEEE Journal of Quantum Electronics, v.QE-23, n.10, p.1703-1717, 1987.

KARU, T.I. Primary and secondary mechanisms of action of visibletonear-IR radiationon cells. Photo chemistry and Photobiology. B., v.49, p.1-17, 1999.

KARU, T.I. Low-power laser therapy. In: VO-DINH, T., Editor. Biomedical Photonics Handbook, CRC Press, cap.48, 2003.

SMITH, K. The photobiologicalbasisoflow-level laser radiationtherapy. Laser Therapy, v.3, n.1, p.19-24, 1991.

RAMIRES, C. R.; MEJIA, D. P. M. Os Efeitos do Laser no Tratamento de Úlceras de Decúbito-Revisão Bibliográfica. Tese (Dissertação de mestrado) Pós-graduação em Fisioterapia Dermatofuncional Faculdade Ávila. Goiânia, 2012.

BAGNATO, V.S. Novas técnicas óticas para as áreas da saúde. Física ELd, editor. São Paulo, 2008.

FIGUEIREDO, A.L.P et al. Laser terapia no controle da mucosite oral: um estudo de metanálise. Rev Assoc Med Bras, 2013.

FOOTE, C.S. "Definitionoftype I andtype II photosensitizedoxidation. Photo chemistry and photo biology vol. 54, 1991. 
GENOVESE, J.W. Laser de baixa potência: aplicações terapêuticas em odontologia. São Paulo: Lovisa, 2000.

KELNER, N; CASTRO, J. F. L. D.Laser de baixa intensidade no tratamento da mucosite oral induzida pela radioterapia: relato de casos clínicos. Rev. bras. cancerol;v. 53, $n$. 1, p. 29-33,2007.

MORTON, C.A; MCKENNA, K.E; RHODES, L.E. Guidelines for topical photodynamictherapy: update. The British jornal of dermatology vol. 159, 2008.

RIBEIRO, M.S; ZEZELL, D.M. Laser de baixa intensidade. In: Eduardo CP, Gutknecht N (org.). A Odontologia e o laser: atuação do laser na especialidade odontológica. São Paulo: Quintessence Editora Ltda; 2004.

SILVA, V. C. R. D. S. Eficácia da terapia fotodinâmica (PDT) e da fotobiomodulação (FBM) no controle da mucosite oral quimioinduzida de pacientes oncológicos pediátricos. Tese (Pós Graduação em Odontologia) - Centro de Ciências da Saúde da Universidade Federal de Pernambuco, 2018.

NEVILLE,B. W.; DAMM, D. D.; ALLEN, C. M.; CHI, A. C. ORAL AND MAXILLOFACIAL PATHOLOGY. 4o ed. Rio de Janeiro. Elsevier Editora Ltda, 2016.

SCHIRMER, E. M.; FERRARI, A.; TRINDADE, L. C. T. Evolução da mucosite oral após intervenção nutricional em pacientes oncológicos no serviço de cuidados paliativos. Rev Dor. São Paulo. v. 13, n. 2, p. 141-6, 2012.

VAN SEBILLE, Y. Z.; STANSBOROUGH, R.; WARDILL, H. R. et al. Management of Mucositis During Chemotherapy: From Pathophysiology to Pragmatic Therapeutics. Springer Science. New York. Curr Oncol Rep. v. 17, n. 11, p. 50, 2015.

FIGUEIREDO, A. L. P.; LINS, L.; CATTONY, A. C.; FALCÃO, A. F. P. Laser terapia no controle da mucosite oral: um estudo de metanálise. Brasil. Rev da Assoc Méd Brasile V. 59, p. 467-474, 2013.

MOSLEMI, D; NOKHANDANI, A. M.; OTAGHSARAEI, M. T. et al. Management ofchemo/radiation-induced oral mucositis in patients with head and neck cancer: A review of the current literature. Iran. Radio ther Oncol. V.120, n. 1, p. 13-20, 2016.

DE SANCTIS, V.; BOSSI, P.; SANGUINETI, G. et al. Mucositis in head and neck câncer patients treated with radiotherapy and systemic therapies: Literature review and consensus statements. Crit Rev Oncol Hematol. v. 100, p. 147-66, 2016.

CAILLOT, É.; DENIS, F. Mucites radio-induites bucco pharyngées: actualités surla priseen charge. Cancer/Radiothérapie. v. 16, p. 358-363, 2012.

BLAKAJ, A.; BONOMI, M.; GAMEZ, M. E, et al. Oral mucositis in head and neck cancer: Evidence-based management and review of clinical trial data. Estados Unidos. Oral Oncology. v. 95, p. 29-34, 2019. 
RAPOSO, B. S.; et al. Abordagem clínica e terapêutica da mucosite oral induzida por radioterapia e quimioterapia em pacientes com câncer. Rio de Janeiro. Rev. Bras. Odontol. vol.71 n.1, 2014.

VOLPATO, L. E. R.; SILVA, T. C.; OLIVEIRA, T. M.; SAKAI, V. et al. Mucosite bucal rádio e Quimioinduzida. Brasil. Rev Bras Otorrinolaringol. V.73, n. 4, p. 562-68, 2007.

CAVALCANTI, T. M. et al. Conhecimento das propriedades físicas e da interação do laser com os tecidos biológicos na odontologia. Anais Brasileiros de Dermatologia, v. 86, p. 955-960, 2011.

MOREIRA, F. C. L. Manual prático para uso dos lasers na odontologia. Goiânia: CegrafUfg, 2020. 


\title{
CAPITULO XXI \\ IMPORTÂNCIA DA HIGIENE ORAL E DA DOENÇA CARDIACA: UMA REVISÃO INTEGRATIVA
}

\author{
DOI: 10.51859/AMPLLA.EPC757.1121-21
}

\author{
Natália Franco Brum ${ }^{1}$ \\ Mariana Sobreira Bezerra ${ }^{1}$ \\ Aline Sobreira Bezerra ${ }^{2}$ \\ Flávia Kolling Marquezan ${ }^{3}$ \\ Patricia Kolling Marquezan ${ }^{4}$
}

\begin{abstract}
1 Graduanda do Curso de Odontologia. Universidade Federal de Santa Maria, Santa Maria-RS, Brasil
2 Docente do Departamento de Ciência e Tecnologia de Alimentos. Universidade Federal de Santa Maria, Santa MariaRS, Brasil

${ }^{3}$ Docente do Curso de Odontologia. Universidade Franciscana, Santa Maria-RS, Brasil

4 Docente do Departamento de Microbiologia e Parasitologia. Universidade Federal de Santa Maria, Santa Maria-RS, Brasil
\end{abstract}

\section{RESUMO}

A Endocardite Bacteriana (EB) se apresenta como uma doença infecciosa que possui uma vastidão de fatores etiológicos, dentre eles, a presença de bactérias orais, que se faz constante nessa patologia. Dada a presente relação e a notoriedade do assunto, é de fundamental importância que o Cirurgião-Dentista aprofunde os conhecimentos a esse respeito. Em vista disso, o objetivo do estudo foi avaliar o mecanismo de desenvolvimento da EB e a relação com higiene oral. Uma revisão de literatura foi realizada, com buscas nas bases de dados: Biblioteca Virtual em Saúde (BVS), EMBASE e PubMed, utilizando os descritores das plataformas MeSH e DeCs relacionados ao assunto. Após as pesquisas, foram selecionados 9 artigos para compor a revisão de literatura. Inicialmente, realizou-se a análise de títulos e de resumos, com a posterior leitura na íntegra. Os estudos relatam, que a falta de higienização oral em indivíduos portadores de desordens cardiovasculares pode se apresentar como um fator de predisponente ao desenvolvimento da $\mathrm{EB}$, devido à interação dos microrganismos e dos mediadores pró-inflamatórios. Portanto, ressalta-se a relevância de profissionais Cirurgiões-Dentistas compreenderem o papel da manutenção da higiene oral, sendo esta fundamental para a redução do acúmulo e da agregação microbiana e, consequentemente, da EB.

Palavras-chave: Bacteremia, Endocardite, Odontologia 


\section{INTRODUÇÃO}

A Endocardite Infecciosa (EI) apresenta-se como uma causa frequente de morbidade e mortalidade em crianças e adolescentes, apesar da evolução no manejo e profilaxia (BARROSO et al., 2014; HUBERS et al., 2020). A doença se constitui em uma infecção no endocárdio ou em dispositivos nele presentes, causada por múltiplos fatores que podem culminar no óbito do indivíduo (SIVIERO et al., 2009; BARROSO et al., 2014). A El inclui a endocardite bacteriana aguda e subaguda, bem como endocardite não bacteriana causada por vírus, fungos e outros agentes microbiológicos.

Das El, a mais preocupante na área odontológica é a Endocardite Bacteriana (EB) devido à presença de bactérias quali e quantitativamente distintas (MARSH \& MARTIN, 2005). A maioria dos casos é causada por estreptococos viridans, Streptococcus gallolyticus, Staphylococcus aureus, estafilococos coagulase-negativos, organismos HACEK (Haemophilus,Aggregatibacter, Cardiobacterium, Eikenella, Kingella) e enterococos. Organismos mais raros incluem pneumococos, Candida, bacilos gramnegativos e organismos polimicrobianos (GALAR et al., 2019; LAUMAY et al., 2019).

Dentre os fatores de risco para o desenvolvimento da EB estão: idade (superior a 60 anos), sexo masculino, uso de drogas injetáveis ou procedimentos odontológicos, presença de válvula protética ou dispositivo intracardíaco, história de doença valvar (doença cardíaca reumática, prolapso da válvula mitral, doença da válvula aórtica, regurgitação mitral, etc), doença cardíaca congênita (estenose aórtica, válvula aórtica bicúspide, estenose pulmonar, defeito do septo ventricular, persistência do canal arterial, coarctação da aorta e tetralogia de Fallot), cateter intravenoso de demora, imunossupressão e pacientes em hemodiálise (GALAR et al., 2019; VILCANT \& HAI, 2020).

Muito embora procedimentos odontológicos sejam considerados fatores de risco para o desenvolvimento da $\mathrm{EB}$, a disseminação de bactérias presentes na cavidade oral para a corrente sanguínea também pode acontecer diariamente, por meio da rotina de cuidados bucais (uso do fio dental e escovação) e processos fisiológicos (mastigação) (GALAR et al., 2019). A bacteremia que ocorre em eventos cotidianos é comumente chamada de bacteremia transitória, sendo que a prevalência apresenta-se próxima de 20-68\%, sendo maior do que em procedimentos odontológicos invasivos ou não (7-50\%) 
(VILCANT \& HAl, 2020), surgindo uma reflexão sobre a importância dos cuidados orais diários (FERNÁNDEZ et al., 2018).

Além disso, estudos mostraram que a maioria dos enfermos com EB apresentavam problemas dentários, má higiene oral e não realizavam consultas odontológicas regulares (FERNÁNDEZ et al., 2018).

Nesse sentido, frente à notoriedade do assunto, torna-se imprescindível aprimorar os conhecimentos da comunidade odontológica sobre microrganismos patogênicos e o mecanismo de indução da resposta inflamatória sistêmica crônica em indivíduos suscetíveis, o que culmina ao desenvolvimento da EB.

\section{METODOLOGIA}

A revisão de literatura seguiu os preceitos do estudo exploratório, por meio de uma pesquisa bibliográfica em livros e artigos científicos sobre o tema. A busca foi realizada nas bases de dados PubMed, EMBASE e Biblioteca Virtual da Saúde (BVS), tendo ocorrido uma busca complementar no Google Scholar e referências dos artigos previamente selecionados. Os descritores MeSH e DeCs utilizados foram: "endocarditis", "bacteremia" e "oral hygiene" e seus derivados, inter-relacionados por meio de operadores booleanos ("AND", "OR"), adaptados para cada banco de dados e idioma (inglês e português).

Todas as buscas foram realizadas entre os meses de Junho a Agosto de 2020, por uma única pesquisadora. Dentre os critérios de inclusão estavam artigos que relacionassem a endocardite bacteriana com a odontologia, sem restrição de delineamento. Os estudos que não relacionavam endocardite bacteriana com a higiene oral/odontologia, ou não se encontravam disponíveis on-line ou ainda que apresentavam uma amostra de indivíduos portadores de aparelho ortodôntico não foram considerados elegíveis para o estudo.

Após a busca nas bases de dados, os estudos foram selecionados inicialmente através dos títulos e resumos, sendo eliminados os artigos que não se enquadravam no critério de inclusão. O segundo passo foi a remoção de duplicatas e leitura crítica dos textos na íntegra, sendo excluídos aqueles artigos que fugiam do tema (estudo de tratamento ou profilaxia antibiótica para endocardite, por exemplo) ou não se 
relacionavam a odontologia ou ainda aqueles indisponíveis online. O fluxograma que resume o processo de seleção dos estudos está descrito na Figura 1.

Figura 1 - Fluxograma dos estudos atribuídos à revisão de literatura.
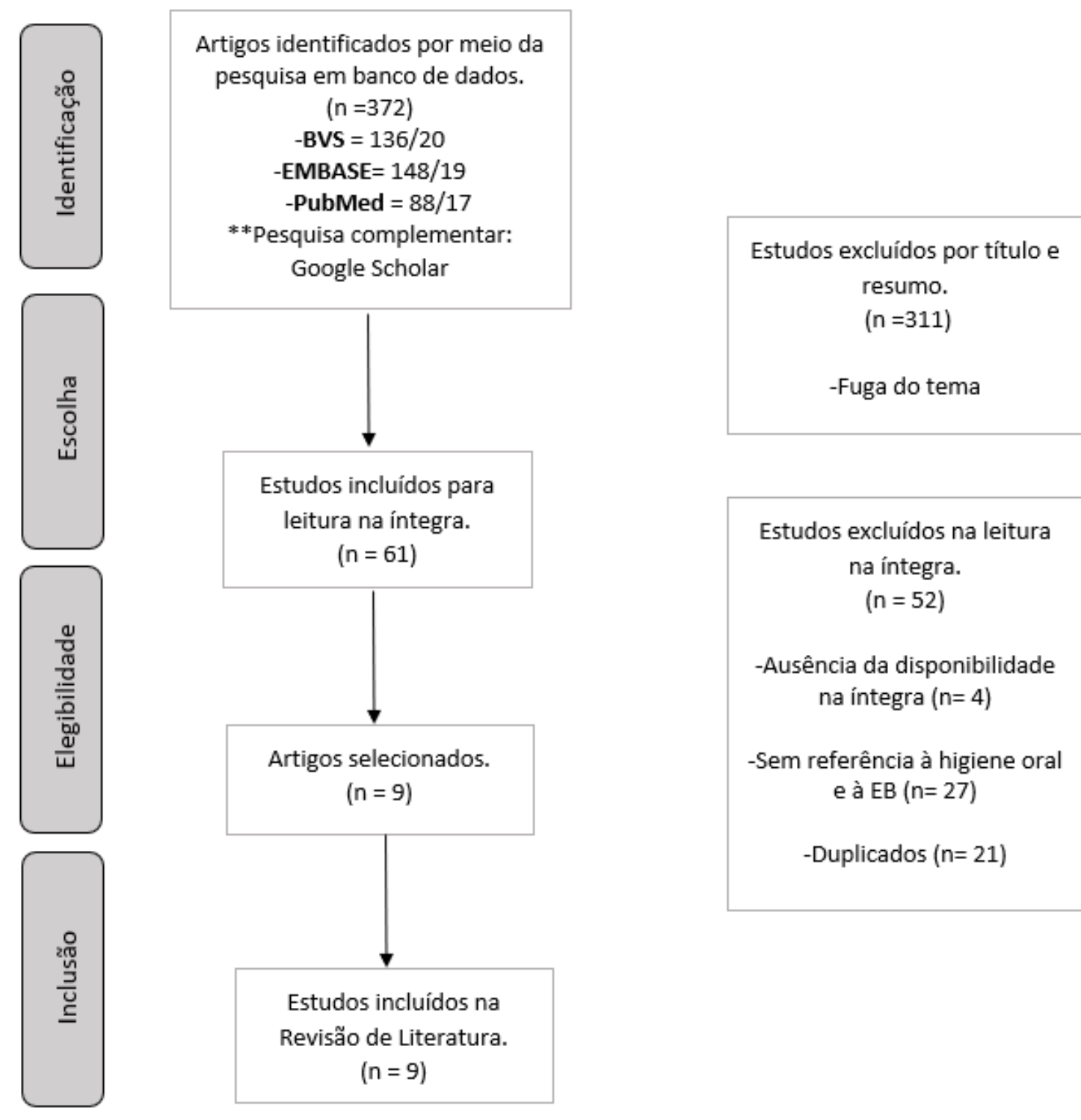

Estudos excluídos na leitura

$$
\begin{gathered}
\text { na íntegra. } \\
(n=52)
\end{gathered}
$$

-Ausência da disponibilidade na íntegra $(n=4)$

-Sem referência à higiene oral e à $E B(n=27)$

-Duplicados $(n=21)$

Fonte: Autoria Própria, 2021.

\section{RESULTADOS}

Para a extração dos dados dos artigos selecionados, foi realizada a leitura exploratória de todo o material selecionado. A interpretação dos resultados foi feita por meio de uma leitura analítica, com a finalidade de organizar a apresentação dos 
achados. Dos 372 artigos encontrados apenas 9 compuseram a revisão, sendo

explanadas as principais características no Quadro 1.

Quadro 1 - Análise detalhada do estudos incluídos na revisão.

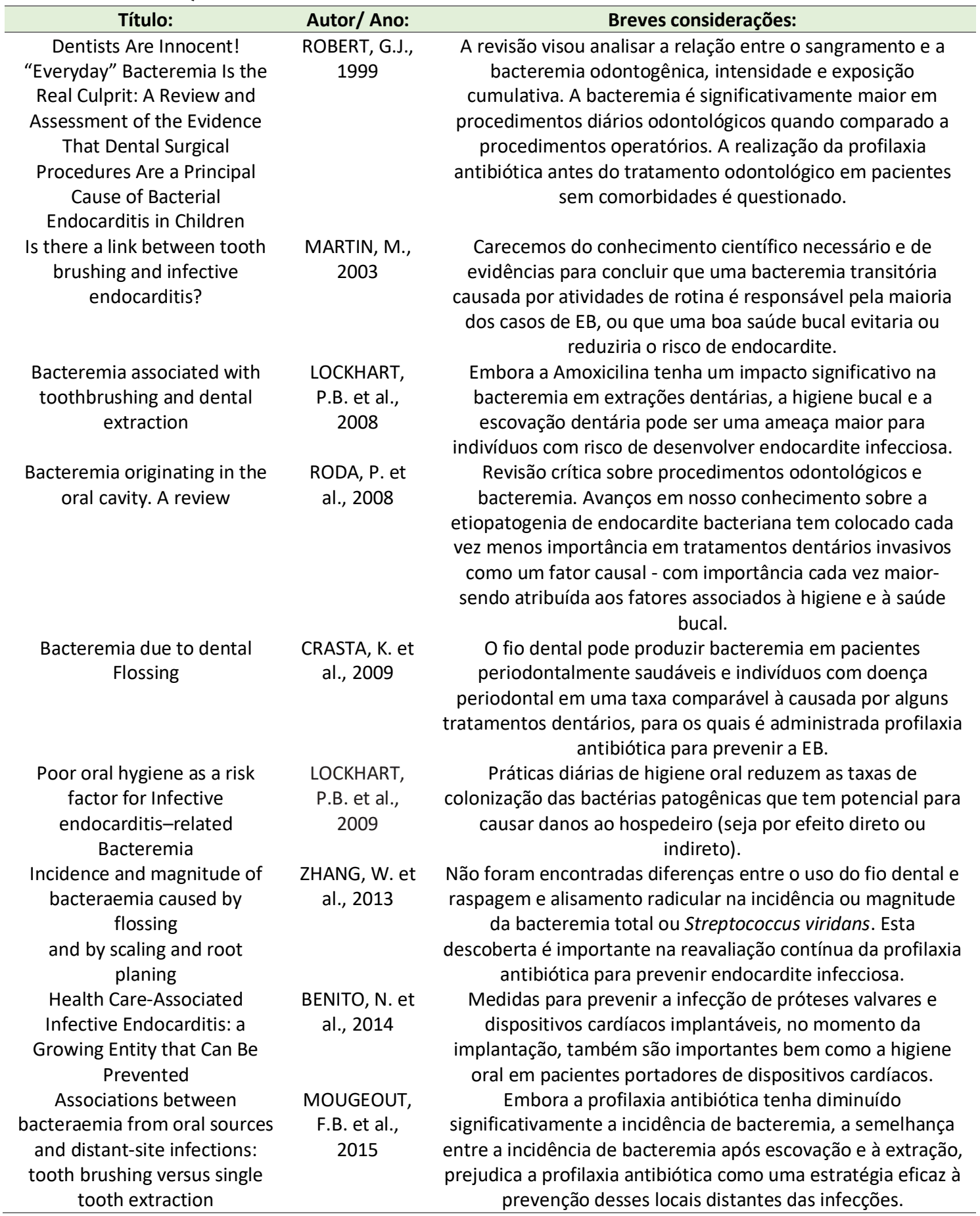

Fonte: Autoria Própria, 2020.

\section{DISCUSSÃO}

Apesar dos avanços tecnológicos em procedimentos diagnósticos e em pesquisa

científica, a EB continua sendo uma doença com mau prognóstico e alta mortalidade 
(BENITO et al., 2014). Por essas razões, assim como pelas mudanças recentes na epidemiologia da Endocardite e a descoberta de que as bactérias orais tem uma alta influência nessa doença, instigaram um novo olhar para essa relação (SY \& KRITHARIDES, 2010), bem como a ênfase em aumentar o conhecimento por parte dos CirurgiõesDentistas sobre o assunto.

Para a compreender a associação entre a bactérias orais e EB é necessário ter ciência que a cavidade bucal proporciona condições adequadas ao desenvolvimento de 700 espécies de microrganismos, como as bactérias comensais, que são necessárias à homeostase corpórea (FERNÁNDEZ et al., 2018). Entretanto, para que esses microrganismos não sejam eliminados pela deglutição ou descamação da mucosa, organizaram-se na forma de biofilmes dentários (MARSH \& MARTIN, 2005).

Apesar do ambiente harmônico em condições normais, quando há aumento do consumo de carboidratos fermentáveis pelo indivíduo, há o favorecimento da proliferação de bactérias as acidogênicas e as acidúricas (Streptococcus mutans, por exemplo) no biofilme acumulado na superfície dentária (MARSH \& MARTIN, 2005). Sendo assim, a organização de um biofilme pelas bactérias apresenta-se como uma forma de proteção aos agentes externos e permite o crescimento e agregação de espécies mais virulentas, tornando o biofilme prejudicial. Se não tratada, o biofilme pode invadir sítios subgengivais alterando a microbiota, aumentando a probabilidade de invasão da corrente sanguínea e a fixação em outros locais (LAUMAY et al., 2019).

A partir do momento em que há a presença de bactérias na corrente sanguínea, principalmente as bactérias periodontais, esses microrganismos liberam substâncias pró-inflamatórias e elevam os níveis da Proteína C Reativa, visando a permanência e o alcance de outros tecidos, como o cardíaco, elevando o risco de doenças cardiovasculares (LAUMAY et al., 2019). Após a colonização desses locais, há um processo de maturação, no qual os microrganismos aproveitam os mecanismos coagulantes, como o fibrinogênio e a fibrina para resistirem à destruição pelo sistema imune do indivíduo (WERDAN et al., 2014).

O próximo passo é a destruição das células do hospedeiro. Isso acontece através dos múltiplos mecanismos de virulência com a liberação de mediadores inflamatórios, como toxinas e enzimas, alfa-hemolisina e modulinas, as quais se fixam às válvulas cardíacas (superfície com colágeno) e aos biofilmes, formando um nicho ecológico que 
favorecem a expansão bacteriana e contribuem à morte celular (ZHANG et al., 2013; MANG-DE LA ROSA et al., 2014).

As bactérias orais alcançam a corrente sanguínea por meio de procedimentos odontológicos invasivos como extrações dentárias que causam bacteremias ditas transitórias e responsáveis por cerca de 10\% das EB, segundo Mang-de la Rosa et al. (2014) e outra forma se dá através da higiene oral e das atividades cotidianas. Vários estudos publicados desde 1954 já relatavam a presença de bacteremias decorrentes da escovação dentária. Entretanto esses trabalhos devem ser vistos com cautela, visto que apresentavam limitações inerentes da época, como ausência de tecnologia molecular.

A porta de entrada para as bactérias estreptococos viridans - responsáveis por $50 \%$ dos casos de EB- na corrente sanguínea em atividades cotidianas, acontece por meio da superfície do tecido gengival crevicular ao redor dos dentes na escovação dentária (LOCKHART et al., 2008). Estima-se, que as bacteremias decorrentes da escovação oral ocorre mais de duzentas vezes por ano (ROBERTS, 1999; MARTIN, 2003; LOCKHART et al., 2008; POVEDA-RODA et al., 2008; LOCKHART et al., 2009; CRASTA et al., 2009; MOUGEOT et al, 2015).

Lockhart et al. (2008), em seu ensaio clínico randomizado, analisou a incidência bacteriana cumulativa no sangue para um grupo que realizou a escovação dentária, enquanto outro grupo utilizou Amoxicilina após extração dental unitária (de acordo, com as recomendações da American Heart Association- AHA) e um terceiro grupo, o qual efetuou extração com medicação placebo semelhante à Amoxicilina. Os resultados mostraram uma diferença estatisticamente significante entre os grupos, sendo que a Amoxicilina apresentou uma redução quanto à presença bacteriana na corrente sanguínea a partir de uma única extração dentária. A escovação dos dentes rompeu uma área de superfície muito maior no tecido localizado nas fendas gengivais e apresentou uma incidência bacteriana na circulação, a partir da atividade de higiene oral diária comum (LOCKHART et al., 2008).

Além disso, em outro desfecho do estudo (Lockhart et al., 2009), a presença de sangramento generalizado após a escovação dentária foi associada ao aumento de quase oito vezes no risco de desenvolver bacteremia. Os autores descobriram que os índices de higiene oral e de doenças gengivais estavam associados, significativamente, com a presença de bacteremia relacionada à El após a escovação dentária. Participantes 
com alto índice de placa e cálculo dental apresentavam um risco 3,78 e 4,43 vezes maior de desenvolver bacteremia quando comparado àqueles pacientes com baixa média de sítios com placa e com cálculo, respectivamente. A presença de sangramento generalizado após a escovação foi associada ao aumento de oito vezes no risco de desenvolver bacteremia em comparação àqueles sem sangramento generalizado (LOCKHART et al., 2009).

Outros estudos encontraram que atividades cotidianas, como comer alimentos, mascar chiclete ou usar palitos também induz à bacteremia detectável em uma porcentagem variável de sujeitos (POVEDA-RODA et al., 2008). Segundo Mougeot et al. (2015) e Poveda-Roda et al. (2008), a intensidade da bacteremia produzida pelo tratamento odontológico invasivo, como a extração dentária é semelhante àquela induzida pelas atividades da vida diária.

Entretanto, o risco de bacteremia após o uso do fio dental não está claro na literatura científica, pois há pouca evidência publicada disponível. Uma avaliação crítica destes estudos revelou a presença de deficiências metodológicas, como falta de um diagnóstico periodontal, por exemplo. Já no estudo de Castra (2009) delineado como um ensaio clínico, descobriu-se que a incidência de bacteremia é comparável àquela que ocorre em procedimentos realizados no tratamento periodontal, como sondagem, escala ultrassônica, irrigação subgengival e profilaxia (ZHANG et al., 2013). Em 2015, Zhang e colaboradores, em um estudo transversal, avaliou a magnitude e a diversidade bacteriana da bacteremia devido ao uso de fio dental em comparação à raspagem e ao alisamento radicular, não encontrando diferença entre os grupos analisados (ZHANG et al., 2013).

Os autores descobriram que os índices de higiene oral e de doenças gengivais foram significativamente associados à bacteremia relacionada à El após a escovação dentária. No entanto, carecemos do conhecimento científico necessário para concluir firmemente, que a bacteremia transitória causada por atividades de rotina é responsável pela maioria dos casos de EB ou que uma boa saúde bucal reduziria o risco de endocardites. A maioria dos autores aponta para a necessidade para ensaios clínicos multicêntricos randomizados, para examinar essa hipótese mais aprofundada (POVEDARODA et al., 2008; ZHANG et al., 2013). 


\section{CONCLUSÃO}

Essa revisão apresenta uma síntese integrativa da literatura, visando analisar o papel da higiene oral ao desenvolvimento da endocardite bacteriana. Segundos os artigos, a falta de higiene oral em indivíduos com desordens cardiovasculares pode causar bacteremias e ser fator predisponente à EB. Entretanto, destaca-se a necessidade do cirurgião-dentista conhecer o mecanismo de desenvolvimento para que consiga atuar de forma mais segura, entendendo a importância da Odontologia nesse processo para o paciente. Além disso, são necessários maiores estudos, a fim de melhorar o entendimento da influência dos patógenos orais no desenvolvimento de endocardite em pacientes suscetíveis.

\section{REFERÊNCIAS}

BARROSO, M.G.; CORTELA, D.C.B.; MOTA, W.P. Endocardite bacteriana: Da boca ao coração. Revista Ciência e Estudos Acadêmicos de Medicina, v. 2, n. 2, p. 47-57, 2014.

BENITO, N.; et al. Health Care-Associated Infective Endocarditis: a Growing Entity that Can Be Prevented. Current Infections Disease Reports, v. 16, n. 11, p. 439-444, 2014.

CRASTA, K.; et al. Bacteraemia due to dental flossing. Journal Clinical Periodontology, v. 36, n. 4, p. 323-332, 2009.

FERNÁNDEZ, E.; et al. Relevancia de profilaxis antibiótica ante procedimientos dentales generadores de bacteriemias transitorias. Revista Médica de Chile, v. 146, n. 7, p. 899-906, 2018.

GALAR, A.; et al. Methicillin-Resistant Staphylococcus aureus Prosthetic Valve Endocarditis: Pathophysiology, Epidemiology, Clinical Presentation, Diagnosis, and Management. Clinical Microbioly Reviews, v. 32, n. 2, p.e00041-18, 2019.

HUBERS, S.A.; et al. Infective Endocarditis: A Contemporary Review. Mayo Clinical Proceedings, v. 95, n. 5, p. 982-997, 2020.

LAUMAY, F.; et al. Temperate Prophages Increase Bacterial Adhesin Expression and Virulence in an Experimental Model of Endocarditis Due to Staphylococcus aureus From the CC398 Lineage. Frontiers in Microbiology, v. 24, n. 10, p. 742750, 2019.

LOCKHART, P.B.; et al. Bacteremia associated with toothbrushing and dental extraction. Circulation, v. 117, n. 24, p. 3118-25, 2008. 
LOCKHART, P.B.; et al. Poor oral hygiene as a risk factor for infective endocarditis-related bacteremia. Journal American Dental Association, v. 140, n. 10, p. 1238-1244, 2009.

MANG-DE LA ROSA, M.R.; et al. The bacteremia of dental origin and its implications in the appearance of bacterial endocarditis. Medicina Oral, Patologia Oral, Cirurgia Bucal, v. 19, n. 1, p. 67-74, 2014.

MARSH \& MARTIN. Microbiologia oral. 4. ed. São Paulo: Editora Santos, 2005.

MARTIN, M. Is there a link between tooth brushing and infective endocarditis? International Dental Journal, v. 53, n. 3, p. 187-90, 2003.

MOUGEOT, F.K.B.; et al. Associations between bacteremia from oral sources and distant-site infections: tooth brushing versus single tooth extraction. Oral Surgery, Oral Medicine, Oral Pathology, Oral Radiology, v. 119, n. 4, p. 430-435, 2015.

POVEDA-RODA, R.; et al. Bacteremia originating in the oral cavity. A review. Medicina Oral, Patologia Oral, Cirurgia Bucal, v. 13, n. 6, p. 355-62, 2008.

ROBERTS, G.J. Dentists are innocent! "Everyday" bacteremia is the real culprit: a review and assessment of the evidence that dental surgical procedures are a principal cause of bacterial endocarditis in children. Pediatric Cardiology, v. 20, n. 5, p. 317-25, 1999.

SIVIERO, M.; et al. Evolução das alterações e atualizações do protocolo 2007 da American Heart Association para prevenção da endocardite infecciosa. Revista do Instituto de Ciências da Saúde, v. 23, n. 2, p. 176-180, 2009.

SY, R.W.; KRITHARIDES, L. Health care exposure and age in infective endocarditis: results of a contemporary population-based profile of 1536 patients in Australia. Europa Heart Journal, v. 31, n. 15, p. 1890-1897, 2010.

VILCANT, V.; HAI, O. Bacterial Endocarditis. 2020 Aug 10. In: StatPearls [Internet]. Treasure Island (FL): StatPearls Publishing; 2021 Jan-. PMID: 29262218.

WERDAN, K.; et al. Mechanisms of infective endocarditis: pathogen-host interaction and risk states. Nature Reviews Cardiology, v. 11, n. 1, p. 35-50, 2014.

ZHANG, W.; et al. Incidence and magnitude of bacteraemia caused by flossing and by scaling and root planing. Journal Clinical Periodontology, v. 40, n. 1, p. 41-52, 2013. 


\title{
CAPITULO XXII \\ PROTOCOLOS DE ATENDIMENTO ODONTOLÓGICO NO PRÉ-OPERATÓRIO DE CIRURGIA CARDIOVASCULAR
}

\author{
DOI: 10.51859/AMPLLA.EPC757.1121-22
}

Pedro Paullo Alves Gonçalves ${ }^{1}$
César Augusto Abreu-Pereira ${ }^{2}$
Maria Áurea Lira Feitosa $^{3}$
Natália de Castro Corrêa $^{4}$
Rosana Costa Casanovas $^{3}$

${ }^{1}$ Graduando em Odontologia. Universidade Federal do Maranhão - UFMA
${ }^{2}$ Doutorando em Odontologia. Universidade Estadual Paulista - UNESP
${ }^{3}$ Professora Associada do Departamento de Odontologia I. Universidade Federal do Maranhão - UFMA
${ }^{4}$ Cirurgiã Dentista. Prefeitura Municipal de Chapadinha/MA

\section{RESUMO}

Objetivo: O propósito desse estudo é elucidar os protocolos existentes na literatura para atendimento odontológico em pré-operatório de cirurgia cardiovascular, possíveis complicações e condutas terapêuticas. Métodos: Revisão de literatura, realizada através de busca ativa nas bases de dados Medline, Pubmed, Lilacs e Scielo, de trabalhos publicados entre 2013 e 2021 e utilizando os descritores "dental care", "cardiovascular surgical procedures" e "dentistry". Foram adotados como critérios de inclusão: artigos com disponibilidade de texto completo em suporte eletrônico; e como exclusão: teses, livros, relatos de caso e artigos com acesso limitado. Resultado: $O$ total de referências obtidas com a busca foi de 78 artigos, sendo 13 selecionados. Foram incluídos outros 11 artigos a partir das referências bibliográficas, totalizando 24. Conclusão: A condição de saúde bucal de pacientes que serão submetidos a cirurgias cardiovasculares tem implicações diretas na saúde sistêmica, contudo, existem controvérsias entre os diversos protocolos pré-operatórios existentes, não havendo um padrão para triagem odontológica, sendo necessários mais estudos para isso.

Palavras-chave: Tratamento odontológico. Pré-operatório cardiovascular. Equipe Hospitalar de Odontologia. 


\section{INTRODUÇÃO}

A má higiene bucal associada a presença de patologias, como as doenças cárie e periodontal e abcessos dentais, contribui para a incidência de bacteremias odontogênicas em pacientes que serão submetidos a cirurgias cardíacas (GUALANDRO et al., 2017; FOLWACZNY et al., 2019). Essas infecções ocorrem quando os microrganismos se propagam para outras regiões do corpo, podendo ocorrer por continuidade anatômica ou através da entrada de patógenos na corrente sanguínea (CARRIZALES-SEPÚLVEDA et al., 2018), tendo alto potencial para o desenvolvimento de comorbidades sistêmicas e mortalidade de pacientes no período pós-operatório (PEDERSEN et al., 2016).

Os microrganismos de focos infecciosos bucais, como por exemplo Porphyromonas gingivalis, Treponema denticola, Staphylococcus aureaus e suas toxinas, têm a capacidade de gerar respostas inflamatórias sistêmicas e, uma vez presentes na corrente sanguínea, podem contribuir para o desenvolvimento de complicações cardíacas e disfunções endoteliais, entre elas a aterosclerose, endocardite bacteriana, infarto agudo do miocárdio, acidente vascular cerebral, síndrome coronariana aguda, complicações em outros órgãos vitais, além de possuir uma maior chance de insucesso no procedimento cirúrgico cardiovascular (SMITH et al., 2014).

A aterosclerose é uma condição caracterizada pela formação de uma placa nas paredes de médias e grandes artérias em razão de uma lesão e posteriores disfunções endoteliais e resposta inflamatória. O processo inflamatório aumenta a permeabilidade dos vasos, assim vários componentes plasmáticos entram no espaço subintimal. Partículas de lipoproteínas de baixa intensidade (LDL) são aprisionadas e oxidadas. Além disso, as células endoteliais lesionadas produzem moléculas de adesão surfactantes, gerando adesão e acúmulo de células imunes. Durante a resposta inflamatória, os macrófagos degradam as moléculas de LDL, sendo essa uma das principais causas para formação de células espumosas que formam a placa ateromatosa. A cronicidade deste processo leva ao estreitamento do vaso e consequente insuficiência circulatória de órgãos alvos, causando infarto agudo do miocárdio e acidente vascular cerebral (GHEORGHITA et al., 2019). 
A endocardite infecciosa é uma doença rara, mas potencialmente fatal. Acomete principalmente a valva mitral, seguido pela valva aórtica e em mais de $30 \%$ dos casos está relacionada com o Streptococcus viridans, um microrganismo encontrado na cavidade bucal (CHEE \& HOW, 2013).

O acompanhamento odontológico no pré-operatório de cirurgias cardiovasculares é fundamental para remoção de focos infecciosos, melhorando a condição clínica do paciente. (AKASHI et al., 2018). Não existe um protocolo padrão para triagem odontológica que relacione o controle de infecções e o período adequado para realização dos procedimentos antes da cirurgia cardiovascular (COTTI et al., 2019). A inexistência de um protocolo padrão está associada, principalmente, à desvinculação vigorosa entre o corpo e a boca reforçada por profissionais de saúde, onde o conhecimento das condições bucais é visto por profissionais da área médica como limitados aos profissionais de odontologia (FONSECA et al., 2016). Nesse sentido, este estudo tem o objetivo de elucidar quais os protocolos existentes na literatura para atendimento odontológico em pacientes que serão submetidos às cirurgias cardíacas, possíveis complicações e condutas terapêuticas.

\section{METODOLOGIA}

A pesquisa bibliográfica baseou-se na revisão de literatura através de artigos científicos utilizando as bases de dados: Medline, Pubmed, Lilacs e Scielo. Foram utilizados operadores booleanos em associação às palavras-chave "dental care", "cardiovascular surgical procedures" e "dentistry". Adotou-se os seguintes critérios de inclusão: artigos com disponibilidade de texto completo em suporte eletrônico publicados entre 2013 e 2021; e exclusão: teses, livros, relatos de caso e artigos com acesso limitado. Foram obtidos 78 artigos, dos quais 13 foram selecionados após a leitura do resumo. As listas de referência dos artigos selecionados foram examinadas para inclusão de informações adicionais, sendo selecionados mais 11 documentos, totalizando 24. A partir do conteúdo obtido, realizou-se uma análise sobre o tema abordado. 


\section{REVISÃO BIBLIOGRÁFICA}

Muitos pacientes não têm consciência dos seus problemas bucais, tão pouco da associação entre esses problemas e a condição cardiovascular (AMARAL et al., 2016). Uma consulta odontológica detalhada com obtenção de exames de imagem no préoperatório é frequentemente ignorada em detrimento de outros aspectos da saúde sistêmica do paciente que são priorizados (KUMAR \& RAI, 2018).

\subsection{EXAME E PROCEDIMENTOS ODONTOLÓGICOS PRÉ-OPERATÓRIOS}

Segundo as diretrizes da American Heart Association (AHA), são imprescindíveis a avaliação dentária pré-operatória e a remoção, antes da cirurgia de válvula cardíaca ou reparo de doença cardíaca congênita, dos focos infecciosos, diminuindo significativamente as chances de desenvolvimento de endocardite (WILSON et al., 2007).

De acordo com a Sociedade Europeia de Cardiologia, os focos infecciosos dentários devem ser eliminados pelo menos duas semanas antes da realização da cirurgia para substituição de válvula cardíaca protética, exceto em casos de urgência (HABIB et al., 2015).

Nos casos de cirurgias cardíacas eletivas os pacientes devem ser submetidos a exame odontológico e os tratamentos necessários devem ser oferecidos para garantir que o paciente esteja bem-preparado e livre do risco de endocardite infecciosa (JENKINS et al., 2015). A avaliação odontológica deve ser realizada com semanas de antecedência, possibilitando a realização de todos os tratamentos necessários: eliminação de focos infecciosos agudos, extrações de dentes comprometidos com periodontite apical sintomática ou mobilidade patológica, terapia periodontal não cirúrgica, procedimentos restauradores e endodônticos (MILLOT et al., 2017).

Quando o período pré-operatório é curto, Akashi et al. (2018) contraindicam a realização de procedimentos invasivos, como exodontias e raspagem, para evitar hemorragias inesperadas e o adiamento da cirurgia cardiovascular. Contudo, em casos de dentes com drenagem purulenta persistente ou com periodontite avançada e risco de avulsão durante a intubação, os autores indicam a exodontia, mesmo um dia antes da cirurgia cardiovascular, e ressaltam que durante o pós-operatório os pacientes 
devem receber manejo oral profissional de rotina e os demais procedimentos poderão ser realizados quando houver estabilidade no quadro clínico.

Millot et al. (2017) alertam que em casos de cirurgias de urgência para intervenção valvar, o período pré-operatório é limitado, portanto deve-se identificar os sítios infecciosos mais ativos para redução da carga bacteriana e diminuição do risco de bacteremia de alto grau. Para os autores, após exames físico e de imagem, o manejo terapêutico deve englobar a eliminação de celulite facial, abscesso periodontal e pericoronarite em fase aguda de infecção, extrações de dentes associados a periodontite apical sintomática ou mobilidade patológica. Além disso, eles propõem o uso da tomografia computadorizada para os casos de difícil diagnóstico de focos infecciosos, principalmente quando há dúvidas sobre o estado endodôntico do dente restaurado ou lesões periapicais. Ademais, os pacientes devem realizar bochechos com clorexidina $0,12 \%$ ou $0,2 \%$ após as refeições durante as 24 horas que antecedem a cirurgia cardíaca (MILLOT et al., 2017).

De acordo com Amaral Júnior et al. (2020), tratamentos restauradores atraumáticos e raspagem supragengival são indicados para eliminação de focos infecciosos. Tratamentos endodônticos e exodontias só são indicados para os pacientes que não apresentam risco de agravo sistêmico em decorrência dos procedimentos, após avaliação multiprofissional.

Rao et al. (2020) estabeleceram dois protocolos de atendimento odontológico para pacientes em pré-operatório de cirurgia cardiovascular. No primeiro, chamado de abordagem focada, foram realizados exame clínico e radiográfico apenas nos sítios com infecção evidente. No segundo, abordagem compreensiva, além de exame clínico detalhado, foram realizadas radiografias panorâmicas e periapicais de todos os sítios bucais. Observou-se que os pacientes submetidos a avaliação odontológica mais rigorosa tiveram uma maior quantidade de alterações bucais passíveis de complicações pré-operatórias diagnosticadas. Dos pacientes atendidos pelas duas abordagens, 40 pacientes (2,18\% do total) apresentaram histórico de endocardite infecciosa. Destes, 26 foram atendidos pela abordagem focada e 14 pela abordagem compreensiva. A taxa de mortalidade em 90 dias foi de 23,1\% (6 pacientes) para abordagem focada e $0 \%$ para abordagem compreensiva. 


\subsection{PROFILAXIA ANTIBIÓTICA}

A AHA e a Sociedade Brasileira de Cardiologia (SBC) recomendam a profilaxia antibiótica associada ao atendimento odontológico para procedimentos que envolvam manipulação direta do tecido gengival, manipulação da região periapical dos dentes ou procedimentos que envolvem perfuração e comprometimento da mucosa oral em paciente com alto risco de desenvolvimento de endocardite infecciosa (quadro 1). Não se tem conhecimento sobre a eficácia da profilaxia antibiótica para pacientes com níveis moderados ou baixos, podendo as reações adversas superarem os benefícios, não sendo indicada, portanto (WILSON et al., 2007; GUALANDRO et al., 2017).

Quadro 1 - Condições cardíacas de alto risco para o desenvolvimento de endocardite infecciosa segundo a American Heart Association.

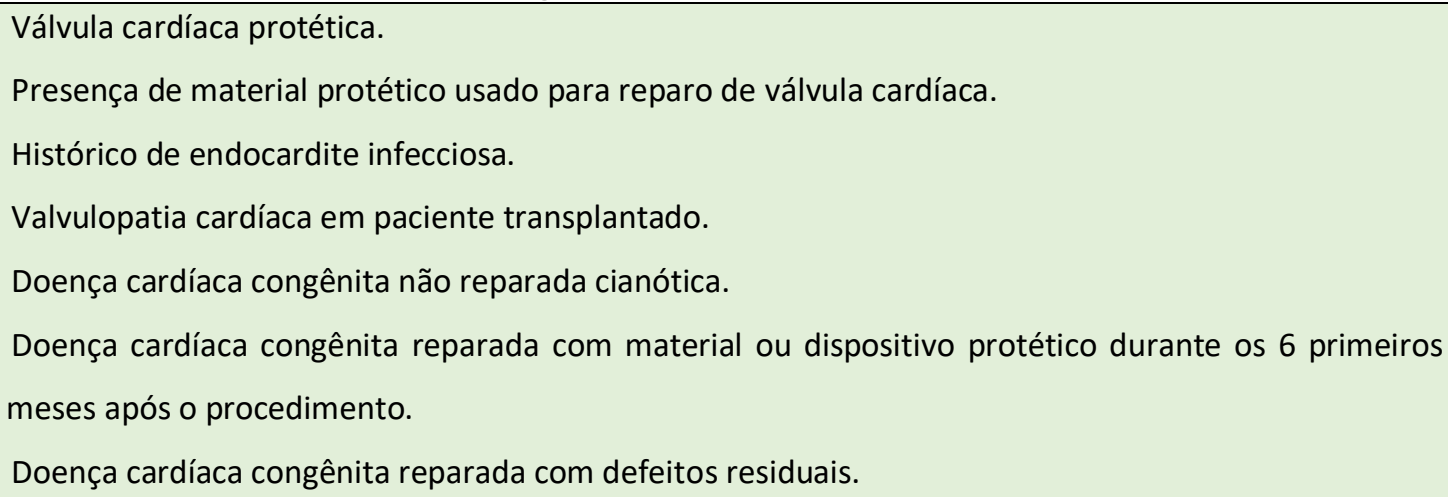

Fonte: American Heart Association.

Para profilaxia antibiótica por via oral (quadro 2), indica-se amoxicilina em razão de sua ótima absorção pelo trato gastrointestinal e concentrações séricas altas e sustentadas. Para alérgicos à penicilina recomenda-se cefalexina ou outras cefalosporinas de primeira geração (clindamicina, azitromicina ou claritromicina). As cefalosporinas não poderão ser administradas em pacientes com histórico de anafilaxia, angioedema ou urticária quando tratados com penicilinas, pois poderão ocorrer reações cruzadas. Quando a terapia oral é inviabilizada, os pacientes podem ser tratados com ampicilina, ceftriaxona, cefazolina ou clindamicina por via intramuscular ou intravenosa (GUALANDRO et al., 2017). 
Quadro 2 - Posologia para profilaxia antibiótica antes de tratamentos odontológicos segundo a American Heart Association.

\begin{tabular}{|l|l|l|l|}
\hline Administração & Antibiótico & Dose adulto & Dose criança \\
\hline Via oral & Amoxicilina & $2 \mathrm{~g}$ & $50 \mathrm{mg} / \mathrm{kg}$ \\
\cline { 2 - 4 } & Clindamicina & $600 \mathrm{mg}$ & $20 \mathrm{mg} / \mathrm{kg}$ \\
\cline { 2 - 4 } & Cefalexina & $2 \mathrm{~g}$ & $50 \mathrm{mg} / \mathrm{kg}$ \\
\cline { 2 - 4 } & Azitromicina & $500 \mathrm{mg}$ & $15 \mathrm{mg} / \mathrm{kg}$ \\
\cline { 2 - 4 } & Claritromicina & $500 \mathrm{mg}$ & $15 \mathrm{mg} / \mathrm{kg}$ \\
\hline & Ampicilina & $2 \mathrm{~g}$ & $50 \mathrm{mg} / \mathrm{kg}$ \\
\cline { 2 - 4 } & Cefazolina & $1 \mathrm{~g}$ & $50 \mathrm{mg} / \mathrm{kg}$ \\
\cline { 2 - 4 } & Ceftriaxona & $1 \mathrm{~g}$ & $50 \mathrm{mg} / \mathrm{kg}$ \\
\cline { 2 - 4 } & Clindamicina & $600 \mathrm{mg}$ & $20 \mathrm{mg} / \mathrm{kg}$ \\
\cline { 2 - 4 } & Cefazolina & $1 \mathrm{~g}$ & $50 \mathrm{mg} / \mathrm{kg}$ \\
\cline { 2 - 4 } & Ceftriaxona & $1 \mathrm{~g}$ & $50 \mathrm{mg} / \mathrm{kg}$ \\
\hline
\end{tabular}

Fonte: American Heart Association.

\section{DISCUSSÃO}

A presença de focos infecciosos na cavidade bucal pode desencadear complicações pós-operatórias, pois a incidência de bacteremias odontogênicas aumenta significativamente na presença de doença periodontal e lesões endodônticas (GUALANDRO et al., 2017). As condições de saúde bucal dos pacientes em préoperatório cardiovascular revelam elevados índices de necessidade de tratamento odontológico, indicando uma considerável lacuna no atendimento (ALFONSín et al., 2019). No Brasil, a taxa de morbidade dentária auto referida é de $75,2 \%$ na faixa etária de 35 a 44 anos e 46,6\% na faixa etária de 65 a 74 anos (BRASIL, 2012).

Os cirurgiões dentistas nem sempre são informados sobre o momento de intervenção e os médicos cardiologistas geralmente não têm ciência da importância e complexidade do tratamento odontológico que o paciente necessita (GANDHI \& SILVAY, 2015).

Os estudos demonstram que ainda não existe um protocolo padrão estabelecido para o atendimento odontológico direcionado a pacientes que serão submetidos a cirurgias cardíacas, como também mostra o estudo de Cotti et al. (2019). Extrações de dentes infeccionados no pré-operatório de cirurgia cardíaca são indicadas com certa frequência para diminuir os riscos de infecções sistêmicas importantes (RAO et al., 2020; 
AMARAL JÚNIOR et al., 2020). Contudo, o estudo de Smith et al. (2014) mostrou que 8\% dos pacientes que foram submetidos a exodontias desenvolveram resultados adversos antes ou depois da cirurgia cardíaca, como acidente vascular cerebral, síndrome coronariana aguda e óbito. Pacientes submetidos à cirurgia de prótese valvar apresentam risco elevado de desenvolvimento de endocardite bacterina, o tratamento periodontal pré-operatório tem a capacidade de melhorar o estado de saúde bucal dos pacientes antes e depois da cirurgia, desta forma, pacientes que tem todos os focos infecciosos eliminados apresentam febre durante menos dias (SUZUKI et al., 2019; RAO et al., 2020).

A condição de saúde oral deficiente dos pacientes é proveniente, principalmente, do acesso deficiente aos serviços de odontologia (AMARAL et al., 2016). Por isso é importante a inclusão de ambulatórios odontológicos em unidades hospitalares para a realização dos procedimentos conforme as portarias 1032 , de 5 de maio de 2010 e 526, de 24 de junho de 2020 do Ministério da Saúde (BRASIL, 2010; BRASIL, 2020). Desta forma, os cirurgiões dentistas tornam-se membros regulares envolvidos no processo de preparação cirúrgica (COTTI et al., 2017).

Os cuidados e a educação em saúde motivam o paciente a alcançar condições de saúde adequadas (SUZUKI et al., 2019). Estes devem ser orientados quanto a relação entre a saúde bucal e a saúde sistêmica, pois os hábitos de higiene pessoal diários são o fator mais importante para manutenção de uma saúde adequada, além do acompanhamento regular por um cirurgião dentista (KUMAR \& RAI, 2018; GUALANDRO et al., 2017).

É importante destacar que os pacientes devem ser tratados como um todo, não sendo reduzidos a diagnósticos anatômicos, para isso, é fundamental a interação entre os profissionais de odontologia e outras áreas da saúde para a tomada de decisões quanto a realização de procedimentos (FONSECA et al., 2016). É necessário que haja fortalecimento do sistema de referência e contra referência em saúde, pois permite que os profissionais tenham conhecimento do histórico de saúde do paciente e facilita a realização de exames de imagem (ANDRADE, 2019). 


\section{CONSIDERAÇÕES FINAIS}

Existem controvérsias entre os diversos protocolos de atendimento odontológico em pré-operatório de cirurgias cardiovasculares, portanto, mais estudos são necessários para estabelecimento de um protocolo padrão que direcione os profissionais quanto as intervenções odontológicas que devem ser realizadas e o momento mais adequado para isso. As necessidades dos pacientes devem ser avaliadas pelo cirurgião dentista em conjunto com os demais profissionais da equipe médica, visando um transoperatório livre de intercorrências.

\section{REFERÊNCIAS}

AKASHI, M. et al. Perioperative intervention by oral medicine team in cardiovascular surgery patients. General Thoracic and Cardiovascular Surgery, Japão, v. 2, n. 67, p. 197202, 5 out. 2018. DOI 10.1007 / s11748-018-1020-0. Disponível em: https://link.springer.com/article/10.1007/s11748-018-1020-0\#citeas. Acesso em: 15 maio 2021.

ALFONSÍN, A. E. et al. Dynamics of the medical-dental relationship in a University Hospital in Buenos Aires, Argentina. Acta Odontol. Latinoam., Buenos Aires, v. 32, n. 2, p. 5764, $2019 . \quad$ Disponível em: http://www.scielo.org.ar/scielo.php?script=sci_arttext\&pid=S1852$48342019000200002 \&$ Ing=es\&nrm=iso. Acesso em: 15 maio 2021.

AMARAL JÚNIOR, O. L. et al. A atuação da odontologia hospitalar em uma unidade cardiovascular intensiva. Extensio: Revista Eletrônica de Extensão, Florianópolis, v. 17, n. 36, p. 33-40, ago. 2020. DOI 10.5007 / 1807-0221.2020v17n36p33. Disponível em: $\quad<$ https://antigo.periodicos.ufsc.br/index.php/extensio/article/view/18070221.2020v17n36p33/43985>. Acesso em: 15 maio 2021.

AMARAL, C. O. F. et al. Oral health evaluation of cardiac patients admitted to cardiovascular pre-surgery intervention. Rev Gaúch. Odontol., Campinas, v. 64, n. 4, p. 33-40, 2016. DOI 10.1590/1981-863720160003000082979. Disponível em: https://www.scielo.br/j/rgo/a/XyR5hWdYBnFQJcX3vHHtVnz/?lang=en. Acesso em: 17 maio 2021.

ANDRADE, L. de S.; FRANCISCHETTI, I. Referência e Contrarreferência: Compreensões e Práticas. Saúde e Transformação Social, Florianópolis, v. 10, n. 1/2/3, p. 54-63, 2019. Disponível

em: http://incubadora.periodicos.ufsc.br/index.php/saudeetransformacao/article/view /5281/5636. Acesso em: 02 junho 2021. 
BRASIL. Ministério da Saúde. Secretaria de Atenção à Saúde. Secretaria de Vigilância em Saúde. SB Brasil 2010: Pesquisa Nacional de Saúde Bucal: resultados principais. Brasília: Ministério da Saúde; 2012.

BRASIL. Ministério da Saúde. Gabinete do Ministro. Portaria no 1.032, de 05 de maio de 2010. Brasília, 2010. Inclui procedimento odontológico na Tabela de Procedimentos, Medicamentos, Órteses e Próteses e Materiais Especiais do Sistema Único de Saúde - SUS, para atendimento às pessoas com necessidades especiais. Diário Oficial da União. Brasília, DF, 2010.

BRASIL. Ministério da Saúde. Secretaria de Atenção Especializada à Saúde. Portaria n 526, de 24 de junho de 2020. Inclui, altera e exclui procedimentos da Tabela de Procedimentos, Medicamentos, Órteses, Próteses e Materiais Especiais do SUS. Diário Oficial da União. Brasília, DF, 02 de jul. 2020.

CARRIZALES-SEPÚLVEDA, E. F. et al. Periodontal Disease, Systemic Inflammation and the Risk of Cardiovascular Disease. Heart Lung Circ., Austrália, v. 27, n. 11, p. 1327 1334, 2018. DOI 10.1016/j.hlc.2018.05.102. Disponível em: https://www.heartlungcirc.org/article/S1443-9506(18)30597-3/fulltext. Acesso em: 20 maio 2021.

CHEE, F. Y.; HOW, C. H. Doctor, my dentist wants your opinion. Singapore Med J., Singapura, v. 54, n. 1, p. 11-14, 2013. DOI 10.11622/smedj.2013004. Disponível em: http://www.sma.org.sg/Uploadedlmg/files/SMJ/5401/5401practice1.pdf. Acesso em: 21 maio 2021.

COTTI, E. et al. The perioperative dental screening and management of patients undergoing cardiothoracic, vascular surgery and other cardiovascular invasive procedures: A systematic review. Eur J Prev Cardiol., [s.I.], v. 24, n. 4, p. 409-425, $2017 . \quad$ DOI 10.1177/2047487316682348. Disponível em: https://academic.oup.com/eurjpc/article/24/4/409/5926781. Acesso em: 22 maio 2021.

COTTI, E. et al. Perioperative dental screening and treatment in patients undergoing cardiothoracic surgery and interventional cardiovascular procedures. A consensus report based on RAND/UCLA methodology. Int J Cardiol., [s.I.], v. 292, n. 1, p. 78-86, 2019. DOI 10.1016/j.ijcard.2019.06.041. Disponível em: https://www.internationaljournalofcardiology.com/article/S0167-5273(19)330852/fulltext. Acesso em: 22 maio 2021.

DA SILVA, P. L. N.; DAMASCENO, R. F. Infecções hospitalares em pacientes submetidos à cirurgia cardíaca: uma revisão das incidências quanto aos fatores de risco póscirurgia. Journal of Management \& Primary Health Care, Uberlandia, v. 12, n. 1, p. 1-23, 2020. DOI 10.14295/jmphc.v12.462 Disponível em: https://www.jmphc.com.br/jmphc/article/view/462. Acesso em: 22 maio 2021.

FOLWACZNY, M.; BAUER, F.; GRÜNBERG C. Significance of oral health in adult patients with congenital heart disease. Cardiovasc Diagn Ther., Hong Kong, v. 9, n. 2, p. 377-387, 
2019. DOI 10.21037/cdt.2018.09.17. Disponível em:

https://cdt.amegroups.com/article/view/21794/26218. Acesso em: 23 maio 2021.

FONSECA, G. S. et al. A clínica do corpo sem boca. Saude soc., São Paulo, v. 25, n. 4, p. 10391049, dez. 2016. DOI 10.1590/s0104-12902016163946. Disponível em http://www.scielo.br/scielo.php?script=sci_arttext\&pid=S0104-

12902016000401039\&lng=en\&nrm=iso. Acesso em: 24 maio 2021.

GANDHI, N.; SILVAY, G. How important is dental clearance for elective open heart operations? Annals of Thoracic Surgery, Chicago, v. 99, n. 1, p. 377, jan. 2015. DOI 10.1016/j.athoracsur.2014.04.145. Disponível em: https://www.annalsthoracicsurgery.org/article/S0003-4975(14)01496-9/fulltext. Acesso em: 5 junho 2021.

GHEORGHITA, D. et al. A fogágybetegség mint az atheroscleroticus cardiovascularis betegség rizikófaktora. Orvosi Hetilap., Budapeste, v. 160, n. 11, p. 419-42, mar. 2019. DOI 10.1556/650.2019.31301. Disponível em: https://akjournals.com/configurable/content/journals\$002f650\$002f160\$002f11\$ 002farticle-

p419.xml?t:ac=journals\%24002f650\%24002f160\%24002f11\%24002farticlep419.xml. Acesso em: 24 maio 2021.

GUALANDRO, D. M. et al. 3a Diretriz de Avaliação Cardiovascular Perioperatória da Sociedade Brasileira de Cardiologia. Arq Bras Cardiol 2017, Rio de Janeiro, v. 109, n. 3, p. 1-104, 2017. DOI 10.5935/abc.20170140. Disponível em: http://publicacoes.cardiol.br/2014/diretrizes/2017/01_DIRETRIZ_AVALIACAO.asp. Acesso em: 25 maio 2021.

HABIB, G. et al. ESC Scientific Document Group, 2015 ESC Guidelines for the management of infective endocarditis: The Task Force for the Management of Infective Endocarditis of the European Society of Cardiology (ESC) Endorsed by: European Association for Cardio-Thoracic Surgery (EACTS), the European Association of Nuclear Medicine (EANM), European Hearth Journal, [s.I.], v. 36, n. 44, p. 30753128, 2015. DOI 10.1093/eurheartj/ehv319. Disponível em: https://academic.oup.com/eurheartj/article/36/44/3075/2293384. Acesso em: 1 junho 2021.

JENKINS, G. W. et al. What is the role of the oral and maxillofacial department in the preoperative management of patients awaiting cardiac operations? $\mathbf{B r} \mathbf{J}$ Oral Maxillofac Surg., Reino Unido, v. 53, n. 5, p. 442-445, 2015. DOI 10.1016/j.bjoms.2015.02.013. Disponível em: https://www.bjoms.com/article/S0266-4356(15)00066-2/fulltext. Acesso em: 26 maio 2021.

KUMAR, A.; RAI, A. Oral Health Status, Health Behaviour and Treatment Needs of Patients Undergoing Cardiovascular Surgery. Brazilian Journal of Cardiovascular Surgery, São Paulo, v. 33, n. 2, p. xxx, 2018. DOI 10.21470/1678-9741-2017-0137. Disponível em: Acesso em: 27 maio 2021. 
MILLOT, S. et al. Position paper for the evaluation and management of oral status in patients with valvular disease: Groupe de Travail Valvulopathies de la Société Française de Cardiologie, Société Française de Chirurgie Orale, Société Française de Parodontologie et d'Implantologie Orale, Société Française d'Endodontie et Société de Pathologie Infectieuse de Langue Française. Archives of Cardiovascular Diseases, Paris, v. 110 n. 8-9, p. 482-494, 2017. DOI 10.1016/j.acvd.2017.01.012. Disponível em:

https://www.sciencedirect.com/science/article/pii/S1875213617301134?via\%3Dih ub. Acesso em: 29 maio 2021.

PEDERSEN, P. U.; LARSEN, P.; HÅKONSEN, S. J. The effectiveness of systematic perioperative oral hygiene in reduction of postoperative respiratory tract infections after elective thoracic surgery in adults: a systematic review. JBI Database System Rev Implement Rep., Adelaide, v. 14, n. 1, p. 140 - 173, 2016. DOI 10.11124/jbisrir-2016-2180. Disponível em: https://journals.Iww.com/jbisrir/Abstract/2016/01000/The_effectiveness_of_syste matic_perioperative_oral.12.aspx. Acesso em: 29 maio 2021.

RAO, N. R. et al. Preoperative dental screening prior to cardiac valve surgery and 90-day postoperative mortality. J Card Surg., [s.I.], v. 35, n. 11, p. $2995-3003,2020$. DOI 10.1111/jocs.14957. Disponível em: file:///E:/Artigos/1.\%20Rao,\%202020.pdf. Acesso em: 30 maio 2021.

SMITH, M. M. al. Morbidity and Mortality Associated with Dental Extraction Before Cardiac Operation. Annals of Thoracic Surgery, Chicago, v. 97, n. 3, p. 838-844, mar. 2014. DOI 10.1016 / j.athoracsur.2013.10.034. Disponível em: https://www.annalsthoracicsurgery.org/article/S0003-4975(13)02348-5/fulltext. Acesso em: 06 junho 2021.

SUZUKI, $\mathrm{H}$. et al. Preoperative periodontal treatment and its effects on postoperative infection in cardiac valve surgery. Clin Exp Dent Res., [s.I.], v. 5, n. 5, p. 485-490, 2019. DOI 10.1002/cre2.212. Disponível em: https://onlinelibrary.wiley.com/doi/10.1002/cre2.212. Acesso em: 30 maio 2021.

WILSON, W. et al. Prevention of infective endocarditis: guidelines from the American Heart Association: a guideline from the American Heart Association Rheumatic Fever, Endocarditis, and Kawasaki Disease Committee, Council on Cardiovascular Diseases in the Young, and the Council on Clinical Cardiology, Council on Cardiovascular Surgery and Anesthesia, and the Quality of Care and Outcomes Research Interdisciplinary Working Group. Circulation, Dallas, v. 116, n. 15, p. 1736-1754, 2007. DOI 10.1161 /CIRCULAÇÃOAHA.106.183095. Disponível em: https://www.ahajournals.org/doi/10.1161/CIRCULATIONAHA.106.183095?url_ver= Z39.88-2003\&rfr_id=ori:rid:crossref.org\&rfr_dat=cr_pub\%20\%200pubmed. Acesso em: 1 junho 2021. 


\title{
CAPITULO XXIII \\ CUIDADOS PALIATIVOS NA ODONTOLOGIA
}

\author{
DOI: 10.51859/AMPLLA.EPC757.1121-23
}

\author{
Sâmia Mendes Furtados ${ }^{1}$ \\ Wendel Chaves Carvalho ${ }^{2}$ \\ Antônio Fabrício Alves Ferreira ${ }^{3}$ \\ Silvia Milena Martins ${ }^{4}$ \\ Gerson Luís Castro Ferreira ${ }^{5}$ \\ Mayra Moura Franco ${ }^{6}$
}

\begin{abstract}
${ }^{1}$ Graduanda do curso de Odontologia. Faculdade Pitágoras de São Luís - MA.
${ }^{2}$ Graduando do curso de Odontologia. Faculdade Pitágoras de São Luís - MA.

${ }^{3}$ Graduando do curso de Odontologia. Faculdade Pitágoras de São Luís - MA.

${ }^{4}$ Graduanda do curso de Odontologia. Universidade Potiguar de Caicó-RN.

${ }^{5}$ Graduando do curso de Odontologia. Centro Universitário Dom Bosco - UNDB, São Luís - MA.

${ }^{6}$ Doutora e Mestre em Odontologia pela Universidade Federal do Maranhão. Especialista em Periodontia pela Faculdade Sete Lagoas. Especialista em Educação a Distância pela Universidade Católica Dom Bosco. Especialista em Saúde Coletiva e da Família pela Faculdade São Leopoldo Mandic. Especialista em Odontologia do Trabalho pela Faculdade Serrana de Ensino Superior (FASEP). Atualmente professora do Curso de Odontologia da Universidade CEUMA e Faculdade Pitágoras.
\end{abstract}

\section{RESUMO}

A higiene bucal é um dos componentes mais importantes da qualidade de vida e do bem-estar, portanto, deve ser uma garantia de vida para o paciente terminal que necessita de cuidados paliativos. É compreensível que um paciente em estágio avançado ou em estado de doença progressiva requeira a máxima atenção de todos os profissionais de saúde envolvidos em seu cuidado e devam trabalhar juntos para proporcionar o melhor tratamento possível. Portanto, os profissionais devem atuar da melhor forma para tratar e proporcionar conforto aos pacientes. Dessa forma, o objetivo geral deste trabalho foi demonstrar a importância da inserção e promoção de cuidados paliativos na área da odontologia. Assim, foi realizado um trabalho de revisão bibliográfica, qualitativo e descritivo, com materiais publicados do período de 2000 a 2020, por meio de busca ativa de informações nas seguintes bases de dados: Biblioteca Científica Eletrônica Online (Scientific Electronic Library Online-SciELO), Google Acadêmico, Medline e Catálogo de Teses e Dissertações. Foram incluídos estudos transversais, longitudinais e revisões de literatura, em português e inglês. Foram excluídos trabalhos sem o texto completo disponível. Com o avanço da ciência e o aumento da expectativa de vida, uma odontologia com foco em cuidados paliativos está gradativamente transformando um novo campo de atuação para o dentista. Portanto, deve haver um cirurgião-dentista na equipe multidisciplinar do hospital. Seria necessária também a implantação de um programa de treinamento teórico - prático em saúde bucal, principalmente relacionado às doenças terminais, entre os profissionais de saúde e que fazem parte da equipe multiprofissional para os Cuidados Paliativos.

Palavras-chave: Cuidados Paliativos. Saúde Bucal. Assistência Odontológica. 


\section{INTRODUÇÃO}

A higiene bucal é uma das partes mais importantes quando o assunto é qualidade de vida e bem estar, portanto deve ser uma garantia na vida de pacientes portadores de doenças em estado terminal, que necessitam dos cuidados paliativos e, portanto, de uma atenção multidisciplinar o que inclui o cirurgião-dentista (CD). Em conjunto com outros profissionais, os CD trarão uma melhor qualidade de vida para esse paciente, que se encontra num estado tão delicado (WHO, 2002; LIMA, et al. 2011).

Entende-se que o CD é necessário na equipe de cuidados paliativos (CP), pois a odontologia está diretamente relacionada à qualidade de vida, porém ainda é uma área em que os profissionais da área da saúde bucal não estão frequentemente inseridos. Ao $C D$ é dada a responsabilidade de diagnosticar, prevenir, tratar ou controlar qualquer patologia do sistema oral do paciente, antes e durante o tratamento médico. Existe uma variedade de doenças bucais que se manifestam em pacientes portadores de doenças terminais em tratamento como, por exemplo, a xerostomia, condição comum em pacientes que fazem radioterapia (HESPANHOL, et al 2010; LIMA, et al., 2021).

Compreende-se que um paciente em estado terminal ou em estado de doença progressiva requer o máximo de atenção de todos profissionais da saúde relacionados aos cuidados deste, e devem trabalhar juntos para oferecer o melhor tratamento possível, visto que o ser humano é complexo e repleto de necessidades. Sendo assim, os profissionais devem trabalhar na melhor maneira de tratar e oferecer conforto para seus pacientes, principalmente os que se encontram em estado de doença terminal e hospitalizados (HERMES, et al 2013). Nesse contexto, qual a importância da inserção dos cuidados paliativos na odontologia?

A inserção dos cuidados paliativos na odontologia é indispensável, pois é uma abordagem que gera melhoras na qualidade de vida de pacientes e seus familiares que enfrentam problemas associados às doenças crônicas progressivas e que ameaçam a vida. A odontologia com foco em cuidados paliativos está surgindo agora como um novo campo de atuação para os cirurgiões-dentistas por conta dos avanços científicos e do aumento da expectativa de vida. Portanto, se faz necessária a presença dos cirurgiõesdentistas nas equipes multidisciplinares dos hospitais (AMARAL, et al., 2013; LIMA, et al., 2021). 
Dessa forma, o objetivo geral deste trabalho foi demonstrar a importância da inserção e promoção de cuidados paliativos na área da odontologia e, especificamente, descrever o conceito e os princípios dos cuidados paliativos, estudar as indicações de quando devem ser aplicados os cuidados paliativos e discutir o impacto gerado pela promoção de cuidados paliativos na saúde bucal de pacientes e o papel do cirurgiãodentista nesse âmbito. Assim, foi realizado um trabalho de revisão bibliográfica, qualitativo e descritivo, com materiais publicados do período de 2000 a 2020, por meio de busca ativa de informações nas seguintes bases de dados: Biblioteca Científica Eletrônica Online (Scientific Electronic Library Online-SciELO), Google Acadêmico, Medline e Catálogo de Teses e Dissertações. A busca foi realizada utilizando-se os termos "cuidados paliativos"; "saúde bucal"; "assistência odontológica". Foram incluídos estudos transversais, longitudinais e revisões de literatura, em português e inglês. Foram excluídos trabalhos sem o texto completo disponível.

\section{REVISÃO BIBLIOGRÁFICA}

\subsection{CONCEITO E PRINCÍPIOS DOS CUIDADOS PALIATIVOS}

Cuidado Paliativo é a abordagem que promove qualidade de vida de pacientes e seus familiares diante de doenças que ameaçam a continuidade da vida, através de prevenção e alívio do sofrimento. Requer a identificação precoce, avaliação e tratamento impecável da dor e outros problemas de natureza física, psicossocial e espiritual (OMS, 2002).

Os cuidados paliativos surgiram como uma abordagem terapêutica centrada no alívio do sofrimento, diante de doenças que ameaçam a vida. Está norteada por princípios em que se busca o alívio da dor, bem como de outros problemas de natureza física, psicossocial e espiritual. Nessa perspectiva, para o enfrentamento da doença, uma equipe interdisciplinar deve estar habilitada para ajudar o paciente e sua família no que diz respeito às mudanças causadas pela doença (HERMES; LAMARCA, 2013).

Um dos focos dos profissionais é cuidar também dos familiares, pois "a família experiencia, assim como o doente, de um período de muitas dúvidas e se depara com uma situação para a qual não se preparou previamente" (COSTA et al., 2019). Os Cuidados Paliativos não estão relacionados somente à pacientes com câncer, também 
abrangem pacientes com enfermidades de outras áreas e de diversas faixas etárias como pediatria, geriatria, com HIV/AIDS, doenças crônicas e outras (DAVIES; HIGGINSON, 2004).

A OMS publicou em 1990 e revisou em 2002, os princípios que regem a atuação da equipe multiprofissional de Cuidados Paliativos:

\begin{abstract}
1- Promover o alívio da dor e de outros sintomas desagradáveis. 2- Afirmar a vida e considerar a morte um processo normal da vida. 3- Não acelerar nem adiar a morte. 4- Integrar os aspectos psicológicos e espirituais no cuidado ao paciente. 5- Oferecer um sistema de suporte que possibilite ao paciente viver tão ativamente quanto possível até o momento da sua morte. 6- Oferecer sistema de suporte para auxiliar os familiares durante a doença do paciente e o luto. 7- Oferecer abordagem multiprofissional para focar as necessidades dos pacientes e seus familiares, incluindo acompanhamento no luto. 8Melhorar a qualidade de vida e influenciar positivamente o curso da doença. 9- Iniciar o mais precocemente possível o Cuidado Paliativo, juntamente com outras medidas de prolongamento da vida, como quimioterapia, radioterapia, e incluir todas as investigações necessárias para melhor compreender e controlar situações clínicas estressantes. Pela primeira vez, uma abordagem inclui a espiritualidade entre as dimensões do ser humano. A família é lembrada e assistida após a morte do paciente, no período de luto. No Brasil os primeiros serviços de cuidados paliativos iniciaram na década de 80 (GOMES; OTHERO, 2016, p.155).
\end{abstract}

“O termo 'palliare' também tem origem no latim e significa proteger, amparar, cobrir, abrigar, ou seja, a perspectiva de cuidar e não somente curar surge amplamente, trazendo a essência da medicina como foco principal" (MELO, 2008).

Os Cuidados Paliativos em odontologia caracterizam-se pelo manejo de pacientes portadores de doenças ativas, progressivas ou avançadas, em função do envolvimento direto ou não da cavidade oral pela doença ou seu tratamento e que prioriza a qualidade de vida do paciente (PORTAL DA EDUCAÇÃO, 2016). Desta maneira, "uma conduta abrangente e completa se torna essencial para atender de forma satisfatória às inúmeras necessidades dos pacientes terminais, permitindo uma morte digna" (RIVIERA-FLORES, 2015).

Apesar de comumente ser visto como o cuidado oferecido a doentes que não recebiam qualquer tratamento ativo e que iriam de fato morrer da doença, os cuidados paliativos são igualmente aplicáveis à fase inicial, para a doença potencialmente curável, como para fase terminal de uma doença com risco de vida, se estendendo ao período de luto após a morte do paciente (SEPÚLVEDA et al., 2002). 
A prática dos Cuidados Paliativos baseia-se no controle dos sintomas de natureza física, psicológica, social e espiritual, tendo como base os seguintes princípios (NETO, 2006):

- Avaliar antes de tratar;

- Explicar as causas dos sintomas;

- Não esperar que um doente se queixe;

- Adotar uma estratégia terapêutica mista;

- Monitorizar os sintomas;

- Avaliar regularmente as medidas terapêuticas;

- Cuidar dos detalhes;

- Estar disponível.

A aplicação dos Cuidados Paliativos deve ser ajustada a cada país ou região de acordo com aspectos relevantes como: acessibilidade de recursos materiais e humanos, tipo de planejamento em saúde existente, características culturais e sociais da população atendida. Algumas definições sugeridas foram desenvolvidas a partir de discussões em grupos de trabalho, como o formado no Conselho Regional de Medicina do Estado de São Paulo e na Academia Nacional de Cuidados Paliativos (ANCP, 2007). Não são normas ou imposições oficiais, mas podem servir como sugestão para a formulação de políticas locais de Cuidados Paliativos.

Paciente terminal: A literatura mundial o define de formas diferentes, como a existência de doença incurável, o período compreendido entre o final do tratamento curativo e a morte, ou, ainda, como a fase designada como processo de morte, que inclui duas fases distintas: últimas semanas de vida e últimas horas de vida.

Paciente elegível para Cuidados Paliativos: A pessoa portadora de doença crônica, evolutiva e progressiva, com prognóstico de vida supostamente encurtado a meses ou ano. Em doenças de progressão lenta como o Mal de Alzheimer, algumas síndromes neurológicas e determinados tipos de tumor, considera-se o período de alta dependência para as atividades de vida diária, com possibilidade de um prognóstico superior a um ano de vida.

Paciente em processo de morte: Aquele que apresenta sinais de rápida progressão da doença, com prognóstico estimado a semanas de vida a mês. 
Fase final da vida: Aquele período em que supostamente o prognóstico de vida pode ser estimado em horas ou dias.

Paliação: Toda medida que resulte em alívio de um sofrimento do doente.

Ação paliativa: Qualquer medida terapêutica, sem intenção curativa, que visa diminuir, em ambiente hospitalar ou domiciliar, as repercussões negativas da doença sobre o bem-estar do paciente. É parte integrante da prática do profissional de saúde, independente da doença ou de seu estágio de evolução.

Os cuidados paliativos também se estendem às áreas além dos métodos tradicionais, como avaliação social e questões éticas no final da vida. Eles podem e devem ser fornecidos ao doente juntamente com os tratamentos modificadores da doença (WILSON et al., 2007).

\section{QUANDO EMPREGAR OS CUIDADOS PALIATIVOS}

De acordo com o estudo de Costa e Othero (2014), a prevenção e o controle dos sintomas é o "núcleo duro" da assistência em cuidados paliativos. Embora cada área profissional tenha sua especificidade, cada membro da equipe deve ser capaz de reconhecer os sintomas e compreender as técnicas e / ou recomendações básicas de gestão. Ouvir, apoiar e orientar os familiares são conteúdos inerentes ao cuidado.

O cuidar para com o sofrimento humano é a essência dos cuidados paliativos, sendo a forma de transmissão dos conhecimentos dos profissionais que atendem nessa área, independentemente de onde o paciente se encontre. Juntamente com o cuidar do indivíduo com uma doença incurável, progressiva e que ameaça a vida, é necessária uma atenção especial aos familiares, portanto, deve-se entender como uma unidade de cuidado com o paciente e sua família. A família é o alicerce fundamental na vida destas pessoas que passam a conviver com uma doença crônica e muitas vezes em cuidados de fim da vida (COSTA et al, 2019).

O atendimento em Cuidados Paliativos deve ser realizado por uma equipe multidisciplinar e interdisciplinar de maneira humanizada e personalizada. O seu foco não é a cura da doença, mas sim, o cuidado da pessoa de forma integral. Portanto, é importante que os nutricionistas, fonoaudiólogos, psicólogos, médicos, enfermeiros, fisioterapeutas, terapeutas ocupacionais, dentistas, assistentes sociais, entre outros 
profissionais da saúde, estejam em sintonia em relação a o tratamento (SAAR; TREVISAN, 2007).

Autonomia e independência, aspectos fundamentais da reabilitação, são metas importantes da assistência em cuidados paliativos. Mesmo antes da definição da OMS, Twycross (2000), apontou que os pacientes devem ser ajudados a atingir seu pleno potencial, com foco em proporcionar dignidade e autoestima, ao invés de focar em realizar coisas.

Durante muito tempo os cuidados paliativos foram entendidos como uma abordagem feita ao paciente terminal "quando não havia mais nada a fazer". O entendimento atual é que os cuidados paliativos podem ser uma opção terapêutica definida inclusive no momento do diagnóstico de uma doença que ameaça a vida, sendo, portanto, decisão a ser tomada em conjunto pelo paciente, seus familiares ou pessoas mais próximas de sua confiança, e a equipe de saúde envolvida (MACIEL, 2008).

Dentre os $\mathrm{CP}$, os tratamentos das complicações bucais estão entre os mais importantes e necessários para o paciente que possui poucos dias de vida. Considerando que uma parcela importante de PT manifesta complicações bucais, estas são resultados de diversos os efeitos colaterais dos tratamentos de quimioterapia e radioterapia. As complicações que levam a alterações bucais mais comuns em pacientes oncológicos terminalmente doentes são: mucosite, estomatite, náuseas, vômitos, candidíase, deficiência nutritiva, desidratação, alteração do paladar e xerostomia (WISEMAN, 2006).

A parcela da população mais acometida por doenças progressivas e crônicas são os idosos, muitas vezes por doenças neurodegenerativas. Essas patologias muitas vezes os deixam acamados, seja em domicílio ou em hospitais, por longos períodos. Em doenças de progressão lenta, como a Doença de Alzheimer, algumas síndromes neurológicas, e determinados tipos de tumor, considera-se o período de alta dependência para as atividades de vida diária, com prognóstico superior a um ano de vida como um paciente elegível para os cuidados paliativos (MACIEL, 2008).

Os cuidados paliativos tentam ser uma resposta e um caminho entre os tratamentos "agressivos" ou vida intensiva e "prolongada", ajuda a ter "uma vida digna até a morte", mais do que uma "morte digna". Isso é conseguido com o manuseio adequado do dor e todos os outros sintomas incômodos, como astenia, dispneia, náusea, etc. Os cuidados paliativos permitem que o paciente se sinta no controle e aliviar a dor e também fortalecer os relacionamentos com entes queridos e eles asseguram conforto para estes. 
O imperativo categórico kantiano enfatiza a necessidade de tratar pessoas como fins e não como instrumentos, respeitando-os e respeitando seus autonomia e sua racionalidade. Um bom modelo pode ser o contratual, onde exerce, por um lado, a autoridade ética e de conhecimento por parte do médico, em conjunto à livre responsabilidade do paciente (DE SIMONE; TRIPODORO, 2006, p.4).

Para se concretizar o objetivo de oferecer a todos os que necessitem cuidados paliativos de qualidade, é necessária uma estratégia pública que disponibilize a melhor abordagem com base no mais elevado conhecimento científico e perícias suportadas em cuidados de saúde baseados na evidência, com um elevado grau de efetividade. Para melhorar a eficiência, é necessária uma comunicação adequada entre o setor público de saúde e os serviços prestados por entidades privadas ou outras (comunidades, etc.), e a participação da comunidade / sociedade sem dúvida aumentará a eficiência (STJERNSWARD; FOLEY; FERRIS; 2007).

Os tratamentos curativos e paliativos não são mutuamente exclusivos, mas é uma questão de ênfase. Assim, os profissionais irão gradualmente aplicar um maior número e proporção de medidas paliativas quando a doença progride e o paciente para de responder a um tratamento específico. Em alguns tipos de câncer, isso acontece mais cedo do que em outros, por exemplo, câncer de pulmão escamoso em comparação com alguns tumores hematológicos (SECPAL, 2014).

Uma forma de medir o declínio funcional e clínico do paciente é a escala de desempenho de Karnofsky que foi desenvolvida para pacientes com câncer como um meio objetivo de documentar a evolução patológica do paciente, avaliando a capacidade de realizar determinadas atividades básicas. A maioria dos pacientes com uma escala Karnofsky inferior a 70\% tem indicação precoce de assistência de Cuidados Paliativos. Desempenho de $50 \%$ nesta escala é um indicador de terminalidade, reafirmando que estes são pacientes elegíveis para Cuidados Paliativos, a menos que exista um ganho previsivelmente benéfico em sustentar terapia para a doença de base, que seja simultaneamente disponível e possam ser tolerados (MATSUMOTO, 2012).

Vale ressaltar que todos os pacientes com indicação de transplante de órgãos sólidos (incluindo transplante de coração) são candidatos oficiais aos cuidados paliativos, pois estão sofrendo da doença e podem ter experimentado graves sintomas de desconforto. Doença cardiovascular crônica traz muita dor ao paciente, a morte geralmente ocorre em hospitais. Embora essa tendência possa corresponder às 
preferências dos pacientes e seus familiares, os pacientes com doenças cardiovasculares são aqueles que recebem menos assistência domiciliar e cuidados paliativos (MATSUMOTO, 2012).

\section{CUIDADOS PALIATIVOS NA SAÚDE BUCAL DE PACIENTES E O PAPEL DO CIRURGIÃO-DENTISTA NESSE ÂMBITO}

A presença de um cirurgião-dentista se faz necessária na equipe de cuidados paliativos, pois muitas afecções podem estar presentes na cavidade bucal de pacientes críticos, desde o acúmulo de biofilme, por deficiência de higiene, bem como a presença de cáries, doença periodontal, lesões traumáticas, além de outras lesões precursoras de infecções virais e fúngicas sistêmicas (RABELO; QUEIROZ; SANTOS, 2010).

Para estas condições serem adequadamente tratadas, faz-se necessária a presença de um cirurgião dentista em âmbito hospitalar como suporte no diagnóstico das alterações bucais e como coadjuvante na terapêutica médica; seja na atuação em procedimentos emergenciais frente aos traumas, em procedimentos preventivos quanto ao agravamento da condição sistêmica ou o surgimento de uma infecção hospitalar, e procedimentos curativos e restauradores na adequação do meio bucal e maior conforto ao paciente (ABIDIA, 2007).

A cavidade bucal tem vital importância no bem estar, pois está diretamente ligada às questões de saúde nutricional, sendo a preservação da capacidade de alimentação via oral uma das metas a serem alcançadas. Mesmo pacientes com suporte nutricional de gastrostomia podem ser beneficiados pela alimentação de conforto, que é a possibilidade de manter o prazer de saborear um alimento de sua preferência. A odontologia deve estar presente na equipe de cuidados paliativos, porque a boca pode estar sendo afetada diretamente pela doença, como as diferentes formas de câncer na região maxilo-facial, bem como sofrer efeitos colaterais de tratamento de várias outras doenças que não sejam de origem bucal, como exemplo a mucosite desenvolvida após o tratamento com quimioterápicos (FRIEDMAN, 2014).

Os cuidados com o paciente "englobam, neste, os estados físico, nutricional, emocional, espiritual e fisiológico do paciente, definindo o tipo de tratamento odontológico a ser preconizado, assim como sua aplicação ou não" (MARINI et al, 2018, 
p.158). O manual de cuidados paliativos, publicado pela Academia Nacional de Cuidados Paliativos, traz que apesar dos avanços é necessário conjugar a necessidade desses doentes por problemas decorrentes do tumor, com a possibilidade de doenças odontológicas corriqueiras, várias delas infecciosas, que comprometem mais ainda a condição de saúde do paciente. Dessa forma, a participação do cirurgião-dentista contribui para o diagnóstico e os tratamentos em sua área, mas também para a realização de Cuidados Paliativos orais que possam beneficiar esses doentes. Orientar doentes e cuidadores e discutir esses aspectos com a equipe multiprofissional ajuda na integração nesse importante segmento da área da saúde (SIQUEIRA; JALES, 2009).

Um dos sintomas mais frequentes em pacientes sob CP é a xerostomia (boca seca). De acordo com a experiência registada pela Sociedade Espanhola de Cuidados Paliativos (SECPAL, 2014), cerca de 60-70\% dos doentes com doença oncológica avançada e progressiva apresentavam inúmeros problemas na boca, incluindo a secura.

Muitas vezes as medidas possíveis de tomar são de caráter puramente paliativo e assentam nos seguintes pilares fundamentais: controlar o uso de medicamentos que possam ocasionar xerostomia; controlar a doença de base, como muitas doenças que causam xerostomia não têm cura, o controle da doença de base nem sempre é linear e simples; fatores psicológicos também devem ser considerados; a hidratação oral é uma parte importante do tratamento, seja ela aplicada topicamente ou tomando grandes quantidades de água e outros líquidos pela boca (FEIO; SAPETA, 2005).

As complicações mais comuns em pacientes oncológicos associadas à cavidade bucal incluem dor, infecções virais, bacterianas e fúngicas, instabilidade de próteses dentárias, disfagia, problemas nutricionais, xerostomia, pneumonia por aspiração, estética facial e incapacidade ou prejuízo na comunicação oral. Além de úlceras, feridas tumorais, halitose, trismo, mucosite, cáries, doenças periodontais, osteorradionecrose, disgeusia, sialorreia, disfagia e desfiguração (MATSUMOTO, 2012).

Estudos já comprovaram que a melhora da higiene oral e o acompanhamento por profissional qualificado reduzem significantemente a progressão da ocorrência de doenças respiratórias entre pacientes adultos considerados de alto risco e mantidos em cuidados paliativos, e principalmente, os pacientes internados em UTI (AZARPAZHOOH; LEAKE, 2006). 
Além dos cuidados de suporte para garantir a saúde bucal, proteção contra infecções e dores, os dentistas também contribuem com intervenções específicas às suas áreas de atuação profissional. As complicações das doenças e dos seus tratamentos já são bem conhecidas, entretanto em pacientes em Cuidados Paliativos elas podem tomar dimensões exageradas (MATSUMOTO, 2012). As principais recomendações para os cuidados da cavidade bucal são:

\begin{abstract}
-1 Escova infantil macia para dentes e língua. É o mais eficaz mesmo em pacientes inconscientes. -2 Cotonete ou dedo indicador protegido com luva ou gaze. É mais ineficaz na remoção da placa, mas pode ser mais confortável e útil para umidificação e sinais de sangramento. -3 Mastigue abacaxi ou goma de mascar sem açúcar. -4 Para higiene após as refeições, escovação e enxágüe normais. - 5 Para umidificação, pequenos goles de água, sucos de frutas com cubos de gelo, camomila com limão (anestésico local e estimulante de saliva, respectivamente) e / ou saliva artificial à base de metilcelulose, essência de limão e água (facilmente preparável por qualquer farmacêutico). Eles devem ser usados com frequência, a cada 2-4 horas. Uma solução de base de vaselina líquida, limão, camomila e gelo é útil e eficaz em estados mais terminais ou agonizantes, pois a vaselina pode ser desagradável devido a sua viscosidade. -6 Para remover o tártaro, use peróxido de hidrogênio diluído (exceto na estomatite), perborato de sódio que não pode ser engolido, solução de bicarbonato de sódio, muito eficaz, mas de sabor desagradável (não pode ser usado em tratamentos antifúngicos) ou um pequeno fragmento de vitamina C. -7 Como anti-séptico, inibindo a formação de placa bacteriana, use uma solução de clorexidina $0,2 \%$, ou solução aquosa de iodo diluída em pequenas quantidades a cada 12 horas (embora geralmente seja desagradável). -80 uso de anestésicos locais em úlceras dolorosas antes de cada refeição, como xilocaína (lidocaína) ou topicaína em um vaporizador. -90 diagnóstico e deteç̧ão precoce de candidíase oral e o uso de solução nistatina a cada 4 horas 1 colher de sopa, enxágue e cuspa, e outra colher de sopa, enxágue e engula, e às vezes o cetoconazol por via oral. Você tem que se lembrar disso embora os sintomas desapareçam após 7 dias, é necessário continuar o tratamento por 14 dias. -10 Cuidado especial com a prótese dentária, que favorece as infecções. No caso de candidíase deve ser submerso todas as noites em solução de hipoclorito a $1 \%$, caso contrário existe metal, ou em solução de nistatina. -11 Gargarejo de iodo povidona $7,5 \%$ em casos de halitose por boca séptica e / ou neoplasia oral (SECPAL, 2014 p.31-32).
\end{abstract}

\title{
5. CONSIDERAÇÕES FINAIS
}

Os pacientes portadores de doenças em estado terminal necessitam dos cuidados paliativos e, portanto de uma atenção multidisciplinar. Incluído nessa equipe está o cirurgião-dentista, e em conjunto eles irão trazer uma melhor qualidade de vida para esse paciente que se encontra num estado tão delicado. 
O papel da odontologia é importante, pois justamente os cuidados e intervenções devem ocorrer desde o início do processo de tratamento da patologia, inclusive em simultaneidade aos outros tratamentos. O cirurgião-dentista tem a responsabilidade de realizar os procedimentos que promovam conforto, cuidados de suporte e gerenciamento de sintomas.

Com o avanço da ciência e o aumento da expectativa de vida, uma odontologia com foco em cuidados paliativos está gradativamente transformando um novo campo de atuação para o dentista. Portanto, deve haver um cirurgião-dentista na equipe multidisciplinar do hospital. Seria necessária também a implantação de um programa de treinamento teórico - prático em saúde bucal, principalmente relacionado às doenças terminais, entre os profissionais de saúde e que fazem parte da equipe multiprofissional para os Cuidados Paliativos.

\section{REFERÊNCIAS}

AMARAL, Cristhiane Olívia Ferreira do et al. Importância do cirurgião-dentista em Unidade de Terapia Intensiva: avaliação multidisciplinar. Rev. Assoc. Paul. Cir. Dent. [online]. 2013, vol.67, n.2, pp. 107-111. ISSN 0004-5276.

ABIDIA, Randa. Oral care in the intensive care unit: a review. The Journal of Contemporary Dental Practice, v. 8, p. 76-82, 2007. ACADEMIA NACIONAL DE CUIDADOS PALIATIVOS. Critérios de qualidade para os cuidados paliativos no Brasil. Rio de Janeiro: Diagraphic editora; 2007.

AZARPAZHOOH, Amir; LEAKE, James. Systematic review of the association between respiratory diseases and oral health. Journal of Periodontology, v. 77, p. 14651482, 2006.

COSTA, A. P. P.; OTHERO, M. B. Conceitos, princípios e formação em Cuidados Paliativos. In: Reabilitação em Cuidados Paliativos. Loures, Portugal: Lusodidacta, 2014. p. 23-36.

COSTA, Laura Emmanuela Lima; SUTO, Cleuma Sueli Santos; OLIVEIRA, C. C. S. SILVA, R. S. A família no contexto dos cuidados paliativos. In. SILVA, Rudval Souza; AMARAL, Juliana Bezerra; MALAGUETTI, William. Enfermagem em Cuidados Paliativos: cuidando para uma boa morte. São Paulo: Martinari, p. 261-70, 2019.

DAVIES, Elizabeth; HIGGINSON, Irene. The solid facts: palliative Care. Geneva: WHO; 2004. WHO. Definition of Palliative Care http://www.who.int/cancer/palliative/definition/en/, acessado em 18 de janeiro de 2015. 
FEIO, Madalena; SAPETA, Paula. Xerostomia em Cuidados Paliativos. Rev. Acta Med. Port. v. 18, p. 460-463, 2005.

FRIEDMAN, Paula. Geriatric dentistry caring for our aging population. Elsevier. 1 ed. 2014.

GOMES, Ana Luisa Zaniboni; OTHERO, Marilia Bense. Cuidados paliativos. Estudos Avançados, v. 30, n. 88, p. 155-166, 2016.

HERMES, Hélida Ribeiro; LAMARCA, Isabel Cristina Arruda. Cuidados Paliativos: uma abordagem a partir das categorias profissionais de saúde. Ciências e Saúde Coletiva, v. 18, n.9, p.2577-2588, 2013.

LIMA, D.C.D. et al. A importância da saúde bucal na ótica de pacientes hospitalizados. Ciência \& Saúde Coletiva, 16(Supl. 1):1173-1180, 2011

LIMA, L. C. S.; ANDALÉCIO, M. M.; ANDRADE, R. S. de; MACHADO, F. C.; NOVAIS, V. R.; CARVALHO, T. de A. . Implicações clínicas orais e a importância dos cuidados odontológicos em pacientes sob cuidados paliativos: Revisão integrativa da literatura. Research, Society and Development, $[S$. I.], v. 10, n. 9, p. e52410918356, 2021. DOI: 10.33448/rsd-v10i9.18356. Disponível em: https://rsdjournal.org/index.php/rsd/article/view/18356. Acesso em: 13 ago. 2021.

MACIEL, Maria Goretti Sales. Definições e princípios. Cuidado paliativo. CREMESP, (1I): 18-21, 2008.

MARINI, Morgana Zambiasi; ARRIEIRA, Isabel; JACOTEC, Cleusa. Relato de experiência da equipe odontológica em atenção domiciliar em um hospital-escola na cidade de Pelotas, RS, Brasil. Revista da Faculdade de Odontologia da Universidade de Passo Fundo, v. 22, n. 2, p. 158-161, 2018.

MATSUMOTO DY. Cuidados paliativos: conceito, fundamentos e princípios. In: Carvalho RT, Parsons HA. Manual de cuidados paliativos ANCP. 2a Edição. Porto Alegre: Sulina; 2012, p. 59-370.

MELO, Ana Georgia. Os Cuidados Paliativos no Brasil. Revista Brasileira de Cuidados Paliativos, v. 01, p. 5-8, 2008.

NETO, IG. Princípios e filosofia dos cuidados paliativos: manual de cuidados paliativos. Lisboa: Núcleo de Cuidados Paliativos, Centro de Bioética, Faculdade de Medicina de Lisboa: 2006.

PORTAL DA EDUCAÇÃO. Cuidados paliativos em pacientes com câncer: o papel da Odontologia. $10 \mathrm{abr}$ 2016. Disponível em: http://www.portaleducacao.com.br/odontologia/artigos/58698/cuidadospaliat 
ivos-em-p acientescom-cancer-o-papel-da-odontologia\#ixzz45oLkyvVW. Acesso em 14 março 2021.

RABELO, Gustavo Davi; QUEIROZ, Cristiane Inês; SANTOS, Paulo Sergio da Silva. Atendimento odontológico ao paciente em unidade de terapia intensiva. Arquivos Médicos, v. 2, n. 55, p. 67-70, 2010.

RIVIERA-FLORES L.G. et. al. Manejo tardio de manifestações estomatológicas em um paciente pediátrico com leucemia no terminal: Relatório de caso clínico. Acta Ped México, v. 36, n. 2, p. 97-104, 2015.

SAAR, Sandra Regina da Costa; TREVISAN, Maria Auxiliadora. Papéis profissionais de uma equipe de saúde: visão de seus integrantes. Revista Latino-Americana de Enfermagem, v. 15, n. 1, p. 106-112, 2007.

SEPÚLVEDA C, MARLIN A, YOSHIDA T, ULRICH A. Palliative Care: the World Health Organization's global perspective. J Pain Symptom Manage. 2002.

SOCIEDADE ESPAÑOLA DE CUIDADOS PALIATIVOS - SECPAL. Guia de Cuidados Paliativos. España: O autor. Recuperado de http://www.secpal.com/biblioteca_guia-cuidados-paliativos-1, 2014, p. 5-32.

STJERNSWARD J, FOLEY KM, FERRIS F. The Public Health Strategy for Palliative Care. J Pain Symptom Manage. 33(5): 486-93, 2007.

TWYCROSS R. Medicina Paliativa: filosofia y consideraciones éticas. Acta Bioethica, v.6, n.1, p.27- 46, 2000.

WILSON KG, CHOCHINOV HM, MCPHERSON CJ, LEMAY K, ALIARD P, CHARY S. GAGNON PR, MACMILLAN K, DE LUCA M, O'SHEA F, KUHL D, FAINSINGER RL. Suffering with advanced cancer. J Clin Oncol. 2007.

WORLD HEALTH ORGANIZATION. Better palliative care for older people. Geneva: WHO; 2004

WORLD HEALTH ORGANIZATION (WHO). National cancer control programmes: policies and managerial guidelines. 2.ed. Geneva: WHO, 2002.

Hespanhol, F. L., Tinoco, E. M. B., Teixeira, H. G. de C., Falabella, M. E. V., \& Assis, N. M. de S. P. (2010). Manifestações bucais em pacientes submetidos à quimioterapia. Ciência \& Saúde Coletiva, 15(suppl 1), 1085-1094. doi:10.1590/s141381232010000700016 


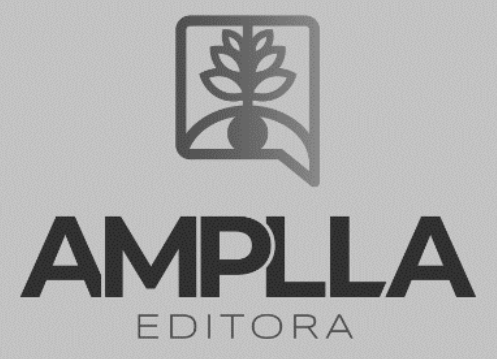

2021 


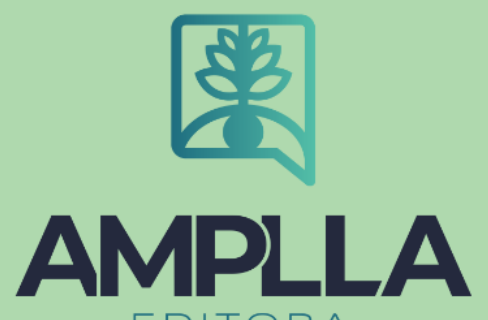

EDITORA

2021

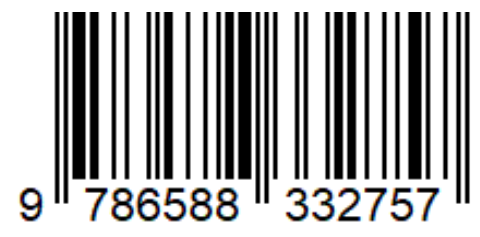

